Portland State University

PDXScholar

\title{
Attachment and Adolescent Offending: An Examination of the Links between Sexually Abusive Behavior and the Level of Attachment to Parents and Peers
}

Lee Anna Knox

Portland State University

Follow this and additional works at: https://pdxscholar.library.pdx.edu/open_access_etds

Part of the Applied Behavior Analysis Commons, and the Cognitive Psychology Commons Let us know how access to this document benefits you.

\section{Recommended Citation}

Knox, Lee Anna, "Attachment and Adolescent Offending: An Examination of the Links between Sexually Abusive Behavior and the Level of Attachment to Parents and Peers" (2014). Dissertations and Theses. Paper 1634.

https://doi.org/10.15760/etd.1633

This Dissertation is brought to you for free and open access. It has been accepted for inclusion in Dissertations and Theses by an authorized administrator of PDXScholar. Please contact us if we can make this document more accessible: pdxscholar@pdx.edu. 
Attachment and Adolescent Offending: An Examination of the Links between

Sexually Abusive Behavior and the Level of Attachment to Parents and Peers

\author{
by \\ Lee Anna Knox
}

A dissertation submitted in partial fulfillment of the requirements for the degree of

\title{
Doctor of Philosophy \\ in \\ Applied Psychology
}

\author{
Dissertation Committee: \\ Keith L. Kaufman, Chair \\ Cynthia Mohr \\ William Feyerherm \\ Kris Gowen \\ Yves Labissiere
}

Portland State University

2014 
(C) 2014 Lee Anna Knox 


\begin{abstract}
Child sexual abuse (CSA) is recognized as a public health problem with consequences affecting all levels of the ecological model. In recent years it has been recognized that up to $40 \%$ of reported sexual offenses occur at the hands of adolescent offenders (Burton, 2000), who are defined as children aged 12-18 years. In recent years, research has suggested that attachment deficits contribute to sexual offending behavior in adolescence. The current study augments the sparse research with adolescent offenders and by exploring of the participant's perceived attachment to important others (mother/mother figures, father/father figures, and peers/friends). Participants included 101 Juvenile sex offenders (JSO) and 97 Juvenile Delinquents (JD) detained in Oregon Youth Authority (OYA) facilities during the summer of 2010. Significant differences were found in adolescents' attachment to father/father figures in both overall attachment and a perceived degree of trust. Additionally JSO also showed a higher level of alienation from father/father figures and lower in overall perceived degree of trust with all important others. These findings may provide an opportunity for early intervention strategies, as well as support programs designed to strengthen or develop connections between adolescent offenders and positive male role models to enhance the effectiveness of juvenile sex offender treatment.
\end{abstract}




\section{DEDICATION}

The following research is dedicated to the primary, secondary, and tertiary victims of childhood sexual abuse.

May we all find ways to heal from past and prevent future abuse.

\section{PERSONAL DEDICATION}

To Bill, quite simply, there are not enough words... 


\section{ACKNOWLEDGMENTS}

First, I acknowledge the members of my dissertation committee: Dr. Keith Kaufman, Dr. Cynthia Mohr, Dr. William Feyerherm, Dr. Kris Gowen, and Dr. Yves Labissiere.

I owe an enormous debt of gratitude to the young men who graciously completed measures and spent time sharing their personal experiences so that treatment and prevention efforts can be improved.

Thank you to the Oregon Youth Authority for their permission and assistance in allowing our research team to gather information from the unique and wonderful youth in their care.

To my parents, Alice and Richard Wagner, who graciously accepted the news 25 years ago when I left college with an Associate's Degree, because I knew I would never follow in their footsteps and become a teacher. More importantly, they never said "I told you so" when I finally found my way back to school after a 16-year "spring break" and along with it a passion for teaching.

Finally, to my husband, Bill, my friend Dr. Lauren Murphy, and everyone else who has helped along my journey, I know I would not be who I am today without all of you. 


\section{TABLE OF CONTENTS}

Abstract $\quad$ i

Dedication $\quad$ ii

Acknowledgements $\quad$ iii

List of Tables $\quad$ ix

List of Figures $\quad$ X

Chapter 1: INTRODUCTION 1

$\underline{\text { Background and Incidence }} \quad 2$

Underreporting 3

Gender differences in abuse $\quad 5$

Challenges in incidence research on CSA

$\underline{\text { Definitions }}$

$\begin{array}{ll}\text { Child Sexual Abuse (CSA) } & 7\end{array}$

Juvenile Sex Offenders (JSO) 9

Juvenile Delinquents (JD) $\quad 11$

Chapter 2: A REVIEW OF THE LITERATURE 12

$\underline{\text { Juvenile Sexual Offenders' Role in CSA }} 12$

$\begin{array}{ll}\text { Consequences of CSA Victimization } & 14\end{array}$

$\begin{array}{ll}\text { Victims } & 16\end{array}$

$\begin{array}{ll}\text { Perpetrators of CSA } & 20\end{array}$

$\begin{array}{ll}\text { Physical Consequences } & 21\end{array}$

Financial Consequences $\quad 24$ 
$\begin{array}{ll}\text { Psychological Consequences } & 25\end{array}$

Misconceptions regarding offender recidivism rates 25

Sex Offender Registration Requirements 29

The family and friends of victims $\quad 30$

The family and friends of offenders 31

Community and society $\quad 32$

The Oregon Youth Authority (OYA) and Oregon Revised Statutes (ORS) 35

History of the Oregon Youth Authority (OYA) and enforcement guidelines 38

Chapter 3: CHILD SEXUAL ABUSE MODELS 40

$\underline{\text { Single Factor Models }} \quad 40$

$\begin{array}{ll}\text { Biological } & 40\end{array}$

Behavioral 42

Socio-cultural theory $\quad 43$

Attachment/Intimacy $\quad 44$

$\underline{\text { Multi-factor Models }} \quad 46$

Integrated Theory of Offending (ITO) 47

Confluence Model of Offending (CMO) 48

$\begin{array}{lr}\text { The Pathways Model (TPM) } & 50\end{array}$

Relapse Model (RM) $\quad 51$

$\begin{array}{ll}\text { Current Treatment Modalities } & 53\end{array}$

$\begin{array}{ll}\text { Chapter 4: ATTACHMENT THEORY } & 57\end{array}$

History of Attachment Theory $\quad 57$ 
John Bowlby's Attachment Theory $\quad 57$

$\begin{array}{lr}\text { Mary Ainsworth's contribution } & 58\end{array}$

Evaluating the Impact of Additional Attachment Figures 61

$\begin{array}{ll}\text { Fathers } & 61\end{array}$

$\begin{array}{ll}\text { Peers } & 63\end{array}$

Peer relationships in early childhood

Peer relationships in middle childhood $\quad 67$

Peer relationships in early adolescence $\quad 70$

$\underline{\text { Peer relationships in late adolescence through }}$

young adulthood $\quad 78$

$\underline{\text { Attachment and Adult Sex Offenders }} \quad 86$

Attachment in Juvenile Sex Offenders 95

$\begin{array}{ll}\text { Ongoing Unpublished Research } & 106\end{array}$

$\begin{array}{ll}\text { Synopsis of the Existing Literature } & 107\end{array}$

$\begin{array}{ll}\text { Conclusion } & 116\end{array}$

$\begin{array}{ll}\text { Participant characteristics } & 117\end{array}$

$\begin{array}{ll}\text { Improved measurement } & 117\end{array}$

$\begin{array}{ll}\text { Compressed data collection time } & 118\end{array}$

$\begin{array}{lr}\text { Hypotheses } & 119\end{array}$

Chapter 5: RESEARCH DESIGN AND METHODS 126

$\begin{array}{lr}\text { Participants } & 126\end{array}$

$\begin{array}{ll}\text { Measures } & 127\end{array}$ 
Cover sheet

Demographics

The Inventory of Parent and Peer Attachment (IPPA; Armsden \& Greenberg, 1987)

Rosenberg Self-Esteem Scale (RSES; Rosenberg, 1965)

$\underline{\text { Data Collection Procedure }}$

$\underline{\text { Data Preparation }}$

Data Cleaning \& Data Exclusion

Creation of Subscale Scores

Classification of Participants' Criminal Charges

Chapter 6: RESULTS

Hypothesis Testing

$\underline{\text { Study Implications }}$

Group differences in attachment subscales

Attachment and Self Esteem

$\underline{\text { Limitations }}$

$\underline{\text { Future Directions }}$

$\underline{\text { Conclusions }}$ 168 


\section{APPENDICES}

Appendix A: Oregon Revised Statutes (ORS)

Appendix B: Residency Restriction Zones

2234

Appendix C: Charge List

Appendix D: Cover Sheet:

JD

Appendix E: DEMOGRAPHICS

JSO

JD

Appendix F: IPPA

Appendix G: RSE

Appendix I: Oregon Sentencing Guidelines (2010) 
$\underline{\text { List of Tables }}$

$\begin{array}{ll}\text { Table 1: Criminal Referrals by Category } & 170\end{array}$

$\begin{array}{ll}\text { Table 2: Measure 11 Mandatory Sentences } & 171\end{array}$

Table 3: Most recent sexual charges_- JSO 172

Table 4: Most recent charges - JD 173

$\begin{array}{ll}\text { Table 5: Participants' placement in criminal } & 174\end{array}$

Table 6: Total Attachment Score by Group $\quad 175$

$\begin{array}{ll}\text { Table 7: Statistical Results } & 176\end{array}$

Table 8: Confirmatory Factor Analysis Eigenvalues $\quad 179$

Table 9: Inventory of Parent and Peer Scale Reliability 182 


\section{$\underline{\text { List of Figures }}$}

Figure 1: Bronfenbrenner's Ecological Model 183

Figure 2: Bartholomew's Four Category Model of Attachment 184

Figure 3: Maslow's Hierarchy of Needs 185

Figure 4: Ethnicity of Participants 186 


\section{Chapter 1: INTRODUCTION}

It is well documented that childhood sexual abuse (CSA) affects a large proportion of the United States population. The data collected between 2005 and 2006 for the Fourth National Incidence Study of Child Abuse and Neglect found that $24 \%$ of maltreated children have been sexually abused (Sedlak, Mettenburg, Basena, Petta, McPherson, Greene, \& Li, 2010). This number is staggering when we consider that research has documented that the consequences of CSA can be long-lasting, not only for the primary victim, but also for the victim's and the offender's families and friends, as well as for their communities and society as a whole.

In light of the ripple effect mentioned above that is associated with CSA, it's likely that most, if not all, individuals in the United States have been affected either directly or indirectly by CSA. This includes: the primary victims, i.e. the individuals who experienced sexual victimization; the secondary victims, i.e. the family members or friends of a victim or a perpetrator; and, finally the tertiary victims, i.e. the members of the community at large. Secondary victims are often the unseen victims of CSA that are impacted in a multitude of ways (e.g., worry, shame, guilt, compelled to answer others' questions). Furthermore, the effects of CSA are felt by community members who live with fears regarding their own vulnerability and safety. Finally, taxpayers shoulder the burden of paying for the collateral damages of CSA (i.e., law enforcement, assessment, treatment, and prevention services).

This manuscript first explores the existing literature surrounding CSA, with a focus specifically on information available concerning juvenile perpetrators. It then 
goes on to identify and summarize existing theories, specifically those related to attachment surrounding the etiology of juvenile sex offending. Next, it goes on to present and then critique existing literature in this area. Finally, the design of the current research study is discussed, explaining how it builds on the existing research literature and strengthens our understanding of the links between attachment and juvenile sexual offending behavior.

\section{$\underline{\text { Background and Incidence }}$}

This section examines the prevalence of childhood sexual abuse (CSA), explores reasons for the underreporting of this phenomenon, and identifies some of the consequences of CSA. It is important when contemplating the effects of CSA to consider that while the $24 \%$ figure mentioned earlier is overwhelming in its own right, the real incidence of CSA may be much higher. Many authors, including Wyatt, Loeb, Solis, Carmona, and Romero (1999), have suggested that child sexual abuse is widespread and largely underreported. CSA underreporting may exist for any number of reasons, including the distrust of authority figures (Friedrich, 2006), the taboo of discussing sexuality with children (Chaffin, Lawson, Selby, \& Wherry, 1997; Finkelhor, 1994; MacMillian, Fleming, Trocome, Boyle, Wong, \& Racine, 1997;

Widom \& Morris, 1997; Williams, 1994), fear of retribution from the offender (NSPCC, 2005), victims' inaccurate memories of events (Fergusson, Horwood, \& Woodward, 2000; Widom \& Morris, 1997; Freyd, 1996) and the lack of identification or recognition of the experience as abuse (NSPCC, 2005). 


\section{Underreporting}

It has been widely suggested that national CSA statistics, such as those published by the United States Bureau of Justice Statistics, are underestimates (Bachman \& Saltzman, 1995; Finkelhor, 1994; Green, 1996; Kessler \& Hyden, 1991; Russell, 1983; Siegel, Sorenson, Golding, Burnam, \& Stein, 1987). There is a wealth of reasons for underreporting, including a general distrust of social service departments and public safety personnel (e.g., Tuskegee; Friedrich, 2006), a desire to protect the offender in cases of intra-familial abuse (Widom \& Shepard, 1996), and a fear some victims have about stigmatization (Ryan, 2010). Finally, one of the biggest obstacles to eradicating CSA may well be what Judith Levine terms the "conspiracy of silence about our sexuality" (Levine, 2002).

When we as a society do not feel comfortable talking about any subject, it becomes "taboo." Levine's (2002) discourse on sexuality explains that although sex is viewed as the sine qua non of personal fulfillment in our culture, it is also seen as having the greatest "potential for societal devastation. Levine goes on to state that our biggest fears surround the vulnerability of women and children. Many researchers suggest that our society's discomfort with sexuality, in conjunction with instructions to act within the societal standards, puts children at a disadvantage when someone in charge of them does something they feel is sexually inappropriate (Baron-Cohen, O’Riordan, Stone, Jones, \& Plaisted, 1999; Briggs, McVeity, \& Love, 2001; Hanna, Risden, \& Alexander, 1997). Beyond the implicit direction to obey their elders, normally developing children are extremely skilled at interpreting social cues and will 
not bring up issues they believe will lead to embarrassment, either of themselves or others. These issues can be compounded or exacerbated by the fact that children also frequently feel guilt and responsibility for the acts of abuse or for what may happen to their abusers, if they disclose (Wissow, 1996).

It is important to recognize that many offenders, even juvenile offenders, develop quite elaborate plans before committing their assaults and may utilize modus operandi (i.e., patterns of perpetration) that discourage victims from recognizing their experience as inappropriate. Offenders often veil the abuse as a "special game," "secret," or a normal way of showing love and affection (Kaufman, Hilliker, Lathrop, \& Daleiden, 1998; NSPCC, 2005). These strategies can sometimes make it difficult for children and even teens to accurately identify these sexual interactions as abusive. Additionally, offenders may intimidate their victims using threats of punishment, as well as threats to hurt a family member or a family pet, in order to guarantee compliance and silence (NSPCC, 2005). Finally, CSA can also be "cloaked" within other forms of child maltreatment. In 1999, The World Health Organization released a narrative from the "Report on the Consultation on Child Abuse Prevention" that defined neglect as:

The failure to provide for the development of the child in all spheres: health, education, emotional development, nutrition, shelter, and safe living conditions, in the context of resources reasonably available to the family or caretakers and causes or has a high probability of causing harm to the child's health or physical, mental, spiritual, moral or social development. This includes the failure to properly supervise and protect children from harm as much as is feasible (WHO, 1999). 
This is important when considering that some researchers have argued that any form of childhood abuse happens within a context of neglect (Ryan, Gillies, Kent, Baker, Durfee, Winterstein, \& Knapp, 2001) and that children who are victims of one form of abuse are more likely to experience other forms of abuse. Higgins and McCabe (2001) used the term "multi-type maltreatment" when referring to the coexistence of one or more types of abuse (i.e., physical, psychological, sexual abuse or child maltreatment and neglect). In their review of 29 studies, these authors found that a substantial proportion of maltreated individuals experience multi-type maltreatment. This finding was consistent with earlier work by Mullen, Martin, Anderson, Romans, and Herbison (1996).

Gender differences in abuse

It is important to recognize there is marked gender disparity in the selfreported incidence of CSA. Researchers including Johnson, Ross, Taylor Williams, Carvajal, and Peters (2006) and Wyatt (1985) acknowledged that, while there is a wealth of research on CSA, the victims studied are most often female and that societal norms regarding what it means to be "male" discourages male victims from reporting CSA.

\section{Challenges in incidence research on CSA}

Along with the many challenges associated with the obviously "murky" statistics surrounding the incidence of CSA, the biggest obstacle in this field lies in the fact that there is simply no agreed upon definition of CSA (Johnson et al., 2006). This problem includes not only differences in how acts are defined as appropriate or 
inappropriate in different situations, but also in the fact that CSA laws and statutes vary not only from state to state, but also at the federal level (18 U.S.C. § 2241 to 18 U.S.C. §2248). A second, equally important, challenge relates to cultural and ethnic differences in reporting practices. Finally, the perspective and purpose of the research impacts its design, how it is conducted, and even how findings are framed and disseminated. Each of these factors has contributed to ambiguous, if not inconsistent findings in the CSA literature for more than thirty years.

It is with an understanding of the challenges detailed above that the subsequent portions of this paper will describe the completed study focusing on issues related to attachment in juvenile sexual offenders. This dissertation will:

- Define important CSA study-related terms, including child sex abuse (CSA), juveniles that sexually offend (JSO), and juveniles that engage in delinquent behavior (JD).

- Identify why the population included in the existing study (i.e., juvenile sex offenders) was an important population to study;

- Discuss the consequences of CSA to primary, secondary, and tertiary victims of this phenomenon;

- Review existing theories regarding the etiology of sexually offending behavior and how these theories have been developed primarily for use with an adult population and then subsequently applied to juvenile offenders;

- Define the concept of attachment and the history of attachment theory; 
- Provide a brief history of the Oregon Youth Authority (OYA), the agency charged with the custody of this population and describe the laws enacted in the state of Oregon that have been applied to the participants in completed study;

- Describe the Inventory of Parent and Peer Attachment, a commonly used measure of attachment (IPPA; Armsden \& Greenberg, 1987);

- Critique the relevant literature on attachment and explain how this study research improves upon the current research base;

- Describe the study, the methods utilized to conduct the investigation, and the data analysis performed;

- Review the impact of this study's findings on the literature, practice, and prevention efforts; and

- Finally, discuss future directions for research based on the results of this endeavor.

$\underline{\text { Definitions }}$

\section{Child Sexual Abuse (CSA)}

In 1986, researchers pointed out that there had already been more than eight decades of research on the sexual abuse of children by adult perpetrators (Wyatt $\&$ Peters, 1986). Unfortunately, it is difficult to compare this research base because, as Gough pointed out in 1996, there were many different working definitions of CSA. Finkelhor (1994) stated that although CSA had been used to describe a variety of behaviors, up until the early 1990's there were two essential elements commonly used 
in the legal and research definitions. These definitions included (a) particular types of sexual activities (i.e., activities engaged in for sexual pleasure involving a minor) and (b) either a large age gap between the victim and offender, or coercion on the part of the perpetrator to ensure victim's compliance. Individual state legislative bodies routinely adopt specific legal definitions for CSA-related terms, such as molestation, sex abuse, rape, and sodomy. These definitions are then ratified by the state's executive branch. It is common practice, however, to use the term "sexual offense" as a generic term to cover many more clearly defined abusive acts.

Within the research literature, it has become somewhat common practice to differentiate sexual offenses into two separate categories: hands-off or hands-on offenses. Hands-off offenses are often seen as less serious and involve no physical contact between the offender and victim (Cooper, Murphy, \& Haynes, 1986; Greenberg, Bradford, Firestone, \& Curry, 2000). These offenses include exposing victims to sexually explicit pictures or video images; sexualized emails, text messages, or obscene phone calls; and instances where the perpetrator exposes his/her genitalia to the victim (Kaufman, 2001). In contrast, hands-on offenses involve actual physical contact between an offender and victim. Crimes of this nature are often divided into three different subcategories: (a) fondling and non-penetrative acts committed by the perpetrator, (b) forcing the victim to commit non-penetrative acts on the offender or others, and (c) penetrative offenses committed by the offender against the victim or forcing the victim to commit these acts upon the offender or others (Kaufman, 2001). 
Another operational difference in the literature involves how the term "child" is defined. First, differing definitions of childhood may be related to variations in state laws. While laws vary from state to state, most states include adolescents between 16 and 18 years of age as potential child victims when defining CSA (Finkelhor, 1991). Individual researchers, however, may not recognize individuals in this particular age group as potential CSA victims. For example, individual researchers have elected to use definitions that require at least a three-year (Finkelhor, Hotaling, Lewis, \& Smith, 1990) or five-year (Russel, 1983) age difference between the offender and victim. Further, including international research may complicate comparisons even further as the age of consent is much younger in other countries as compared to the United States. For example, the age of consent was only 14 in Canada as recently as 2006. Researchers have also indicated that the age of consent is as young as 13 in Argentina and Spain, and 14 in Austria, Germany, Italy, and Brazil (Robertson, 2009). Cultural differences therefore create serious concerns about including CSA research conducted in different countries in a literature review regarding etiology, policies, or treatment in regards to an American juvenile population.

\section{Juvenile Sex Offenders (JSO)}

As the true population of interest in this study was "juvenile sex offenders," it is important to discuss past confusion around that term and establish what operational definitions were used during the course of the research. One of the biggest problems in research of this nature may be the diversity of individuals included in the umbrella term "juvenile sex offender." The diversity of youth included in this category is 
eloquently provided in the following description by a leading researcher in the field,

Mark Chaffin (2008, p.117):

Youth labeled as juvenile sex offenders include traumatized young girls reacting to their own sexual victimization; persistently delinquent teens who commit both sexual and nonsexual crimes; otherwise normal earlyadolescent boys who are curious about sex and act experimentally but irresponsibly; generally aggressive and violent youth; immature and impulsive youth acting without thinking; so called Romeo and Juliet cases; those who are indifferent to others and selfishly take what they want; youth misinterpreting what they believed was consent or mutual interest; children imitating actions they have seen in the media; youth ignorant of the law or the potential consequences of their actions; youth attracted to the thrill of rule violation; youth imitating what is normal in their own family or social ecology; depressed or socially isolated teens who turn to younger juveniles as substitutes for age-mates; seriously mentally ill youth; youth responding primarily to peer pressure; youth preoccupied with sex; youth under the influence of drugs and alcohol; youth swept away by the sexual arousal of the moment; or youth with incipient sexual deviancy problems.

For the purposes of this study, a juvenile sex offender (JSO) was defined as an individual who has been adjudicated or convicted in Oregon, for committing a sexual offense, as defined by Oregon Revised Statutes, while between the ages of 11 and 18 . As with any research, a comparison group to the population of interest is needed. In the current study, juveniles adjudicated or convicted for non-sexual offenses were included and are hereafter referred to as "juvenile delinquents (JD)." It is important to note that minors placed within the custody of The Oregon Youth Authority (OYA) are considered to be "within the jurisdiction of the court" and adjudicated, rather than "convicted," of a crime, unless they were charged and convicted as an adult. This distinction will be clarified (i.e. in "The Oregon Youth Authority (OYA) and Oregon Revised Statutes [ORS]).” 
Juveniles Delinquents (JD)

Since juveniles who have committed delinquent acts (JD) were included in the existing study as a control group, it is important to clearly define these participants as well. For the purposes of this study, a juvenile delinquent (JD) is defined as an individual who has been adjudicated on a non-sexual criminal offense as defined by Oregon Revised Statutes while between the ages of 11 and 18. A list of sexual and non-sexual offenses as defined by Oregon Revised Statutes are provided in Appendix A and discussed in a later section entitled "History of the Oregon Youth Authority (OYA) and the Oregon Revised Statutes (ORS)." First, however, it is important to review the significance of studying juveniles that have sexually offended (JSO) in order to ground the current research study. 


\section{Chapter 2: A REVIEW OF THE LITERATURE}

\section{$\underline{\text { Juvenile Sexual Offenders' Role in CSA }}$}

This study investigated juveniles who had been adjudicated for criminal acts (sexual and non-sexual). As such, it is important to examine and discuss the research literature that supports the significance of investigating the behavior of this population. The following section will explore the reasons why juvenile offending has been largely ignored or minimized up until recently. It will then go on to highlight the number of sexual offenses committed by juveniles, discuss why many adolescent offenders have been overlooked as research participants, and finally discuss what hurdles exist to those who try to investigate the etiology of juvenile sexual offending. Until the early 1980's, sexual offenses committed by juveniles were often minimized and dismissed by family members, professionals, and the public alike (Ryan, 1999a; Ryan, 2010). Harrison (2009) established that in the past, incidents of sexual abuse originating at the hands of children were interpreted as maliciousness, the product of children's fantasy lives, or failure of children's ability to differentiate between sexual desires and reality and were therefore often overlooked. Thankfully, over the past thirty years, a substantial degree of concern has developed surrounding juvenile sex offenders and their offending behavior. In 2000 Burton offered that the number and seriousness of sexual assaults committed by adolescents is serious and widespread.

Currently, juvenile offenders of sexual crimes are overrepresented in the National Incident-Based Reporting System maintained by the Federal Bureau of 
Investigation (Caldwell, 2002). In fact, many recent investigators have documented that juveniles are responsible for a large proportion of sexual offenses. For example, Finkelhor, Ormrod, and Chaffin (2009), in a recent Juvenile Justice Bulletin, reported that juvenile sex offenders comprise more than one-quarter $(25.8 \%)$ of all recognized sex offenders and more than one-third (35.6\%) of sex offenders with minor victims. Murphy and Page (2000) referenced research documenting that up to 50\% of child molestation and $20 \%$ of rapes in the United States occur at the hands of juveniles. Earlier on, Celini (1995) found that $47-58 \%$ of adult sex offenders committed their first sex offense as adolescents or younger.

In 1995, more than 16,100 adolescents were arrested for sexual offenses in the United States for crimes not including rape and prostitution (Sickmund, Snyder, \& Poe-Yamagata, 1997). At the same time, evidence suggests that only a fraction of sex offenses are reported to the police (CSOM, 2002) and as previously noted, crime statistics fail to reflect the true scope of the problem. Concerns result in uncertainties about the actual incidence of adolescent perpetrated CSA. Elliot, Huiznga, and Morse (1985) reported that, on average, for each rape a male adolescent had been arrested, he has likely committed approximately 25 other rapes that went unreported.

For many years, research on juveniles who sexually offend has been sparse. This dearth of studies may be due to a number of factors. First, in many states, juvenile records can be sealed or expunged (USDJ Bulletin, 1998), which makes them unavailable for research purposes. Second, there is a continuing societal belief in the need for secrecy surrounding sexuality in childhood (Alter-Reid, Gibbs, Lachenmeyer, 
Sigal, \& Massoth, 1986). It has long been recognized that child sexual abuse often occurs within the context of families (Finkelhor, 1994), and much of it remains known only to those within this context. This may explain, in part, why only one-fourth of identified cases of sexual abuse has been available for research (Alter-Reid et al., 1986). Third, it is also telling that much of what is known about juvenile sex offenders comes from retrospective studies of adult sex offenders (Ford \& Linney, 1995). This information may not provide accurate assessments of juvenile behavior. Years of research on recalled events and clinical practice make it clear that memories are not perfect records of long past events (Lindsay \& Read, 1994). Recent improvements in research on juveniles who sexually offend include assessing their behavior within a much shorter time period after their offenses occur to negate memory confounds.

Based on the information already discussed, it is obvious that juvenile sex offenders constitute a significant criminal population in the United States and are worthy of study. It is also important to recognize that there have been many obstacles in researching this population, including underreporting and inconsistent definitions, leading to the obscurity of the weight and seriousness of the problem. As a result of these and other issues, this population has been largely ignored by mainstream researchers until very recently, resulting in gaps in the literature. Before this literature is discussed in more detail, it is important to examine the impact of CSA.

\section{Consequences of CSA Victimization}

Researchers have found that CSA is associated with a variety of negative short- and long-term consequences for the victim (McMahon \& Puett, 1999; Polusny 
\& Follette, 1995; Banyard \& Williams, 1996; Mullen, Martin, Anderson, Romans, \& Herbison, 1996). Although it is important to recognize the detrimental effects on the victim, it is equally important to recognize that sexual offending is now considered both a public health problem (McMahon and Puett, 1999) and a major social problem resulting in significant psychological and emotional costs to victims and their families (Johnston \& Ward, 1996). This section provides an overview of key short- and longterm consequences associated with CSA. Specifically, this section will address the best documented general and specific symptoms associated with childhood sexual victimization, including general links between CSA and mental health disorders, substance abuse, and self-harming behavior. An exploration of the literature detailing consequences to specific populations of interest, including victims, perpetrators, the families of both, their communities, and society as a whole will follow.

Brier and Elliott (2003) explained that CSA is not only "endemic" in our western culture, but is likely to result in significant long-term "psychological dysfunction" in victims. Researchers have also recognized that CSA is associated with a wide variety of psychological symptoms ranging from psychiatric disorders to chronic mental health problems (Molnar, Buka, \& Kessler, 2001; Banyard, Williams, \& Siegel, 2001). Koenig, Doll, O’Leary, and Pequegnat (2004) and Rind and Tromovitch (1997) identified correlations between childhood sexual victimization and self-harm, substance misuse, and both physical and mental health problems, as well as sexualized behavior and other antisocial behavior. 
Seto, Kjellgren, Priebe, Mossige, Goran, Svedin, and Langstrom (2010) recently discussed the results of the U.S. National Co-morbidity Survey, which attributed between nine and thirty percent of mood, anxiety, substance misuse disorders, and thoughts of suicide in female patients and five to six percent in male patients to sexual victimization. This supports the premise that the repercussions of CSA are long lasting and widespread. Investigators have illustrated that the long-term effects of CSA may reach far into adulthood and affect more than just the primary victim of abuse (Wang \& Holton, 2007). CSA has been examined in medical journals in relation to somatic disorders; in social science research in association with the behavior of victims and their families; and in a variety of agency and institutional reports describing financial costs to victims, families, and society at large. The widespread interest by divergent disciplines demonstrates the need to examine the consequences to secondary victims of CSA in detail. These secondary victims can include family members (Rumstein-McKean \& Hunsley, 2001) and friends (Cearney, 1995) of the victim and perpetrator as well as the community (Wang \& Holton, 2007) and society, as a whole.

In order to provide a deeper understanding of both who the victims are and how CSA affects them, the next section will explore the consequences to victims at the individual, familial, community, and societal levels.

\section{Victims}

In an article published on the website for The National Center for Victims of Crime Finkelhor, Turner, Ormrod, and Hamby (2009) stated that child abuse is not 
unique to a particular segment of society; it crosses all racial, gender, socio-economic, and demographic boundaries. Studies of the long-term effects on the victim have identified wide-ranging impacts from sexualized behavior (Kendall-Tackett, Williams, \& Finkelhor, 1993) to suicide (Mullen et al., 1996; Polusny \& Follette, 1995; Brown, Cohen, Johnson, \& Smailes, 1999; Dube, Anda, Whitfield, Brown, Felitti, Dong et al., 2005). These researchers have analyzed the after-effects of CSA from the immediate physical symptoms to more subtle, long-term psychological effects.

Kendall-Tackett et al. (1993) noted that $20-40 \%$ of children who are seen by health professionals for suspected sexual abuse show no physical signs or symptoms of sexual abuse. Although in many cases there may not be immediate physical signs of CSA (Botash, 2008), when present, symptoms can include: bleeding and discharge from the anus, penis, or vagina (Lahoti, McClain, Girardet, McNeese, \& Cheung, 2001); rectal and vaginal abnormalities (Botash, 2008); and bruises to the skin on the arms, legs, and genital areas, as well as abrasions on the wrists and ankles. Children have also reported general fatigue, abdominal pain, headache, incontinence, diarrhea, and constipation (Botash, 2008). In a recent article in the Journal of the American Medical Association, Paras, Murad, Chen, Goranson, Sattler, Colbenson et al. (2010) examined twenty-three studies and found significant links between CSA and gastrointestinal disorders, psychogenic seizures, chronic pain, and other nonspecific chronic pain. Belsky, Jonassaint, Pluess, Stanton, Brummett, and Williams (2009) found that women who had experienced childhood sexual abuse demonstrated low monoamine oxidase A (MAOA) activity in their brains. Low MAOA has been 
associated with both impulsive and aggressive behavior (Frazzetto, Lorenzo, Carola, Proietti, Sokolowska, \& Siracusano, 2007). Long-term medical consequences linked to CSA have also included obesity (Gilbert, Spatz, Widom, Browne, Fergusson, Webb, \& Janson, 2008) and increased rates of sexually transmitted infections (Botash, 2008; Gilbert et al., 2008; Lahoti et al., 2001; Gutman, St. Clair, \& Weedy, 1991).

Beyond the physical side effects of CSA, behavioral impacts and developmental sequelae have also been noted. Deficits have included delays in social and cognitive functioning and significant shifts in behavior such as regression to early childhood practices like thumb sucking and use of a blanket for "security," fitful or reduced sleeping patterns, and changes in eating and behavioral problems in school (Wang \& Holton, 2007). Lahoti and colleagues (2001) indicated that some of the behavioral changes include aggressive outbursts directed toward others.

More specifically, Kendall-Tackett (1993) and her colleagues found that victims of CSA displayed two consistent symptoms: (a) PTSD (post-traumatic stress disorder) and (b) sexualized behavior. PTSD is defined as "a mental health condition that is triggered by a terrifying event" (Mayo Clinic, 2011). Individuals with PTSD suffer from flashbacks, nightmares, and severe anxiety, as well as rumination on the triggering event. Sexualized behavior is often conceptualized as activity that is sexual in nature and is either compulsive or developmentally inappropriate. Sexualized behavior, in and of itself, can result in harmful consequences including an earlier age of first consensual intercourse, greater than average number of sexual partners 
throughout an individual's lifetime, and increased risks of contracting sexually transmitted diseases and infections (Senn, Carey, \& Vanable, 2008).

Other researchers (Thomas \& Femouw, 2009; Basile, Black, Simon, Arias, Brener, \& Saltzman, 2006; Glasser, Kolvin, Campbell, Glasser, Leitch, \& Farrelly 2001; Paolucci, Genuis, \& Violato, 2001) have explored the transformation of CSA victims into perpetrators of violence. Basile et al. (2006) found that male survivors of CSA are at an increased risk of engaging in dating violence. They also found an association between victimization as a child and the perpetration of CSA. Thomas and Fremouw (2009) called this phenomenon the "victim to offender cycle." Although the vast majority of children who experience CSA do not grow up to be perpetrators themselves, the research clearly shows that a high percentage of incarcerated perpetrators report their own history of childhood sexual victimization.

Despite the fact that the majority of children who suffer CSA do not go on to perpetrate CSA, the impact of neglect and maltreatment (including sexual abuse) experienced within the family can be an important influence on child development. These factors can have a profound effect on the closely linked relational areas of attachment and sexuality (Hawkes, 2011). Given that up to $27 \%$ of CSA victims are under the age of five and that the average age of first assault is two years of age (USDJ, 1999), the impact on attachment can be quite significant. Most developmental theorists accept that the core sense of the self, others, and the world in general are generated from early experience and affect all domains of life (Magnavita, 2006). A 
more detailed analysis of attachment and its relationship to CSA will be provided in a later section of this dissertation.

Perpetrators of CSA

It is easy to see that society views CSA as a heinous crime. In fact, Wright (2008) stated,

American society has decided that there is no greater villain than the sex offender. Terrorists, drug dealers, murderers, kidnappers, mobsters, gangsters, drunk drivers, and white-collar criminals do not elicit the emotions and evoke the political response that sex offenders do (p.17).

Statutes dealing with sex abuse crimes are both extensive and remarkably punitive. These restrictions, which include mandatory registration as a sex offender, residency restrictions, and limited freedoms associated with exclusionary zones, will all be reviewed in this section. It is important to recognize, however, that these methods of deterrence may actually have the antagonistic effect of increasing recidivism and reducing community safety. This is particularly true in juvenile sex offenders when we consider that most adolescent perpetrators respond well to treatment.

The practices of ignoring the consequences of these highly punitive policies for the perpetrators, their families, and community safety have become commonplace. The following sections will first outline the physical, financial, and psychological consequences to offenders as well as delineate common misconceptions surrounding the recidivism rates for juvenile sexual offenders (JSO). The discussion will go on to explore how current practices which are meant to protect communities and societies might, in fact, can cause more harm than good. 


\section{Physical Consequences}

This section details often overlooked consequences to JSOs that have the potential of increasing recidivism and reducing community safety. First, evidence suggests that convicted sex offenders have a higher incidence of alcoholism than nonoffenders (Motiuk \& Porporino, 1992), as well as increased rates of suicide (OMHSAS, 2006). Second, although inmates are the only individuals with a guaranteed right to health care in the United States, there is a long history of inadequate and substandard health care for incarcerated persons (Morris, 2005). During their periods of imprisonment, juvenile offenders commonly lack regular access to preventive health care and suffer significantly greater health difficulties, including underlying psychosocial disorders, chronic illnesses, exposure to illicit drugs, and physical trauma when compared with adolescents who avoid the juvenile justice system (Pickering, 2003). Third, because of "sex offender" stigma, many individuals face an increased risk of assault not only from other inmates while incarcerated (Stewart, 2007), but from community members following release.

Examples of the all too real possibility of physical harm to offenders in the community have been detailed by authors including Freeman-Longo and Reback (2002) and Levenson and Cotter (2005a). Levenson and Cotter stated that $16 \%$ of the participants in their study reported being physically assaulted because of their status as a registered sex offender.

Tewksbury (2005) discussed other consequences to living life as a registered sex offender. He stated that the most common barriers faced by an individual 
identified as a "sex offender" are those which stand in the way of successful reintegration into society, including finding a place to live and employment (Zevitz \& Farkas, 2000; Tewksbury, 2005). Most jurisdictions have enacted residency restrictions that are imposed on sex offenders post-release that limit where sex offenders can live and often dictate how far their residence must be from places where children congregate (e.g., schools, daycare centers). A brief overview of these statues can be found in Appendix B.

In the state of Oregon, where the participants of the current study lived before and will likely live after their release from custody and registration, the legislature mandated that the Oregon Department of Corrections (ODOC) establish criteria to be considered in the residential placement of sex offenders. The criteria enacted by the ODOC include prohibitions from living near any location where children are the primary occupants or users (Oregon Revised Statute ORS 144.642, 2008). Similar restrictions have been enacted by The Oregon Youth Authority (OYA), which is the corrections agency in the state of Oregon responsible for the care and supervision of minors. While these restrictions may seem to make sense, they often make it virtually impossible for a sex offender to live anywhere within a city's limits that has any proximity to schools, jobs, or support systems. This can be particularly challenging for a youthful offender returning to the community and seeking to live in his/her family's home. Oregon law is unique in the fact that residency restrictions are based on a matrix reflecting an offender's level of risk to the community. An offender labeled as a "predatory sex offender" (i.e. the highest level of risk) is subject to stricter 
requirements, including the distribution of information about his/her identity, convictions, place of residence, and specific contact restrictions posted on publicly accessible web sites (sexoffenders.oregon.gov). Oregon Statues define a predatory sex offender as someone "who exhibits characteristics showing a tendency to victimize or injure others and has been convicted (or adjudicated) of a sex crime" (ORS 181.585). Specific constraints on liberty include ORS 163.476, which bans "predatory" offenders from being anywhere minors regularly congregate (e.g., schools, parks, day care centers, skate parks). These policies were intended to protect children and make communities safer. However, they are generally based on the misconception that children need to be protected from "stranger danger" perpetrated by unknown "sexual predators" (Meloy, Miller, \& Curtis, 2008). In fact, Greenfield (1997) stated that up to 90\% of CSA is committed by people known to child victims. Greenfield (1997) reports that $43 \%$ of CSA victimization was at the hands of an immediate family member, while other offenders included babysitters, extended family, and caretakers. In fact, rather than making the community safer, current residency restrictions may increase risks for re-offense (Levenson \& Cotter, 2005b) and in turn actually increase dangers to the community.(Community consequences will be discussed in detail later in the section entitled "Community and Society").

Housing restrictions are especially punitive and often limit the number of residency options for offenders. This often results in a greater number of sex offenders living in a concentrated area, often in less than ideal circumstances. This can decrease their integration into the general community, increase isolation, and create financial 
and emotional distress (Levenson \& Cotter, 2005b). In 1962, Goffman wrote that labeling and limiting the options of offenders may actually cause them to reoffend because the offender may feel that his case is helpless and that he will always be seen in a negative light. An offender's sense of hopelessness at such a situation may lead him to believe that reoffending has no greater consequences than those he is already suffering. This scenario was identified as commonplace more recently by many authors including: Zevitz and Farkas (2000); Tewksbury (2005); Levenson and Cotter (2005b); and Tofte (2007). All of these researches have discussed how residency restrictions create barriers to offenders' successful community reintegration, which in turn can foster re-offenses. In her report compiled for Human Rights Watch in 2007, Tofte offered that housing restrictions often force offenders out of metropolitan areas, which in turn limits their access to social support, employment opportunities, treatment centers, and social services.

\section{Financial Consequences}

Beyond the consequences of housing restrictions and the limited freedom of movement discussed above, sexual offenders often suffer financially as well. In addition to the obvious expenses of court and legal fees, many offenders may be required to make restitution to his/her victim and pay for their own treatment after release from custody (Tewksbury, 2005). This can be a particularly high hurdle when offenders find it so challenging to obtain employment. Both the obvious gaps in employment that occur while serving a prison sentence and carrying the label of "sex offender" make finding employment for most released offenders challenging at best. 


\section{Psychological Consequences}

Many sexual offenders also suffer mental health consequences that can be attributed to their having committed CSA. Although most may not meet diagnostic criteria for major mental illness, they often show signs of low self-esteem and assertiveness deficits (Marshall, 1993). Most importantly, the stigma of being labeled a sex offender has the potential to isolate him/her further from peers, adults, and potential sources of social and psychological support, which could then increase his/her risk of reoffending (Becker, 1998).

Finally, the fear of harm after the community has been apprised of their return to the neighborhood ("community notification" is required by offender registration laws) understandably affects many sex offenders (Meloy, 2006). Levenson and Cotter (2005a) found that fear often materializes into reality given that between one-third to one-half of sex offenders subjected to community notification in Florida reported dire consequences (e.g., the loss of a job or home, threats, harassment, or property damage). The consequences to juvenile sex offenders are wide-ranging and serious, as well. This is especially disquieting considering that the impetus for policies and procedures surrounding registration and community notification have been drafted based on inaccurate and outlandish recidivism rates or in response to isolated, highly publicized, horrific CSA cases.

Misconceptions regarding offender recidivism rates

Although it is the general public's perception that sex offenders have the highest recidivism rates among criminals, they are in fact among the least likely 
offenders to be rearrested for new sexual offenses as a group (Levenson, Brannon, Fortney, \& Baker, 2007; Sample \& Bray, 2003). Hanson and Bussiere (1998) found that recidivism rates for all sexual offenders (i.e., after treatment) to be $13.4 \%$, which is much lower compared to the recidivism rates of those individuals that commit nonsexual offenses. For example, Langan and Levin (2002) found that individuals arrested for property crimes recidivated at a rate of $73.8 \%$, while individuals arrested for motor vehicle theft recidivated at a rate of $78.8 \%$ within 3 years of release. Hilton, Harris, Rice, Houghton, and Eke (2008) found that perpetrators of domestic violence recidivate at a rate of 49\%. A report authored by Langan and Levin in 2002 found that individuals who were released in 1994 after serving their sentence for a conviction of non-sexual assault were arrested at a rate of $65 \%$ within 3 years. Their actual reported recidivism rate for non-sexual assault was $22 \%$.

Juveniles who sexually offend have recidivism rates even lower than their adult counterparts. Available treatment outcome research suggests that identified sexual relapses among teenage offenders who have been in treatment programs are as low as 5\% (Chaffin \& Bonner, 1998). This number is particularly interesting considering that estimates suggest that between 2 and $4 \%$ of all adolescent males have committed a sexual assault at some point during their development (Waite, Keller, McGarvey, Wieckowski, Pinkerton, \& Brown, 2005). There is, therefore, little difference between the general incidence of sexual abuse by adolescents and the rate of re-offense by identified "juvenile sex offenders.” Letourneau and Miner (2005) 
concluded that juveniles appear to be less likely to reoffend sexually and most often do not continue as career sex offenders.

Perhaps the general public's confusion about recidivism rates can be explained by the different ways in which the term "recidivism" is applied. The common use of the word "recidivate" denotes falling back or relapsing into crime. Of course, there is a difference in recidivism rates when discussing recidivism for new sex crimes or arrests for non-sexual crimes, probation and parole violations, and new charges for previous crimes. A study evaluating recidivism for adult sex offenders released from custody in 15 states in 1994 (Arizona, Maryland, North Carolina, California, Michigan, Ohio, Delaware, Minnesota, Oregon, Florida, New Jersey, Texas, Illinois, New York, and Virginia) found that $43 \%(4,163)$ were rearrested for any type of crime within 3 years of release (Langan, Schmitt \& DuRose, 2003). However, it is important to note that only $5.3 \%$ (or 517) of these individuals were re-arrested for sex crimes. Overall, arrest statistics were much higher for a comparative group of non-sexual offenders $(161,410$ individuals) with $68 \%(4,163)$ arrested within 3 years. Interestingly, of this group of non-sex offenders, $1.3 \%$ was arrested for a sex crime during that same 3 -year post release time period. Letourneau and Miner (2005) found one significant difference between adult sex offenders and juvenile sex offenders: the mean recidivism rate for adult sex offenders (ASP) in their review of 61 studies was $13.4 \%$ as opposed to $9 \%$ (from 25 studies) for juvenile sex offenders (JSOs).

In 2005, Waite, Keller, McGarvey, Wickowski, Pinkerton, and Brown examined the follow-up arrest rates for a period 10 years post release for 256 juvenile 
sex offenders in Virginia. Data were compiled from information gathered from the Department of Juvenile Justice by corrections employees. Re-arrest data was organized into three categories: sexual offenses (rape, child molestation, and aggravated sexual battery), nonsexual person offenses (simple assault, felony assault, robbery, attempted murder, and murder) and property offenses (fraud, drug possession, firearm possession, and breaking and entering). The participants were divided into two groups: (a) a group comprised of 144 males who had been housed in a more intensive self-contained treatment facility in which all residents were sexoffenders, and (b) a group comprised of 112 males who received prescriptive “outpatient" treatment. Although overall recidivism rates were high, $47.2 \%$ and $70.5 \%$ for the self-contained and prescriptive groups respectively, re-arrest rates for sexual offenses were both low at $4.9 \%$ (self-contained) and $4.5 \%$ (prescriptive). A nonpublished study (CCJD, 2010), conducted by the author of this dissertation and her colleagues, followed adolescent offenders supervised in a metropolitan county in Oregon. Findings of a 5-year follow-up of 123 participants mirrored the CCJD (2010) findings. Overall, non-sex offender recidivism rates were $31.7 \%$ while sex-offense recidivism rates were only $4.1 \%$. The largest percentage of rearrests for sex offenders in this study was for failure to register (9.8\% or 12 individuals) and what Waite et al. (2005) would have labeled property offenses (16.3\% or 20 individuals). Alexander's (1999) meta-analysis found that juveniles who have sexually offended respond well to treatment. JSOs adjudicated on rape had recidivism rates of $5.8 \%$ and youth adjudicated on child molestation had recidivism rates of $2.1 \%$. 
Alexander (1999) also pointed out that most, if not all, adolescents adjudicated on a sex offense will return to the community at some point. Other recent studies have identified recidivism rates for juvenile sexual offenders receiving treatment at about 5\% (i.e., exactly 5.17\%; Worling \& Curwin, 2000; 4.9\%; Waite et al., 2005). These obviously low recidivism rates become especially salient when the long-term effects of being labeled a "sex offender" for life, including alienation, ostracism, restriction of movement, danger of vigilante justice, and the resulting mental health problems and financial consequences to these members of society is considered. Clearly when the general public refers to high sex offender recidivism rates, they are reacting to widely circulated misinformation rather than factual statistics. Sex Offender Registration Requirements

The Jacob Wetterling Crimes against Children and Sexually Violent Offender Registration Act was passed by Congress in 1994 (42 U.S.C. $\$ 14071$, et seq.). That statute mandated that all 50 states, the District of Columbia, the Commonwealth of Puerto Rico, the Virgin Islands, American Samoa, Guam, and the Commonwealth of the Northern Mariana Islands enact registration for all sex offenders with their local law enforcement agencies. The original purpose of this procedure was to facilitate the ability of local agencies to identify and keep track of the location of known sex offenders and therefore be able to notify the public of their whereabouts (Tofte, 2007). The practical effect of the Jacob Wetterling Act was to make public the names and addresses of registered sex offenders, which ostensibly alienates them and brands them with the modern day version of "The Scarlet Letter." This practice may seem 
logical at first glance. However, research shows that this approach is ineffective and the associated ostracism may increase recidivism risk factors and reduce community safety.

Beyond the negative mental health outcomes affecting released sex offenders, researchers have found that the consequences of abuse extend far beyond the primary victim and perpetrator. The following sections will explore the consequences to secondary victims, including the family and friends of victims and perpetrators.

Defining violence as a public health issue acknowledges the need to assess and address the problem at multiple levels across the ecological model (i.e., individual, family, community, and society). In order to fully comprehend the public health impacts of CSA, it is necessary to examine its consequences not only on the primary victims, but also to those on each level of Bronfenbrenner's ecological model. The following sections explore the impact of abuse on the secondary victims, the families and friends of the victims, and offenders.

\section{The Family and Friends of Victims}

As previously noted the consequences to the victim (i.e., the "individual" ecological level) can be severe and are often the primary focus of the literature. However, the consequences to those close to the victim are also of critical concern. This focus is at the family and community (e.g., peers) level of the ecological model. Johnston and Ward (1996) recognized that sexual offending continues to emerge as a major social crisis that can result in significant psychological and emotional costs to victims' family members. As family and friends support and care for the primary 
victim, they too can suffer many adverse consequences. In response to the abuse disclosure, an initial consequence may be what has been called "compassion fatigue." While these individuals' function as the victim's support network, the act of caring for the victim becomes physically and emotionally exhausting (Cerney, 1995).

Compassion fatigue was first used to describe burnout in nurses exposed to traumatic work-related experiences (Johnson, 1992). "Secondary traumatic stress" (STS) has also been applied as a label for this phenomenon (Stark \& Flitcraft, 1988; Williams 1994).

Lieb, Quinsey, and Berliner (1998) reported that $60 \%$ of boys and $80 \%$ of girls sexually victimized as children were assaulted by someone they knew. Freyd and her colleagues (Freyd, Putnam, Lyon, Becker-Blease, Cheit, Siegel et al., 2005) agreed that most CSA is committed by family members or individuals close to the child. When CSA occurs within a family context, it is easy to recognize how disintegration of the family unit due to divorce or other conflicts resulting from the abuse disclosure can take a significant toll on all family members.

\section{The Family and Friends of Offenders}

It is also important to take into account the physical, financial, psychological, and other consequences to the families of offenders (i.e., the family level of analysis of the ecological model). Often, offenders' family members become targets of public criticism. They may be subjected to ostracism and harassment from community members and may suffer emotional difficulties as well (Tewksbury, 2005). Family 
members may lose the social support of friends, work colleagues, and extended family members for choosing to continue their involvement with the offender.

In 2007, a report authored by Sarah Tofte and published by the Human Rights Watch on sex offender laws included interviews with individuals affected by residency restrictions placed on offenders. Many of the interviews with offenders and their family members describe how registration laws have adversely affected their lives (e.g., losing homes and jobs as well as having to live separately). Families of offenders may also face the financial burdens of being expected to shoulder the responsibility of paying costs associated with both the legal proceedings and treatment of the offender. Additionally, in cases where the offender has been assigned to provide restitution, family members may suffer from diminished financial resources as the offender meets his or her restitution obligations. In some cases, families must relocate, either to avoid harsh social consequences and/or to be involved in the offender's treatment while he or she is incarcerated. In some cases, it is easy to see that the families of intra-familial juvenile offenders may take the "hardest hit", paying for offender, victim, and family treatment costs as well as legal fees.

\section{Community and Society}

Finally, as pointed out in the introduction, all members of society are affected by CSA in some way. Therefore, it is important to evaluate the impact CSA has on the local community and on society as a whole. Quantifiable consequences to the community include: reduced feelings of safety; a decreased sense of freedom to have their children play unsupervised safely; a waning trust of others with enhanced 
concerns about neighbors and babysitters; and greater taxpayer responsibility to cover the expenses associated with CSA-related investigations, prosecutions, incarcerations, and treatment. These expenses also include funding for police, judicial and children's services employees, victims' services staff, and prevention programs. A 1996 report from the United States Department of Justice estimated that the rape and sexual abuse of children cost American taxpayers $\$ 1.5$ billion in medical expenses and $\$ 23$ billion annually overall (Putnam, 2001). This estimate demonstrates how costly CSA is to us as a society. Public funds are used to provide support for victims, to support our public safety and judicial systems, to pay for incarceration and treatment for offenders, and to pay for personnel to monitor offenders on parole and probation. Shanahan and Donoto's (2001) cost-benefit analysis of treating adult offenders of child sex abuse was one of the few peer-reviewed articles to discuss the costs of sexual offending beyond those incurred by justice-related institutions. Previously, a study by Prentky and Burgess (1990) was recognized as the only attempt at gathering data on the costs incurred by the families of victims and to society at large. Shanahan and Donoto (2001) estimated that the tangible cost to victims averaged \$1,000 (1998 Australian dollars). This would have been equivalent to $\$ 1,650$ in US currency (FRB, 1998) per identified victim. They also recognized that the intangible damages are the most difficult to calculate and were, perhaps, the most difficult to overcome. In a comprehensive report prepared by the United States Department of Justice on the economic costs of crime, the injuries compensated for in child sex abuse were found to be the most expensive of all crime categories. The report estimated the intangible costs 
of child sex abuse to be approximately $\$ 90,000$ (1993 US dollars) per criminal victimization (Miller, Cohen, \& Wiersma, 1996).

At the same time, questions remain regarding the efficacy of community-level efforts, including offender registration and community notification. According to Tofte (2007), there is insufficient evidence to determine whether posting information about registered sex offenders on the Internet is a valuable and effective public safety tool. Research suggests that registration laws and subsequent community notification actually result in the community developing a false sense of security (USDJ, 1997). Additionally, because a majority of sex offenders do not appear on registration lists, a child may be in close proximity to or endangered by sex offenders without parents ever realizing it (Matson \& Lieb, 1996).

Offenders may not appear on registration lists for a variety of reasons, including the fact that each state has different requirements and procedures surrounding registration of sex offenders (USDJ, 2008). For example, some offenders plead to lesser charges in legal proceedings, and thus, avoid registration requirements (Ingram, 1999). Finally, it is important to consider that many offenders do not face any charges because they are simply never caught (Salter, 2003).

In some cases, notification may actually cause immediate problems for the community. Zevitz (2004) suggested that residents notified of a convicted sex offender moving into their neighborhood actually experienced negative consequences that include a heightened sense of vulnerability, a lack of control over their environment, and a sense of helplessness and anxiety. The acceptability of these unintended 
consequences is questionable given the current lack of evidence supporting the efficacy of notification initiatives.

In order to better understand the policies and laws directly applicable to participants included in the current study (i.e., youth within the jurisdiction of the Oregon Youth Authority), the following section will provide detail regarding the legislative measures and statues that shaped the environment, as well as clarify important historical milestones during the development of sentencing guidelines. The Oregon Youth Authority (OYA) and Oregon Revised Statutes (ORS)

There has been considerable discussion about how to reduce the cost for incarceration of prisoners, since this is often one of the most discussed societal consequences. In the state of Oregon, incarceration of minors is referred to as "detention". One of the most effective ways to lower the cost of juvenile offenders' detention would be to reduce the number of offenders that need this service. In order to have a better understanding of how crimes by youth are classified in Oregon, the next section will provide some basic statistical information about juveniles in OYA's custody. This information will include: the number of individuals detained, a breakdown of crimes for which youth have been adjudicated, details on budgetary expenditures related to crimes, and the seriousness of youths' crimes and sentencing guidelines established as a result of Oregon Ballot Measure 11.

It is important to clarify some basic OYA terminology before discussing the population of interest in the current study. The term "referral" denotes any time a youth's information is passed to a Juvenile Department for the purpose of 
investigation of a crime as defined by Oregon Revised Statutes. "Committed" describes the action taken by a juvenile court judge where a youth is placed into OYA's legal custody. A child may be placed within OYA's legal custody and remain in his/her home under the supervision of parents or be placed in a foster home in conjunction with the Department of Human Services (DHS). Committed youth may be required to attend an organized program in the community, which can include education, counseling, job skills training, or any combination thereof. When one is under the jurisdiction of a juvenile court and not in detention, he/she is supervised by an OYA Juvenile Parole/Probation Officer (JPPO). When a juvenile is placed in detention, he/she is removed from the parental home or foster home and housed within an OYA facility. In other words, detention is synonymous with the term incarcerated in the adult prisoner population.

A report released by OYA in March of 2009 stated that during 2007, 11,176 Oregon youth between the ages of 10 and 17 years of age had been placed in detention. The vast majority of these youth were male and $85 \%$ of these youth remained in custody for more than 31 days (JJIS. 2009). The report also provided an ethnic breakdown for the sample as follows: White $-60 \%$; Hispanic $-22 \%$; African American - 10\%; Native American - 4\%; Asian - 1\%; and 3\% as "Other" or “Unknown”. The bi-annum budget for OYA from July 1, 007 through June 30, 2009 was $\$ 12,040,000$ (JJIS, 2009), with an annual budget of approximately $\$ 6,000,000$. Of course, not all youth referred to OYA are placed into detention. For the calendar year 2007, 26,189 youth received services through OYA. State reports for 
that period of time indicated that 17,270 youth were referred to OYA for criminal charges and 6,677 youth were referred for non-criminal charges. An additional 2,242 youth were referred for dependency code violations (see Table 1) during this same time period. The Oregon Juvenile Justice Department (OJJD) breaks charges down into five categories: person, property, public order, substance/alcohol, and other nonspecific criminal charges.

Table 1 reflects the percentage of individuals referred based on the five major crime categories, as well as sub-categories for those offenses. In Oregon, offenses fall into two categories: crimes (felony or misdemeanors) and violations. An individual convicted or adjudicated of a crime can be sentenced to jail or prison time, while violations or non-criminal offenses can only result in fines. Non-criminal charges include: substance/alcohol, alcohol minor in possession, curfew, and possession of less than one ounce of marijuana, as well as motor vehicle, tobacco, and other non-detailed offenses. Dependence charges include contact by law enforcement officers for runaway calls.

Table 1 clearly demonstrates that almost $70 \%(17,270)$ of the youth involved with OYA in 2007 were there as a result of criminal charges and less than $3.7 \%$ (638) were involved with OYA due to sex offense charges. This information is important in relation to the population in the current study.

In order to understand the sentencing and custody arrangements for the youth included in the current study, the following sections will outline a basic history of OYA and Oregon Ballet Measure 11. 
History of the Oregon Youth Authority (OYA) and enforcement guidelines

In 1995, the Oregon legislature passed Senate Bill 1, which created the Oregon Youth Authority (OYA) as an independent department to operate juvenile correction facilities, parole supervision, and other programs. At the time of its creation, OYA had under its control five regional facilities and five "camp" facilities designed to house work and school programs for youth within the custody of OYA. In Oregon, Oregon Revised Statute (ORS) 163 delineates criminal charges into categories including: crimes against persons, crimes against property, and crimes involving fraud or deception, as well as crimes against the public order and crimes against the public health and decency. A list of Oregon Revised Statutes can be found in Appendix A. Another important enforcement guideline relevant to the discussion of the detention of juveniles in Oregon is Measure 11. Ballot Measure 11 was approved by Oregon voters on November 8, 1994, and it established mandatory minimum sentences for 16 felonies. Measure 11 also required that any youth 15 years or older who was charged with a Measure 11 crime to automatically be prosecuted as an adult. Under Measure 11, minimum sentences were mandated for a number of sex crimes or crimes related to sex crimes as shown in Table 2. Under the Statues of the State of Oregon, adolescents aged 16 years or younger are mandated to remain in the care of OYA. However, individuals 16-18 years of age and adjudicated on crimes covered under Measure 11 are placed into the custody of the Oregon Department of Corrections (DOC) and then transferred into the care of OYA, and may remain in their care until their $25^{\text {th }}$ birthday. Juveniles who pose a security or disciplinary risk can be 
returned to the custody of DOC after their $18^{\text {th }}$ birthday to serve the remainder of their sentences. It is possible that those who do not pose a risk will complete their sentence within facilities run by OYA up until age 25 .

While no definitive causal or correlational links have been uncovered to explain the etiology of sexual offending behavior, there is a thirty plus year history of research in this area that provides significant insight. Researchers have examined numerous variables associated with offending behavior, including offender socioeconomic status, race, and seriousness of any offenses, personal victimization history, and patterns of perpetration. Numerous researchers, including Dalaiden, Kaufman, Hilliker, and O’Neil (1998); Smallbone and McCabe (2003); and Hunter, Figueredo, Malamuth, and Becker (2003), found that sex offenders are a heterogeneous group, and therefore there is no one-size-fits-all approach to understanding the perpetration of sexual crimes. Thus, it is reasonable that numerous etiological theories have been proposed. The next section will review some of the more popular theories of sexual offending. 


\section{Chapter 3: CHILD SEXUAL ABUSE MODELS}

Research on juvenile sex offenders can be traced back more than 50 years. Yet, most of what is known is due to a surge of interest in the mid-1980s (Chaffin, Letourneau, \& Silovsky, 2002). Many theories have been offered by researchers and clinicians alike to explain the etiology of adolescent sexual offending. Most of these theories have been borrowed from the adult sex offender literature. This section provides a brief overview of the predominant single and multi-factor models intended to explain adolescent sex offending behavior. First, a description of single factor models will be provided, including Biological, Behavioral, Socio-cultural, and Attachment/Intimacy models. Following the single factor model explanations, a brief overview of the four most common multi-factor models will then be offered. These models include the Integrated Theory of Offending, the Confluence Model, the Pathways Model, and the Relapse Model. Finally, the significant role of attachment theory in these theories will be highlighted.

\section{$\underline{\text { Single Factor Models }}$}

Single factor models represent attempts to explain child sexual abuse perpetrated by juvenile offenders based on one key underlying dimension. These models represent a broad array of explanations from more physiologically oriented explanations to more culturally based ones.

\section{Biological}

The Biological model explains sexual offending by suggesting that biological factors predispose individuals to sexually offend. One of the most common biological 
factors implicated in this relationship is the presence of high levels of testosterone, i.e. higher levels of testosterone have been found to be associated with an increased sex drive and heightened aggression levels (Brooks \& Redden, 1996; Choi, Parrott, \& Cowan, 1990).

Biological theories, such as the testosterone theory, have recently fallen out of favor. This is due, in part, to the fact that we as a society want our "criminals" to be held accountable for their actions, and thus punishment is appropriate. Acceptance that there could be a biological cause to certain types of offending behavior would not place responsibility on behaviors under one's volitional control. Ryan (2010) suggested that although physiological/biological theories seem to be a promising area of research, they are less palatable. According to Ryan, "If offenders are helpless to control their behavior because of an inborn condition, then society is also helpless, and neither can be held responsible" (2010, p. 16).

Another reason that biological theories, especially those that involve testosterone, have fallen out of favor has been explained by researchers such as Book, Starzyk, and Quinsey (2001). They offer that although strong links have been identified in animal studies, research with more complex and more social populations, like humans, this biological aggression is moderated by social, cognitive, and emotional cues. Archer (1991) also offered that although there are correlational links between high testosterone levels and aggressive behavior, research has shown that we may be putting the cart before the horse. Evidence suggests that testosterone increases after aggressive and competitive incidences (Archer, 1991). 


\section{Behavioral Theory}

Models which posit that sexual offending behavior develops as a result of conditioning or learning have been referred to as "behavioral models." An example of a behavioral model would be one that suggests that individuals raised in a familial environment where a father (or other male role model) commits domestic violence against that individual's mother (or another female partner) results in an individual who learns it is acceptable to demean and degrade women (Ward, Hudson, \& Keenan, 1998; Ryan, 2010). This theory, of course, would only explain male-on-female sexual perpetration.

Behavioral models would also include those suggesting that viewing pornography serves as a model for engaging in sexual aggression. The deleterious effects of pornography have been explored for many years. The first large-scale exploration occurred with the creation of the Presidential Commission on Obscenity and Pornography (1970). Although the commission found no causal relationship between exposure to pornography and deviance, criminality, or delinquency (USDJ, 1986), researchers have continued to explore this possibility. Seto, Maric, and Barbaree (2000) performed a meta-analysis of the existing research literature on the association between pornography and sexual aggression, including Marshall, Laws, and Barbaree (1990); Schachter and Singer (1962); Brownmiller (1980); Bandura (1973, 1977); Kutchinsky (1991); Allen, D'Alessio, Emmers, and Gebhardt (1996); and others. In their study, Seto et al. (2001) found little support for a direct causal link between pornography use and sexual aggression. This finding demonstrates that 
behavioral models may not be as important to the prevention and treatment of sexual abuse as once thought.

\section{Socio-cultural Theory}

Socio-cultural models emphasize that it is actually social and cultural norms that shape the way individuals view violent behavior (Ryan, 2010). A socio-cultural model would suggest that an individual who is exposed to violent video games and graphic media will be encouraged to engage in violence and the domination of women.

An exploration of this model can be found in the early work of Burt (1980). This research demonstrated that there is a complex web of attitudes and beliefs surrounding rape in western culture, which allows Americans to dismiss and minimize reports of sexual assault. Specifically, she found that more than half of her sample of 598 American adults agreed with statements including: "A women who goes to the home or apartment of a man on the first date implies she is willing to have sex," "In the majority of rapes, the victim was promiscuous or had a bad reputation," and that a woman reporting rape "was trying to get back at a man she was angry with" or "was trying to cover up an illegitimate pregnancy" (Burt, 1980, p.223). These statements are often referred to as rape myths.

Franiuk, Seefelt, and Vandello (2008) say these models and even the perpetuation of myths continue because they act as a coping mechanism that allows people to explain away negative events. In other words, bad things only happen to bad people and if I am not a bad person I am safe from bad things happening to me. It 
allows for a sense of control and protects us from the uncomfortable truth that victims and perpetrators are just like us and our close friends and family members. Franiuk et al. (2008) also found that there is a wealth of research showing that current media still contains messages that reinforce rape myths and blames the victim. These reinforcements can be found in entertainment, news, and print. In their analysis, they found that almost $10 \%$ of newspaper headlines reporting sexual assaults supported rape myths, and even more, $23 \%$ were biased against the victims. Perhaps the most important suggestion by these researchers is that media coverage not only perpetuates rape myths, but causes harm by discouraging future victims to report crimes due to self-blame and fear of judgment (Franiuk et al., 2008).

Capella, Hill, Rapp, and Kees (2010), on the other hand, offer that there may be an alternative explanation for the link between violent media and sexual assaults perpetrated by men against women (i.e., men are more likely to view this type of entertainment than women). Haridakis (2006) offered that indeed it may be the individual's preference and personal characteristics that influence what they watch, how the exposure affects them, and how it ultimately shapes any resulting behavior. Attachment/Intimacy Theory

Finally and more directly related to this research, attachment theory suggests that individuals who did not develop a healthy relationship with their primary care givers do not have "tools" needed to engage in developmentally appropriate relationships (see “General Attachment Theory” for a more detailed discussion). Although wholly intertwined, "attachment" and "intimacy" do have slightly different 
definitions. Attachment was defined by Bowlby (1969) as "a lasting psychological connectedness between human beings" (p.194). In other words, attachment is demonstrated in a lasting pattern in a long-term relationship. Intimacy has been conceptualized as a feeling that can only be understood as the subjective experience of closeness toward another person, or "a feeling of connection or joint belongingness" (Camarena Sarigiani, \& Petersen, 1990, p. 20).

William Marshall $(1989,1993)$ connected these two concepts in sex abuse research when he defined attachment issues as an "intimacy deficit," which results in individuals who cannot find age and developmentally appropriate romantic partners; therefore, they engage instead in "abusive" or inappropriate acts. Ward, Polaschek, and Beech (2006, p.11) stated that "attachment theory was an advance on the social skill deficit hypotheses, and offered considerable heuristic value, greater explanatory depth, external consistency and greater unifying power" in explaining sexual offending behavior. That same year, Rich (2006) detailed the history of research on the association between attachment deficits and sexual offending. He acknowledged that although attachment is not the "X factor" that explains all sexual offending behavior; it has become an important avenue to explore. He further recognized that Marshall, Hudson, Ward, Smallbone, and others started this exploration in the mid1990s. A more detailed exploration of the existing research evaluating the relationship between attachment and sexual offending can be found in later sections entitled Attachment and Adult Sex Offenders and Attachment in Juvenile Sex Offenders. 


\section{$\underline{\text { Multi-factor Models }}$}

Multi-factor theories are just that, integrated theories that combine a number of single factor theories into a more comprehensive explanation of interactions that lead to an environment that results in sexual offending behavior (Gannon, Collie, Ward, \& Thakker, 2008). These integrated theories are assembled from multiple single factor biological, situational, and developmental models and incorporate environmental and cultural influences, individual vulnerabilities, and situational factors to explain particular phenomenon.

The four most discussed multi-factor models include: the Integrated Theory of Offending, the Confluence Model, the Pathways Model, and the Relapse Model. It is important to note that many of the multi-factor models were developed in an effort to explain the etiology of child sexual abuse and include attachment components as part of their theory. These models recognize that failing to develop quality relationships with parents or care givers early in life can result in an inability to form appropriate, intimate connections; therefore, these failings become risk for offending behavior (Sprott, Jenkins, \& Doob, 2000).

The following section examines the four most widely accepted multi-factor models of sexual offending by providing: 1) a definition of each model; 2) recognition of the individual(s) credited with developing the particular model; 3) an assessment of how well the model explains juvenile sexual offending, and finally 4) an explanation and clarification of the model's relationship to attachment. 
Integrated Theory of Offending (ITO)

The influential Integrated Theory of Offending (ITO) suggests that offending behavior may be the result of a combination of biological, developmental, environmental, and cultural influences; individual vulnerabilities; and situational factors. This theory, developed by William Marshall and Howard Barbaree, proposes that sexual abuse occurs as a result of interacting distal and proximal factors. One of the main premises of this theory is directly based on attachment theory in that it stipulates that when an individual grows up in an environment where they experience poor parenting and inconsistent and/or harsh discipline and physical or sexual abuse; they develop distorted "internal working models" of relationships. The term "internal working model" is the cornerstone of John Bowlby's theoretical work, which will be elaborated in a later discussion of General Attachment Theory.

In addition to the inability to form healthy attachments, Marshall, Laws, and Barbaree (1990) asserted that individuals with this distorted internal working model establish poor social and self-regulation skills from an early age, which makes the critical transition into adolescence even more difficult than normal. Specifically, when an individual is deficient in the competence to create and maintain appropriate relationships with peers, they behave in an "anti-social" manner. This predisposition to anti-social behavior interacts with the biological rush of hormones that occurs when they reach puberty and amplifies awkward interactions with potential intimate partners. When faced with rejection, this exaggeration results in lower self-esteem and increased anger and negative attitudes towards peers. 
ITO theory goes on to suggest that these powerful negative emotions, fueled by normal sexual desires, can lead to the development of deviant sexual fantasies. Ward and Beech (2006) suggest that an adolescent that "lacks the capacity to manage his feelings of unhappiness and anxiety" i.e.: suffers from a lack of emotional regulation, may develop deviant thought patterns and often begin to seek relationships with younger children because they are perceived as inherently less threatening, more trustworthy, and less likely to reject their relationship overtures.

ITO has been explained as an elegant theory that incorporates the ecological, social learning, circumstantial, and biological factors needed to explain sexual offending behavior (Ward \& Beech, 2006). These same authors also found a number of problems with ITO. First, they suggested that the incorporation of self-regulation into this theory was problematic. In fact, they found that only a small number of sex offenders have self-regulation difficulties. A second problem Ward and Beech (2006) identified with ITO involved a general lack of cohesiveness. In other words, by including a number of possible antecedents to sexual offense behaviors, ITO recognizes that offenders are individuals and that there is not a one-size-fits-all approach when understanding etiology or developing treatment plans for offenders. Confluence Model of Offending (CMO)

Developed at about the same time that Marshall, Laws, and Barbaree first published information on ITO, the Confluence Model of Offending (CMO) was offered as an alternative explanation for sex offending. This model shares many of the same basic presumptions with ITO. Created by Neil Malamuth and his colleagues 
(Malamuth, 1996; Malamuth, Heavey, \& Linz, 1993; Malamuth, Sockloskie, Koss, \& Tanaka, 1991), the confluence model is based on feminist and social learning theories but was expanded to include various aspects of evolutionary psychology. Malamuth asserted that rape developed in the context of "natural selection," in that the strongest men had to be able to function sexually even without a willing partner. The CMO theory borrowed from evolutionary psychology in asserting that differing "mating" patterns between men and women evolved because of their divergent commitments to parentage. According to Ward and Beech's (2006) description of CMO, men need only minutes to contribute their genes to offspring while women need many months. Early contributions from social learning theory also remained a part of the tenants of CMO and added the idea that environmental influences could account for individual differences in the risk of sexual offending behavior.

These environmental influences are drawn from early childhood developmental experiences, peer influences, and cultural contexts. In other words, individuals who offend do so because their early relationships do not allow the development of the interpersonal skills needed for mature socio-sexual relationships (Ward \& Beech, 2006). Individuals with this “antisocial orientation” rely on domination and coercion to get what they want rather than seeking intimacy within a caring relationship. Although CMO is based on extensive theoretical frameworks, including social learning theory, evolutional psychology, and attachment theory, Malamuth's work focused exclusively on research done with male college students. Further, Malamuth's analyses revealed that only parental violence and childhood 
abuse (sexual and physical) were strong predictors of sexual aggression (Malamuth, 1996). Ward and Beech (2006) point out in their review of the theory that CMO does not fully discuss recent work on attachment, intimacy deficits, victim empathy, and self-regulation styles and is therefore not a fully realized theory. This shortcoming may be due to the fact that Malamuth's original research sample was limited to high functioning college males in the 1980s.

\section{The Pathways Model (TPM)}

The Pathways Model (TPM) model was first developed by Tony Ward and Richard Siegert (2002) in an effort to "knit" together the best parts of many etiological theories of CSA to provide a "a comprehensive aetiological theory" (Ward \& Beech, 2006, p.44). The authors hoped this new blended theory would account for "the wealth of cognitive, emotional, interpersonal and sexual factors evident in child sex offenders." The original model proposed that there were five distinct "pathways" that led to offending behavior: (1) intimacy and social skills deficits, (2) distorted sexual scripts, (3) emotional dysregulation, (4) anti-social cognitions, and (5) multiple dysfunction deficits, or a combination of two or more of the first four pathways (Ward $\&$ Seigert, 2002).

The most salient pathway of Ward and Seigert's (2002) model for this examination is the one that focuses on intimacy and social skill deficits. In describing this pathway, Ward and Beech (2006) acknowledged that in the 15 years between 1990 and 2005, many theorists had attributed deficits in intimacy and social competency to insecure attachment styles. These authors went on to explain that for 
some individuals, early developmental experiences result in distorted "internal working models." Someone with this distorted model has an expectation that people around them are "emotionally unavailable" when they need them (Ward \& Beech, 2006, p. 63). Further, insecurely attached offenders see the world as a "dangerous place" and believe that they cannot disclose their true perspective or feelings for fear of rejection and/or punishment. Ward and Beech (2006) also acknowledged that insecure infant attachment sets a "template" for subsequent "adult intimate relationships" (p. 64), which does not allow for true intimacy. These "attachment" concepts are taken directly from the work of Bowlby, 1969, 1973, 1980, 1988; Main, 1981, 1990; and Bartholomew, 1990, 1991). TPM was expressly designed to be broadly applicable and explicitly address a wide range of etiological variables to provide a deep explanatory account of child molestation (Ward, Hudson, \& Keenan, 1998; Ward \& Beech, 2006). Due to this theory’s flexibility, as well as the recognition that there is not a "one size fits all" pattern to the evolution of sexual offending behavior, this model seems the most pertinent of the theories seeking to explain JSO behavior.

\section{The Relapse Model (RM)}

The final model to be reviewed is the Relapse Model (RM). This multi-factor model is often used to conceptualize not only how sexually abusive behavior develops, but also how it can be prevented as part of an offender's treatment goals. This model evolved over the last 25 years. Originally developed by Marlatt and George (1984) to explain relapse behavior in drug and alcohol abusers, RM proposes that negative life 
events, current obligations, and everyday hassles create stress and motivate an individual to indulge in the use or abuse of mind altering substances. It also explains that relapse can develop as a result of a series of apparently irrelevant decisions that undermine an individual's sense of self-control.

At approximately the same time as G. Alan Marlatt published his work with William George (1984), Marlatt was also working with Pithers, Marques, and Gibat (Pithers, Marques, Gibat, \& Marlatt, 1983) to expand RM theory by saying that as an offender develops a sense of self control with periods of offense-free behavior, they often place themselves into high-risk situations (HRS) without awareness. Pithers et al. (1983) also recognized that offenders suffer from cognitive distortion, allowing for rationalization and denial, and they concluded that treatment programs that include cognitive behavioral therapy can reduce relapse.

In applying RM to sex offenders, Ward, Polaschek, and Beech (2006) explained that "an excess of obligations, hassles and negative life events" rather than "pleasant events" creates stress and motivates an individual to give into urges and cravings (p. 214). They specifically named "a lack of connectedness to others and poor social skills" among the unpleasant life events that can trigger offense behavior.

RM is often considered to be a high-risk prevention model (Ward et al., 2006), and therefore geared more towards treatment than etiology. Ryan (2010) explains that "high-risk cycle" theories such as RM are helpful in the prevention setting because they offer opportunities for clinicians to help their patients identify patterns that may lead to offending behavior. For instance, Ryan (2010) suggests that many youth 
identified as sex offenders progress from having "normal" sexual thoughts to developing deviant fantasies and carrying out plans that are sexually abusive. She goes on to say that abusive youth often lack both the social skills and the opportunity to be with age appropriate mates and become unable to cope with stress in their daily lives (Ryan, 2010). The key link between RM of offending and attachment can be seen in the stages of hopelessness, isolation, and fantasy in the exploration of Ryan's (2010) cycle of risk. In "normal” development, a child learns how to interact appropriately with others based on the quality of attachment in their early relationships with their caregivers (Bowlby, 1969, 1973, 1980, 1988). When an individual's pattern of relating to others does not develop into a "secure attachment style," the individual is more prone to feel alone and isolated. She/he is also not equipped to participate in healthy and appropriate peer relationships.

Clearly, existing theories point to multiple underlying factors associated with the etiology of sexual offending. Moreover, agreement on the existence of multiple pathways to offending underscores the importance of careful individual assessment of offenders and the development of tailored treatment plans to enhance treatment efficacy and prevent recidivism. At the same time, much is still to be learned about the effective treatment approaches of JSOs.

\section{$\underline{\text { Current Treatment Modalities }}$}

Ryan (2010) indicated that much of the early development of juvenile treatment programs has been modeled after treatment regimens used with adults. She indicated that in the 1980's, offenders' behaviors were studied in order to develop 
"offense-specific treatment strategies" to address attitudes, beliefs, and thinking that rationalize abusive behavior (p. 263). Ryan (2010) has suggested that successful treatment of juvenile offenders requires a more comprehensive approach that includes both the evaluation and treatment of contextual and developmental risks to decrease deficits and increase strengths.

In 1999, the Center for Sex Offender Management (CSOM) released a brief report outlining the accepted research, treatment, and management practices regarding JSOs. This report concluded while it appeared that JSOs responded well to both cognitive behavior therapy and relapse prevention programs, the best designed investigation indicated that Multisystemic Therapy (MST) was most effective (Borduin, Henggeler, Blaske, \& Stein, 1990). Over the years, a number of studies have confirmed significant reductions in recidivism with the use of MST for JSOs (Letourneau, Henggeler, Borduin, Schewe, McCart, Chapman, \& Saldana, 2009; Schaeffer \& Borduin, 2005).

MST has been described as an intensive family and community-based treatment plan that addresses the many aspects of anti-social behavior, including sexual offending (CSOM, 1999). In fact, this approach includes not just the treatment provider and primary "client" but involves a broad array of treatment collaborators (e.g., family members, peers, school staff, community members, and justice representatives). The primary goal of MST is to promote a positive change in the behavior of the youth within their natural environment, building on the existing support structures to facilitate change. As one of the primary goals of MST is to 
improve family and other relationships (i.e., attachment to others), its focus is directly related to the aims of the current research project.

Beyond MST, Steinberg (2006) found in her review of the literature that juvenile treatment programs, which include components aimed at improving primary interpersonal relationships and peer support, prove most successful. Heppler (1997) concluded that bolstering the positive aspects of family influence and enhancing emotional support can increase positive outcomes in children that have previously engaged in sexually abusive behavior.

When these studies refer to bolstering positive family influence and emotional support, they are really talking about increasing the level of attachment or what Bowlby (1980) described as a "lasting psychological connectedness between human beings" (p.169). Recent research demonstrates that an attachmentinformed perspective to treatment and rehabilitation can be effective in working with juveniles who have sexually offended (Rich, 2010).

At a seminar held in Clackamas County, Oregon, Dr. Rich (2010) delineated seven critical elements necessary to understand attachment in relation to adolescent offending behavior. He indicated that early attachment experiences, especially during the first 5-18 months of life, form the building blocks for all future relationships, including social interactions, social attitudes, and social behaviors. The seven elements identified by Dr. Rich are the development of: (1) meta-cognition, (2) empathy, (3) moral reasoning, (4) the capacity for selfregulation, (5) trust and confidence in others, (6) trust and confidence in self, and 
(7) the development and capacity for a sense of social connectedness. Dr. Rich has identified these seven elements based on years of clinical experience and research.

This concept of attachment or how family structure is related to delinquency is not new. Cernkovich and Giordano (1987) wrote about the importance of family interaction and social control theories of delinquency more than 25 years ago. Cernkovich and Giordano's (1987) research was based on the early work of John Bowlby, who is often recognized as the father of attachment theory. Bowlby's (1944) work examined family structure and its connection to juvenile offending behavior. According to Bowlby (1990), a strong relationship with or an attachment to parents/caregivers and other family members represents an important aspect of normal interpersonal development. It follows logically that identifying a relationship between a JSO's dysfunctional family interactions or disordered attachment style and the etiology of juvenile offending would support the notion that interventions fostering stronger, more positive relationships with family members, peers, and community should reduce offense recidivism.

As mentioned above, attachment theory has been used in the evaluation of juvenile behavior since early in its conception. John Bowlby first discussed the importance of family interaction in the histories of juvenile non-sexual offenders in his paper entitled "Forty-four juvenile thieves: Their characters and home lives" (Bowlby, 1944). Bowlby expanded his conception of attachment in his trilogy of books on the subject published in 1969, 1973, and 1980. The following section will describe and provide a brief review of attachment theory beginning with Bowlby’s work. 


\section{Chapter 4: ATTACHMENT THEORY}

\section{History of Attachment Theory}

\section{John Bowlby's Attachment Theory}

Attachment theory has been used to describe and explain an individual's enduring pattern of relationships from birth to death. According to Bowlby (1980) and Ainsworth (1989), the love between a mother and an infant is the result of an attachment bond formed during the first year of life. Moreover, interactions between a child and his/her mother form behavioral patterns that shape later relationships. Attachment has also been conceptualized as the stable tendency of an individual to seek and maintain proximity to and contact with one or a few specific individuals (Montebarocci, Codispoti, Baldaro, \& Rossi, 2004). Prominent researchers in the field of attachment have included John Bowlby, Mary Salter Ainsworth, Mary Main, and Kim Bartholomew.

Early in his career, John Bowlby (1944) became convinced of the significance of real-life events on the course of child development. Specifically, he chose to focus on a child's early separation from his/her mother. This was due, in part, to the fact that information regarding familial separation was available through existing records, while documentation of disturbed family interactions was very difficult to obtain (Ainsworth \& Bowlby, 1991). Bowlby's investigations led to the formulation of his attachment theory (Bowlby, 1969, 1973, 1980). In this theory, he proposed that early in life, all human children are dependent on others for their basic needs. To meet those needs, they form relationships with other individuals, who he referred to as 
"attachment figures." Bowlby described attachment as an emotional bond that impacts behavior from the cradle to the grave. This insight revolutionized thinking about a child's connection to his/her mother and the long-term harm caused by disruption of this relationship through separation, deprivation, or bereavement (Bretherton, 1992). Bowlby's view of the significance of attachment relationships is reflected in the following statement, "Attachment behavior is any form of behavior that results in a person attaining or maintaining a proximity to some other individual who is conceived as better able to cope with the world" (Bowlby, 1988, p.27). Bowlby (1969) stated that the mental representations or "working models" of self and others form in the context of the child-caregiver relationship. He also suggested that these working models carry forward and influence thought, feeling, and behavior in teen and adult relationships.

\section{Mary Ainsworth's Contribution}

Mary Ainsworth also began her research career concerned about how secure an infant felt with his/her caregiver (Ainsworth \& Bowlby, 1991). In graduate school in the 1940's, Ainsworth worked with William Blatz and studied his Security Theory (Blatz, 1966). In the early 1950's, Ainsworth worked as part of Bowlby's research team, which she often said shaped her work tremendously (Bretherton, 1992). During the 1950's and 1960's, Ainsworth continued her attachment work with a focus on infants. She developed a system for classifying infants into one of three categories: (1) securely attached, (2) insecurely attached, and (3) non-attached (Ainsworth \& Bowlby, 1991). During the 1970’s, Mary Ainsworth expanded her work on attachment with the development of a laboratory experiment she called the "Strange Situation." Bretherton 
provided the most concise explanation of The Strange Situation in her paper entitled, "The Origins of Attachment Theory," in which she described it as:

...a 20-minute miniature drama with eight episodes. Mother and infant are introduced to a laboratory playroom, where they are later joined by an unfamiliar woman. While the stranger plays with the baby, the mother leaves briefly and then returns. A second separation ensues during which the baby is completely alone. Finally, the stranger and then the mother return (Bretherton, 1992, p. 771).

During the observation phase of the experiment, Ainsworth, Blehar, Waters, and Wall (1978) watched the children (i.e., 12 to 18 months of age) and recorded their behavior in response to their primary caregiver leaving or returning to the research laboratory where the study was conducted. The research team watched for a variety of behavioral indicators, including signs of anxiety, anger, positive affect, and avoidance. All of these behaviors share a focus on maintaining proximity or closeness to a caregiver and reflect attachment behaviors triggered by a perceived threat. Based on these observations, Ainsworth, Blehar, Waters, and Wall (1978) concluded that there were three major "styles" of attachment: (1) secure attachment, (2) ambivalentinsecure attachment, and (3) anxious-avoidant attachment.

According to Ainsworth, a child who is secure will explore freely while the mother is present, engage with strangers, be visibly upset when the mother departs, and be happy to see the mother when she returns. However, a secure child will not engage with a stranger if his/her mother is not in the room. A child that is ambivalentinsecure will be wary of exploration and strangers even when the mother is present. When the mother leaves the room the child will be extremely distressed, and will be ambivalent when she returns. In other words, the child will behave in a way that 
demonstrates a desire to remain close but also indicates resistance when the mother initiates closeness. Finally the anxious-avoidant child demonstrates through behavior that he/she is not attached to his/her mother. These children will display little or no emotion when the mother leaves or returns. The child may, in fact, run away from his/her mother when she approaches and/or fail to "cling" to her when he or she is picked up. Additionally, an anxious-avoidant child will not explore, regardless of whether strangers are or are not in the room. In fact, strangers are treated in much the same fashion as the child's mother. Moreover, little affect is displayed at all regardless of whether his/her mother is in the room, a stranger is in the room, or if he/she is left alone. Findings from Ainsworth's work contributed to the conceptualization of an "attachment figure" as a secure base from which an infant can explore his/her world. She also formulated the concept of maternal sensitivity to infant signals and its role in the development of infant-mother attachment (Bretherton, 1992).

Following Ainsworth's development of the Strange Situation paradigm, a number of other researchers began to explore a variety of different aspects regarding the attachment relationship between mothers and infants. This led to the identification of exceptions to the three-category system (Main \& Weston, 1981; Lyons-Ruth, Connell, Zoll, \& Stahl, 1987). Eventually, a fourth model category was conceptualized and referred to as the "disorganized" attachment style (Main \& Solomon, 1990). Disorganized attachment is aptly named, as it reflects a lack of recognized coherence and organization in the behavior of the child (Martorell, 2009). As might be expected, disorganized attachment has been related to physical child abuse at the hands of 
parents (Carlson, Cicchetti, Barnett, \& Braunwald, 1989), maternal depression (Radke-Yarrow, Cummings, Kuczynski, \& Chapman, 1985), and to less severe, although still frightening, parental behavior such as intrusive or hostile caregiving (Lyons-Ruth, Repacholi, McLeod, \& Silva, 1991). While Ainsworth's original three attachment styles can be conceptualized as existing on a continuum from normal behavior to disorganized attachment, it is thought to be a marker of problems in the infant-caregiver relationship (Martorell, 2009).

Evaluating the Impact of Additional Attachment Figures

As described previously, many early studies surrounding attachment theory discussed only the quality or strength of the relationship between the child and his/her mother. Although research has shown that this primary relationship is an important one, there is also a wealth of research demonstrating that the relationship between a child and his/her father (or a father figure) or peers are just as important. The following section will discuss these "other" important relationships to healthy human development. First, the important relationship between an individual and his/her father will be explored, followed by a discussion of peer and romantic partner relationships. These will be examined within a developmental framework in order to provide an understandable trajectory of these important attachment relationships.

\section{Fathers}

Phares (1992), in her article entitled "Where's Poppa: The relative lack of attention to role of fathers in child and adolescent psychopathology," pointed out that in the normative child development literature there are more similarities than 
differences in the mothers' and fathers' roles in adolescent development. Phares further elaborated that although many children and adolescents may not live with their biological fathers, most have some contact with both biological fathers and other "father figures," including stepfathers (Phares, 1992). Other authors have also documented the importance of fathers to the healthy development of children and teens. For example, Main and Weston (1981) found that the father-child relationship was a significant predictor in the behavior of toddlers. Main, Kaplan, and Cassidy (1985) found similar results in children as old as six years of age. Further, Suess, Grossmann, and Sroufe (1992) found that secure attachment to a father resulted in less negative affect during playtime with other children. Bowlby (1990) himself said the role a father plays closely resembles that of the mother figure and may be just as important when looking at the links between offending and attachment.

Building on the theorists above additional analysis on adolescent offenders' relationships with their fathers is important for two reasons. First, in predominant United States sub-cultures, fathers or father figures are more involved in parenting children than in years past (Cabrera, Tamis-LeMonda, Bradley, Hofferth, \& Lamb, 2000). Second, early work by Marshall, Hudson, and Hodkinson (1993) suggested that when evaluating delinquent behavior by adolescents, their relationship (or lack thereof) with their fathers may be a better predictor of behavior than an individuals' attachment to their mothers. This has been supported by more recent work by Smallbone and Dadds (2001) who found that insecure attachment with fathers significantly predicted coercive sexual behaviors while attachment to mothers did not 
in a group of offenders. In other words, evaluating the strength of relationships between fathers and their sons may contribute more to our understanding of the etiology of offending behavior than only looking at the mother/child paradigm. In fact if a strong correlation is found between deficit attachments to fathers is found, interventions aimed at improving the relationship between youth and male role models may hold great promise for reducing recidivism as a part of offender treatment programs.

Peers

Beyond attention given to the father - child relationship, researchers have suggested the importance of peer relationships in the development of socially appropriate adolescent behavior. As children age and reach adolescence, they become less dependent on their parents and look to peer relationships to define who they are as individuals. In fact, teenagers have a high need to conform to either win approval or avoid disapproval of their peers (Craig \& Dunn, 2010). Allen \& Land (1999) suggested that during adolescence, individuals develop a new integrated strategy of attachment, which aids in the development of both long-term romantic relationships and productive careers.

As already discussed, attachment theory was first used as a way to understand how young children bond to their parents or primary caregivers. Many theorists, researchers, and professionals now realize that consistent patterns emerge in individuals as they develop through early childhood, adolescence, and into adulthood (Waters, Hamilton, \& Weinfield, 2000; Zimmerman \& Becker-Stoll, 2002; Berger, 
Jodi, Allen, \& Davidson, 2005). These individual differences are often referred to as attachment styles. In order to understand how these attachment styles continue to germinate and manifest in the development of people in general, it is important to review some of the literature exploring a significant relationship other than the parentchild relationship, that of peers. Allen, Porter, McFarland, McElhaney, and Marsh (2005) said that while we have a growing body of research on the quality of the relationship between the mother and child, we know extremely little about how security is linked to interactions with the other major relationships, including close friends and romantic partners, throughout individuals' lives.

Research on peer relationships has been conducted with various research samples, including participants as young as early childhood and as old as college students. Rose and Rudolph (2006) completed a review of the literature surrounding peer relationships and found that the benefits from friendships include a feeling of closeness, sense of security, and acceptance. It is important to point out that all of these concepts duplicate the same concepts underlying attachment theory (Bartholomew, 1990; Mikulincer \& Shaver, 2005; Bauminger, Finzi-Dottan, Chason, \& Har-Even, 2008). Successful interaction with peers builds a person's sense of social competency (Waters \& Sroufe, 1983) and is an important part of the human developmental process. The following sections will explore some of the existing studies surrounding peer relationships following the developmental trajectory of early childhood, middle childhood, early adolescence, and finally late adolescence through early adulthood. 


\section{Peer Relationships in Early Childhood}

This section will briefly discuss germane work regarding peer relationships in early childhood. It will also review the way in which theorists and researchers have conceptualized how these affiliations shape social skills during this developmental stage, as well as identify some of the measurable constructs discussed in the relevant literature. Finally, these ideas will be tied to attachment theory.

As early as 1953, Sullivan proposed that peer relationships are essential in order for children to develop and understand concepts such as respect, equality, and reciprocity. In turn, these concepts are closely linked to the quality of attachment to others. An individual who develops an understanding of equality, mutuality, and reciprocity acquires enhanced pro-social behavior (Liable, Carlo, \& Roesch, 2004). Pro-social behavior is often defined as demonstrating caring for or sharing with others; in other words, having a secure attachment style.

In 1982, Rubin looked at this same notion, but from the opposite view, one of isolation rather than connectedness. He offered that there are two distinct types of social isolation that affect children: active isolation and social withdrawal. Rubin (1982) stated that active isolation results from the purposeful rejection by peers because children are seen as misfits. The perception of these children as different can be due to ethnic differences, social immaturity, aggressive behavior, and interests that are outside the norm. The second type of social isolation Rubin (1982) described was social withdrawal, which occurs when children remove themselves from peers because they feel anxious, have low self-esteem, or feel that they do not fit in. 
In 1982, while evaluating a group of 122 four-year old preschoolers, Rubin set out to identify which children engaging in solo play did so due to active isolation as opposed to social withdrawal. Mikulincer (1998) offered that individuals who are actively rejected by others develop insecure attachment styles because they experience others as both undependable and hurtful, and often they develop a sense of unworthiness as a result of these interactions. This lack of trust in others and self is analogous to insecure attachment or having a poor "internal working model" of relationships. The children in Mikulincer's study were observed for brief 10-second intervals over a period of 30 days, and their behaviors were coded based upon a standardized checklist. This checklist measured whether the participants involved themselves in solo, parallel, or group play and whether the children engaged in unoccupied, onlooker, reading or being read to, rough-and-tumble, exploration, or conversational behavior. The children's behavior was then rated in four social categories: (a) popularity, (b) competence, (c) problem solving, and (d) vocabulary. Rubin found that children who were observed as being either unoccupied or engaged in repetitive non-motor behavior (talking to themselves) were the children their teachers identified as being maladjusted and having fewer friends. Although this correlation is interesting, it is impossible to determine any directional causality of this relationship due to the research design. In other words, did the maladjusted children play alone because they were rejected or were they rejected because they played alone? 
It is important to note in this study that children who did not fit in with or have good relationships with their peers were also perceived by their teachers as being "abnormal" or "disturbed." In a later review of the literature, Rubin, Coplan, Bowker, and Menzer (2010) found that large amounts of either type of social withdrawal in early childhood could lead to the development of loneliness, peer rejection, victimization, anxiety, and depression and that these children would suffer from impaired social interactions and relationships with peers throughout life.

\section{Peer Relations in Middle Childhood}

The next stage of human development is middle childhood. This section will briefly cover key studies that evaluate the importance of peer relationships during this developmental stage. This abridged review will identify relevant concepts examined by researchers as well as show how they are closely related to attachment theory.

Booth-Laforce, Oh, Kim, Rubin, Rose-Krasnor, and Burgess (2006) suggested that the paucity of research regarding attachment with children ages 8-12 might be a result of the inherent measurement difficulties in assessing attachment in this age group. Previously, attachment had been measured by Ainsworth and her colleagues (Ainsworth, Blehar, Waters, \& Wall, 1978) in infants by observing their attempts to obtain physical proximity to their caregivers when distressed and by Rubin (1982) who observed play behavior in preschool children. In their literature review, BothLaforce et al. (2006) concluded that the available research only evaluated attachment relationships to mothers, and it did not examine how strong children's relationships were with their fathers. 
In 1993, Parker and Asher published their findings from a large-scale investigation into peer acceptance and friendship in 881 third, fourth, and fifth graders. In their study, the researchers measured children's participation in friendships with other children and the quality of those friendships. The underlying constructs in this study were: validation and caring, conflict and betrayal, companionship and recreation, help and guidance, and intimate exchange and conflict resolution. Many, if not all, of these constructs seek to gauge the same ideas explained in Bowlby's internal working model (i.e., whether individuals view others in a positive or negative light), as well as their appraisal of whether or not others care and feel concern for them, which in turn shapes how they view their self-worth.

This study used both a battery of self-report questionnaires and a nomination procedure. In the nomination exercise, the participants self-reported how much they liked to play with each of their classmates and asked them to identify their three closest friends and single best friend. These assessments resulted in participant placement in a three-category model based on their level of acceptance by others: better accepted, accepted, and less-accepted. Parker and Asher (1993) found that children who were "better-accepted" (i.e., rated higher by their peers as playmates) were also more likely to have close friends. Conversely, the participants the researchers identified as lonely were "less-accepted" by others. These unattached individuals not only identified fewer close friends, but they scored any existing friendships as more problematic (i.e., suffering from conflict and betrayal). 
Parker and Asher's (1993) study included a robust sample and found no significant differences between participants at either end of the age range. The authors did acknowledge two important limitations of their work. First, some of the differences found in relationship quality in participants could be attributed to gender differences. Parker and Asher (1993) said that socio-culturally, boys tend to engage in more group play while girls tend to engage in play in a more dyadic structure. The second limitation noted by the researchers was the difference in within-group variability. The less-accepted group suffered a significantly larger discrepancy on scores for five of the six relationship concepts. The research team suggested that this category of individuals might have actually been composed of two distinct types of participants: those who engaged in aggressive behavior and those who were socially withdrawn or introverted.

In their attachment study, Booth-Laforce and her colleagues (2006) examined 37 female and 36 male fifth graders utilizing questionnaires and role play exercises. They found that participants' attachment to parents in middle childhood was significantly related to positive social functioning with peers (Booth-Laforce et al., 2006). Specifically, secure attachment to both mother and father were significantly related to social competence. Their findings also revealed that the children's attachment to their mothers was related more strongly to positive self-worth than attachment to fathers. This study had many strengths; for example, information was gathered from three separate sources, including the child participant, parents, and teachers, and a composite score was used to measure relationships between social 
competence and attachment. However, there were also a number of concerns related to this investigation. First, the measures used with fathers were designed for use with mothers. Second, missing data on five of the 73 father figures may have impacted study findings. Finally, it was unclear if the missing data were due to absent or nonparticipatory fathers.

\section{Peer Relations in Early Adolescence}

The next developmental stage is that of early adolescence. Hair, Jager, and Garrett (2001) offered that for many individuals their relationships with peers become more important than those with their parents during this time of change. Additionally, research demonstrates that the negative consequences experienced by insecurely attached or alienated individuals are very serious. Erickson's 8-stage theory of development outlined that during this stage an individual's sense of self emerges. It is also within this time frame that children begin to develop secondary sexual characteristics and begin their first forays into romantic relationships. These important milestones will be examined in this section within the context of a handful of the studies that have identified how healthy peer relationships continue to shape both behavior and social development. The studies will be discussed in terms of samples, methodology, and conceptual links to attachment.

Adolescence has been viewed as a time when peer group involvement gradually replaces the influence of parents. In 1993, Warr noted that adolescents spend more of their waking hours away from their parents either in school or engaged in social activities than with members of their family unit. He also suggested that 
relationships with both parents and peers can influence behavior in teens. Laible, Carlo, and Raffaelli, in 2000, set out to explore whether peers and parents play similar or unique roles in adolescent development and adjustment. Their research sample contained 89 adolescents (46 females, 43 males) recruited from one public middle school and one public high school in a midsized Midwestern city. Laible et al. (2000) examined differences and similarities in the attachment of youth with peers and their parents. They also investigated the relationship between attachment (i.e., with peers and their parents) and a variety of mental health outcomes (e.g., depression, anxiety, aggression).

Laible et al. (2000) found that as children age they feel less connected (or attached) to their parents. Their results also indicated that peer attachment was positively correlated with sympathy and negatively correlated with aggression. Strong parental attachment was significantly negatively related to depression and aggression. Adolescents who reported a greater degree of peer attachment were found to endorse higher levels of sympathy toward others, and they were more effective in using language. These participants also exhibited lower levels of depression and aggression. The most significant finding of this study was that parent and peer attachment were both related to adolescent adjustment and that strong relationships with both peers and parents decreased the chances of suffering from depression or exhibiting aggressive behavior.

Descharme, Doyle, and Markiewicz (2002) were also interested in how attachment relationships to both parents and peers affected young teens. Their sample 
consisted of 150 adolescents ( 75 female, 75 male). Their participants completed a seven-day diary and a self-report questionnaire to ascertain if attachment style was related to conflict resolution style. In the seven-day diary, each participant was asked to track at least one parent and one peer interaction per day, resulting in 14 entries over the seven-day period. In addition to the seven-day diary, participants completed the Relationship Questionnaire (RQ; Bartholomew \& Horowitz, 1991) and the Emotional Expressivity Scale (EES; Kring, Smith, \& Neale, 1994). The authors hypothesized that teens that have a more secure attachment or closer relationship to their parents are better able to resolve conflict when it occurs.

Participants were evaluated in three categories consisting of attachment style, degree of emotional expressivity and conflict occurrence, along with how well conflicts were resolved. As expected, Descharme et al. (2002) found that individuals who were identified as having secure attachment styles were less likely to experience conflict with parents and peers, and they were more emotionally expressive. Additional analyses demonstrated that participants who were insecurely attached to both parents were less likely to express emotions and more likely to exhibit a negative affect. Specifically, those who were categorized as having a dismissing attachment style experienced more conflict with their peers. Those "secure" individuals who did experience conflict with their peers were able to employ both compromise and negotiation techniques to resolve their disagreements.

Unfortunately, while Descharme and her colleagues set out to evaluate attachment to parents in both male and female participants using separate sub-scales 
for mothers and fathers, their findings were not reported in a way that allowed for the differentiation of those two unique relationships. Although the researchers did find significant differences between adolescent males and females (i.e., their attachment styles), these differences were identified based on their self-reported communication with others. This finding could be problematic because while female participants were more expressive in their diaries than their male counterparts, these differences may be due to gender socialization and developmental differences rather than attachment style. In fact, in their 2006 meta-analysis, Rose and Rudolph stated that it is generally accepted that there are significant gender differences in peer relationships in males and females. Chaplin, Cole, and Zahn-Waxler (2005) stated that specifically in the United States female children are socialized to be more relationship-oriented than male children. They went on to say girls are more likely to express emotions and be increasingly likely to be focused on pleasing others and will express sadness and anxiety more often than boys.

It is also generally accepted that girls mature earlier than boys (Santrock, 2009) and that in adolescence girls put more importance on close friendships than boys do (Ma \& Huebner, 2008; Hay \& Ashman, 2003; Cross \& Madson, 1997; Claes, 1992). It is therefore apparent that gender could be an important confound in the findings of Descharme et al.'s (2005) study.

As previously noted, adolescents typically spend less time with family and more time with friends. At the same time, peer relationships are complemented by the development of romantic relationships (McElhaney, Antonishak, \& Allen, 2008). 
Ellis, Crooks, and Wolfe (2009) suggested that children who are able to master appropriate social skills in same-sex peer relationships are better equipped for romantic relationships, both during teenage years and later in life. They also suggested that during late adolescence romantic partners replace parents as primary attachment figures. Ellis et al. (2009) explored how peer relationships, both platonic and romantic, were related to aggression. The authors focused on ninth graders in an effort to understand these dynamics early in the process and at a time when intervention could prevent negative mental health (e.g., anxiety, self-doubt, depression) and behavioral (e.g., delinquency) outcomes. The study sample included 1,279 ninth graders divided between 646 females and 633 males with an average age of 14 years.

In order to evaluate the peer relationships, participants completed four measures at two points in time with an average of four months between the administrations. The four measures included: the Peer Relational Aggression Scale (PRA; Linder, Crick, \& Collins, 2002); the Dating and Relational Aggression Scale (DRA; McCreary Centre Society, 2004); as well as measures of delinquency and adjustment taken from the National Longitudinal Study of Children and Youth (NLSCY).

Ellis et al. (2009) found that $59 \%$ of female and $51 \%$ of male participants reported some type of victimization involving relational aggression. Interestingly, $56 \%$ of the female and $39 \%$ of the male ninth graders also reported perpetrating the same type of relational aggression towards their peers. The results of this study indicated that children who experienced high levels of relational aggression were also likely to 
score high on measures of delinquency and low on levels of adjustment. Ellis et al. (2009) concluded that children who are victimized often go on to perpetrate similar behaviors, both as a coping mechanism to control social relationships and as a strategy to establish a sense of belonging within their group.

In their recent study, Myrick and Martorell (2011) found evidence to support the link between a secure attachment style and increased social competence in both minority and non-minority samples. Further, a link between mastering social relationships in adolescence and aggressive behavior has been supported by the work of McEhlaney, Antonishak, and Allen (2008). They evaluated whether self-perceived social acceptance and popularity were related to aggression and hostility. In their sample of 164 adolescents ( 78 female, 86 male), the authors followed participants over a period of approximately one year utilizing a self-report measure of perceived social acceptance, which involved a multi-participant nomination strategy, observational ratings, and 3 peer reported measures administered at two points in time.

The self-reported measure asked participants how closely they subscribed to statements about making friends and popularity (Adolescent Self-Perception Profile; Harter, 1988). The multiple-participant nomination exercise included not only the participants, but their "best friends" and two other individuals chosen by the participants. The study was designed to measure the popularity of the primary participants amongst their peers. During the observational assessment, researchers rated participants and their same-sex best friend on their degree of support (Supportive Behavioral Task; Allen et al., 1999). Measures were also included that asked 
individuals identified by the primary participants as "best-friends" to rate the primary participant's level of aggression (Child Behavior Checklist; Achenbach, 1991), their desirability as a companion (Friendship Quality Questionnaire; Parker \& Asher, 1993), and the primary participant's degree of social withdrawal (Pupil Evaluation Inventory; Pekarik, Prinz, Liebert, Weintraub, \& Neale, 1976).

The most important finding from this research study was the consistency with which adolescents perceived themselves and others perceived the adolescents. McEhlaney and her colleagues (2008) also found that self-reported social acceptance at the first assessment was significantly correlated with peer-reported aggression, companionship, and withdrawal at second assessment. Those adolescents who felt a sense of belonging were seen by others as exhibiting less aggression, being better companions, and displaying less withdrawal. Further, popularity as measured by the nomination strategy (Parker \& Asher, 1993) during the first assessment was positively and significantly related to a perceived sense of belonging as measured by Harter's (1988) measure at both time periods. This research demonstrates that how an individual sees himself or herself is often mirrored in the perceptions of others. This finding provides support for the use of self-report measures in evaluating the strength of an individual's social relationships. Although neither Ellis nor McEhlaney's studies (Ellis et al., 2009; McEhlaney et al., 2008) evaluated “attachment" per se, both studies used a recognized "measure of attachment," as they address how social relationships in adolescence are related to aggressive behavior. 
Allen and Land (1999) discussed how peer friendships and dating relationships are manifestations of “attachment organization” during adolescents' developmental period. This book chapter by Allen and Land (1999) is often cited in discussions of attachment research and it defines the period of adolescence as the bridge between the attachment relationships as a child in the parent-child relationship to that of a parent with their own child. Allen and Land also concluded that relationships developed during the adolescent stage of growth are especially important because they teach the individual how to process information in a less selfish manner. This is an important advance over earlier developmental stages, which are more egocentric. It is during early adolescence, the stage of development identified by Erickson (1980) as the formal operational period, where interactions with peers help shape friendships. These friends in turn become people who an individual may depend on for the remainder of his/her life, providing feedback, forming partnerships, and forging intimacy (Allen \& Land, 1990). This is the epitome of being "securely attached."

So far the important relationships with parents and friends have been viewed as the primary attachment relationships that matter to the developing individual. In the primary cultures in North America, the transition from early adolescence to late adolescence marks the transition to independence. Although teens become less dependent on caregivers during this time period for the security and protection that Ainsworth discussed (Ainsworth, Blehar, Waters, \& Wall, 1978), most people still seek to maintain an emotional connection to important others. 


\section{Peer Relations in Late Adolescence through Young Adulthood}

As people mature, their relationships with others fulfill different needs. During the transition to late adolescence and young adulthood, relationships become more about developing a sense of self and becoming autonomous (McLean \& Thorne, 2003). This section strives to explore important excerpts from the literature that examines peer and romantic relationships during this important developmental transition. First, Bartholomew's Four-Category Model of Attachment will be explored to ground our discussion linking attachment style to romantic relationships. Next, research assessing the importance of a secure attachment orientation and how it contributes to successful romantic pairings will be examined. Finally, the importance of love and sexual intimacy will be discussed using existing theories.

In the late 1980's and early 1990’s, Kim Bartholomew began exploring how attachment styles affect the intimate personal relationships that develop as people leave adolescence and move into adulthood. She developed a framework that conceptualized attachment styles or internal working models in late adolescents and adults into four categories: (a) secure, (b) preoccupied, (c) fearful, and (d) dismissing (Bartholomew, 1990). Earlier in this dissertation the term "internal working model" was discussed and how it was first introduced by Bowlby (1969, 1973, and 1980) in his work as a way of understanding the dynamic and functional way in which a person views both himself and those around him. Bartholomew's four categories can be understood as the confluence of an individual's positive or negative model of self (or level of "dependence") and others, also referred to as "avoidance" (Bartholomew, 
1990). This framework expanded on the working models first conceptualized by Bowlby in 1973. Figure 2 depicts these four different categories and their placement within Bartholomew's conceptualization of the internal working model.

As described above, Bartholomew's model categorized individuals' attachment styles based on the four different combinations of positive or negative view of self and positive or negative view of others (Bartholomew, 1990). The first attachment type Bartholomew labeled as secure. This category represented those individuals who have a positive view of themselves and a positive view of others. Secure individuals were described as exhibiting high coherence, high self-confidence, a positive approach to others, and high levels of intimacy in relationships.

Bartholomew's second category is labeled fearful. The fearful attachment style is analogous to the disorganized attachment style used in earlier attachment research by Mary Main (Main et al., 1985) and other investigators (e.g., Shaver \& Clark, 1996). This form of attachment represents those individuals who have a negative view of self and a negative view of others. Key features of fearful individuals include: low selfconfidence and avoidance of intimacy due to fear of rejection, conflicting motives of both wanting and fearing intimacy, and high self-consciousness. The third type of attachment defined by Bartholomew is pre-occupied. This category reflects individuals with a negative view of self and a positive view of others. The key features of a preoccupied individual include being consumed with relationships, discussing relationships in an incoherent and idealizing manner, being highly dependent on others for self-esteem, and using an approach orientation in relationships. Bartholomew's 
final attachment type, dismissing, reflects those individuals with a positive view of self and a negative view of others. The key features of a dismissing individual include: having a less developed understanding of the individuals around them, including what is appropriate behavior with those individuals; downplaying the importance of relationships; exhibiting high self-confidence; avoiding intimacy; and being compulsively self-reliant. Bartholomew utilized self-report questionnaires and interviews to assess individuals' perception of the quality of their relationships, and the extent to which they have a positive or negative view of both the self and others in order to situate them within her model. Bartholomew pointed out that although most clinicians recognize that a few individuals suffered from unhealthy or pathological dependence, it is equally important to understand why some "healthy" individuals avoid close affectionate bonds.

Adult relationships have been studied in an attachment context by many researchers. These studies have included a focus on: motivation for "affairs" outside of romantic relationships (Allen \& Baucom, 2004); romantic love, relationship satisfaction, and commitment (Collins \& Read, 1990; Feeney \& Noller, 1990; Simpson, 1990); stability of romantic relationships over time (Kirkpatrick \& Davis, 1994); partner jealousy (Sharpsteen \& Kirkpatrick, 1997); trust (Mikulincer, 1998); seeking and giving of support (Simpson, Rholes, \& Nelligan, 1992); and intimate partner violence (Roberts \& Noller, 1998). Overall, findings demonstrate that individuals with a secure orientation have more successful romantic relationships. 
Hazan and Shaver's (1987) research focused on romantic attachment using Ainsworth's three category model. They conceptualized their categories as avoidant, anxious-ambivalent, and secure. In their research they sought to prove that individuals categorized within the different attachment types experienced romantic relationships in different manners.

Hazan and Shaver (1987) recruited a sample of 620 participants (205 men, 415 women) via a questionnaire published in a newspaper in Denver, Colorado. The ages of the participants ranged from 14 to 82 years, with a mean age of 36 . The questionnaire was broken down into three subscales assessing demographics and childhood crushes, attachment style, and 12 personal constructs (happiness, friendship, trust, fear of closeness, acceptance, emotional extremes, jealousy, obsessive preoccupation, sexual attraction, desire for union, desire for reciprocity, and love at first sight).

Fifty-six percent of the individuals were classified as secure, $25 \%$ as avoidant and $19 \%$ as anxious-ambivalent. This was done using a measure asking participants to choose which paragraph best described how they relate to others. As hypothesized, these researchers found that individuals with different attachment styles do, in fact, experience romantic relationships in divergent ways. Hazan and Shaver (1987) found that secure individuals not only experienced romantic relationships as happy, friendly, and trusting, they were able to support their partners and be accepting of their faults. The secure individuals' relationships lasted on average significantly longer than those of individuals classified in either of the other two attachment styles. Conversely, those 
participants classified as avoidant were more likely to experience a fear of intimacy, be jealous, and experience emotional highs and lows in their relationships.

One of the more important findings from this study was that individuals in the different attachment style categories did not differ in their frequency of experiencing separation from their parents during childhood. Specifically, parental divorce was unrelated to attachment style. What did matter was how the respondents perceived their individual relationship with each parent and how well their parents got along with each other, even when unmarried or divorced.

Another important term to examine when discussing romantic relationships in late adolescence and young adulthood is the word "love." In 1986, Sternberg proposed the Triangular Theory of Love. In this theory, Sternberg (1986) described three components that can be identified in a "love" relationship: intimacy, passion, and decision/commitment. Sternberg explained that the first component, intimacy, can be explained as a feeling of closeness, connectedness, and bondedness. He said the second component, passion, can be understood as the drive that leads to romance, physical attraction, and the desire to have sex. Finally, he offered that the concept of love also involves a decision or commitment to maintain the relationship. Sternberg (1986) also stated that love "appears to derive in part from genetically transmitted instincts" (p. 120) and is therefore part of being human.

In 1992, Acker and Davis examined Sternberg's Triangular Theory using a sample of 208 participants recruited from the St. Petersburg, Florida area. They set out to evaluate how strong participants felt their relationships were. In other words, how 
securely attached they felt to their romantic partners. Their sample included 111 females and 93 males ranging from 18 to 68 years of age. The mean age of their participants was slightly more than 38 years old and the average length of their romantic relationships were 9.5 years long. Each participant completed a questionnaire that measured how they felt, how they perceived their partner felt, and how they wished their partners felt about the relationship. This research found support for the three factor model and found no differences based on participant gender. The research of Sternberg (1986) and Acker \& Davis (1992) is important to the current research project because it recognizes that humans not only desire romantic relationships, but that intimacy and sex are important components in these relationships and to the attachment dynamic.

Maslow (1943) also suggested that sex, affiliation, and relationships were critical basic human needs. Although Maslow did not specifically discuss attachment, the concepts he discussed are closely related to the attachment literature because they explore the idea of reciprocal relationships that provide security and a sense of connectedness. Maslow's perspective is contained in what is commonly referred to as "Maslow's Hierarchy of Needs" (see Figure 3). Maslow (1943) proposed that the physiological or most basic human needs include those that are required to sustain us. In his model, humans are biologically driven to engage in sexual activity. He also pointed out that if basic needs remain unsatisfied, all other needs become a secondary focus of attention. He went on to say that after physiological and safety needs, love, affection and belongingness are the next most powerful human drives. Maslow 
suggested that people will "strive for great intensity" or "hunger for affectional relations" with "friends, a sweetheart and children" (Maslow, 1943, p.378).

Many of the ideas outlined in Maslow's Hierarchy of Needs relate very closely to those that are considered part of the attachment construct. For instance, the step entitled "safety needs" is similar to the ideas expressed by both Bowlby and Ainsworth when they offered that individuals seek to maintain proximity to others in order to be both protected and cared for. In his section entitled "love needs," Maslow addressed the important friendships and attachments that humans seek. This step in his hierarchy highlights the importance of feeling connected to others in supportive relationships either as part of a family or in an intimate relationship.

In her doctoral dissertation, Eves (2007) provided an even stronger link between attachment and sexual activity in young adults. The author used both Hazan and Shaver's (1987) three category model and Bartholomew’s (1981) four category model of attachment to assess the sexual practices of college students. Eves collected data from 998 heterosexual, able-bodied college students between the ages of 17 and 24 years. Five measures were included for analysis during this research undertaking: a demographic questionnaire; a measure identifying peer-group norms (Ratliff-Crain, Donald, \& Dalton, 1999); a questionnaire regarding sexual behavior (The National Health and Social Life Survey (NHSLS); Laumann, Gagnon, Michael, \& Michaels, 2000); the Relationship Questionnaire (Bartholomew \& Horowitz, 1991), which was used to identify attachment style; and the Contingencies of Self-Worth Scale (Crocker, Luhtanen, Cooper, \& Bouvrette, 2003). 
Participants were evaluated to see if attachment style could predict which individuals were more likely to engage in specific sexual behaviors with and at what frequency. Eves found that attachment style was significantly related to participation in casual sex. Specifically, the groups containing individuals identified as having dismissing and_preoccupied attachment styles self-identified as having more one-night stands. Additionally, Eves found that being identified as having a dismissing or fearful attachment style significantly predicted an increased incidence of cheating. Although participation in all risky sexual behavior could not be predicted by attachment style, this research demonstrated that both casual sex and engaging in sex outside of a monogamous relationship can be related to an individual's internal working model.

Recently, attachment style has also been researched as an important predictor of interpersonal problems and may be a means of "acting out" in individuals with mental health concerns (Berry, Barrowclough, \& Wearden, 2008). Berry et al. (2008) found that individuals with either a dismissing or preoccupied type of attachment style had a more difficult time in developing a therapeutic relationship with mental health providers and that patients suffering from psychosis may engage in self-destructive behavior, including participating in risky sexual practices. The previous section addressed how important both romantic and sexual bonds are to humans. In recognizing the importance of emotional and physical intimacy, the link between offending behaviors in individuals with poor attachment begins to materialize. It is therefore important to delve into some of the existing literature that has examined this relationship between insecure attachment and sexual offending behavior more directly. 
$\underline{\text { Attachment and Adult Sex Offenders }}$

In this section, important research assessing the connection between attachment and sexual offending behavior in adults will be explored. Each study will be discussed in a similar fashion. First, the researchers involved will be identified. Then brief descriptions of their methodology, participant samples, and hypotheses will be presented. Next, a summary of relevant results will be offered and finally, the important strengths and limitations of the study will be outlined.

One of the first research teams to investigate the link between sexual offending and attachment was Marshall and Mazzucco (1995). They utilized a battery of five self-report measures: (1) the Social Self-Esteem Inventory, (2) the Parental Acceptance-Rejection Questionnaire, (3) the Family Violence Scale, (4) the Childhood Sexual Abuse Scale, and (5) Jackson's (1984) Personality Questionnaire to measure self-esteem and the quality of parental attachment. Two of these measures, the Parental Acceptance-Rejection Questionnaire (PARQ) and the Childhood Sexual Abuse Scale (CSAS) contain components related to attachment theory.

Their participant sample was comprised of 24 adult child molesters and 23 adult non-offenders. The child molester group was recruited from an inpatient treatment facility but had not yet received treatment before their participation in the research study. The participants averaged just over 35 years of age and had female child victims. The individuals in the comparison group were recruited from a community employment agency, and were paid $\$ 10$ for their participation. Their average age was just over 30 years old. 
Marshall and Mazzucco (1995) found a significant correlation between maternal rejection and low self-esteem. This is important in that these researchers also found that child molesters often experience difficulty in social situations. Marshall, Barbaree, and Fernandez (1995) identified three important characteristics in individuals with social deficits: experiencing social anxiety, exhibiting a lack of assertiveness, and low self-esteem. Unfortunately, direct links between offending and rejection were not supported in Marshall and Mazzucco's study because there was not a significant difference in overall parental rejection between the two groups. Important limitations in this exploration included an incorporation of a non-incarcerated control group, as well as the fact that individuals in the offense group represented only a very limited offender category (i.e., adult child molesters with female victims). The first limitation is notable because incarceration has been linked to depression (Boothby \& Durham, 1999), and depression could affect participant perceptions when answering questions during a research study. The second limitation is equally noteworthy because the limited offender category restricts generalizability to other types of sexual offenders. Finally, the fact that all participants in this early research were adults, limits the findings generalizability to younger offenders. This important research was considered exploratory and helped shape the subsequent research examining the link between attachment and sexually offending behavior elaborated below.

Ward, Hudson, and Marshall (1996) utilized Bartholomew’s (1990) self-report scales to assess romantic attachment; yielding scores on one secure (labeled "secure") and three insecure (labeled "dismissing," "fearful," and "preoccupied") scales for a 
sample of 147 incarcerated males. The participants in this study were divided into four pre-existing groups of offenders: (a) adult child molesters $(\mathrm{n}=55)$; (b) adult rapists ( $\mathrm{n}$ $=30)$; (c) violent non-sexual offenders $(\mathrm{n}=32)$; and (c) non-violent non-sexual offenders $(n=30)$. Two study hypotheses were evaluated: (1) that both categories of sexual offenders would be insecurely attached; and (2) that rapists would score higher on the dismissing scale, while the child molesters would earn higher scores on the preoccupied and fearful scales.

Ward and his colleagues' (1996) findings did not support their first hypothesis, but indicated partial support for their second prediction. Child molesters were found to have scored higher than both non-sexual offending groups on the preoccupied dimension but did not differ significantly from the rapist group. Interestingly, both child molesters and violent offenders scored significantly higher on the fearful dimension than the other two study groups.

Although Ward et al. (1996) found only limited support for their overall model, they did find significant group differences in attachment style. It is important to note that two important differences existed among the four groups that may have confounded this study's results. First, the mean ages for the participant groups were significantly different (i.e., child molesters [42.4 years], rapists [34.7 years], nonsexual violent offenders [26.2 years], and non-violent non-sexual offenders [25.4 years]).

The second potential confound involved the differences in the groups' average length of prison sentence. Rapists had the longest average sentences (88.2 months), 
followed by violent offenders (75.8 months), child molesters (50.8 months), and finally the non-violent non-sexual offenders (16.4 months). On the one hand, it is possible that offenders were at a similar point in their sentences and this would not necessarily be an issue. However, this was not clarified by the authors. Different sentence durations reflect important differences in crime severity. It would also be possible that the more serious offenders (i.e., those who had been removed from their family and friends for a longer period of time) felt more isolated because of the passage of time, rather than differences in attachment style. This is not addressed in the study design or discussion. Ward and his colleagues (1996) did suggest that future research should examine the relationship between offense types/levels and attachment style.

Smallbone and Dadds (2000) explored links between different styles of childhood attachment and coercive sexual behavior. With this goal in mind they utilized four self-report questionnaires: (1) Hazan and Shaver's (1986) Childhood Attachment Measure, (2) Bartholomew's Relationship Scales Questionnaire (Griffin \& Bartholomew, 1994), (3) The Relationship Scales (RSQ; Million, Million, \& Davis, 1994), and (4) Sexual Experiences Survey (SES; Koss \& Oros, 1982). They utilized a participant sample of 162 male undergraduates recruited from justice administration and psychology courses at colleges in Brisbane, Australia. Their study examined two research questions: (1) would childhood attachment styles predict adult attachment styles?; and, (2) would insecure attachment be associated with aggression, antisociality, and coercive sexual behavior? 
Smallbone and Dadds (2000) found that the strength of paternal childhood attachment was a better predictor of adult attachment than the strength of maternal attachment. Additionally, a minor negative correlation was found between secure childhood attachment to mother and anti-sociality. Conversely, anxious childhood attachment to mother was moderately correlated to both aggression and anti-sociality. Paternal attachment, as expected, was minimally correlated with anti-sociality and aggression.

This research provided some of the first statistical evidence supporting a link between attachment and sexual aggression. Additionally, this study demonstrated that how a child perceives his/her relationship with his/her father has long-term effects. The results of this study are limited by the use of an Australian non-adjudicated, college student sample. This may limit generalizability to U.S. samples, specifically; non-college aged adolescents, and incarcerated offenders.

Marsa et al. (2004) conducted research that focused on adult offenders and the relationship between their attachment style and offending behavior. It was conducted in Ireland and utilized a participant sample of 119 adult men in three incarcerated offender categories and one community control group. Participants were: (a) child sex offenders ( $n=29)$, (b) violent offenders $(n=30)$, (c) nonviolent offenders $(n=30)$, and (d) non-offending community controls $(n=30)$. The sex offenders were assessed before their enrollment in a prison-based treatment program. The second and third groups were recruited from prisons in Ireland, and the fourth group was recruited from a university research panel, a local business, and a vocation training center in Dublin. 
All participants included in the Marsa et al. study completed seven self-report questionnaires including: (a) a demographic questionnaire; (b) the Experiences in Close Relationships Inventory (ECRI; Brennan, Clark, \& Shaver, 1998); (c) the Parental Bonding Instrument (PBI; Parker, Tupling, \& Brown, 1979); (d) the University of California Los Angeles (UCLA) Emotional Loneliness Scale (EL; Russell, Peplau, \& Cutrona, 1980); (e) The Nowicki-Strickland Locus of Control Scale (LOC; Nowicki, 1976); (f) Novaco Anger Scale (NAS; Novaco, 1994); and (g) the Social Desirability Scale from the Personal Reaction Inventory in order to evaluate the participants attachment to parents as children, level of emotional loneliness, locus of control, and anger management skills (Beech, Fisher, \& Beckett, 1998). Their study set out to develop an attachment profile of Irish sex offenders to enhance prevention programs and improve assessment and treatment of offenders. Their findings pointed to the fact that many sexual offenders have insecure attachment styles as a result of ineffectual relationships with caregivers early in life. Consequently their offending behavior is a result of their striving to form some type of connection with others (Marsa et al., 2004).

Marsa et al. (2004) found that the sex offenders with child victims experienced more loneliness and were more likely to be categorized as "fearful" than members of any of the other three groups. Additionally, their anger management profiles were more similar to the non-violent offenders and community controls than the violent offenders. Compared to the participants in the other groups, these individuals perceived their parents as significantly less caring. Although this study found strong 
links between childhood attachment and sexual offending behavior, the individuals in the participant groups were not similar in age or SES. Further, childhood attachment was based on recollections from many years previous to the data collection. Moreover, no demographic information regarding ethnicity was provided, thereby limiting its generalizability to populations outside Ireland.

In an effort to find support for multi-factorial models of sexual offending (including those examining attachment deficits), Lyn and Burton (2005) recruited 178 participants for their study from a large Midwestern U.S. prison. This sample was comprised of 144 incarcerated sex offenders and 34 incarcerated non-sexual offenders. Participants completed a battery of voluntary, anonymous surveys, including measures to assess attachment, anger, and anxiety. Three hypotheses were tested that suggested: (1) anger, generalized anxiety, and insecure attachment are significantly related to sexual offending; (2) sexual and non-sexual offender groups differ significantly on measures of insecure attachment, anger, and generalized anxiety; and (3) a multivariate regression model (utilizing these three variables) will predict offender status (i.e., sex offender vs. non-sex offender).

Study participants completed six measures: (a) a demographic questionnaire that asked about age, race, and education; (b) the Thought Disturbance Subscale of the Carlson Psychological Survey (CPS; Carlson, 1981); (c) the Balanced Inventory of Desirable Responding (BIDR; Paulhus, 1991); (d) the Close Relationships Inventory (ECRI; Brennan, Clark, \& Shaver, 1998); (e) the Multi-Dimensional Anger Inventory (MAI; Siegel, 1986; Tricker, Casaburi, Storer, Clevenger, Berman, Shirazi, \& Bhasin, 
1996); and (f) a modified version of the eight-item anxiety subscale of the Trauma Symptom Checklist-40 (TSC-40; Elliott \& Briere, 1992).

As predicted, Lyn and Burton (2005) found that anger, generalized anxiety, and insecure attachment were related. They also found that sex offenders scored higher on attachment-related anxiety and that there was a statistically significant relationship between attachment and sexual offending. Further, insecurely attached participants were more than $5 \frac{1}{2}$ times as likely as securely attached participants to be in the sexual offender group. In contrast, their model, intended to predict sex offender status, was not supported.

Craissati, Webb, and Keen (2008) conducted research that focused on the "victim to offender cycle." Craissati et al. (2008) suggested that there has been "a long standing interest in the role of key developmental variables as antecedents in pathways to offending ...especially in the areas of attachment" (p. 120). They went on to say that child molesters have a history of suffering from poor attachment with their parents, physical abuse, neglect, and a prolonged history of difficulties in creating and maintaining peer friendships. They set out to explore the link between developmental challenges in childhood with psychological dysfunction in adulthood and the ability to use these markers as a way of assigning risk status for sex offenders.

Their participant sample included 241 adult sex offenders divided into two categories: (a) 162 were perpetrators of CSA (i.e., child molesters) and (b) 79 had adult victims (i.e., rapists). These participants were evaluated both on mental health case files and police and probation reports as well as the administration of 
standardized measures, including the Million Clinical Multi-axial Inventory version 3 (MCMI-III; Million, Million, \& Davis, 1994), a broad-based mental health screening tool; the Static-99 (Hanson \& Thornton, 2000), a sexual recidivism risk screening tool; and the PCL-R (Hare, 1991), a psychopathy assessment device. In addition to having participants complete the above measures, researchers viewed the participants' justice files to evaluate their scores on the Offender Assessment System (OASys), OASysMental Health Need, and OASys-Dangerous and Severe Personality Disorder (DSPD). These tools are utilized by the prison and probation systems in England and Wales, and reflect screening assessments for recidivism and psychological/psychiatric difficulties.

The results of the Craissati et al. study found that individuals in the child molester group suffered from significantly more personality dysfunction and reported significantly more CSA in their own childhood than the rapists. Additionally, the average age was significantly lower in the rapists' group, and they came from more diverse backgrounds than the child molesters. In evaluating the authors' second hypothesis (i.e., related to attachment), the researchers found that there was a strong relationship between adverse developmental experiences (abuse, sex abuse, and neglect) and sexual offending. Although the researchers acknowledged that childhood attachment is an important consideration in the etiology of CSA and have evaluated developmental challenges that have been highly correlated with low parental attachment, they did not actually include recognized attachment measures in their investigation. Finally, it is important to note that Craissati et al. (2008) acknowledged 
that the institutional files reviewed as part of this study were incomplete and contained inconsistent records. These limitations may have impacted study results and could have affected the applicability of findings to both the research world and clinical treatment settings.

The studies reviewed in this section were restricted to investigations focusing on adult sex offender populations. The evidence presented has suggested that attachment may play a role in the perpetration of adult sexual offending. However, as this study is specific to adolescents, the following section explores how attachment may contribute to offense behavior in this younger population. It reviews the limited literature that has investigated juvenile sex offenders. $\underline{\text { Attachment in Juvenile Sex Offenders }}$

This scarcity of research on juvenile perpetrators may be due, in part, to the fact that social scientists have debated the ethics of including juvenile offenders in attachment research. Other contributing factors to the paucity of research in relation to this population may include the historical lack of prosecution of minors, the lack of access to arrest and sentencing records for individuals in this group due to court seals or expungements, and finally, the lack of access to juveniles who have sexually offended because "the overwhelming majority of youth that engage in sexually aggressive behavior are never detected by law enforcement and do not appear in official records" (Caldwell, 2007, p. 3). Morrows and Richards (1996) offered that although developmental psychologists had a great deal of experience working with children, social scientists in the fields of behavioral psychology, social psychology, 
and criminology did not have the same depth of expertise. These authors went on to say that the term "child" had been applied to individuals under the age of 18 and this minor status implied the need for parental consent. It is understandable that many parents want to protect their children from yet another person talking to them about their sexual behavior, even when it has been deemed abusive. It is therefore understandably difficult to obtain parental consent for interviews or assessment for research purposes. Other researchers, including Bowman (2008), have spoken about the existence of other gate keepers that restrict access to adolescents for research purposes, including directors of treatment or residential facilities. This restriction may not be due to a desire to protect the individual offender but instead may be in part due to concerns about the stigma associated with being responsible for the housing and/or treatment of CSA perpetrators.

Another important consideration in the lack of research on incarcerated youth is that until the mid-1990s there was not a coordinated statewide juvenile justice system in most states. In Oregon, for example, this coordination did not occur until 1995 when the Oregon Youth Authority (OYA) was established. Until that point in time juvenile correction issues were handled within the child welfare system (OYA, 2011). The creation of the OYA and the passage of Oregon Ballet Measure 11 established consistency and allowed a better atmosphere for researchers to collect data with this population. The history of the adjudication of juvenile offenders and the juvenile court system in Oregon is explained more completely in an earlier section entitled The Oregon Youth Authority (OYA) and Oregon Revised Statutes (ORS). 
Despite the acknowledgment by many that there is limited research available on adolescent offenders (Ryan, 2010; Barbaree \& Marshall, 2008; Reitzel \& Carbonell, 2006; Righthand \& Welch, 2001; Prentky, Harris, Frizzell, \& Righthand, 2000), it is important to talk about a selected sample of the research that is available. The following section provides a review of key historical studies that shaped the completed study.

The following section takes a chronological approach to explore attachment deficits as a precipitating event in juvenile offending behavior. First, the seminal work of John Bowlby will be discussed. Following the examination of this early work, important evolutionary studies will be briefly discussed in order to outline the evolution of attachment research in juvenile offenders. Finally, existing research will be related to ongoing research studies currently in progress by recognized leaders in the sex offender field.

As previously mentioned, John Bowlby is considered the father of attachment theory. The dearth of juvenile research on attachment seems ironic given that Bowlby's initial research involved juvenile offenders. During the years 1936-1939, while working at The London Guidance Clinic in England, Bowlby became convinced that many of the young people who were in legal trouble shared one specific characteristic, a lack of maternal attachment. He noted that these children were reared without their mothers (i.e., due to death) or had mothers who did not express affection toward their children. He also found that some of the mothers who made efforts to connect with their children still had youngsters who did not for some reason "attach" 
or develop affection for their mothers. Of course, this early work was only exploratory and did not involve juveniles labeled as "sex offenders."

Saunders, Awad, and Levene's (1984) early studies were also exploratory. These were undertaken with three aims: (1) to collect data about a large number of JSOs to augment the sparse research literature, (2) to categorize these offenders, and (3) to investigate treatment modalities for JSOs. Although this study did not specifically set out to evaluate attachment style, the authors did examine both family and peer relationships and how they were related to the perpetration of sexual crimes. Their participants included 24 adolescent male sex offenders referred to family court in 1980 and 1981 in Toronto, Ontario, Canada, as well as a control group of 24 nonsexual offenders matched by age and socio-economic status from the same area.

Participants were coded on a 300-item questionnaire designed specifically for this study. Each participant's questionnaire was completed by researchers using information gathered from clinical interviews and file reviews. The interviews took place during routine clinical evaluations, which included psychological testing; at least two interviews with the adolescent; interviews with the parents; and a review of school, police, medical, social welfare, and psychiatric records.

Participants were compared on ten categories: (a) nature of offense, (b) recidivism, (c) delinquency history or demographics, (d) family background, (e) medical history, (f) psychiatric history, (g) sexual history, (h) intellectual functioning, (i) school history, and (j) peer relationships. The researchers found that in the sex offender group, $84 \%$ of their victims were female and $16 \%$ of their victims were male 
and all were younger than the perpetrator. The majority of the sex offenders $(87 \%)$ committed their first offense after the age of 13. More of the non-sexual offenders (75\%) had a history of court appearances for minor misdemeanors than the sex offenders (50\%). Both groups had high levels of family instability with a larger percentage $(63 \%)$ of the sex-offenders reported having "rejecting" fathers as opposed to $50 \%$ in the non-sex offenders. The sex-offenders scored significantly lower on intellectual functioning than the non-sex offenders. Almost half of the sexual offenders (46\%) were classified as loners as opposed to only $17 \%$ of the controls.

While only small differences were found by the researchers in this initial study, two interesting themes emerged in many of the childhood histories of individual in the sexual offender group. These themes were feeling rejected by their fathers and experiencing a lack of peer relationships. One important limitation of this study was that it utilized a subjective assessment by the researchers rather than having participants complete valid and reliable attachment assessment.

A handful of researchers have explored difficulties in JSOs closely related to attachment deficits, such as social and interpersonal problems. In their review of the existing literature, Marshall, Hudson, and Hodkinson (1993) referenced a small number of studies, which demonstrated links between attachment and sexual offending. The first study, by Fehrenbach, Smith, Monastersky, and Deisher (1986), reported significant social and interpersonal difficulties in a sample of 305 juvenile sex offenders. A majority of participants in their sample of juvenile sex offenders displayed signs of social isolation (65\%). Additionally, 34\% had no close friends, and 
$32 \%$ had no friends at all. Marshall and his colleagues (1993) also reported on the work of Fagan and Wexler (1988) who examined the behavior of 242 incarcerated chronic violent offenders, 34 of whom were juvenile sex offenders. Fagan and Wexler (1988) found that individuals in their sample of JSOs were characterized as having poor social relationships with peers. These researchers also suggested that juvenile sex offenders were more likely to come from families with significant dysfunction, including spousal violence, child abuse, and sexual molestation. They also found that the JSOs were more socially isolated and less likely to have girlfriends than their nonsexually offending counterparts.

Fleming, Jory, and Burton (2002) included familial attachment as an important variable in their research comparing juvenile offenders that victimize animals to juvenile offenders with human victims. Their sample was comprised of 381 incarcerated, adjudicated, male youth offenders from three institutions in a Midwestern state. The participants were divided into three pre-existing groups: animal offenders, human-only sex offenders, and non-sex offenders. All participants completed six measures: a demographic questionnaire; a modified version of the Sexual Abuse Exposure Questionnaire (SAEQ; Ryan, Rodriguez, Rowan, \& Foy, 1992) assessing participants own history of victimization; the Self Report Sexual Aggression Scale (SERSAS; Burton \& Fleming, 1998); the Childhood Trauma Questionnaire (CTQ: Bernstein, Ahluvalia, Pogge, \& Handelsman, 1997), which screens for child neglect, physical, emotional, and sexual abuse; the Family Attachment and Changeability Index 8 (FACI-8; McCubbin, Thompson, \& Elver, 
1995); and the Family Problem Solving and Communication Index (FPSC; McCubbin, Thompson, \& Elver, 1995)

Fleming et al. (2002) found that participants in the two sexual abusive groups were alike in that they came from families with less affirming and more incendiary communication styles as well as low attachment. Additionally, both sexual offending groups came from less positive family environments than the non-sexual offenders. Overall, the animal offending group scored lowest on positive family communication and had the lowest mean positive family score. Their investigation also found that participants in the sexual offending groups had experienced more neglect, physical, emotional, and sexual abuse as children than the non-sexual offending group. Interestingly, a majority of those individuals with animal victims also admitted to perpetrating sexual crimes against humans. Although the main purpose of this investigation was to assess whether beastiality should be considered "normal" behavior in the juvenile population, it provided clear evidence that sexual offenders very often come from dysfunctional backgrounds and suffer from low attachment to family members.

Although a number of theorists, clinicians, and social scientists have uncovered a link between attachment and sexual offending behavior, there are a relatively limited number of researchers investigating this particular relationship especially in juveniles. A handful of studies that have focused on this important relationship are briefly reviewed in the following segment. 
Shi and Nicol's (2007) article provided a clinical case study of a youth identified as "Freddie" in order to illustrate a clinical conceptualization and treatment recommendations from an "attachment perspective." Freddie was described as an adolescent male who had been placed in a residential treatment facility after committing several sexual offenses. Freddie experienced maternal separation from the ages of 2-12 due to parental divorce, sexual abuse by an older cousin, and living in a blended family after his father remarried. Freddie displayed behavior problems and sexually abused two child victims. When he was reunited with his mother at age 12 , Freddie described her as more interested in her boyfriend than her son. At the same time, he indicated that he was not close with his father.

Shi and Nicol (2007) described Freddie as suffering from a lack of maternal attachment, including a "sense of abandonment" due to his mother's 10-year absence. Although Shi and Nicol (2007) did not directly categorize Freddie as falling into one of the four accepted attachment styles, they did say that his "controversial behavior was closely associated with his internal working model" (p. 399) and that "any subtle suggestion of abandonment was magnified and reacted upon with intense feelings of anger and turmoil” (p. 399). Based on these characteristics, Freddie would be classified as fearful in Bartholomew's model (1990).

Although this study built a case between lack of parental attachment and offending behavior, it was a descriptive single case study. The information provided was cursory and did not take into account any factors other than the strained relationships between the parents and what Freddie perceived as rejection from both 
parents. Finally, details were not provided about Freddie's offenses. These concerns greatly limit both the value of this study in providing support for the link between attachment and CSA and the generalizability of the findings to other individuals.

Michael Miner at the University of Minnesota has been described as the "most advanced investigator in research concerning attachment and juvenile sex offending" (Rich, 2006). Miner and his team (Miner, Robinson, Knight, Berg, SwinburneRomine, \& Netland, 2010) have been gathering data since 2004 in an attempt to find individual characteristics that can predict sexual offending behavior. He has presented "preliminary" results of his ongoing work at conferences over the last 5 years. In 2010, Miner et al. published the results of an elaborate investigation of factors potentially associated with sexual offending. His study included face-to-face interviews, and a computerized survey comprised of subsections from three different measures: The Minnesota Multiphasic Personality Inventory (MMPI), the short version of the Multidimensional Inventory of Development, Sex and Aggression (MIDSA), and the Denver Youth Survey.

The participant sample for this impressive study included 278 adolescent males between 13 and 18 years of age. Participants were recruited from residential and outpatient sex offender specific treatment centers, juvenile probation departments, and juvenile detention facilities in the state of Minnesota. Participating youth were categorized into three offense categories: sex offenders with child victims $(n=107)$; sex offenders with peer/adult victims $(n=49)$; and non-sexual offenders $(n=122)$. 
One component of the data collection consisted of a two-part tape-recorded interview. The first part involved open-ended questions designed to explore childhood and family relationships. On average, this portion of the interview lasted an hour. The second portion of the interview involved 21 open-ended questions about leisure activities, friends, and sexual experiences and on average lasted about 10 minutes. All interviews were performed by four trained psychology graduate students working under the direction of Dr. Miner. The recorded interviews were scored by two independent consultants trained by Kim Bartholomew.

The computerized survey included 228 questions incorporating the SelfEsteem, Perceived Isolation, and Peer Isolation scales from the Denver Youth Survey; the cynicism scale from the MMPI; and a short version of the MIDSA.

Findings reflected significant differences in attachment, cynicism, involvement with friends, and both hyper-sexuality (increased sexual urges and/or sexual activity and lowered sexual inhibitions) and socio-sexuality (sexual interactions without any commitment or relationship). Miner and his colleagues suggested that in adolescence, attachment anxiety has an indirect effect on sexual abuse perpetration. In explanation, young men who feel isolated from peers have difficulty both in relating to girls or women and experience anxiety about interacting with age appropriate peers. Indirectly, this leads those with anxiety to seek intimacy or sexual gratification in inappropriate or abusive ways, most often with younger victims.

Although this investigation found evidence to link attachment and sexual offending by juveniles, it was labor intensive and time-consuming. This caliber of 
exploration requires considerable funding and manpower, which are not typically available to mental health providers, members of local juvenile departments, or even smaller research teams. More cost effective methods of investigating this phenomenon are needed.

In an unpublished Master's thesis, the author of this dissertation (Knox, 2009) explored issues related to attachment, including the participants' perceived relationship to parental figures utilizing archival data. The participant sample included 837 males between the ages of 12 and 18 years categorized into three groups: (1) juvenile sex offenders (JSO; $\mathrm{n}=273$ ); (2) juvenile delinquents (JD; $\mathrm{n}=304)$; and (3) a juvenile community control group (JC; $\mathrm{n}=260)$.

The thesis study focused on participant responses to three self-report measures: (a) a demographic questionnaire, (b) the Perceived Relationship with Supervisor form (PRS), and (c) participants' history of abuse.

The demographic questionnaire asked participants questions regarding their sex, ethnicity, age, and education. The Perceived Relationship with Supervisor form (PRS) is a 27-item questionnaire designed to examine the participant's relationship with his/her parent/supervisor and contained three subscales: (a) activities with supervisor, (b) relationship with supervisor, and (c) communication with supervisor.

Participants' responses were coded into the four accepted attachment categories (i.e., secure, dismissing, preoccupied, and fearful) based on their view of others (VOO), utilizing information obtained on the PRS, and their view of self (VOS), based on their reported history of abuse. The number of individuals who were placed into 
each attachment category was as follows: secure (397), preoccupied (211), dismissing (105), and fearful (124). Results demonstrated that the assigned attachment styles were significantly related to offending category. Specifically, there were a higher percentage of secure individuals in the control group and more individuals in the JSO group being labeled as preoccupied or fearful than those in the JD or JC groups. A multinomial logistic regression indicated that the log odds of group membership could be successfully predicted in a better than chance fashion. While producing significant insights about attachment in these populations, the study had a number of limitations. First, participants were classified into categories based on a "proxy measure" of attachment. In other words, rather than including one of the measures traditionally used in studies of this nature, items tapping similar attachment dimensions were utilized. This was a necessary compromise since the larger study from which the archival data was gleaned did not have the original purpose of assessing attachment. Second, both sex offenders and non-sex offenders included in the thesis project, while recognized in the literature as heterogeneous groups, were assessed only in terms of their larger group status. Given the exploratory nature of the investigation, it made sense to begin by looking for larger group differences rather than exploring possible subgroup comparisons (e.g., based on level of offense, chronicity, and age at first offense).

Ongoing Unpublished Research

David Burton is another one of the handful of researchers interested in the link between attachment and adolescent offending. During the conceptualization stage of 
the current research, the author met in person with and corresponded with Dr. Burton. At the time, he was in the data collection stage of a large-scale research study which included assessing the relationship between attachment and juvenile offending as part of a multifactor model intended to explain juvenile sex offending. Measures included in the larger study were the Inventory of Parent and Peer Attachment (IPPA; Armsden and Greenberg, 1987) and portions of David Lisak's measure assessing attachment to mother and father figures (Lisak, 1991). At last communication, Dr. Burton's preliminary analysis had been completed and he was in the draft stage of writing up the results for publication (personal communication, November, 2012).

After a rather extensive review of the literature in this chapter, it is important to reflect on some of the most relevant research. The following chapter will briefly outline general attachment theory, its past applications in research as an important developmental concept, and provide the roadmap to this exploration, as well as review the critiques provided above on past studies with both adult and juvenile sex offenders as their target population.

\section{$\underline{\text { Synopsis of the Existing Literature }}$}

In the previous chapter, a review was provided detailing the importance of attachment theory as a developmental concept. This chapter outlines how this literature both directed and shaped the current study. It will not only paraphrase the information in Chapter 4, but critique the concepts presented in past studies that examine the relationship between attachment and offending behavior in both adult and juvenile sex offenders. 
Like many professionals who work with troubled youth, John Bowlby tried to identify a cause for their unacceptable behavior. Bowlby found a common thread in the stories of most young men he met. He suggested that it was the loss of one of the most important figures in their lives, their mothers, which was at the root of their acting out behavior. In his inaugural paper (Bowlby, 1944), he identified the motherchild relationship as the most important developmental relationship, one that shaped not only how a child grew biologically, but also psychologically.

Like most researchers, Bowlby chose to study a sample that was readily available and of whom information was easily obtainable. Due to the scarcity of research in this area, Bowlby only examined adolescent male offenders whose mothers had passed away either during childbirth or early in their lives. Of course we now recognize that both mothers and fathers are important attachment figures and that parents can be absent from a child's life for a myriad of reasons other than death. The review of the existing literature on this topic was designed to address the limitations of Bowlby's early work by including both mothers and fathers and by examining the perceived strength of these relationships from the child's perspective.

As discussed in the previous chapter, Ainsworth observed infants in the context of her "Strange Situation" paradigm (Ainsworth, Blehar, Waters, \& Wall, 1978). Since the population of interest in Ainsworth's research was extremely young and non-verbal, the categorization of attachment style was based solely on the subjective interpretation of both the affect and behavior of study participants. Beyond this important limitation, these studies did not account for individual differences that 
exist in non-nuclear families nor the unique bonds that develop between children and other non-maternal caregivers.

The current project addresses a much older population; adolescents aged 12 to 18 years. Participants were classified on their self-reported responses to multiple questions designed to gauge their perception of how caring, warm, and supportive their individual parental figures were to them rather than subjectively observable behaviors. Older participants are seen as being in a better position to provide their perceptions of attachment. Moreover, the use of multiple questions aimed at exploring attachment to multiple figures is seen as a methodological improvement over earlier attachment approaches.

Beyond both of the important parent-child relationships, many researchers have recognized that both peers and romantic partners are important attachment figures, as well. Laible, Carlo, and Raffaelli (2000) and Descharme, Doyle, and Markiewicz (2002) examined the importance of platonic social relationships during the teen years. Although both research groups involved in these studies point out the importance of the mother-child and the father-child relationships as well as peer-peer relationships in healthy social development, neither publication seems to explore the unique contribution of mother-child and father-child attachments. The current research addresses this concern by comparing individual outcomes based on the perception of the two separate and unique parental figures. Additionally, the recognition by both Laible et al. (2000) and Descharme et al. (2002) that platonic peer relationships are important reinforces the need to assess attachment to peers in the current investigation. 
The participants' perception of their peer relationships were evaluated in the current study specifically for this reason.

Attachment style has been assessed in many different ways throughout the existing literature, but all investigations include at least one self-report measure to obtain the participants' perspective on how well relationships meet their needs. Given the internal cognitive nature of this area, it is important to utilize a well validated assessment measure to tap various underlying constructs involved in attachment. As a result, the current study incorporated the Inventory of Parent and Peer Attachment (Armsden \& Greenberg, 1987), which is a well-established, valid and reliable measure designed specifically to assess attachment in our target population of adolescents.

As identified by both Maslow $(1943,1954)$ and Sternberg (1986), sexuality is an important part of being human. Attachment has been used as a lens to appraise sexual behavior, including consensual, deviant, and abusive sexual behavior. Eves (2007), for example, utilized attachment style to predict risky sexual behavior, including unprotected sex, one-night stands, and extra-relational affairs. This exploration was done with a slightly older target population (17-24 year olds) and examined behavior that is deemed both socially acceptable and legal in U.S. culture. Additionally, the attachment assessment instrument utilized in Eve's research (i.e., RQ; Bartholomew \& Horowitz, 1991) is an abbreviated survey designed for use with young adults in consensual romantic relationships. In an effort to enhance the measurement of attachment, the current research evaluated this dimension with an 
unabridged measure that was specifically designed for use with adolescents, The Inventory of Parent and Peer Attachment (IPPA, Armsden \& Greenberg, 1987).

Given that the foundational purpose of this research endeavor was to examine attachment styles in the etiology of juvenile sexual offending behavior, it is important to briefly critique the existing adult sex offenders (ASO) and juvenile sex offenders (JSO) literature previously reviewed. Previously, in this document the work of Marshall and Mazzucco (1995), Ward et al. (1996), Smallbone and Dadds (2000), Marsa et al. (2004), Lyn and Burton (2005), and Craissati et al. (2008) were discussed in considerable detail. At this point, a brief review is necessary to put the current work into context.

Although it has long been recognized that humans have a need for affiliation (Maslow, 1943), research into how a lack of close affiliation or attachment can result in sexually abusive behavior is a relatively recent enterprise. Brief descriptions of individual research endeavors have already been provided; therefore it is important to identify some of the conceptual problems and methodological flaws within the existing research in order to guide improved studies in this area. The following section will highlight concerns with the existing literature regarding the way that many studies have been conceptualized, examine sampling concerns, and discuss measurement issues.

To begin, it is important to address problems associated with the conceptualization of attachment research and its application to an adolescent population. As previously discussed, there have been many socio-cultural hurdles 
placed in the way of professionals and researchers alike in examining this population. Most research conducted with sex offenders has been done with adult offenders, either in evaluating adult offenders with child victims (Marshall \& Mazzucco, 1995; Ward et al., 1996; Smallbone \& Dadds, 2000; Marsa et al., 2004, Lyn \& Burton, 2005; Crassati et al., 2008) by asking offenders to complete questionnaires many years (sometimes decades) after they sexually abused others as a juvenile offender (Ford \& Linney, 1995; Glasser et al., 2001) or by asking adolescents to recall experiences as the victim of sexual abuse (Higgins \& McCabe, 2001). Lindsay and Read (1994) demonstrated that research based on the recollection of long past events can be problematic. Additionally, as the population of interest for this study is adolescent offenders, research done with adults may not be generalizable due to differences in both psychological development and motives for offending (Ryan, 2010).

The second conceptual limitation found throughout attachment research in general (Bowlby, 1944; Ainsworth et al., 1978; Main et al., 1985) and specifically with sex offenders (Smallbone \& Dadds, 1998; Marshall, Hudson, \& Hodkinson, 1993) has been the evaluation of only one primary attachment figure, that of the participant's biological mother. The American family has changed dramatically over time. The nuclear family is now a minority in American society (Bengtson, 2001) and determining attachment using only one "important other" does not take into account the different individuals with whom participants may feel connected. Riggs and Gottlieb (2009, p. 208) offered that "grandparents, siblings, aunts and uncles, nonbiological co-parents (e.g., stepparents or lesbian/gay partners) church members, and 
others" often form a network vital to a child's development. This is especially salient with regard to investigations of adolescent populations. Researchers and theorists have identified peers as important attachment figures during this developmental period. Adolescents spend more of their waking hours with peers in school and social activities than with parents (Warr, 1993). Clearly it is important to acknowledge that their sense of connectedness may not be tied specifically to their biological mother. The current study contributes to the literature by examining the quality of the participants' attachment to fathers or father figures, peers as well as their mothers or mother figures.

A third conceptual confound in the research relates to how the term "sex offender" is applied. Due to the enactment of both the Jacob Wetterling Act and Megan's Law, community notification is required for many offenders in the United States. The public shame of being labeled a juvenile sex offender has resulted in alternative sentencing policies within small jurisdictions and the acceptance of plea bargains in lieu of conviction for registerable sex offenses. Although many other developed countries do require sex offender registration, only the United States, South Korea, and a handful of Canadian provinces make that registry information publicly available (Logan, 2011). This is an important conceptual problem when considering the generalizability of research done outside of the United States to the population of interest, adolescent sex offenders in Oregon.

Beyond the conceptual concerns in the literature, previous research has been conducted utilizing flawed methodology, chiefly the use of small participant pools and 
inappropriate assessment instruments. Narrow samples in attachment research utilizing juvenile sex offenders have ranged from limited case studies (Shi \& Nicol, 2007) to that of 24 participants with similar types of convictions (Saunders, Awad, \& Levine, 1984). It is easy to recognize that the broad application of any findings from a case study to a wider population is problematic. Generalizability from a homogenous sample containing not only participants of only one ethnicity but of only one type of offender are equally troubling considering that it is widely accepted that sex offenders come from varying ethnic groups and perpetrate many different types of offenses. In fact, Tabachnick and Fidell (1996; 2001) have recommended a minimum sample size of 50 for each comparison category with comparison groups of similar size.

Additionally, researchers have included non-incarcerated control groups in their studies (Marshall \& Mazzucco, 1995; Marsa et al., 2004). This design may result in inflated differences between offender and non-offender groups as findings may be due to separation from society and social support as a result of incarceration as well as factors specific to living in a "prison" environment. Related research design concerns include comparing incarcerated sex offenders to non-sex offenders, not accounting for offenders' duration of incarceration at the time of testing, a lack of attention to offense severity (sometimes reflected in the length of sentence), and finally, participants being in different stages of development at the time that they participate in the research protocol. For example, it makes sense that a sex offender who has served five years of his mandatory 6-year 3-month sentence for Rape II may feel more isolated than an 
individual in his $3^{\text {rd }}$ month of a 6-month sentence for drug possession. This difference in time spent incarcerated might result in a lower sense of attachment to others.

Significant pre-existing group differences in study participants in adult offenders are also a significant concern (Marsa et al., 2004). For example, recognition that brain development continues in males until the average age of 25 (Fischer \& Pruyne, 2002) means that studies comparing adult sex offenders with an average age of 40 to violent non-sex offenders with an average age of 22 is problematic.

Several troubling issues with measurement in research involving adolescent offenders are noteworthy, as well. These include the use of surveys designed for adults that have been "adapted" for use with adolescents. Other researchers have used their own subjective assessment of participants' case files, both from criminal and child protective agencies, in-lieu-of administering measures to or collecting self-report information from the participants directly (Smallbone \& Dadds, 2000; Shi \& Nicol, 2007; Craissati, 2008). This type of proxy evaluation may result in inaccurate appraisal of attachment. In measuring how attached one feels to others, it is the individual's perception that matters, especially in adolescents (Riggs \& Gottlieb, 2009). Finally, studies that collect data over long periods of time and in divergent jurisdictions can be problematic, as well. Individual jurisdictions (i.e., countries and states) define crimes in an idiosyncratic fashion that often does not allow comparison across venues. Bennett and Lynch (1990) suggested that differing definitions in across jurisdictions diminish the possibility of directly comparing crimes. Moreover, data collections conducted over a long period of time may fall victim to the shifting 
implementation of new laws or modifications in criminal definitions and/or sentencing guidelines. These changes may impact participant selection in an unplanned manner.

\section{Conclusion}

In summary, the current research improved upon the existing research literature regarding the etiology of juvenile sexual offending in a number of ways. First and foremost, study data were gathered only from adolescent males. In contrast to the majority of existing attachment research with adults, this study minimized the amount of time between the youth's offense and the assessment of their attachment (i.e., during data collection). Collecting data from adolescents also reduced any concerns related the inclusion of participants from multiple developmental stages (i.e., adolescence [12-19], young adulthood [20-40], middle adulthood [40-60] and late adulthood $[60+])$, which can be found in some existing research findings. The current study assured that all participants are in the same stage of development (11-18 years of age). Second, in order to take into account the unique bonds adolescents may have in non-traditional families, attachment to father figures as well as mother figures was evaluated. Further, to more broadly understand adolescent attachment, participants’ relationship to peers was evaluated as part of this study. To provide a more in-depth assessment of the attachment construct, each relationship (i.e., mother, father, and peer) was evaluated from three critical underlying perspectives: (a) trust; (b) communication, and (c) alienation.

In order to alleviate any confounds that might exist in comparing participants with dissimilar offense behaviors or jurisdictional labels, only those participants who 
had been found guilty of "equivalent" crimes were compared in this study. Moreover, since there have been no major changes to the Oregon Criminal Code since between the inception of Measure 11 in 1995 and data collection in 2010, there were fewer threats to the internal validity of this study, specifically regarding the passage of time or related to changes in statutes.

\section{Participant Characteristics}

To remediate some of the concerns regarding the size of past research samples, a number of improvements were included in this study's the research design. In order to have a robust participant sample, not only for statistical analysis but to strengthen generalizability, data were included from approximately 110 juvenile sex offenders and 110 juvenile delinquents incarcerated in the same facilities with a broad spectrum of offense histories. Further, to enhance the generalizability of research findings, this study incorporated OYA youth from four distinct offense categories: a) non-sexual, property crimes; b) non-sexual, person crimes; c) sexual, hands-on crimes with one victim; and d) sexual, hands-on offenses with multiple victims. Additionally, great care was taken during data collection to include participants of all ethnic groups represented within the Oregon Youth Authority's population.

\section{Improved Measurement}

The final design improvement in the current research was related to measurement. First, the attachment measure chosen addresses some of the concerns inherent in previous literature. The attachment instrument selected for the current study allowed for the collection of self-reported perceptions of adolescents' 
relationships to important others (i.e.: mothers or mother figure, fathers or father figure, and peers). Further, the Inventory of Parent and Peer Attachment (IPPA; Armsden \& Greenberg, 1987) used in this study, is a widely accepted measure that was designed specifically for the assessment of attachment in adolescents.

This instrument has shown strong reliability and validity. Cronbach's alpha measures for the IPPA have ranged from .87 to .93 (University of Washington, 2013).

\section{Compressed data collection time}

The second area of measurement improvement involves enhancements in data collection. All study data were collected within a 4-month window during the summer of 2010 by members of the same research team. No significant changes have been made to the Oregon Revised Statutes in the past 5 years that would impact how the participants had been classified. Further, the measures utilized for this study were selected with an eye towards keeping the entire data collection process for the overall study to less than 90 minutes. This was done for three reasons: 1) to address the limited attention spans of our sample participants; 2) to minimize the demands on facility staff; and finally, 3) the accepted reliability and validity of the IPPA measure.

In order to establish a link between attachment and self-esteem, a subsample of the population was evaluated utilizing a widely used measure of self-esteem, the Rosenberg Self Esteem Scale (RSES; Rosenberg, 1965). As self-report measures are standard in research with populations involved in behavior that can lead to stigma, all data was collected using anonymous self-report measures. 
Based on the literature review and in light of the summary just presented, the next section details the hypotheses evaluated in the current study. First, each research question will be outlined, followed by the hypothesis or hypotheses designed to explore that objective. Finally, for each hypothesis, support will be provided to demonstrate its relevance for inclusion in this study.

\section{Hypotheses}

Research Question \#1: Do juvenile sex offenders feel less attached to others as compared to juvenile delinquents?

This research question is based on the early theoretical work of Marshall, which has connected an "intimacy deficit" or "social skill deficit" to the perpetration of inappropriate or abusive sexual acts (Marshall, 1989, 1993; Marshall, Laws, \& Barbaree, 1990; Marshall, Hudson, \& Hodkinson, 1993; Marshall \& Mazzucco, 1995). As already mentioned, it has been theorized that juveniles engage in sex offending when they are unable to find age and developmentally appropriate romantic partners to fulfill their intimacy needs. Attachment is generally understood as a multi-faceted construct representing the manner in which an individual seeks out and maintains close relationships with important others (Montebarocci, Codispoti, Baldaro, \& Rossi, 2004). It has been suggested that attachment can only be understood as the subjective experience of an individual (Camarena, Sarigiani, \& Petersen, 1990). As a result only information received from participant self-report will be analyzed in exploring this dimension. Rather than classify participants into attachment styles, this research used a 
continuous-variable approach examining the degree to which participants are attached to others. This led to the first proposed hypothesis:

$\mathrm{R}_{1} \mathrm{H}_{1}-$ Juveniles who have committed a sexual offense will have lower overall attachment scores than juveniles who have committed a non-sexual offense. As already discussed, attachment is a somewhat complex concept that is comprised of a number of underlying constructs. It is therefore important to tease out some of the more important attachment components which may be relevant to sexual offending. Many researchers have identified trust as one of the most important components in feeling connected to others (Bowlby, 1969, 1972, 1980, 1988; Marshall \& Barbaree, 1990; Acker \& Davis, 1992; Mikulincer, 1998; Rich, 2010). Individuals whose internal working model does not allow them to trust others have been labeled as insecure (Bartholomew \& Horowitz, 1991). Therefore the second hypothesis stated: $\mathrm{R}_{1} \mathrm{H}_{2}-$ Juveniles who have committed a sexual offense will score lower on items measuring level of trust than juveniles who have committed a non-sexual offense.

An additional underlying construct important to the development of a secure working model includes open and effective communication (Bowlby, 1973, 1981;

Bretherton, 1980, 1985; Main et al., 1985). Therefore, a third hypothesis was proposed:

$\mathrm{R}_{1} \mathrm{H}_{3}$ - Juveniles who have committed a sexual offense will have lower scores on items measuring communication than juveniles who have committed a nonsexual offense. 
The third fundamental tenant in attachment is most often described as feeling connected with and cared for by another (La Guardia, Ryan, Couchman, \& Deci, 2000). This is often measured by researchers as the degree to which an individual feels alone or alienated from his/her family and community. In other words, people who feel alienated are not connected and are often labeled as insecurely attached (Ainsworth, 1989; Ainsworth, Blehar, Waters, \& Wall, 1978; Bartholomew, 1990; Bartholomew \& Horowitz, 1991; Bowlby, 1944, 1969, 1973, 1980, 1988, 1990; Hazan \& Shaver, 1987). Therefore, the final hypothesis within this research question proposed that:

$\mathrm{R}_{1} \mathrm{H}_{4}$ - Juveniles who have committed a sexual offense will score lower on items measuring alienation (before reverse coding) than juveniles who have committed a non-sexual offense.

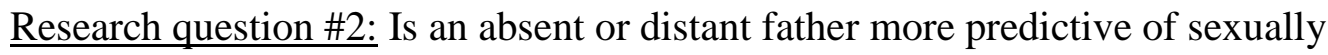
abusive behavior in adolescent males than attachment to a mother or mother figure?

In recent years developmental researchers and theorists have identified the need for healthy male role models within the family or community as essential for helping boys learn appropriate and healthy patterns for relating to others (Main \& Weston, 1981; Phares, 1992; Werner, 1995). Specifically, in the area of sex abuse research, Smallbone and Dadds (2000) found attachment to fathers, rather than mothers, to be a better predictor of perpetration of sexually abusive behavior. Additionally developmental psychologists and researchers alike have noted that it is not necessarily an individual's biological father that serves as a male role model in an 
adolescent male's life. Often individuals use the term father-figure to represent a biological father, step-father, grand-father, uncle or family friend. The hypothesis related to this research question stated that:

$\mathrm{R}_{2} \mathrm{H}_{1}-$ Juveniles who have committed a sexual offense will score lower on items measuring attachment to fathers or father figures than juveniles who have committed a non-sexual offense.

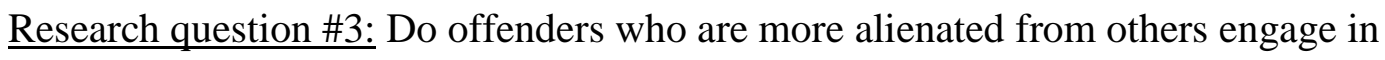
more serious crimes?

Our society measures crimes in degrees of seriousness. Crimes against persons are considered more disturbing than those that involve property damage or theft. In the state of Oregon, Measure 11 was enacted in 1995 as a reaction to how heinous the citizenry deems violent crime, including sex offenses. Crimes with the strictest sentencing guidelines under this public mandate include rape, sodomy, murder, assault, robbery, sexual penetration, and kidnapping, all of which are crimes against persons. Existing empirical research with both adult and minor participants has found that sex offenders are less securely attached to important others than their nonsexually offending counterparts. A number of researchers discussed in previous chapters have found that individuals labeled as sex-offenders report feeling a sense of isolation from others and a greater perception of rejection by their mothers and fathers (Marsa, O’Reilly, Carr, Murphy, O’Sullivan, Cotter et al., 2004; Marshall \& Mazzucco, 1995; Miner et al., 2010). In order to evaluate if this holds true with the current participant sample, the following hypothesis was proposed: 
$\mathrm{R}_{3} \mathrm{H}_{1}$ - There will be a negative correlation between items measuring attachment to parents or parent figures and the seriousness of participants' criminal offense.

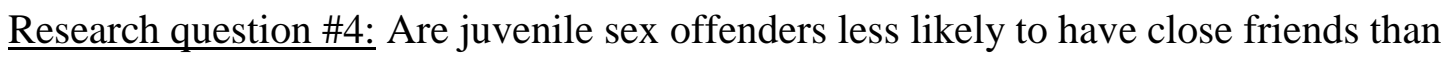
non-sex offenders?

Adolescence is a time of moving away from parents and towards other relationships (Bartholomew \& Horowitz, 1991; Bowlby, 1977; Descharme, Doyle, \& Markiewicz, 2002; Laible, Carlo, \& Raffaelli, 2000). Additionally, peer relationships have been demonstrated to be an important part of social skills development (Allen \& Land, 1999; Craig \& Dunn, 2010; Rubin, 1982; Sullivan, 1953). While engagement in destructive behavior, such as committing property crimes or using illegal substances, can enhance peer esteem and popularity (Allen et al., 2005; Kreager \& Staff, 2009), children who engage in sexually abusive behaviors have been seen as isolated, lacking in friends, and social connections (Fehrenbach, Smith, Monastersky, \& Deisher, 1986; Miner et al., 2010; Rich, 2006, 2010; Ryan, Leversee, \& Lane, 2010 ) It is therefore important to evaluate the strength of attachment to peers independent of parents as a predictor of sexually abusive behavior. The hypothesis associated with this research question stated that:

$\mathrm{R}_{4} \mathrm{H}_{1}$ - Those juveniles who sexually offend will have lower peer attachment scores than those who engage in non-sexual offending.

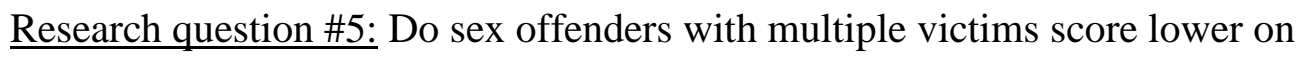
attachment to peers than non-sex offenders? 
As discussed previously, both Maslow (1943) and Sternberg (1986) contended that intimacy is a basic human need. Additionally, researchers have suggested that offending behavior occurs in response to intimacy seeking behavior (Marshall 1989; Miner et al., 2010; Rich, 2010; Ward \& Beech, 2009). It is certainly possible that a perpetrator who offends against multiple victims may be reaching out to more people in a desperate attempt to fulfill the desired need for closeness or intimacy. Ward, Hudson, and Marshall (1996) found that in their sample of adult offenders, fearful individuals (i.e., those least attached) desired both social contact and intimacy and were likely to offend sexually against a greater number of victims and younger victims. In order to explore if this is also true in an adolescent sex offender sample, the following hypothesis was proposed:

$\mathrm{R}_{5} \mathrm{H}_{1}$ - Those juveniles who offended against multiple children (will have lower peer attachment scores than those who have offended against only one child.

Research question \#6: Is adolescent attachment related to self-esteem?

Foundational attachment theorists have long recognized the importance of caring and supportive caretakers (Ainsworth, 1989; Ainsworth, Blehar, Waters, \& Wall, 1978; Bowlby, 1944, 1969, 1973, 1980, 1988, 1990). Moving beyond this basic premise of attachment, researchers have found that individuals scoring low on attachment also suffer from low self-esteem (Rubin, 1982; Armsden \& Greenberg, 1987; Schultheiss \& Blustein, 1994; Lisak, 1994, Marshall \& Mazzucco, 1995; Miner et al., 2010). In order to explore whether self-esteem covaries with attachment in juveniles, an independent measure of self-esteem (SES; Rosenberg, 1965) was 
administered to study participants. For the purpose of this hypothesis, participants' offending status will not be considered. A hypothesis is offered with this idea in mind: $\mathrm{R}_{6} \mathrm{H}_{1}$ - There will be a positive correlation between self-esteem and the overall attachment score. 


\section{Chapter 5: RESEARCH DESIGN AND METHODS}

\section{$\underline{\text { Participants }}$}

The data included for analysis in this study were gathered during the summer of 2010 as part of a larger study by the Sexual Abuse Prevention Lab under the direction of Dr. Keith Kaufman. The scope of this larger study included the investigation of four areas: (a) parental supervision and patterns of sexual offending ("modus operandi") across three ethnic/cultural groups (African American, Hispanic/Latino, European American); (b) the role of attachment as a contributing factor in the etiology of juvenile offending; (c) the contribution of, and the relationship between sexual history and sexual fantasy to sexually offending behavior; and (d) the role of the internet and technology in sexual offending behavior. This undertaking is a continuation of a national study initially funded by a grant from the Centers for Disease Control that was intended to fill critical gaps in the existing juvenile offending literature. Dr. Kaufman began collecting data for the larger study in 1999 from across nine states and currently has data from close to 3000 participants.

The author of this dissertation was present for all data collection trips from which information for this current analysis was gathered. Participants for this study were recruited from four regional juvenile detention facilities in Oregon: (a) the Rogue Valley Youth Correctional Facility located in Grants Pass, (b) the Eastern Oregon Youth Correctional Facility located in Burns, (c) the Tillamook Youth Correctional Facility and Camp Tillamook in Tillamook, and (d) MacLaren Youth Correctional Facility in Woodburn. Participants were in detention for crimes committed while 
under the age of 18 years of age and were all considered wards of the state. All participants had undergone offense specific treatment and were screened by corrections staff before data collection to confirm their desire to participate, availability during the data collection window, and ability to behave in a large group setting with minimal supervision by OYA staff.

As all measures utilized in this study were administered to the participants as part of a much larger data collection, the Internet Modus Operandi Questionnaire (IMOQ; Hayes \& Kaufman, 2010) was completed by participants between the demographic questionnaire and the IPPA. Neither the IMOQ nor any information obtained in this measure will be included as part of the current study. $\underline{\text { Measures }}$

Although data included for the existing study were collected as part of a larger umbrella data collection, only information gathered on four measures was included in the analysis for this investigation: (a) cover sheet (completed by sex offenders only), (b) demographics, (c) the Inventory of Parent and Peer Attachment (IPPA; Armsden \& Greenberg, 1987), and (d) the Rosenberg Self-Esteem Scale (RSES; Rosenberg, 1965). These measures are described in more detail below.

\section{Cover sheet}

All participants "labeled" as sex offenders by the OYA completed a cover sheet asking for information about the number of children they offended against and the age of their victims. A copy of the complete measure can be found in Appendix D. 


\section{Demographics}

Participants in the larger study completed a demographic questionnaire that asked for information that included their age, education, and ethnicity, as well as their offense history. The complete demographics questionnaire can be found in Appendix E. The self-reported ethnicity of the participant sample used in the final analysis for the current study included: $39.9 \%$ White/Caucasian/European, $29.8 \%$ mixed, $14.1 \%$ Hispanic or Latino, 7.1\% black or African-American, 6.6\% American-Indian, 1.5\% Asian/Asian-American/ or oriental, with the remaining 2 individuals or $1 \%$ stating that they either did not know what their ethnic makeup was or that there was not an accurate description available. A visual representation can be seen in Figure 4. The Inventory of Parent and Peer Attachment (IPPA; Armsden \& Greenberg, 1987)

Since the proposed study sought to identify correlations in attachment and offending behavior in adolescents, it was important to utilize a measure specifically designed for use with this population. The IPPA was developed in order to assess adolescents' perceptions of the positive and negative relationships with their parents and close friends. It is based on attachment theory (Armsden \& Greenberg, 1987). The IPPA was designed to assess three dimensions: degree of mutual trust, quality of communication, and extent of anger and alienation. The IPPA is a self-report questionnaire with a 5-point Likert scale response format. The revised version (mother, father, and peer), which was used in the collection of the data for the larger project, is comprised of 25 items in each of the mother, father, and peer sections. This 
results in three individual attachment scores for three subscales (i.e. trust, communication, and alienation). A copy of the IPPA is provided in Appendix F. The IPPA is scored by reverse-coding the negatively worded items and then summing the response values in each section.

It is important to clarify that although the IPPA (Armsden \& Greenberg, 1987) is made up of three separate sections labeled Mother, Father and Peer the Mother section clearly denotes that the participant should think about their "mother, female caregiver, or the person who has acted as your mother (like a step-mother, grandmother, aunt, foster mother, or female non-relative who takes care of you)" while answering any questions. Additionally the Father section clearly denotes that the participant should think about their "father, male caregiver, or the person who has acted as your father (like a step-father, grandfather, uncle, foster father, or male nonrelative who takes care of you)" when answering any questions. This is an important advancement over the existing research that evaluated only participant's attachment to biological mothers or fathers.

The IPPA has been used in a number of research studies evaluating adolescent attachment and looking for correlations to differentiate between various behavioral outcomes. It has been used to study correlations between attachment and adolescence depression (Armsden, McCauley, Greenberg, Burke, \& Mitchell, 1991; Capaldi, 1992; Papin \& Roggmen, 1992; DiFilippo \& Overholser, 2000; Pavlidis \& McCauley, 2001; Sund \& Wichstrom, 2002; Milne \& Lancaster, 2002; Essau, 2004; Abela et al., 2005; Allen, Porter, \& McFarland, 2007; Smith \& Calam, 2009); school and academic 
performance (Cotterell, 1992; Schultheiss \& Blustein, 1994; Kenny \& Rice, 1995; Rhodes, Grossman, \& Resch, 2000), perceived social support (Blain, Thompson, \& Whiffen, 1993); identity formation (Schultheiss \& Blustein, 1994); self-esteem (Paterson, Pryor, \& Field, 1995; O’Koon, 1997); conduct problems including externalizing behavior and aggression (Capaldi \& Stoolmiller, 1999; Formoso, Gonzales, \& Aiken, 2000; Simon, Paternite, \& Shore, 2001; Flight \& Forth, 2007; Gomez \& McLaren, 2007; Allen, Porter, \& McFarland, 2007); and juvenile delinquency (McElhaney, Immese, Smith \& Allen, 2006; Coley \& Medeiros, 2007). Information on reliability and validity for the IPPA has been quite strong. Armsden and Greenberg (2009) reported the Cronbach's alpha internal reliabilities for the three subscales as: .87 for mother attachment; .89 for father attachment; and .92 for peer attachment. Additionally, the developers of the IPPA have demonstrated the validity of the measure by showing that it correlates with the Tennessee Self Concept Scale and to most subscales on the Family Environmental Scale (Armsden \& Greenberg, 1987). They also supported the validity of the measure by demonstrating that scores on the IPPA are associated with personality variables, including selfesteem, life-satisfaction, affective status, depression, anxiety, resentment/alienation, covert anger, and loneliness (Armsden \& Greenberg, 1987; Armsden, 1986). Finally, Armsden found that scores on the IPPA are not significantly related to socio-economic status (Armsden, 1986). 
Rosenberg Self-Esteem Scale (RSES; Rosenberg, 1965)

The Rosenberg Self-Esteem Scale (RSES) is 10-item survey that was developed in the 1960's and utilizes a Guttman scale ranging from strongly agree (1) to strongly disagree (4). It has been found to have solid test-retest reliability with correlations in the range of .82 to .88 , and Cronbach's alpha in the range of .77 to .88 (Blascovich \& Tomaka, 1991; Rosenberg, 1986). Bosson, Swann, and Pennebaker (2000) found in a meta-analysis that multiple studies have demonstrated both concurrent and convergent validity of the RSES (by completing a factor analysis comparing the items measured to other recognized self-esteem scales including the Harter Self-Perception Profile for Adolescents [SPPA; Harter 1988]). In 1997 Bagley, Bolitho, and Bertrand found that more than 1000 studies had used the RSES previously with participants ranging in ages from 13 and 22. These researchers also found the measure to demonstrate significant construct validity with other accepted measures of self-esteem across their entire participant sample (1084 male and 1024 female high school students). The item Rosenberg Self Esteem Scale can be found in Appendix G. Participants rate how strongly they agree with each statement on a 4 item scale ranging from strongly agree to strongly disagree with a total score of 30 . A higher overall score represents higher self-esteem. A copy of the RSE can be found in Appendix I.

\section{$\underline{\text { Data Collection Procedure }}$}

Data were collected in common rooms adjacent to living quarters for youth incarcerated at four Oregon Youth Authority (OYA) facilities. Youth were provided 
general information that a research study was being conducted on a particular day and all available youth were asked to be present to hear about the research so they could make an informed decision as to whether they wanted to volunteer to participate in the study. Dr. Kaufman and his colleagues greeted the youth, explained the larger project, and explained how the data collected would be used. Portland State University Institutional Review Board approved informed assent forms prior to data collection, copies of which can be found in Appendix K. The asset forms were distributed and then read aloud to potential participants. Youth were then asked if they had any questions regarding the assent form and/or the study itself. Participants who volunteered to participate signed their assent forms. Assents were collected and secured before the first questionnaire was distributed to assure anonymity. Youth choosing not to participate left the area with OYA staff. A scripted introduction was read by Dr. Kaufman or trained research team member clarifying how the data would be collected, used and clarifying some of the terminology used on the measures. Instructions for the first questionnaire were provided to participating youth as a group. Instructions for subsequent questionnaires were provided individually as youth completed each questionnaire. Youth were encouraged to ask questions about any content or instructions that they found to be unclear. Dr. Kaufman and his research team were available during the data collection sessions to answer questions. OYA staff members were asked not to interact with youth, except when necessary to assure compliance with rules and assure the safety of the research team while participants were completing measures to afford them privacy. The data collection for all measures 
took participants, on average, 75 minutes. A snack break was provided approximately halfway through the data collection process. The same process and instructions were provided across all data collection meetings. In a few cases, a research team member worked with individuals who had reading difficulties to allow their participation. In these instances, the research associates read questionnaire items while the youth marked their answers on their own copy of the pen and paper measure to ensure their privacy. A copy of the introduction script can be found in Appendix J.

\section{$\underline{\text { Data Preparation }}$}

This section will delineate the steps used to prepare the raw data for analysis, and the statistical analyses completed to evaluate each of the study hypotheses. First, this section will outline how important concepts were measured. Second, the individual hypothesis that was tested will be provided again for clarification. Next, information will be offered identifying which data were analyzed to provide support for this hypothesis. Finally, the results of the statistical analysis will be provided and explained.

\section{Data Cleaning \& Data Exclusion}

Since the data used for the current study was taken from a larger investigation, additional preparation was needed prior to conducting the statistical analyses. The original raw data set included information from a participant sample of 229 including, 110 juvenile sex offenders and 119 juvenile delinquents. The data set had been created by research associates in The Sexual Abuse Prevention Research Lab at Portland State University under the direction of Dr. Keith Kaufman using SPSS during 
the fall of 2010 and winter of 2011. Before analyses began on the current project, the author confirmed all data entry by comparing the SPSS data file to the hard copies of all individual participant surveys. During the data cleaning process participants were excluded if data packets contained unclear or unreadable answers on any of the 4 measures included in the original proposal. Examples include dropping participants who did not provide information clarifying the year they were thinking about when they completed the assessments; if it appeared the participant had purposely falsified their answers (i.e. circled all 3's on the "Mother" section of the IPPA in a continuous motion rather than answer each question; or, if more than 1 out of 25 answers in the individual IPPA subscales (i.e. mother, father, and peer) were missing. Finally, if the descriptions provided by a participant explaining the crime or crimes he had been adjudicated on could not be matched to the Oregon Revised Statutes (ORS) they were eliminated from the current analysis. The final sample consisted of 97 juvenile delinquent (JD) participants and 101 juvenile sex offender (JSO) participants (198 participants in total). Neither the average age (JD: 17.37 years, JSO: 17.64 years) nor education level (JD: grade level 10.12, JSO: grade level 10.43) of participants in the two groups were statistically different from each other.

\section{Creation of Subscale Scores}

Attachment was measured using the Inventory of Parent and Peer Attachment (IPPA; Armsden \& Greenburg, 1987) with a higher overall score representing a greater level of attachment. Each participant answered on a scale ranging from 1 to 5 for a total of 75 questions, or they were also allowed to identify that they did not have 
an appropriate mother, father, or friend to rate. Attachment scores were calculated by first reverse-scoring items on the subscale items as listed below:

$\underline{\text { Attachment Scale }}$

\begin{tabular}{ll} 
& \multicolumn{1}{l}{ Reverse-scored } \\
Mother & $8,9,10,11,14,17,18,23$ \\
Father & $8,9,10,11,14,17,18,23$ \\
Peer & $9,10,11,18,22,23$
\end{tabular}

Second, all scores were added together for each scale. This resulted in an overall attachment score on a continuous scale ranging from 0 to 375 .

In order to confirm that the IPPA measure attachment to three distinct targets (mother/mother figure, father/father figure, and peers) as it was originally designed with this particular sample an exploratory factor analysis was conducted. The dimensionality of the 75 items from the Inventory of Parent and Peer Attachment measure was examined using the maximum likelihood method as detailed in Green and Salkind (2008). Three criteria were used to determine the number of factors to rotate: (1) The a priori factor structure of the IPPA; (2) The scree test; and (3) The interpretability of the factor solution. After all 75 items were entered into SPSS under data reduction options with Eigenvalues greater than 1, the maximum likelihood method with varimax rotated solution yielded three interpretable factors (mother, father, and peer). The first three items accounted for $56.06 \%$ of variance (i.e., $25.23 \%$, $16.54 \%$, and $10.57 \%$ respectively), Table 8 provides the Eigenvalues in greater detail. A scale reliability analysis was conducted using only the items asking participants about their mother or female caregiver and a resulting Cronbach's alpha level of .936 was identified. Likewise all items asking participants about their fathers 
or male caregiver loaded on the "father" factor and accounted for $15.8 \%$ of the item variance. A scale reliability analysis was conducted using only the items asking participants about their father or male caregiver and a resulting Cronbach's alpha level of .987 was identified. Twenty three of the 25 remaining items loaded on the "peer" factor and accounted for $12.6 \%$ of the item variance. Two of the items asking about their relationships with their peers (i.e.: I don't get much attention from....., and I don't trust them....) did not load heavily on any of the three factors. A scale reliability analysis was conducted using only the items asking participants about their close friends and a resulting Cronbach's alpha level of .932 was identified. The three factor confirmatory factor analysis demonstrated that the three separate factors accounted for a total of $53.63 \%$ of the variance in the current sample. A scale reliability analysis was conducted using all 75 items and a resulting alpha level of .957 was identified.

As the individual scales yielded acceptable Cronbach's alpha scores individual scores for participants' feelings towards important others (mother, father and peers) were calculated. As each participant answered 25 questions regarding each important other on a scale ranging from 1 to 5 for 25 questions these subscale scores could range between 0 and 125 .

The IPPA identifies three separate dimensions of attachment (i.e., the degree of mutual trust, quality of communication, and extent of anger and alienation). Overall aggregate scores were calculated on these three dimensions by reverse-scoring the data on the individual questions as described above and then calculating total scores for each dimension as follows: 
Trust was calculated using scores from the following questions with a score in the possible range from 0-150:

\begin{tabular}{ll} 
Important Other & Question number \\
\cline { 1 - 2 } Mother & $1,2,3,4,9,12,13,20,21,22$ \\
Father & $1,2,3,4,9,12,13,20,21,22$ \\
Peer & $5,6,8,12,13,14,19,20,21$
\end{tabular}

A scale reliability analysis was conducted using only the items asking participants about trust (as outlined above) and a resulting Cronbach's alpha level of .922 was identified.

Communication was calculated using scores from the following questions with score in the possible range of $0-130$ :

$\begin{array}{ll}\text { Important Other } & \frac{\text { Question number }}{\text { Mother }} \\ \text { Father } & 5,6,7,14,15,16,19,24,25 \\ \text { Peer } & 5,6,7,14,15,16,19,24,25 \\ & 1,2,3,7,16,17,24,25\end{array}$

A scale reliability analysis was conducted using only the items asking participants about communication (as outlined above) and a resulting Cronbach's alpha level of .90 was identified.

Alienation was calculated using scores from the following questions with a score in the possible range from 0-95:

\begin{tabular}{ll} 
Important Other & Question number \\
\cline { 1 - 2 } Mother & $8,10,11,17.18 .23$ \\
Father & $8,10,11,17.18 .23$ \\
Peer & $4,9,10,11,18,22,23$
\end{tabular}


A scale reliability analysis was conducted using only the items asking participants about alienation (as outlined above) and a resulting Cronbach's alpha level of .831 was identified.

In addition to the aggregate dimension scores, scores on the individual subscales were also calculated by important other (Mother, Father, Peer). Classification of Participants' Criminal Charges

This section begins with a discussion of efforts to classify participants based on their criminal charges. The majority of the section, however, is dedicated to presenting the results of the statistical analyses examining the questions posed as part of study hypotheses.

Based on the self-reported criminal convictions of participants, criminal classification was broken down into two categories: (1) sexual offender; and (2) nonsexual offender, these two categories encompass five subcategories, ranging from least serious to most serious: non-person non-sex crimes; person-on person non-sex crimes; hands off sex crimes; hands-on offense with one victim; and hands-on offenses with multiple victims. Participants in the JD group were not included if they had been adjudicated on any sex charges. All participants in the JSO group had primary sexual assault/abuse related convictions ranging from Harassment of an Intimate Part to Rape I. A breakdown of the individual charges for participants in the JSO group is provided in Table 3 which can be found at the end of this document. It is important to note that the individual in detention for failure to report as a sex offender, which is a misdemeanor, was previously adjudicated on the charge of Rape III. This was also true 
of two of the three individuals in detention for parole violations. The third individual in detention for a parole violation was previously adjudicated on a charge of rape II. Although these four individuals' last convictions were technically for non-person crimes, they were included in the JSO group as their original charges were sex crimes under Oregon Statutes.

A breakdown of the individual charges for participants in the JD group is provided in Table 4. It is important to note that the three individuals in detention for parole violations were previously adjudicated on assault charges; therefore they were included in the JD group in the person, non-sex crime subcategory. As the participants have already been placed into the category of non-sex offender or sex-offender based on their adjudication, these overall categories are pre-existing. For the purposes of this analysis, crimes were categorized as non-sex crimes or sex crimes. Non-sex crimes were broken down into two categories, i.e.: (1) crimes against persons and (2) other crimes (i.e., non-person crimes). Sexual crimes were broken down into hands-on verses hands-off offenses. Finally, offenders adjudicated on hands-on sex crimes were broken down into two categories, those having only one victim or those having multiple victims. Utilizing both the Oregon Sentencing Guidelines available in Appendix K and information gathered from the JSO participants on the cover sheet (Appendix D) mentioned in the Measures section, the participants' offenses were placed into the five categories below classified from least serious to most serious, These definitions were operationalized using the Oregon Revised Statutes 163-167 (www.oregonlaws.org) and the existing literature covered in the literature review. 
1. Non-person, non-sex crimes

2. Person, non-sex crimes

3. Hands off sex crimes

4. Hands-on offense with one victim

5. Hands-on offenses with multiple victims

Based on the crime categories previously provided (on page 133), 53 of the JD participants were adjudicated on crimes against property (non-sex); 44 of the JD participants were adjudicated on crimes against persons (non-sex); 1 participant was adjudicated on a non-person sex crime; 73 were adjudicated on a sex crime and admitted to having one victim; and 27 were adjudicated on a sex crime and admitted to having multiple victims. The frequency distribution for these crimes can be found in Table 5. 


\section{Chapter 6: RESULTS}

Given the exploratory nature of this study it is important to begin by clarifying the approach taken to defining "significance" for this investigation. In social science research an alpha level of .05 is a standard for demonstrating statistical significance. It is also common practice to employ procedures (e.g., a Bonferonni correction) to protect against an increased probability of finding a difference when it is not truly present (Type 1 error). At the same time, in preliminary studies where there is a paucity of existing literature, such as this one, it is also important to avoid missing true differences (Type II error) that may have implications for the development of a "young" and developing area of investigation. Design decisions for this study were made with these considerations in mind. First a standard alpha level of .05 was chosen. Second, only a limited number of t-tests were performed to minimize the experimentwise error rate. Finally no correction was employed, given the exploratory nature of this study.

\section{Hypothesis Testing}

This section will provide the results of analyses performed to examine possible differences related to study hypotheses. First, the research questions will be reviewed, followed by any important details about characteristics of the data. Second, the hypotheses will be provided. Third, the results of statistical analyses will be offered. A statement will then be made clarifying whether statistical support was found for each test of a hypothesis. 
Research Question 1: Hypothesis $1\left(\mathrm{R}_{1} \mathrm{H}_{1}\right)$ - Juveniles who have committed a sexual offense will have lower overall attachment scores than juveniles who have committed a non-sexual offense.

Overall scores for individuals were calculated using the information gathered regarding participants' perceived relationships with their mother or mother figures, father or father figures, and peers on the IPPA.

A t-test comparing the mean IPPA scores for sexual offenders and non-sexual offenders was conducted to evaluate if there was a significant difference between the groups. Although the overall attachment scores were lower for the participants in the JSO group $(M=258.19, \mathrm{SD}=58.82)$ than the scores for those in the JD group $(M$ score $=262.6, \mathrm{SD}=50)$, the difference was not statistically significant; $t(196)=-.567)$, $p=.128$. Therefore, support was not found for Hypothesis $\mathrm{R}_{1} \mathrm{H}_{1}$.

The IPPA is designed to assess three individual components in a relationship: trust; alienation; and communication. The following three hypotheses address each of these relationship components.

Research Question 1: Hypothesis $2\left(\mathrm{R}_{1} \mathrm{H}_{2}\right)$ - Juveniles who have committed a sexual offense will score lower on items measuring level of trust than juveniles who have committed a non-sexual offense.

A t-test comparing the mean IPPA trust scores for sexual offenders and nonsexual offenders was conducted to test this hypothesis. Overall, attachment scores on the trust scale were lower for the participants in the JSO $(M=110 . \mathrm{SD}=26.24)$ than the scores for those in the JD group $(M=111.85$, SD 22.7), however the difference 
was not significant at an alpha level of $.05(t[196]=-.528, p=.075)$. Therefore support was not found for this hypothesis.

Research Question 1: Hypothesis $3\left(\mathrm{R}_{1} \mathrm{H}_{3}\right)$ - Juveniles who have committed a sexual offense will have lower scores on items measuring communication than juveniles who have committed a non-sexual offense.

A t- test was performed comparing the mean IPPA communication scores for the sexual offender and non-sexual offender groups. Overall, attachment scores on the communication scale were higher for the participants in the JSO group $(M=91.06$. $\mathrm{SD}=22.95)$ than the scores for those in the JD group $(M=90.1, \mathrm{SD}=20.53)$, however, the difference was not found to be statistically significant at an alpha level .05 (t[196] $=-.309, \mathrm{p}=.33$ ). As a result, support was not found for this hypothesis.

Research Question 1: Hypothesis $4\left(\mathrm{R}_{1} \mathrm{H}_{4}\right)$ - Juveniles who have committed a sexual offense will score lower on items measuring alienation than juveniles who have committed a non-sexual offense.

A t-test was conducted comparing the overall mean IPPA alienation scores for the sexual offender and non-sexual offender groups. Overall, alienation scores on the alienation scale were lower for the participants in the JSO group $(M=65.73$, $\mathrm{SD}=16.33)$ than the scores for those in the JD group $(M=68.27, \mathrm{SD} 14.4)$, but the difference was not found to be statistically significant at an alpha level of .05 (t[196] $=$ $-1.157, \mathrm{p}=.19)$. Support was not found for this hypothesis. 
Research Question 2: Hypothesis $1\left(\mathrm{R}_{2} \mathrm{H}_{1}\right)$ - Juveniles who have committed a sexual offense will score lower on items measuring attachment to fathers or father figures than juveniles who have committed a non-sexual offense.

A t-test was conducted comparing the mean attachment scores to father/father figures of the two groups, sexual offenders and non-sexual offenders. Only the data obtained from participants regarding their fathers or father figures were used in this analysis.

A significant difference was found in participants' attachment to fathers based on their group membership (JSO vs. JD). The overall mean attachment score for the father subscale was significantly lower for the participants in the JSO group $(M=$ $65.85, \mathrm{SD}=44)$ than the scores for those in the JD group $(M=70.67 . \mathrm{SD}=33.46)$ at a $\mathrm{p}$ value of $.05, \mathrm{t}(196)=-.810), \mathrm{p}=.041$. Additionally, post-hoc analysis found significant group differences when looking at the father -trust subscale for the participants in the JSO group $(\mathrm{M}=27.52, \mathrm{SD}=18.72)$ vs. participants in the JD group $(\mathrm{M}=29.15, \mathrm{SD}=16.92), \mathrm{t}(196)=-.642, \mathrm{p}=.029$ and results trending towards significance on the father-alienation subscale for the participants in the JSO group $(\mathrm{M}=18.6,12.51)$ vs. participants in the JD group $(\mathrm{M}=20.98, \mathrm{SD}=11.35), \mathrm{t}(196)=-$ 1.39), $\mathrm{p}=.057$. Therefore, support was found for hypothesis $\mathrm{R}_{2} \mathrm{H}_{1}$.

Research Question 3: Hypothesis $1\left(\mathrm{R}_{3} \mathrm{H}_{1}\right)$ - There will be a negative correlation between items measuring attachment to parents or parent figures and the seriousness of participants' criminal offense. 
A Spearman Rank Order correlation analysis was conducted using the attachment score as an independent (continuous) variable (IV) and the offense (mixed continuous and categorical) score as a dependent variable (DV) to assess this hypothesis. Support would be found for this hypothesis if an identifiable pattern emerges demonstrating that as attachment scores decrease, offense type increases. Virtually no correlation was present between the overall attachment score and the criminal categories for the overall sample $(r=-.01)$, therefore support was not found for this hypothesis.

Research Question 4: Hypothesis $1\left(\mathrm{R}_{4} \mathrm{H}_{1}\right)$ - Those juveniles who sexually offend will have lower peer attachment scores than those who engage in non-sexual offending.

A t-test was conducted comparing the mean peer attachment scores for sexual offenders and non-sexual offenders. Only the data obtained from participants regarding their peers were used for this analysis.

No significant difference was found in attachment for peers based on their group membership (JSO: $M=93.15, S D=23.21$ and JD: $M=93.22, S D=15.18$ ) $t(192)=-.025, p=.98$. Analysis did not provide support for hypothesis $\mathrm{R}_{4} \mathrm{H}_{1}$ Research Question 5: Hypothesis $1\left(\mathrm{R}_{5} \mathrm{H}_{1}\right)$ - Those JSOs who offended against multiple children will have lower peer attachment scores than those who have offended against only one child.

A t-test was conducted comparing the mean peer attachment scores for JSO participants having one victim as opposed to those having multiple victims. 
Significant statistical differences were not found in peer attachment between the participants in these two sexual offender groups, (JSO multiple M=95.65, $\mathrm{SD}=24.5$, JSO single $\mathrm{M}=92.42, \mathrm{SD}=23),(\mathrm{t}[96]=-.623 \mathrm{p}=.35$. These findings indicate no support for Hypothesis $\mathrm{R}_{5} \mathrm{H}_{1}$.

Research Question 6: Hypothesis $1\left(\mathrm{R}_{6} \mathrm{H}_{1}\right)$ - There will be a positive correlation between self-esteem and the overall attachment score.

A linear regression was conducted using self-esteem (continuous variable) and the overall attachment score (continuous variable) to assess hypothesis $\mathrm{R}_{6} \mathrm{H}_{1}$. When the analysis was done with the participant sample as a whole, the relationship was not significant $(F(1,112)=1.974, p=.163)$. When the analysis was completed separately for the JSO and JD groups, a significant relationship was identified for the participants in the non-sexual offending group $(F(1,31)=4.18, p=.05)$. No significant relationship was found between self-esteem and overall attachment scores for participants in the JSO group $(F(1,79)=.966, p=.33)$. It should be noted that the separate examination of the study groups was conducted as a post hoc analysis.

Based on the results of the analyses discussed above, the final section will discuss the implications, limitations, and conclusions found in the current exploratory study. 


\section{Chapter 7: DISCUSSION}

Juvenile perpetrated sexual offending has detrimental effects at all levels of the ecological model. With this in mind, effective treatment of sex offenders, which reduces recidivism, can be beneficial to everyone involved (i.e., victims, offenders, their families, impacted communities, and society as a whole). As early as 1987, Davis and Leitenberg suggested that efforts to improve treatment effectiveness would benefit from the identification of key etiological factors. Theorists and clinicians alike have identified a lack of attachment to others as a critical area in need of attention to both enhance prevent efforts and reduce recidivism. To date, there has been a paucity of well-designed research available which examines the attachment of adolescent sex offenders. In fact, there have been only a handful of investigations conducted with adolescent offender populations that both accurately assess adolescents' attachment to those significant in their lives (e.g., mothers/mother figures, fathers/father figures, and friends) and examines how the extent of attachment is related to engagement in criminal behavior. The current research study sought to enhance this literature by conducting a carefully designed study of attachment with the intent of identifying critical areas to enhance prevention, offender treatment, and potentially to reduce recidivism.

This final section outlines implications of this study's findings, reviews the limitations of the current project, and suggests future directions for related research and treatment. 


\section{$\underline{\text { Study Implications }}$}

The goal of this study was to investigate possible attachment related differences between juvenile sex offenders and juvenile delinquents that may have implications for enhancing prevention as well as treatment. If researchers, therapists, and other treatment providers can identify significant differences between juvenile sexual offenders and non-sexual offenders, then they can design programs that can more effectively reduce recidivism in this clinical population. In particular, distinguishing the types of attachment deficiencies that exist in an incarcerated juvenile sex offender population can provide support for treatment strategies designed to compensate for these short comings. Further, the identification of such deficits may have implications for the development of prevention efforts to remediate youth with these difficulties.

The relationship between overall attachment scores and group membership (i.e., JSO and JD) in this study was not found to be statistically significant for study participants. This lack of significant findings may have occurred for a number of reasons, as described below.

First, all of the participants in the current study have already been labeled "anti-social" in one way or another. They have all been adjudicated for criminal behavior and removed from society. Ijzendoorn (1997) offered that aggressive behavior in adolescents may be associated with attachment deficits and a lack of empathy. In other word, both groups may have participated in their criminal behavior, 
in part, due to a lack of connection to others (e.g., family, peers). As such, attachment deficits may exist in both participant groups at a relatively similar level.

Second, it is difficult to know if the attachment scores of the participants in either of the research groups are of clinically relevance, since "normative" data for adolescent males on the IPPA was not found to be available. This instrument has been used in numerous studies over the past 25 years, but it was rarely, if ever, used in studies comparing adolescent offenders with non-offenders. A thorough search of the existing literature found only two studies containing non-clinical or incarcerated youth. The mean overall attachment scores for the JSO participants of 258.19 (3.44 average) in the current study is lower than those reported by Armsden (1986) for her non-offending community sample of 169 males (265.7 (3.50 average); Armsden, 2013) and those in a study conducted by Ryzin and Leve (2012) in a medium sized community sample in the Pacific Northwest (279.75 (3.73 average), N=373). Unfortunately, sufficient information was not available to determine if these group means are significantly different form each other. Future studies should explore the potential for overall attachment differences between samples of pre-treatment youthful offenders, and compare identified offenders with a community sample to evaluate if attachment is related to juvenile offending in general or is specific to particular types of criminal behavior on the part of juveniles (e.g., JSOs vs. JDs).

Third, all study participants had completed offense specific treatment prior to their involvement in this study. It is possible that any group differences that existed in participants at the time of their offence have been remediated during the extensive 
offense specific treatment that all participants have completed during their detention by the OYA. This treatment effect might be even stronger for the JSO participants as they have spent significantly more time in detention in their respective facilities than their non-sex offending peers (i.e., JSOs spent approximately 29 months, while JDs spent approximately 16 months in treatment; $\mathrm{t}(196)=5.42, \mathrm{p}=<.01)$, and therefore may have participated longer in treatment. A study designed to assess adolescent sexoffenders as well as a control group of non-sex offenders pre-treatment would offer a variety of advantages. First, as noted, it would provide a more accurate examination of potential differences between juvenile sex offenders and their non-sexually offending counterparts.

Fourth, it is important to remember that the participants in this study have been removed from their families and friends as part of their punishment. In other words, purposely cut off or detached from their social support network. As the measure used in the current study was designed to assess how attached participants feel to the "important others" in their lives, it is likely that their sense of belonging or connectedness has been negatively affected by their detention. It may also be that the shared "sterile" context of detention has impacted JSOs and JDs similarly with regard to their attachment. In fact, Rose \& Clear (1998) argued that incarceration actually weakens family and community structures and causes offenders to become more isolated and less connected to their individual support systems. They also suggested that this lack of connection or attachment to others actually lessons the effects of social control on their behavior and makes them care less about what others think. 
This disconnection was readily apparent in visits to OYA facilities for the purposes of data collection. While well cared for, it was clear that youth's lives were highly regulated, that contacts with family and friends were infrequent, and that there was little that was truly under their control (e.g., permission was necessary to get a drink of water or to go to the bathroom). It is quite possible that the "artificial nature" of institutional living influenced their responses to questions about their significant relationships (i.e., mother/mother figure, father/father figure, and peers/friends) prior to detention.

In order to improve the results of future studies it would be important to assess participants earlier in their sentences to assure their perceptions have not been colored, in either a negative or positive way, due to their institutionalization or specific treatment experiences. This combined with scores from un-incarcerated or normative control groups would offer insights into the unique types of attachment related difficulties that individual JSOs and JDs experience. As such, it would provide directions for either shared or differential strategies that could strengthen individualized treatment for both groups of offenders. Moreover, it may prompt the development of new treatment protocols that are especially beneficial in effectively transitioning youth back into the community following incarceration. Juvenile offenders are particularly dependent upon family and social supports to succeed with community reentry (Arditti \& Parkman, 2011; Osher, Amos \& Gonsoulin, 2001) and returning adolescents to the care of those same important others without improved 
skills for building effective relationships (or attachments) may set them up for failure and increased rates of recidivism.

In their qualitative research study, Arditti and Parkman (2011) found the biggest challenge to reintegration that adolescent offenders face is that they have "unlinked lives" (p.207) and suffer from a lack of social capital. The idea of a "linked life" was first coined by Elder (1998) when he described the social ties and structure that an individual needs to live a successful life. A linked life could be equated to an attached life or a possessing a positive working model of the self and others. Sampson and Laub (2005) believed that a return to crime is more likely when individuals lack pro-social bonds with their family and/or community. Evidence based programs that improve the social capital of released offenders by giving them the tools needed to increase the number and strength of positive relationships can foster successful community reentry as well as decreasing the chance of recidivism.

\section{Group Differences in Attachment Subscales}

When analyzing attachment scores on the trust subscale, the results trended towards significance, but they were not significant at an alpha level of .05 (JSO: $\mathrm{M}=110, \mathrm{SD} 26.24$, and JD: $\mathrm{M}=111.85, \mathrm{SD} 22.70, \mathrm{t}[196]=-.528), \mathrm{p}=.075)$. Among others, Lewis-Beck, Bryman and Liao (2004) suggest that in social science research it may be more dangerous to fail to recognize important differences (Type II error) than to over recognize differences (Type I error). This may be particularly relevant in areas of research that are less well developed, such as attachment in youthful offenders. Previous examinations of trust related to attachment have been conducted by 
Veneziano (2002), Bierman (2004), and Ryan (2012) who encourage the use of treatment approaches that foster offenders' development of empathy, compassion, and social connections that promote the development of trusting relationships with others. Findings from the current study fail to support group differences and therefore, the institution of trust related attachment focused treatment approaches for any given group of offenders. Yet, prior investigations underscore the importance of having treatment resources of this nature available for individual youth are identified as having deficits of this type.

The communication subscale of the attachment measure did not significantly differentiate between JSO and JD groups in this study. At the same time, given the long history of research documenting communication deficits in incarcerated youth, it is difficult to dispute the importance of this type of treatment for juvenile offenders. In fact, Davis, Sanger, and Morris-Friehe (1991) were one of the first research groups to identify this deficit as a risk factor for youth having trouble in school and engaging in subsequent delinquent behaviors. Their research found that a lack of skill in verbal communication causes frustration in youth as they "fall behind their peers" (p. 263), and that frustration increases their participation in antisocial behavior which results in their involvement in the juvenile criminal justice system. A number of other researchers have reported similar adolescent difficulties related to communication deficits (Campbell, Spieker, Vandergrift, Belsky, \& Bruchinal, 2010; Brownlie, Beitchman, Escobar, Young, Atkinson, Johnson, Wilson, \& Douglas (2004); 
Grigorenko, 2006; Hinshaw, 1992; Cantwell \& Baker, 1977; Howlin \& Rutter, 1987;

Silva, 1987; Stevenson, 1984).

Two reasons may account for the lack of significant attachment differences between the JSO and JD groups who participated in the current study. First, it is entirely possible that all of the participants in this study suffer from some degree of attachment deficit which has led, in part, to their participation in criminal behavior. It is also possible that any differences that might have existed at intake were resolved during the many months of treatment that all participants underwent while in the custody of OYA. In the limitations section of this paper, it is noted that there was a statistically significant difference in the average length of time participants in the two groups had been detained by OYA (JSO-37.42 months vs. JD-19.26 months).

Therefore, the average JSO has likely completed more treatment than the average JD and as a result may have made up any relative deficit in attachment associated areas. While a compelling case could not be made for group differences in attachment subscale scores, it is clear that trust and communication areas of attachment will continue to be key areas of treatment for many incarcerated offenders who demonstrate deficits in this area and will remain a promising treatment area to improve upon.

The following section will discuss the implications of findings related to the relationship between attachment and father figures as well as attachment and individual self-esteem. 


\section{Attachment to Father Figures}

As predicted, participants in the JSO group scored significantly lower on their attachment to fathers or father figures than participants in the JD group (M=65.85, SD $44.03 \& \mathrm{M}=70.67, \mathrm{SD}=39.46$ respectively; $\mathrm{t}(196)=-.810, \mathrm{p} .<.05)$. These findings reinforce both anecdotal reports of professionals working in the juvenile justice field (Mancuso, personal communication, 2010; Cambra, personal communication, 2010), and the need for intervention programs that help adolescent offenders create a better connection with either their father or a suitable male role model who can serve as a father figure. Programs designed to assess for and recognize missing attachment figures could also incorporate components that help youth develop strong relationships with positive male role models after release from incarceration. Findings from this investigation echo existing literature on adult sex offenders which highlight problematic father/child relationships in their backgrounds. For example, Lisak \& Roth (1991) found, in their study of fifteen adult sex offenders, that fifty-seven percent $(57 \%)$ of their participants described their fathers using terms such as "distant" and "cold" and less than eighteen percent (18\%) credited their fathers with positive qualities such as "warmth." Marshall and Mazzucco (1995) found that the adult sex offenders that participated in their research displayed higher levels of parental rejection in their lives than their non-offending counterparts. In their study with juvenile offenders, Ryan \& Lane (1991) reported that sex offenders were less likely to come from an intact family than non-offenders, and often lacked a strong connection to a father or father figure. The differences between JSO and JD groups in this study 
associated with both overall attachment to father and trust related to their father/father figure highlights the need to evaluate adolescents' attachment to important figures beyond that of the biological mother. It is interesting to note that $22.8 \%$ (23 out of 101) of the JSO participants said that they did not have a relationship with a father or father figure at all as opposed to only $17.5 \%$ (17 out of 97) JD participants.

Clearly these findings highlight the significance of intervening to promote healthy paternal relationships for incarcerated youth, particularly for youth who have committed a sexual offense. Future studies should further explore the factors that may be at the root of poorer attachment between JSOs and their fathers (or father figures). More specific identification of underlying factors may also help point to risk factors that can serve as the foundation for preventive efforts to ensure early identification of poor father - son relationships as well as the implementation of strategies to enhance the quality of the father - son bond. Future studies should evaluate whether it is simply a lack of father involvement (absent father); a poor relationship tinged with domestic abuse; or a perceived sense of abandonment and distrust of men that is at the root of this attachment deficit.

In the past 30 years there has been an increasing acceptance that teen males without fathers are destined for failure. Even the President of the United States was quoted as relying on a "meme" that highlights this belief:

"We know the statistics, that children who grow up without a father are five times more likely to live in poverty and commit crime; nine times more likely to drop out of schools and twenty times more likely to end up in prison. They are more likely to have behavioral problems, or run away from home, or become teenage parents themselves." — Barack Obama (New York Times, 2008) 
It is also important to consider that that it is not a poor relationship with a father or father figure that results in adolescent offending behavior (or the other problems noted above, but instead, it may be a response to the poverty that often results from growing up in a mother led single parent household. For example, the United States census figures from 2010, report that more than $23 \%$ of children living in Oregon were living in poverty; that number rises to above $44 \%$ for those children living in families led by single mothers (National Woman's Law Center, 2012). Not surprisingly, Jarjoura, Triplett \& Brinker (2002) found a strong link between persistent poverty and juvenile delinquency.

As mentioned in an earlier section discussing the existing theories surrounding sexual offending behavior, the Integrated Theory of Offending developed by Ward and Beech (2006) suggested that a lack of emotional regulation and attachment deficits were both precursors to adolescent sexual offending. Recent medical researchers have started to explore the relationships between poverty, stress and effortful control or emotional regulation (Zalewskia, Lenguaa, Fisherb, Trancikc; Bushd \& Meltzoff). Gillespie, Mitchell, Fisher and Beech (2012) have started looking at how improving one's ability to control their breathing and emotional response can improve social skills and decrease problematic behaviors specifically in sex offenders. It is possible that interventions of this nature may, in the future, position youthful offenders to improve their relationships with peers and family members by fostering better impulse control and the inhibition of behaviors which promote better attachment. 
Attachment and Self Esteem

In exploring the relationship between self-esteem and attachment, a statistically significant difference was not found in either the overall participant sample or in the juvenile sex offender portion of the sample. This may be related, in part, to the procedural error which occurred in the data collection of the larger study where the RSE was left out of the data collection packet for one of the OYA facilities (i.e., Rogue Valley). The participants housed in the Rogue Valley facility are on average one to two years younger than those in other facilities (i.e. Rogue Valley: $M=16.4$ years of age vs. McLaren: $M=18.6$ years of age). It is possible that the systematic exclusion of these participants may have altered study findings. While a comparison of mean overall attachment scores for youth detained at Rogue Valley $(M=258.60)$ as opposed to the McLaren (M=261) OYA facility did not reveal a significant difference $(\mathrm{t}(137)=-.271, \mathrm{p} . .961)$, it is still possible that the youth may have differed in the area of self-esteem. As such, future studies should replicate this portion of the study to determine if there are, in fact differences between JSOs and JDs across a broad age range with regard to the relationship between their attachment and self-esteem scores.

It is important to note that a significant relationship was found, however, between self-esteem and attachment for the non-sexual offending subsample that completed the self-esteem measure (RSES; Rosenberg, 1965). There are a number of reasons why this relationship was identified in the non-sexually offending population while it was not found in the overall sample or in the sexually offending population. 
First of all, research has shown that strong peer relationships have a role in maintaining maladaptive behavior patterns or in promoting the development of maladaptive behavior patterns. In other words, some of the participants in the JD group may have perpetrated their crimes because they have close friends that engage in delinquent behavior (Pataccini \& Zenou, 2009). Rosenberg (1965) defined selfesteem as having a sense of personal worth or feeling respected by others. It has been well documented that many youth participate in delinquent behavior in an effort to portray toughness or earn respect from others (Bernheim, 1994; Anderson, 1999; Wilkinson, 2001; Meares, Katyal, \& Kahan, 2004; Matsueda, Kreager, \& Huizinga, 2006; Bénabou \& Tirole, 2006). It would then follow that youth who participated in criminal activity with their friends and feel that their participation earned them respect from their delinquent peers reported having high self-esteem. The implications of these results are limited however because of the relatively small sample in the current study. Due to the already mentioned procedural error in data collection, the RSE (Rosenberg, 1965) was only administered to 31 non-sexually offending participants which reflects a relatively small sample size.

Overall, findings of the current study indicate that there are some significant differences in attachment for adolescents who have been adjudicated on sexual offenses as compared to non-sexual offenses. Specifically, differences were found between these two participant groups in relationships with their father figures (i.e., on overall attachment). This finding, along with a significant group difference on the trust subscale of attachment to fathers (or father figures) and a trend toward significance in 
group differences on the alienation subscale of attachment to fathers (or father figures) suggests that therapeutic interventions aimed at either strengthening existing relationships with fathers or father figures or building new ones could enhance treatment for adolescent sexual offenders.

Development of a supportive network of family, friends and social services has been referred to as a promising "new mechanism" that is available to reduce recidivism with adolescent sex offenders (Taxman, 2002). Given the critical nature of the community reintegration and re-entry period for the success of juvenile sex offenders transitioning back to the community, this type of strategy should be prioritized. In fact, there is evidence in Oregon that the establishment of such priorities has been the focus of recent additions to psycho-educational treatment modules for juvenile sex offenders preparing to transition back to the community (personal communication Kaufman, November, 2013). Evaluation and tracking of the impact of these interventions will help to clarify their impact on reestablishing key positive parental (i.e., father) and peer bonds to support youth's productive community reintegration.

The current research project augments the dearth of research that exists to support the implementation of treatment programs that strive to strengthen the attachment or connection of adolescent offenders to their support networks such as the Multi-Systemic Therapy approach and other attachment informed treatment modalities discussed by clinicians like Phil Rich (2010). In an atmosphere were government funding requires implementation of evidenced based programs, research identifying 
critical deficits in juvenile sexual offenders can identify important directions that shape more effective treatment approaches. Specifically, identifying how sexual offenders perceive their ability to communicate, trust, and feel close to others (i.e., how attached they are to others) can provide treatment providers and other child welfare professionals with a template for outlining proactive plans to maximize youth's growth in this area.

\section{$\underline{\text { Limitations }}$}

A number of potential study limitations are identified and discussed in the following section. For each limitation, suggestions are offered to improve future research. First, this study was cross-sectional, which means that although there are theoretically sound reasons to assume that the significant findings showing that attachment is related to offending behavior, no solid conclusions regarding causal relationships can be drawn from this study. In order to improve on the current findings, future studies should evaluate participants at multiple times throughout their participation in the juvenile justice system, utilizing a longitudinal research design. Although this improvement would enhance the study design, investigators would have to address the potential for a reduction in the anonymity of study participants.

Second, the average length of detention for the JSO $(M=37.42$ months, $\mathrm{SD}=$ 28.96) and JD $(M=19.26$ months, $\mathrm{SD}=16.09)$ participant groups was significantly different $(\mathrm{t}[196]=5.42, \mathrm{p}<.01)$. Study findings related to attachment may have been affected by differences in the length of time that the participants have been away from their family and friends since they began their period of incarceration. It is also 
possible that the information collected on "length of incarceration" was not completely accurate. The measure specifically asked participants "when they had committed their offense" and "when did they arrive at this facility". Within the OYA detainees are often moved between facilities as they get older or as they near their release date. It is therefore impossible to know if the participants were providing their entire length of detention or the length of time that they have been in their current OYA facility. Finally, the longer length of JSO's detention may reflect greater exposure to treatment that may have mitigated any group differences in attachment related difficulties. Ideally future research should include more sensitive and accurate measurement of how long participants had been removed from the influence (both good and bad) of their parents, role models and friends.

Third, one mitigating factor that should also be considered when looking at group differences is the study participants' individual perceptions of their sentences. As already discussed adolescents often have a strong connection to their family or peers. Juveniles who know that they have a long sentence yet to serve might feel more isolated and develop a greater sense of alienation than youth who know that they have a short time before their release. In this regard, it may also be helpful to include a measure of optimism about the future to better understand youth's perceptions about their incarceration.

Fourth, although care was taken to employ a measure specifically designed for use with an adolescent sample, it is difficult to interpret study findings due to the lack of data available for a non-offending community sample. Without this control group, 
or at least previously collected norms for non-offending adolescent community samples that have completed the IPPA, it is impossible to determine if attachment issues are unique to JSOs or if they are present in both offender groups, just to a different degree. If data from a normative sample had been available, an analysis could have been conducted to evaluate if the average community participant's overall attachment score differed from that of both the JSO and JD samples. Significant differences between the community sample and both clinical samples would have suggested a relationship between attachment deficits and all adolescent offending behavior. Future studies should either include a measure with norms for community based non-offender samples or should involve the collection of data from a community control group.

Fifth, the present study may have limited generalizability given that only incarcerated participants in Oregon were included in this research. In order to evaluate whether the same findings hold true for other groups of offenders nationwide, the results of this study should be compared to findings from similar studies in other areas of the United States or replicated with participants in other jurisdictions. Of course, such a study would more than likely introduce other threats to the validity of findings (e.g., potential confounds related to differences in statutes and laws across U. S. jurisdictions).

Sixth, the data collected for this study utilized exclusively self-report measures. Concerns may exist about data that has been gathered strictly using a selfreport methodology. In such cases, the strength of relationships being investigated can 
be inflated. At the same time, however, this method of data collection has been used successfully with the sexual offending population over time. In fact, evidence suggests that respondents are more likely to reveal sensitive sexual information with the use of an anonymous self-report methodology, particularly in a prison setting (Weinrott \& Saylor, 1991).

Seventh, in the current study a number of a priori statistical tests (i.e., 7 t-tests, 1 Spearman rank order correlation, and 1 regression analysis) along with 4 post-hoc tests ( 2 additional t-tests and 2 additional regression analysis). In any study there is a concern that conducting so many evaluations can increase the cumulative risk of committing a Type 1 error, or finding significant differences by chance when no significant difference truly exists. Although there are available methods for correcting for this type of error, these tools were not applied in this study due to its "exploratory" nature. Since there is such a limited pool of empirical research findings regarding attachment and juvenile sex offenders an alternate path was chosen. When there is both a strong theoretical basis and anecdotal evidence from practitioners working with the population of interest it is common in an exploratory study to plan a larger number of a statistical analysis to confirm conceptual ideas to "lay a foundation" for future research (Geoman \& Solari, 2011). As only a handful of studies have investigated attachment in juvenile offenders, a more liberal approach to significance testing was adopted.

It is also important to speak to the limitations that exist in any social science research related to cultural norms. There may be areas where existing theories do not 
adequately provide guidance for our research. Specifically in the area of attachment with juvenile offenders, there may be problems simply because many existing theories have been developed based on ethnocentric ideals. Attachment theory was developed from a western perspective and is based on what only a handful of theorists conceptualized as normal. The perspective taken by the measure used in the current study assumes a family structure headed by a male (father figure) and female (mother figure). Clearly, it can be harmful to think that there is only one acceptable type of family structure with in our accepted set of cultural norms. Moreover, differences within families may also impact the range of accepted cultural norms. For example, no family is alike; each has different financial and social resources and is made up of unique cultural, religious and family traditions built out of unique experiences (Strong, Devault \& Cohen, 2008). Future researchers could allow participants to describe the individuals that have had the most influence on their feelings and actions rather than only asking about female and male parents and participants' friends.

Finally, the study sample has been biased through a series of "filters." First, a certain percentage of both sexual and not sexual offenders exist that are never identified, either because their crimes go unreported or because they are not caught. Second, only sexual and non-sexual offenders that have passed through the juvenile justice system's multi-layer sieve were included in the study. The third level of filtering was related to prosecution, of those offenders charged, it is common practice for many offenders to negotiate a plea bargain that is less serious than the original crime for which they are originally charged. Finally, other offenders' charges are 
dismissed for lack of evidence. Although this filtering process limits the generalizability to the entire population of juvenile offenders, it is applicable to the population of interest identified in the current research design, that of adolescent sex offenders in detention in Oregon. Further, it should be noted that this process of filtering is not unique to Oregon. As a result, samples drawn in most other states would be similarly affected by this phenomenon.

\section{$\underline{\text { Future Directions }}$}

Ideally, future research would evaluate juvenile offenders both earlier on and at multiple points across their journey through the justice system. A longitudinal design would include formal assessment of participants' attachment to others when first contacted by social service agencies or arrested, and at regular intervals during their incarceration, treatment, and post release. This would allow for more individualized treatment as well as offering research data that would help articulate how intervention impacts different types of attachment deficits across the treatment process. Research data of this nature would also offer the ability to assess how treatment of attachment deficits relates to recidivism. Additionally, the inclusion of participants in a longitudinal study that have had contact with social service agencies as children but have not gone on to perpetrate crimes could provide an important community control group.

Another opportunity to improve future research would be to include measures that have been used in non-clinical samples, have a standardized attachment scores and have been administered to a broad range of clinical and non-clinical adolescent 
samples. Further, recruiting a control group from the community matched with clinical groups (e.g., JSO, JD) on age, ethnicity and socioeconomic status would strengthen the study methodology. This would allow researchers to tease out covariates and evaluate if all offenders are significantly less connected than their non-offending counterparts or if in general adolescents just feel disconnected as a part of a predictable normal developmental process.

As already mentioned one final suggestion for future research would be to allow participants in the ability to individually define each of the key study concepts (i.e., relationship, friendship, and family). This would begin to address differences in cultural norms. For example, in many cultures the immediate family includes multiple generations of related individuals under one roof, in others a family may include nonrelated individuals that share living arrangements. In still others, it may be common for children to be raised by single parents, foster parents, older-siblings, same-sex parents and even multi-dimensional arrangements consisting of step-parents, grandparents and community advocates. Future research should also allow adolescents to describe the important people in their lives without stereotypical labels and assumptions. Simply being a member of an intact nuclear family does not mean one feels attached or connected to these individuals. In an ever evolving society where individuals are connecting through unique relationships and even newer technology it is important to give participants an opportunity to explain what relationships have been supportive without the preconceived notion that every person needs a male/father figure and female/ mother figure in order to live a happy, healthy, and "linked life". 


\section{$\underline{\text { Conclusions }}$}

In their 2012 report, the National Coalitions for the Prevention of Child Abuse includes the following goals for their prevention efforts: to promote safe, stable, nurturing relationships for children in their homes and broader environments to decrease future risk of sexual abuse perpetration; to increase the engagement of effective bystander actions that can aid in the prevention of child sexual abuse and exploitation; and to promote environments that support healthy relationships. The purpose of applied psychology is to contribute to the solution of the world's practical

problems rather than to simply acquire knowledge. Therefore, the goals, measures, and methods employed in this research were chosen specifically for their potential to identify practically related findings to enhance JSO prevention and treatment as well as to promote a safer community.

Although including a newer, more relevant measure of attachment would be ideal in future research studies, the IPPA was chosen specifically for this study because it is quickly administered, easily scored and can be used by frontline professionals working with children, parents and their communities to identify youth in need of services to address attachment deficits. Once identified as having deficits, youth could be encouraged to participate in programs aimed at either strengthening existing or developing new healthy connections to others. Programs can be group based as well as tailored to meet youth's individual needs. Treatment could offer parents strategies to enhance parent-child communication, trust, and engagement. Finally, in an environment that requires evidence based practice, juvenile justice 
departments and other social service agencies can use significant findings in this and other research linking attachment deficits to sexual offending behavior to encourage family member and community participation in the rehabilitation process.

The effects of sexual offending are pervasive and serious. The current exploratory study did identify a few significant differences in attachment between juvenile sex offenders and juvenile delinquents. It augments applied research in the juvenile justice field by providing empirical evidence to support the anecdotal experience of many experienced juvenile counselors and therapists. It examined not only overall attachment in participants but important underlying constructs including trust, communication, and alienation in order to provide avenues for targeted offense specific treatment. This study provides a jumping off point for further research in this important area. 
Table 1: 2007 Youth Criminal Referrals by Category

\begin{tabular}{|c|c|c|c|c|c|}
\hline Person & Number & $\%$ & Female & Males & Unknown \\
\hline Assault & 2659 & $15.4 \%$ & 846 & 1813 & 0 \\
\hline Homicide Related & 38 & $0.2 \%$ & 3 & 35 & 0 \\
\hline Sex Offense & 638 & $3.7 \%$ & 34 & 603 & 1 \\
\hline Person Other & 90 & $0.5 \%$ & 22 & 68 & 0 \\
\hline Total & 3425 & $19.8 \%$ & 905 & 2519 & 1 \\
\hline Property & & $0.0 \%$ & & & \\
\hline Arson & 263 & $1.5 \%$ & 48 & 215 & 0 \\
\hline Burglary & 1119 & $6.5 \%$ & 161 & 958 & 0 \\
\hline Criminal Mischief & 1855 & $10.7 \%$ & 325 & 1529 & 1 \\
\hline Criminal Trespass & 857 & $5.0 \%$ & 188 & 667 & 2 \\
\hline Robbery & 208 & $1.2 \%$ & 34 & 174 & 0 \\
\hline Theft & 4958 & $28.7 \%$ & 2186 & 2766 & 6 \\
\hline Property Other & 70 & $0.4 \%$ & 22 & 48 & 0 \\
\hline Total & 9330 & $54.0 \%$ & 2964 & 6357 & 9 \\
\hline Public Order & & $0.0 \%$ & & & \\
\hline Disorderly Conduct & 831 & $4.8 \%$ & 225 & 605 & 1 \\
\hline Harassment & 812 & $4.7 \%$ & 279 & 531 & 2 \\
\hline Weapons & 367 & $2.1 \%$ & 40 & 326 & 1 \\
\hline Public Order & 111 & $0.6 \%$ & 12 & 99 & 0 \\
\hline Total & 2121 & $12.3 \%$ & 556 & 1561 & 4 \\
\hline Substance/Alcohol & & $0.0 \%$ & & & \\
\hline Substance/Alcohol & 1364 & $7.9 \%$ & 383 & 981 & 0 \\
\hline Total & & $0.0 \%$ & & & 0 \\
\hline Criminal Other & & $0.0 \%$ & & & \\
\hline Criminal Other & 1030 & $6.0 \%$ & 330 & 699 & 1 \\
\hline Total Criminal & 17270 & & & & \\
\hline
\end{tabular}


Table 2: Measure 11 Mandatory Minimum Sentences

\begin{tabular}{|ccc|}
\hline \multicolumn{1}{c}{ Measure 11 Mandatory Minimum Sentences } & \\
Charge & Years & Months \\
\hline Rape I & 8 & 4 \\
Sodomy I & 8 & 4 \\
Unlawful Sexual Penetration I & 8 & 4 \\
Assault I & 7 & 6 \\
Kidnapping I & 7 & 6 \\
Robbery I & 7 & 6 \\
Rape II & 6 & 3 \\
Sodomy II & 6 & 3 \\
Sexual Abuse I & 6 & 3 \\
Assault II & 6 & 3 \\
Kidnapping II & 5 & 10 \\
Unlawful Sexual Penetration II & 5 & 10 \\
S* & & 10 \\
conduct & 5 & 10 \\
Csing a child in a display of Sexually Explicit & 5 & \\
Compelling Prostitution. & &
\end{tabular}


Table 3: $\quad$ Most recent sexual charges - JSO

\begin{tabular}{|l|r|r|}
\hline & Frequency & Percent \\
\hline Valid & 2 & 2.0 \\
Rape III & 2 & 2.0 \\
Rape II & 8 & 7.9 \\
Rape I & 3 & 3.0 \\
Sodomy III & 12 & 11.9 \\
Sodomy I & 2 & 2.0 \\
Sexual Penetration I & 4 & 4.0 \\
Sexual Abuse III & 5 & 5.0 \\
Sexual Abuse II & 25 & 24.8 \\
Sexual Abuse I & 1 & 1.0 \\
Online Sexual Corruption of a Child II & 3 & 3.0 \\
Online Sexual Corruption of a Child I & 1 & 1.0 \\
Contributing to the Sexual Delinquency of a minor & 4 & 4.0 \\
Sexual Misconduct & 2 & 2.0 \\
Harassment/Touch of an Intimate Part & 1 & 1.0 \\
Failure to Report as Sex- Offender Misdemeanor & 3 & 3.0 \\
Failure to Report as a Sex Offender - Felony & 6 & 5.9 \\
Attempted Rape & 2 & 2.0 \\
Attempted Sodomy & 1 & 1.0 \\
Attempted Sexual Penetration I & 6 & 5.9 \\
Attempted Sexual Abuse & 1 & 1.0 \\
Unlawful Use of a Weapon & 1 & 1.0 \\
Luring a Minor & 6 & 1.0 \\
Sexual Assault I & 101 & 100.0 \\
\hline
\end{tabular}

a. group $=J S O$ 


\begin{tabular}{|c|c|c|c|}
\hline \multicolumn{4}{|c|}{ Table 4: Most Recent Charges } \\
\hline & & Frequency & Percent \\
\hline \multirow[t]{37}{*}{ Valid } & Criminal Mischief I & 2 & 2.1 \\
\hline & Theft III & 1 & 1.0 \\
\hline & Assault IV & 1 & 1.0 \\
\hline & Burglary I & 8 & 8.2 \\
\hline & Parole Violation & 3 & 3.1 \\
\hline & Assault I & 9 & 9.3 \\
\hline & Concealed Weapon & 2 & 2.1 \\
\hline & Theft II & 1 & 1.0 \\
\hline & Arson I & 3 & 3.1 \\
\hline & Theft I & 5 & 5.2 \\
\hline & Assault III & 5 & 5.2 \\
\hline & Minor in Possession & 1 & 1.0 \\
\hline & Drug Possession & 1 & 1.0 \\
\hline & Grand Theft Auto & 1 & 1.0 \\
\hline & Unlawful Use of a Weapon & 4 & 4.1 \\
\hline & Kidnapping & 2 & 2.1 \\
\hline & Manslaughter & 4 & 4.1 \\
\hline & Attempted Murder & 2 & 2.1 \\
\hline & Assault III & 2 & 2.1 \\
\hline & Attempted Robbery I & 2 & 2.1 \\
\hline & Riot & 1 & 1.0 \\
\hline & Unlawful Entry & 1 & 1.0 \\
\hline & Robbery & 10 & 10.3 \\
\hline & Robbery II & 5 & 5.2 \\
\hline & Possession of a firearm & 8 & 8.2 \\
\hline & Unlawful use of a deadly weapon & 1 & 1.0 \\
\hline & Attempted aggravated murder & 1 & 1.0 \\
\hline & Identity Theft & 1 & 1.0 \\
\hline & Assault with a weapon & 2 & 2.1 \\
\hline & Escape III & 1 & 1.0 \\
\hline & Physical Harassment & 1 & 1.0 \\
\hline & Tampering of a witness & 1 & 1.0 \\
\hline & Running away & 1 & 1.0 \\
\hline & Attempted assault I & 1 & 1.0 \\
\hline & Unlawful use of a motor vehicle & 2 & 2.1 \\
\hline & Fighting & 1 & 1.0 \\
\hline & Total & 97 & 100.0 \\
\hline Table 4 & Most Recent Charges JD & & \\
\hline
\end{tabular}




\begin{tabular}{|c|c|c|}
\hline \multicolumn{3}{|c|}{$\begin{array}{c}\text { Participant placement in criminal } \\
\text { categories } 1-5\end{array}$} \\
\hline & Frequency & Percent \\
\hline 1. Non-person, non- sex crime conviction & 53 & 26.8 \\
\hline 2. Person, non-sex crime conviction & 44 & 22.2 \\
\hline 3. Non-person, sex crime conviction & 1 & .5 \\
\hline 4. person sex crime conviction & 73 & 36.9 \\
\hline $\begin{array}{l}\text { 5. multiple victim sex crime } \\
\text { conviction }\end{array}$ & 27 & 13.6 \\
\hline Total & 198 & 100.0 \\
\hline
\end{tabular}

Table 5: Participants' placement in criminal category 
Table 6: $\quad$ Total Attachment Score by Group

\begin{tabular}{|l|l|r|c|r|r|}
\hline & group & \multicolumn{1}{|c|}{ N } & Mean & Std. Deviation & Std. Error Mean \\
& & & & & 5.85276 \\
\hline total attachment & JSO & 101 & 258.1881 & 58.81951 & 5.07696 \\
score & JD & 97 & 262.5979 & 50.00222 & 5 \\
\hline
\end{tabular}


Table 7

Results

\begin{tabular}{|c|c|c|c|c|c|c|c|c|c|c|c|}
\hline Hypothesis & Group & $\mathrm{n}$ & Mean & SD & $\mathrm{F}$ & $\mathrm{T}$ & $\mathrm{DF}$ & $\mathrm{P}$ value & $\begin{array}{c}\text { Cohen's } \\
\text { D }\end{array}$ & Effect size & Sig. \\
\hline \multirow[t]{2}{*}{$\mathrm{R}_{1} \mathrm{H}_{1}$} & JSO & 101 & 258.19 & 58.82 & 2.342 & -0.567 & 196 & 0.128 & -0.08 & 0.04 & $\mathrm{NO}$ \\
\hline & $\mathrm{JD}$ & 97 & 262.6 & 50 & & & & & & & \\
\hline \multirow[t]{2}{*}{$\mathrm{R}_{1} \mathrm{H}_{2}$} & JSO & 101 & 110 & 26.24 & 3.21 & -0.528 & 196 & 0.075 & -0.075 & 0.04 & Trends \\
\hline & JD & 97 & 111.85 & 22.7 & & & & & & & \\
\hline \multirow[t]{2}{*}{$\mathrm{R}_{1} \mathrm{H}_{3}$} & JSO & 101 & 91.06 & 22.95 & 0.948 & 0.309 & 196 & -0.33 & 0.044 & 0.02 & NO \\
\hline & $\mathrm{JD}$ & 97 & 90.1 & 20.53 & & & & & & & \\
\hline \multirow[t]{2}{*}{$\mathrm{R}_{1} \mathrm{H} 4$} & JSO & 101 & 65.73 & 16.33 & 1.747 & -1.157 & 196 & 0.19 & -0.165 & 0.08 & NO \\
\hline & JD & 97 & 68.27 & 14.4 & & & & & & & \\
\hline
\end{tabular}

Note: ${ }^{*} \mathbf{p}<.05$ 
Table 7 (continued)

\begin{tabular}{|c|c|c|c|c|c|c|c|c|c|c|c|}
\hline Hypothesis & Group & $\mathrm{n}$ & Mean & SD & $\mathrm{F}$ & $\mathrm{T}$ & DF & $P$ value & $\begin{array}{c}\text { Cohen's } \\
\text { D } \\
\end{array}$ & Effect size & Sig. \\
\hline \multirow[t]{2}{*}{$\mathrm{R}_{2} \mathrm{H}_{1}$} & JSO & 101 & 65.85 & 44 & 4.21 & -0.81 & 196 & $0.041 *$ & -0.116 & 0.06 & YES \\
\hline & JD & 97 & 70.67 & 33.46 & & & & & & & \\
\hline post hoc & JSO & 101 & 27.52 & 18.72 & 4.85 & -0.642 & 196 & $0.029 *$ & -0.092 & 0.05 & YES \\
\hline F-trust & JD & 97 & 29.15 & 16.92 & & & & & & & \\
\hline post hoc & JSO & 101 & 18.6 & 12.51 & 3.66 & -1.398 & 196 & 0.057 & -0.2 & 0.1 & Trends \\
\hline F-alien & JD & 97 & 20.98 & 11.35 & & & & & & & \\
\hline \multirow[t]{2}{*}{$\mathrm{R}_{4} \mathrm{H}_{1}$} & JSO & 99 & 93.15 & 23.21 & 7.12 & -0.025 & 192 & 0.98 & -0.004 & 0 & $\mathrm{NO}$ \\
\hline & JD & 95 & 93.22 & 15.18 & & & & & & & \\
\hline \multirow[t]{2}{*}{$\mathrm{R}_{5} \mathrm{H}_{1}$} & $\begin{array}{l}\text { JSO/ } \\
\text { mult. }\end{array}$ & 26 & 95.65 & 24.5 & 0.5 & -0.623 & 96 & 0.535 & -0.127 & 0.06 & NO \\
\hline & $\begin{array}{l}\text { JSO/ } \\
\text { single }\end{array}$ & 72 & 92.32 & 23 & & & & & & & \\
\hline
\end{tabular}


Table 7 (continued)

\begin{tabular}{llcl} 
Spearman Rank Order Correlation & $\mathrm{N}$ & $\mathrm{r}$ \\
\hline $\mathrm{R}_{3} \mathrm{H}_{1}$ & $\begin{array}{l}\mathrm{IV}=\text { Attachment } \\
\mathrm{DV}=\text { off. }\end{array}$ & 198 & 0.01 \\
& & &
\end{tabular}

\begin{tabular}{clrlr} 
Regression & & $\mathrm{F}$ & $\mathrm{DF}$ & $\mathrm{P}$ value \\
\hline $\mathrm{R}_{6} \mathrm{H}_{1}$ & JSO \& JD & 1.974 & 1,112 & 0.16 \\
post hoc & JSO only & 4.18 & 1,31 & 0.05 \\
post hoc & JD & 0.966 & 1,79 & 0.33
\end{tabular}$*$

Note: $* p<.05$ 
Table 8

Factor Analysis of IPPA items (Mother/Mother figure)

\begin{tabular}{|l|r|r|r|}
\hline & \multicolumn{3}{|c|}{ Factor } \\
\cline { 2 - 4 } Item & \multicolumn{1}{|c|}{2} & \multicolumn{1}{c|}{3} \\
\hline m1.respects feelings & .155 & .089 & .789 \\
m2. good job & .122 & .040 & .730 \\
m3. reverse I wish I had a different mother & .123 & -.063 & .621 \\
m4. accepts me as I am & .092 & .102 & .641 \\
m5. point of view & .005 & .068 & .704 \\
m6. reverse no use letting feelings & -.086 & .066 & .396 \\
m7. can tell when I'm upset & .106 & .131 & .510 \\
m8. rvs talking over my problems & .036 & -.003 & .338 \\
M9. rvs expects too much & -.037 & .079 & .344 \\
m10. rvs upset easily & -.083 & .045 & .303 \\
m11. rvs upset a lot more than she knows about & .081 & .004 & .352 \\
m12. when we discuss she cares about my point of view & .080 & .137 & .723 \\
m 13. trusts my judgment & .138 & .189 & .715 \\
m 14. rvs has her problems & .007 & -.083 & .458 \\
m15. helps me understand myself better & .115 & .179 & .743 \\
m16. I tell her about my problems & .032 & .196 & .664 \\
m17. rvs I feel angry with her & .007 & -.158 & .520 \\
m18 rvs I don't get much attention & -.017 & -.059 & .472 \\
m19. she helps me talk about my difficulties & .095 & .276 & .736 \\
m20. she understands me & .107 & .181 & .809 \\
m21. when I am angry she tries to be understanding & .101 & .195 & .772 \\
m22. I trust her & .029 & .065 & .745 \\
m23. rvs she doesn't understand me these days & -.007 & .061 & .420 \\
m24. I can count on her & .015 & .216 & .714 \\
m25. if she knows something is bothering me she asks & .084 & .188 & .698 \\
\hline
\end{tabular}


Factor Analysis of IPPA items (Father/Father figure items)

\begin{tabular}{|c|c|c|c|}
\hline \multirow[b]{2}{*}{ Item } & \multicolumn{3}{|c|}{ Factor } \\
\hline & 1 & 2 & 3 \\
\hline f1. respects feelings & .948 & .086 & .115 \\
\hline f2. good job & .916 & .060 & .055 \\
\hline f3. rs I wish I had a different father & .848 & -.075 & -.070 \\
\hline f4. accepts me as I am & .937 & .071 & .036 \\
\hline f5. point of view & .931 & .061 & .107 \\
\hline f6. rs no use letting feelings & .726 & -.173 & .043 \\
\hline f7. can tell when I'm upset & .897 & .108 & .035 \\
\hline f8. rs talking over my problems & .729 & -.074 & -.054 \\
\hline f9. rs expects too much & 680 & -.005 & -.005 \\
\hline f10. rs upset easily & .752 & -.081 & -.004 \\
\hline f11. rs upset a lot more than he knows about & .653 & -.047 & .047 \\
\hline f12. when we discuss he cares about my point of view & .930 & .062 & .100 \\
\hline f13. trusts my judgment & 911 & .056 & .084 \\
\hline f14. rs has his problems & .706 & -.120 & .054 \\
\hline f15. helps me understand myself better & .922 & -.015 & .114 \\
\hline f16. I tell him about my problems & 917 & .094 & .169 \\
\hline f17. rs I feel angry with him & .823 & -.087 & -.042 \\
\hline f18. rs I don't get much attention & .815 & -.056 & .026 \\
\hline f19. he helps me talk about my difficulties & .915 & .079 & .124 \\
\hline f20. he understands me & .934 & .078 & .113 \\
\hline f21. when I am angry he tries to be understanding & .921 & .049 & .094 \\
\hline f22. I trust him & .927 & .096 & .058 \\
\hline f23. rs he doesn't understand me these days & .740 & -.027 & .010 \\
\hline f24. I can count on him & .929 & .068 & .132 \\
\hline f25. if he knows something is bothering me he asks & .928 & .030 & .100 \\
\hline
\end{tabular}


Factor Analysis of IPPA items (Peer/Friend items)

\begin{tabular}{|c|c|c|c|}
\hline \multirow[b]{2}{*}{ Item } & \multicolumn{3}{|c|}{ Factor Loadings } \\
\hline & 1 & 2 & 3 \\
\hline p1. respects feelings & .020 & .750 & .190 \\
\hline p2.good job & -.021 & .761 & .161 \\
\hline p3. I wish I had a different & .060 & .774 & .163 \\
\hline p4. rs accepts me as I am & -.117 & .264 & -.008 \\
\hline p5.rs point of view & -.032 & .446 & -.109 \\
\hline p6. no use letting feelings & .064 & .771 & .139 \\
\hline p7. can tell when I'm upset & .065 & .624 & .189 \\
\hline p8. talking over my problems & -.002 & .752 & .109 \\
\hline p9. rs expects too much & -.034 & -.350 & -.153 \\
\hline p10. rs upset easily & -.006 & .246 & .015 \\
\hline p11. rs upset a lot more than they know about & -.067 & .396 & .007 \\
\hline p12. when we discuss they care about my point of view & .037 & .839 & .184 \\
\hline p13. trusts my judgment & .073 & .802 & -.028 \\
\hline p14. has their own problems & .014 & .788 & -.006 \\
\hline p15. helps me understand myself better & .057 & .835 & .055 \\
\hline p16. I tell them about my problems & .140 & .740 & .159 \\
\hline p17. I feel angry with them & .116 & .820 & .105 \\
\hline p18. rs I don't get much attention & -.014 & -.077 & -.057 \\
\hline p19. they help me talk about my difficulties & -.002 & .837 & .070 \\
\hline p20. they understand me & -.036 & .790 & .155 \\
\hline p21. when I am angry they try to be understanding & .044 & .829 & .115 \\
\hline p22. rs I trust them & -.015 & .040 & .030 \\
\hline p23. rs they don't understand me these days & -.158 & .292 & -.028 \\
\hline p24. I can count on my friends & .002 & .825 & .059 \\
\hline p 25. if they know something is bothering me they ask & .034 & .824 & .069 \\
\hline
\end{tabular}

Extraction Method: Maximum Likelihood.

Rotation Method: Varimax with Kaiser Normalization.

a. Rotation converged in 5 iterations. 
Table 9

Inventory of Parent and Peer Scale Reliability

\begin{tabular}{lcc}
\multicolumn{1}{c}{ Scale } & Number of Items & Alpha \\
\hline Total Attachment & 75 & 0.957 \\
& & \\
Mother subscale & 25 & 0.936 \\
Father subscale & 25 & 0.987 \\
Other subscale & 25 & 0.932 \\
& & \\
Trust subscale & 30 & 0.923 \\
Communication subscale & 26 & 0.906 \\
Alienation subscale & 19 & 0.831
\end{tabular}


Figure 1: Bronfenbrenner's Ecological Model

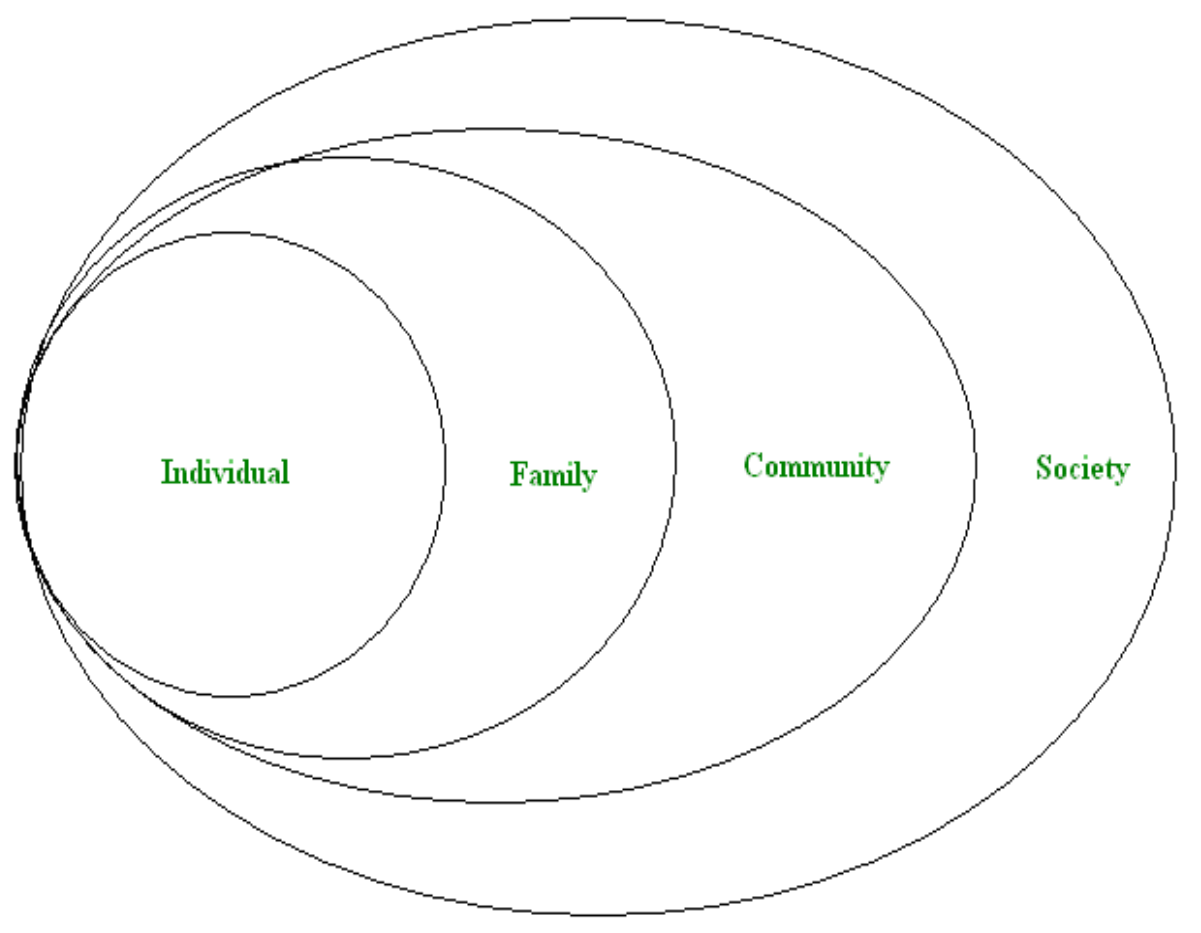


Figure 2: Bartholomew's Four Category Model of Attachment

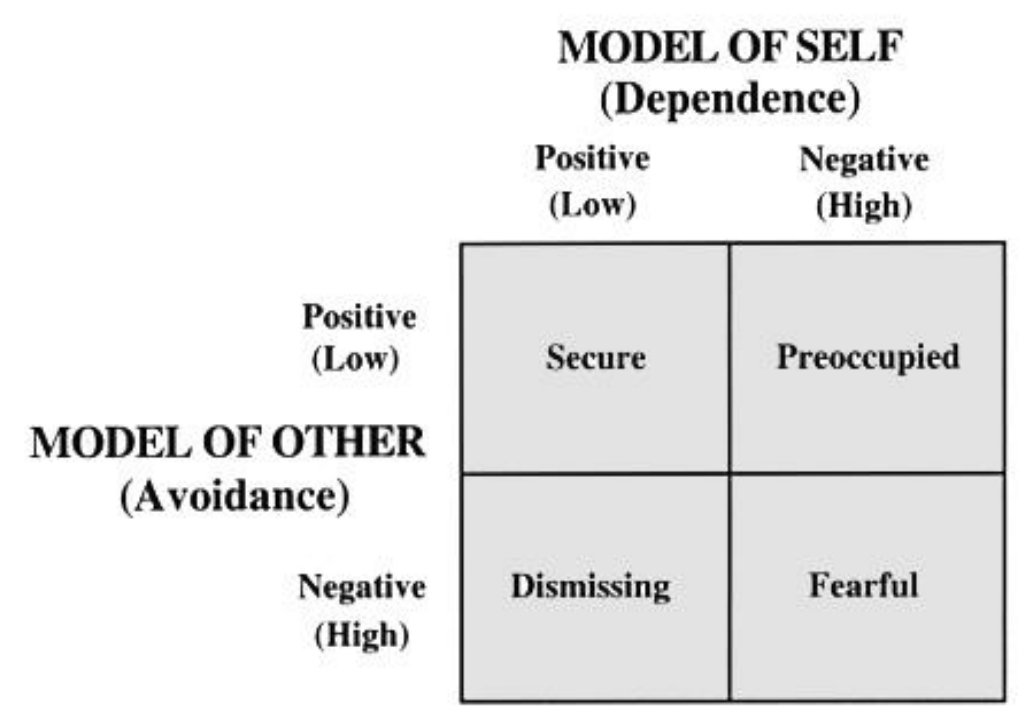


Figure 3: Maslow's Hierarchy of Needs

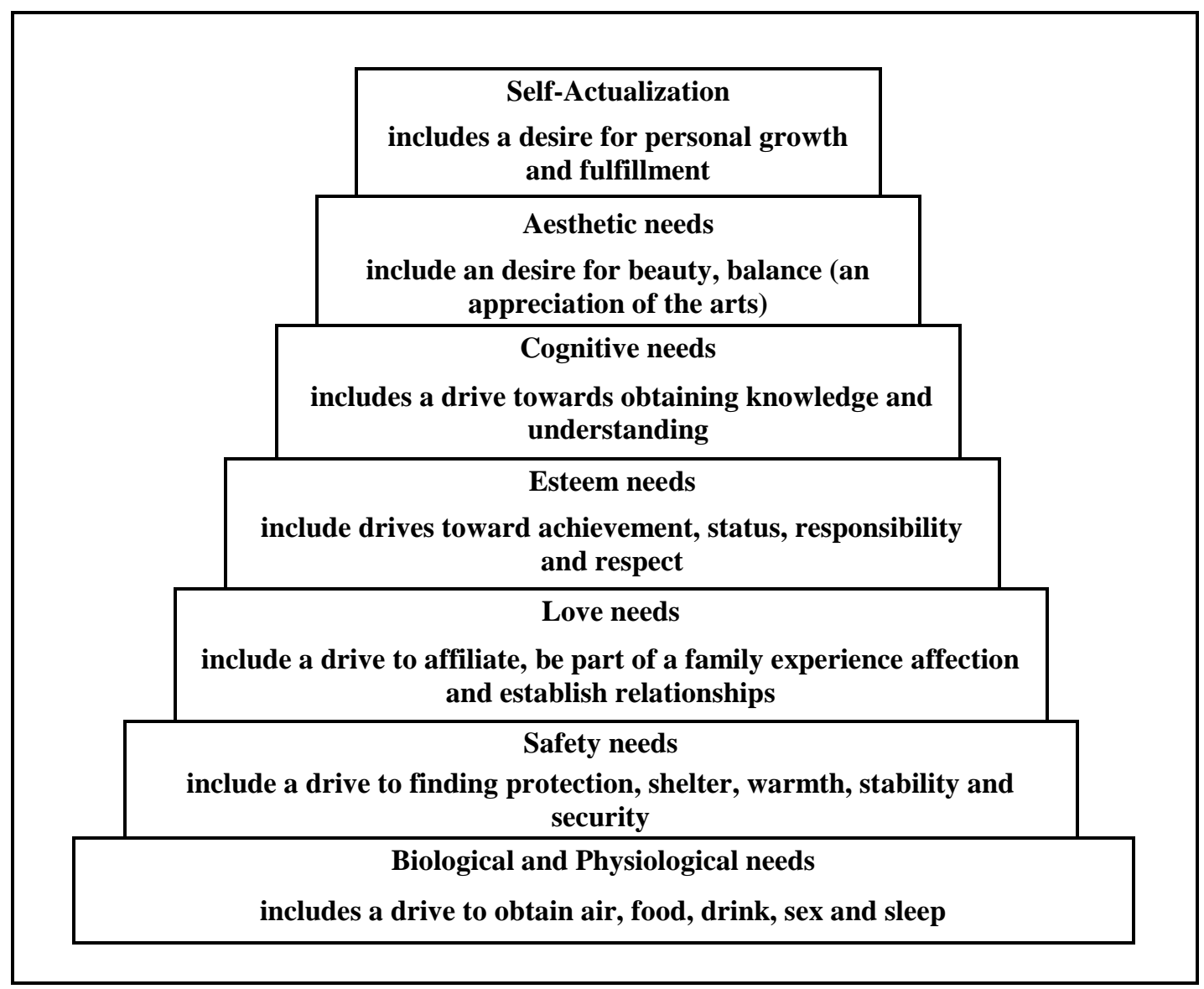


Figure 4: Ethnicity of Participants

$\square$ asian, asian-american, or oriental

$\square$ black or african-american

$\square$ hispanic or latino

$\square$ white, caucasian, european

$\square$ american-indian

$\square$ mixed

$\square$ dont know

$\square$ other

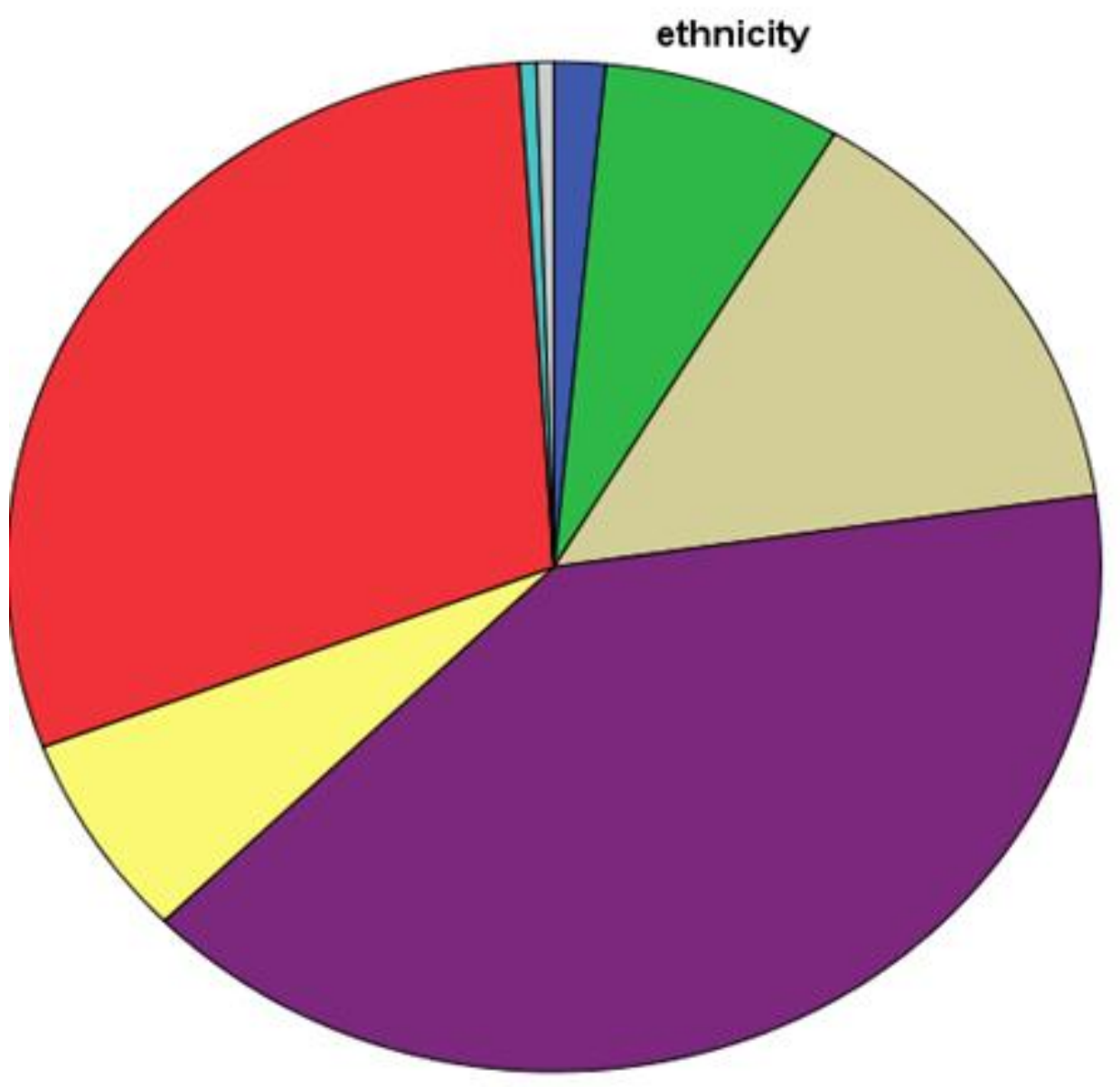




\section{REFERENCES}

Abela, J., Hankin, B., Haigh, E., Adams, P., Vinokuroff, T., \& Trayhern, L. (2005). Interpersonal vulnerability to depressive episodes in high risk children: The role of insecure attachment and reassurance seeking. Journal of Clinical Child and Adolescent Psychology, 182-192

Achenbach, T. (1991). Manual for the youth self-report and 1991 Profile. Burlington: University of Vermont.

Acker, M. \& Davis, M. (1992). Intimacy, passion and commitment in adult romantic relationships: A test of the triangular theory of love. Journal of Social and Personal Relationships. 21-50.

Ainsworth M. (1989). Attachments beyond infancy. American Psychologist. 44, 709716.

Ainsworth, M., Blehar, M. C., Waters, E., \& Wall, S. (1978). Patterns of attachment: A psychological study of the Strange Situation. Hillsdale, NJ: Erlbaum.

Ainsworth, M., \& Bowlby, J. (1991). An ethological approach to personality development. American Psychologist. 46, 333-341.

Allen, E. \& Baucom, D. (2004). Adult attachment and patterns of extra dyadic involvement. Family Process, 43, 467-488.

Allen, J., \& Land, D. (1999). Attachment in adolescence. In: Cassidy J, Shaver PR, editors. Handbook of attachment theory and research. New York: Guilford Press; 1999.

Allen, J., Porter, M., \& McFarland, C. (2005). The two faces of adolescents' success with peers: Adolescent popularity, social adaptation, and deviant behavior. Child Development. 747-760.

Allen, J., Porter, M., \& McFarland, C. (2007). The relation of attachment security to adolescents' paternal and peer relationships, depression, and externalizing behavior. Child Development, 1222-1239.

Allen, M., D’Alessio, D., Emmers, T., \& Gebhardt, L. (1996). The role of educational briefings in mitigating effects of experimental exposure to violent sexually explicit material: A meta-analysis. Journal of Sex Research, 135-141. 
Alexander, P., \& Lupfer, S. (1987). Family characteristics and long term consequences associated with sexual abuse. Archives of Sexual Behavior,, 235-245.

Alexander, M. (1999) Sexual offender treatment efficacy revised. Sexual Abuse: A Journal of Research and Treatment. 11, 101-116.

Alter-Reid, K., Gibbs, M.S., Lachenmeyer, J. R., Sigal, J. \& Massoth, N. A. (1986). Sexual abuse of children: A review of the empirical findings. Clinical Psychology Review, 6, 249-266.

Anderson, E. (1999), Code of the Street, New York: Norton

Archer, J. (1991). The influence of testosterone on human aggression. British Journal of Psychology. 1-28.

Arditti, J., \& Parkman, T. (2011). Young men's reentry after incarceration: A developmental paradox. Family Relations. 205-220.

Armsden, G. (1986). Attachment to parents and peers in late adolescence: Relationships to affective status, self-esteem, and coping with loss, threat and challenges. Unpublished Doctoral Dissertation, University of Washington.

Armsden, G. \& Greenberg. M. (1987). The inventory of parent and peer attachment: Individual differences and their relationship to psychological well-being in adolescence. Journal of Youth and Adolescence. 16, 427-254.

Armsden, G.C., McCauley, E., Greenberg, M. T., Burke, P., \& Mitchell, J. (1991). Parent and peer attachment in early adolescence depression. Journal of Abnormal Child Psychology, 18, 683-697.

Bachman. R., \& Saltzman, L. (1995). Violence against women: Estimates from the redesigned survey, Bureau of Justice Statistics Special Report National Crime Victimization survey, 1-8.

Bandura, A. (1977). Self-efficacy: Toward a unifying theory of behavioral change. Psychological Review. 191-215.

Bandura, A. (1979). Aggression: A social learning analysis. Prentice-Hall. Oxford, England.

Banyard, V., \& Williams, L. (1996). Characteristics of child sexual abuse as correlates of women's adjustment: A prospective study. Journal of Marriage and Family 853-86. 
Banyard, V., Williams, L., \& Siegel, J. (2001). The Long-Term Mental Health Consequences of Child Sexual Abuse: An Exploratory Study of the Impact of Multiple Traumas in a Sample of Women. Journal of Traumatic Stress, 14, 697-715.

Barbaree, H., \& Marshall, W. L. (2008). The Juvenile Sex Offender. Guilford Press. New York, New York.

Barnett, L., Mackay, R., \& Valiquet, D. (2007) Bill C-2: An Act to amend the Criminal Code and to Make Consequential Amendments to Other Acts, Law and Government Division, Parliament of Canada. Retrieved January 30, 2011 from http://www2.parl.gc.ca/Sites/LOP/LegislativeSummaries/Bills_ls.asp?lang=E $\& 1 \mathrm{~s}=\mathrm{c} 2 \&$ source $=$ library_prb\&Parl=39\&Ses $=2$

Baron-Cohen, S., O’Riordan, M., Stone, V., Jones, R., \& Plaisted, K. (1999). Recognition of faux pas by normally developing children and children with Asperger Syndrome or high-functioning autism. Journal of Autism and Developmental Disorders, 29,407-418.

Bartholomew, K. (1990). Avoidance of intimacy: An attachment perspective. Journal of Social and Personal Relationships, 7, 147-178.

Bartholomew, K. \& Horowitz, L. (1991). Attachment styles among young adults: A test of a four-category model. Journal of Personality and Social Psychology, $61,226-244$.

Basile, K. C., Black, M. C., Simon, T. R., Arias, I., Brener, N. D., \& Saltzman, L. E. (2006). The association between self-reported lifetime history of forced sexual intercourse and recent health-risk behaviors: Findings from the 2003 National Youth Risk Behavior Survey. Journal of Adolescent Health. 752 e1-752 e7.

Bauminger, N., Finzi-Dottan, R., Chason. S., \& Har-Even, D. (2008). Intimacy in adolescent friendship: The roles of attachment, coherence, and self-disclosure. Journal of Social and Personal Relationships . 409-428.

Becker, J. (1998). What we know about the characteristics and treatment of adolescents who have committed sexual offenses. Child Maltreatment. 317329.

Beech, A., Fisher, D., \& Beckett, R. (1999). An evaluation of the prison sex offender treatment program. A report for the home office. Home Office Information Publications Group, Queen Anne's Gate, London 
Belsky J, Jonassaint C, Pluess M, Stanton M, Brummett B, Williams R. (2009). Vulnerability genes or plasticity genes? Molecular Psychiatry. 746-754

Bénabou, R., \& Tirole, J. (2006). Incentives and pro-social behavior, American Economic Review, 1652-1678.

Bennett, R. \& Lynch, J. (1990). Does a difference make a difference? Comparing cross-national crime indicators. Criminology. 153-181.

Bengtson, V. (2001). Beyond the nuclear family: The increasing importance of multigenerational bonds. Journal of Marriage and Family. 1 - 16.

Berger, L., Jodi, K., Allen, J., \& Davidson B. M. (2005). When adolescents disagree with others about their symptoms: Differences in attachment organization as an explanation of discrepancies between adolescent-, parent-, and peer-reports of behavior problems, Developmental Psychopathology. 509-528.

Bernheim, B. Douglas (1994), A Theory of Conformity, Journal of Political Economy, 841-877.

Bernstein, D., Ahluvalia, T., Pogge, D., Handelsman, L. (1997). Validity of the childhood trauma questionnaire in an adolescent psychiatric population. Journal of the American Academy of Child and Adolescent Psychiatry, 334340

Berry, K., Barrowclough, C. \& Wearden A. (2008). Attachment theory: A framework for understanding symptoms and interpersonal relationships in psychosis.

Behavior Research and Therapy, 46,1275-1282.

Bierman, K. (2004). Peer rejection; Developmental Processes and Intervention Strategies. The Guilford Press, New York, NY.

Blain, M., Thompson, J., \& Whiffen, V. (1993). Attachment and perceived social support in late adolescence: The interaction of working models of self and others. Journal of Adolescent Research, 226-241

Blascovich, J., \& Tomaka, J. (1991). Measures of self-esteem. In J/ Robinson, P. Shaver, \& L. Wrightsman (eds.). Measures of personality and social psychological attitudes. New York, Academic Press.

Book, A. S., Starzyk, K. B., \& Quinsey, V. L. (2001). The relationship between testosterone and aggression: A meta-analysis. Aggression and Violent Behavior, 66, 579-599. 
Booth-Laforce, C., Oh, W., Kim, A., Rubin, K., Rose-Krasnor, L., \& Burgess, K. (2006) Attachment, self-worth, and peer-group functioning in middle childhood. Attachment \& Human Development. 309-325.

Botash, A. (2008). Pediatrics, Child Sexual Abuse. Retrieved August 22, 2008 from http://www.emedicine.com/emerg/topic369.htm

Bowlby, J. (1944). Forty-four juvenile thieves: Their characters and their home life. International Journal of Psycho-Analysis, 19-52.

Bowlby, J. (1969). Attachment and loss: Vol. 1. Attachment. New York. Basic Books.

Bowlby, J. (1973). Attachment and loss: Vol. 2. Separation. New York. Basic Books.

Bowlby, J. (1980). Attachment and loss: Vol. 3. Loss: Sadness and depression. New York. Basic Books.

Bowlby, J. (1988). A Secure Base: Parent-Child Attachment and Healthy Human Development, Tavistock professional book. London: Routledge.

Bowlby, J. (1990). Charles Darwin: A new biography London: Hutchinson

Bosson, J., Swann, W., \& Pennebaker, J. (2000). Stalking the perfect measure of implicit self-esteem: The blind men and the elephant revisited? Journal of Personality and Social Psychology. 631-643.

Brennan, K. A., Clark, C. L. \& Shaver, P. R. (1998). Self-report measurement of adult attachment: an integrative overview. In J. A. Simpson \&W. S. Rholes (Eds.), Attachment Theory and Close Relationships (pp. 46_/76). New York: Guilford Press.

Bretherton, I. (1992). The origins of attachment theory: John Bowlby and Mary Ainsworth. Developmental Psychology, 28, 759-775.

Briere, J. \& Eliott, D. ( 2003). Prevalence and psychological sequelae of self-reported childhood physical and sexual abuse in a general population sample of men and women. Child Abuse and Neglect, 27, 1205-1222.

Briggs, F., McVeity, M. \& Love, M. (2001). Teaching children to protect themselves: a resource for teachers and adults who care for young children. Crows Nest NSW, Australia, Allen \& Unwin.

Bronfenbrenner, U. (1979). The ecology of human development. Cambridge, MA: Harvard University Press. 
Brooks, J. H. and Reddon, J. R. (1996), Serum testosterone in violent and nonviolent young offenders. Journal of Clinical Psychology, 52: 475-483.

Brown, J., Cohen, P., Johnson, J. G., \& Smailes, E. M. (1999). Childhood abuse and neglect: Specificity of effects on adolescent and young adult depression and suicidality. Child and Adolescent Psychiatry, . 38, 1490-1496.

Brown, D., Scheflin, A.; and Whitfield, C. L. (1999) Recovered memories: The current weight of the evidence in science and in the courts. Journal of Psychiatry and Law. 5-156.

Brownlie, E., Beitchman, J., Escobar, M., Young, A., Atkinson, L., Johnson, C., Wilson, B., \& Douglas, L. (2004). Early language impairment and young adult delinquent and aggressive behavior. Journal of Abnormal Child Psychology. 453-467.

Brownmiller, S. (1980). Against Our Will: Men, Women and Rape." Take Back the Night: Women on Pornography. ed. Laura Lederer. William Morrow and Company. New York

Bumiller, E., Sanger, D. E., \& Stevenson, R. W. (2005). Bush says Iraqi leaders will want U.S. forces to stay to help. New York Times, January 28 p. A1.

Burgess, K. Rubin, K., Wojslawowicz, J. Rose-Krasnor, L.\& Booth, C. (2003). The Extended Class Play: A longitudinal study of its factor structure, reliability, and validity. Poster presented at the biennial meeting of the Society for Research in Child Development; Tampa, FL: Apr. 2003

Burt, M., (1980). Cultural Myths and Supports for Rape. Journal of Personality and Social Psychology. 217-230.

Burton, D. (2011) Personal communication. December 31, 2011

Burton, D. (2000). Were adolescent sexual offenders children with sexual behavior problems? Sexual Abuse: A Journal of Research and Treatment. 12, 37-48.

Burton, D. \& Fleming, W. M. (1998). The self-report sexual aggression scale: A psychometric analysis and examination. Vancouver, BC: Association for the Treatment of Sexual Abusers.

Cabrera, N., Tamis-LeMonda, C., Bradley, R., Hofferth, S., \& Lamb, M. (2000). Fatherhood in the Twenty-First Century. Child Development. 127-136. 
Caldwell, M. (2002). What we do not know about juvenile sexual re-offense risk. Child Maltreatment. 291-302.

Camarena, P., Sarigiani, P., \& Petersen, A. (1990). Gender-Specific Pathways to intimacy in early adolescence. Journal of Youth and Adolescence, 19-32

Campbell, S., Spieker, S., Vandergrift, N., Belsky, J., \& Bruchinal, M. (2010). Predictors and sequelae of trajectories of physical aggression in school-age boys and girls. Development and Psychopathology. P 133-150.

Cantwell, D. P., Baker, L., \& Mattison, R. E. (1979). The prevalence of psychiatric disorder in children with speech and language disorder: An epidemiologic study. Journal of the American Academy of Child Psychiatry, 18, 450-461.

Capaldi, D. (1992). Co-occurrence of conduct problems and depressive symptoms in early adolescence boys: A 2-year follow-up at grade 8. Development and Psychopathology, 125-144.

Capaldi, D., \& Stoolmiller, M. (1999). Co-occurrence of conduct problems and depressive symptoms in early adolescent boys: III Prediction to young-adult development. Development and Psychopathology, 59-84.

Capella, M., Hill, R., Rapp, J., \& Kees. J. (2010) The impact of violence against women in advertisements. Journal of Advertising. 37-52.

(Statistics) Canada (1997). National longitudinal survey of children and youth: User's handbook and microdata guide. Ottawa: Human Resources Development Canada.

Carvalho, Q., Galvão. M., \& Cardoso, M. (2009) Child sexual abuse: the perception of mothers concerning their daughters' sexual abuse. Rev Latino-am Enfermagem. 501-506.

Carlson, K. A. (1981). A modern personality test for offenders: the Carlson Psychological Survey. Criminal Justice and Behavior ,185-200.

Carlson V, Cicchetti D, Barnett D, \& Braunwald, K. (1989). Child maltreatment: theory and research on the causes and consequences of child abuse and neglect. In Finding order in disorganization: Cicchetti D, Carlson VK, (eds) New York: Cambridge University Press, 1989.

Center for Sex Offender Management (CSOM) (2002). Myths and facts about sex offenders. Retrieved April 25, 2008 from http://www.csom.org/pubs/mythsfacts.html. 
Cellini, H. (1995). Assessment and treatment of the adolescent sexual offend. In B. K. Schwartz \& H. R. Celini (eds.) The sex offender: corrections treatment and legal practice, (pp: 6-11). Kingston NJ: Civic Research Institute, Inc.

Cerney, M. S. (1995). Treating the "heroic treaters." In C. R. Figley (Ed.), Compassion fatigue (pp. 131-148). New York: Brunner/Mazel.

Cernkovich, S., \& Giordano, P. (1987). Family relationships and delinquency. Criminology, 2, 295-319.

Chaffin, M. (2008). Our Minds Are Made Up_-Don't Confuse Us With the Facts: Commentary on Policies Concerning Children With Sexual Behavior Problems and Juvenile Sex Offenders. Child Maltreatreatment. 110-121

Chaffin, M., Letourneau, E. J., \& Silovsky, J. F. (2002). Adults, adolescents, and children who sexually abuse children: A developmental perspective. In J. Myers (Ed.), The APSAC handbook on child maltreatment. 205-232. Thousand Oaks, CA: Sage.

Chaffin, M., Lawson, L., Selby, A., \& Wherry, J. N. (1997). False negatives in sexual abuse interviews: Preliminary investigation of a relationship to dissociation. Journal of Child Sexual Abuse, 6, 15-29.

Chaffin, M. \& Bonner, B. (1998) 'Don't shoot, we're your children' Have we gone too far in our response to adolescent sexual abusers and children with sexual behavior problems? Child Maltreatment, 3, 314-316.

Choi, P., Parrott, A., \& Cowan, D. (1990). High-dose anabolic steroids in strength athletes: Effects upon hostility and aggression. Human Psychopharmacology, 349-356.

Cicchetti, D., \& Toth, S. L. (1995). A developmental psychopathology perspective on child abuse and neglect. Journal of the American Academy of Child and Adolescent Psychiatry, 34, 541-565.

Clackamas County Juvenile Department (2010). Alternative Disposition Proposal for youth who sexually offend. Presented March 29, 2010. Clackamas County Oregon.

Claes, M. (1992). Friendship and personal adjustment during adolescence. Journal of Adolescence, 15, $39-55$.

Cobb, S., Brooks, W., Kasl, S., Connelly, G., \& Connelly, W. (1966). The health of people changing jobs: a description of a longitudinal study. The American Journal of Public Health. 1476-1481. 
Coley, R., \& Medeiros, B. (2007). Reciprocal Longitudinal Relations Between Nonresident Father Involvement and Adolescent Delinquency. Child Development, 132-147.

Collins, N. L., \& Read, S. J. (1990). Adult attachment, working models, and relationship quality in dating couples. Journal of Personality and Social Psychology, 644-663.

Cooper, C., Murphy, W., \& Haynes, M. (1986). Characteristics of abused and nonabused adolescent sexual offenders. Sexual Abuse: A Journal of Research and Treatment. 8, 105-119.

Cotterell, J. L. (1992). The relation of attachments and support to adolescent wellbeing and school adjustment. Journal of Adolescent Research, 7, 28-42.

Council of State Government. Residency Restriction Zones. retrieved May 17, 2008 from http://www.csg.org/policy/pubsafety/documents/ResidencyRestrictionLaws.pd f.

Craissati, J., Webb, L., \& Keen, S. (2008). The relationship between developmental Variables, personality disorder, and risk in sex offenders. Sexual Abuse: A Journal of Research and Treatment. 119-138.

Craissati, J., \& McClurg, G. (1997). The Challenge Project: A treatment program evaluation for perpetrators of child sexual abuse. Child Abuse \& Neglect, 21, 637-648.

Crocker, J., Luhtanen, R. K., Cooper, M. L., \& Bouvrette, S. (2003). Contingencies of self-worth in college students: Theory and measurement. Journal of Personality and Social Psychology, 85, 894-908.

Cross, S. E., \& Madson, L. (1997). Models of the self: Self-construal theory and gender. Psychological Bulletin, 5 - 37.

Daleiden, E., Kaufman, K., Hilliker, D. \& O’Neil, J. (1998). The sexual histories and fantasies of youthful males: A comparison of sexual offending, Nonsexual offending, and nonoffending groups. Sexual Abuse: A Journal of Research and Treatment, 195-209.

Davis, M. H. (1983). Measuring individual differences in empathy: Evidence for a multidimensional approach. Journal of Personality and Social. Psychology, 70-87. 
Davis, G. E., \& Leitenberg, H. (1987). Adolescent sex offenders. Psychological Bulletin, 101, 417-427.

Davis, A. D., Sanger, D. D., \& Morris-Friehe, M. (1991). Language skills of delinquent and non-delinquent adolescent males. The Journal of Communication Disorders. 251-266.

DiFilippo, J.M., \& Overholser, J.C. (2000). Suicidal ideation in adolescent psychiatric inpatients as associated with depression and attachment relationships. Journal of Clinical Child Psychology, 155-166.

Descharme, J., Doyle, A., \& Markiewicz, D. (2002). Attachment security with mother and father: Associations with adolescents' reports of interpersonal behavior with parents and peers. Journal of Social and Personal Relationships. 203-231.

Dube, S., Anda, R., Whitfield, C., Brown, D., Felitti, V., Dong, M. \& Giles (2005). Long-Term Consequences of Childhood Sexual Abuse by Gender of Victim. American Journal of Preventative Medicine. 28, 430-438.

Eaves, S. (2007). Attachment style, self-esteem, and perceived peer norms as predictors of sexually risky behavior among 17-24 year old college students. An unpublished doctoral dissertation. Mississippi State University, Mississippi, US.

Edwards. M. (2010). Understanding Food Insecurity and "Hunger" in Oregon. University of Oregon available at http://ruralstudies.oregonstate.edu/sites/default/files/pub/pdf/OregonHunger20 $\underline{10 . p d f}$

Elder, G. (1998). The life course as developmental theory. Child Development, 69, 1 12 .

Elliot, D. M. \& Briere, J. (1994). Forensic sexual abuse evaluations of older children: disclosures and symptomatology. Behavioral Sciences and the Law, 261-277.

Elliot, D. S., Huizinga, D., \& Morse, B. J. (1985). The dynamics of deviant behavior: A national survey report. Boulder, CO: Behavioral Research Institute.

Elliott, W., Fergus, D., \& Friedline, T. (2012). What are the predictors of economic instability on children's educational outcomes: Assets, economic instability, and children's human capital. The University of Kansas School of Social Welfare. Lawrence, Kansas. 
Ellis, W., Crooks, c., \& Wolfe, D. (2009). Relational aggression in peer and dating relationships: links to Psychological and behavioral adjustment. Social Development 253-269.

Erikson E. (1980). Identity and the Life Cycle. Norton, New York, NY: Norton

Essau, C. A. (2004). The Association between family factors and depressive disorders in adolescents. Journal of Youth and Adolescence, 33(5), 365-372.

Fagan, J., \& Wexler, S. (1988). Explanations of sexual assault among violent delinquents, Journal of Adolescent Research, 363-385.

Federal Reserve Bank (FRB) 1998. Foreign Exchange Rates - January 1998. retrieved from http://www.federalreserve.gov/releases/h10/19980126/ on December 18, 2008.

Fehrenbach, P. A., Smith, W., Monastersky, C. and Deisher, R. W. (1986), adolescent sexual offenders: Offender and offense characteristics. American Journal of Orthopsychiatry, 225-233.

Feeney, J. (1990). Attachment style as a predictor of adult romantic relationships. Journal of Personality and Social Psychology, 281-291.

Feeney, J., Noller, P., \& Patty, J. (1993). Adolescents' interactions with the opposite sex: Influence of attachment style and gender. Journal of Adolescence, 169186.

Finklehor, D. (1991). Child Sexual Abuse in violence in America: A public health approach. Mark L. Rosenberg \& Mary Ann Fenly (eds.). Oxford University Press US.

Finkelhor, D. (1994). Current information on the scope and nature of child sexual abuse. The Future of Children, 4, 31-53

Finkelhor, D., \& Brown, A. (1985). The Traumatic Impact of Child Sexual Abuse: A Conceptualization. American Journal of Orthopsychiatry, 55, 530-541.

Finkelhor, D., Hotaling, G., Lewis, I. A., \& Smith, C. (1990). Sexual abuse in a national survey of adult men and women: Prevalence, characteristics, and risk factors. Child Abuse \& Neglect. 19-28.

Finkelhor, D., Ormrod, R., and Chaffin, M. (2009). Juveniles who commit sex offenses against minors. Juvenile Justice Bulletin, 1-11 
Finkelhor, D., Turner, H., Ormrod, R., \& Hamby, S. (2009) Violence, Abuse, and Crime Exposure in a National Sample of Children and Youth. Pediatrics. 1411-1423.

Finnegan, R., Hodges, E., \& Perry, D. (1996). Preoccupied and avoidant coping during middle childhood. Child Development, 1318 - 1328.

Fischer, K., \& Pruyne, E. (2002). Reflective thinking in adulthood: Emergence, development, and variation. The Plenum Series in Adult Development and Aging. 169-198.

Fleming, W. M., Jory, B., \& Burton, D. L. (2002). Characteristics of juvenile offenders admitting to sexual activity with nonhuman animals. Society and Animals, 31-45.

Flight, J., \& Forth, A.. (2007). Instrumentally violent youths: The roles of psychopathic traits, empathy, and attachment. Criminal Justice and Behavior,739-751

Ford, M. E., \& Linney, J.A. (1995). Comparative analysis of juvenile sex offenders, violent nonsexual offenders, and status offenders. Journal of Interpersonal Violence, 10, 56-70.

Formoso. D. Gonzales, N., \& Aiken, L. (2000). Family conflict and children's internalizing and externalizing behavior: Protective factors. American Journal of Community Psychology, 175-199.

Franiuk, R., Seefelt, J., \& Vandello, J. (2008). Prevalence of rape myths in headlines and their effects on attitudes toward rape. Sex Roles. 790-801.

Frazzetto G, Di Lorenzo G, Carola V, Proietti L, Sokolowska E, et al. (2007) Early Trauma and Increased Risk for Physical Aggression during Adulthood: The Moderating Role of MAOA Genotype. PLoS ONE 2(5): e486.

doi:10.1371/journal.pone.0000486

Freeman-Longo, R. \& Reback, D. (2002). Myths and facts about sex offenders. Silver Spring, MD: Center for Sex Offender Management

Freyd, J. J., Putnam, F.W., Lyon, T.D., Becker-Blease, K. A., Cheit, R.E., Siegel, N.B., \& Pezdek, K. (2005). The science of child sexual abuse. Science, 308, 501

Freyd, J. J. (1996). Betrayal trauma: The logic of forgetting childhood abuse. Cambridge, MA: Harvard University Press. 
Friedrich, B. (2006) Child custody litigation: Allegations of child sexual abuse. Kathryn Kuehnle \& Leslie Drozd (eds.) Haworth Press.

Gannon, T., Collie, R., Ward, T., \& Thakker. J. (2008). Rape” Psychopathology, theory and treatment. Clinical Psychology Review. 982-1008.

Garfinkle, E. (2003). Coming of age in America: The misapplication of sex-offender registration and community-notification laws to juveniles, $91 \mathrm{Cal}$. L. Rev. 163. Available at: http://scholarship.law.berkeley.edu/californialawreview/vol91/iss1/4

Geoman, J., \& Solari, A., (2011). Multiple testing for exploratory research. Statistical Science, $584-597$

Gilbert R, Spatz Widom C, Browne K, Fergusson D, Webb E, Janson S. (2008) Burden and consequences of child maltreatment in high-income countries. Lancet 2008; published online Dec 3.DOI:10.1016/S0140-6736(08)61706-7.

Gillespie, S., Mitchell, I., Fisher, D., \& Beech, A. (2012). Treating disturbed emotional regulation in sexual offenders: The potential applications of mindful self-regulation and controlled breathing techniques. Aggression and Violent Behavior, Pages 333-343,

Glasser, M., Kolvin, I., Campbell, D., Glasser, A., Leitch, I., \& Farrelly, S. (2001). Cycle of child sexual abuse: Links between being a victim and becoming a perpetrator. British Journal of Psychiatry, 179, 482-494.

Goffman, E. (1962). Stigma: Notes on the management of a spoiled identity. New York: Touchstone Books.

Gomez, R., \& McLaren, S. (2007). The inter-relations of mother and father attachment, self-esteem and aggression during late adolescence. Aggressive Behavior, 160-169.

Gorey, G. M., \& Leslie, D. R. (1997). The prevalence of child sexual abuse: Integrative review adjustment for potential response and measurement biases. Child Abuse \& Neglect, 21, 391-398.

Green A. H. (1996). Overview of child sexual abuse. In S. J. Kaplan (ed.), Family violence: A clinical and legal guide. pp. 73-104. Washington, DC: American Psychiatric Press. 
Greenberg, D., Bradford, J., Firestone, P., \& Curry, S. (2000). Recidivism of child molesters: a study of victim relationship with the perpetrator. Child Abuse \& Neglect, 24, 1485-1494.

Greenfield, L. (1997). An analysis of data on rape and sexual assault. U. S. Department of Justice retrieved February 16, 2011 from http://www.ojp. usdoj.gov/bjs/pdf/soo.pdf.

Grigorenko, E. (2006). Learning disabilities in juvenile offenders. Child and Adolescent Psychiatric Clinics of North America. 353-371.

Griffin, D.W., \& Bartholomew, K. (1994). The metaphysics of measurement: The case of adult attachment. In K. Bartholomew \& D. Perlman (Eds.), Attachment processes in adulthood (pp. 17-52). London: Jessica Kingsley.

Griffin, L. \& Blacker, K. (2010). Megan's law and Sarah's law: A comparative study of sex offender community notification schemes in the United States and the United Kingdom, Criminal Law Bulletin, 987-1008.

Gutman, L. T., St. Clair, K.K., \& Weedy, C. (1991). Human Immunodeficiency Virus Transmission by Child Sexual Abuse, American Journal of Diseases of Children, 145, 137.

Hair, E. C., Jager, J., \& Garrett, S. (2001). Background for community-level work on social competency in adolescence: Reviewing the literature on contributing factors. Washington, DC: John S. and James L. Knight Foundation.

Hanna, L., Risden, K., \& Alexander, K. (1997). Guidelines for usability testing with children. Interactions. 4, 9-14.

Hanson, R. K., \& Bussière, M. T. (1998). Predicting relapse: A meta-analysis of sexual offender recidivism studies. Journal of Consulting and Clinical Psychology, 66, 348-362.

Hanson, K., \& Thornton, D. (2000). Improving risk assessments for sex offenders: A comparison of three actuarial scales. Law and Human Behaviour, 119-136.

Hare, R. D. (1991). Manual for the Revised Psychopathy Checklist. Toronto, Canada: Multi-Health Systems.

Haridakis, P. (2006). Men, women and televised violence: Predicting viewer aggression in male and female television viewers. Communication Quarterly. 227-255. 
Harrison, L. (2009). The ambiguity of juvenile Sexual offenders. Internet Journal of Criminology retrieved June 14, 2011 from http://www.internetjournalofcriminology.com/Harrison_Juvenile_Sexual_Offe nders_July_09.pdf

Harter, S. (1982). The perceived competence scale for children. Child Development, $87-97$.

Harter, S. (1985). Manual for the Self-Perception Profile for Children. Denver, CO: University of Denver.

Hawkes, C. (2011), Description of a UK study of onset of sexually harmful behaviour before the age of ten years in boys referred to a specialist assessment and treatment service. Child Abuse Review, 2-101.

Harter, S. (1988). Manual for the Self-Perception for Adolescents. Denver, CO: University of Denver.

Hay, I., \& Ashman, A. F. (2003). The development of adolescents' emotional stability and general self-concept: The interplay of parents, peers, and gender. International Journal of Disability, Development, and Education, 78 - 91.

Hazan, C., \& Shaver, P. (1987). Romantic Love Conceptualized as an Attachment Process. Journal of Personality and Social Psychology, 52, 511-524.

Heppler, J. (1997). School Development of children: The role of peers. Social Work in Education, 19, 242-256.

Higgins, D. J. \& McCabe, M. P. (2001). Multiple forms of child abuse and neglect: Adult retrospective reports. Aggression and Violent Behavior. 547-578.

Hightower, A. D. (1994). Parent - Child Rating Scale. Rochester, NY: Primary Mental Health Project.

Hightower, A. D., Work, W. C., Cowen, E., Lotyczewski, B. S., Spinell, A. P., Guare, J. C., et al. (1986). The Teacher - Child Rating Scale: A brief objective measure of elementary children's school problem behaviors and competencies. School Psychology Review, 15, 393 - 409.

Hilton, N., Harris, G., Rice, M., Houghton, R., \& Eke, A. (2008). An in-depth actuarial assessment for wife assault recidivism: The Domestic Violence Risk Appraisal Guide. Law and Human Behavior, 32, 150-163. 
Howlin, P., \& Rutter, M. (1987). The consequences of language delay for other aspects of development. In W Yule \& M. Rutter (Eds.), Language development and disorders (pp. 271-294). Oxford, England: MacKeith.

Hunter, J., Figueredo, A., Malamuth, N. M. \& Becker, J. (2003). Juvenile sex offenders: toward the development of a typology. Sexual Abuse: A Journal of Research and Treatment, 15, 27-48.

Ingram, G. (1999). Sex Offenders. In P. Carlson \& J. Garrett (eds.) Prison and Jail Administration: Practice and Theory. pp 239-145. Sudbury, MA: Jones and Bartlett.

Ijzendoorn, M. (1997). Attachment, emergent morality, and aggression: Toward a developmental socio-emotional model of antisocial behaviour. International Journal of Behavioral Development. 703-727.

Jackson, D. (1984). Personality questionnaire. Personality Research Form Manual, 3rd ed. Port Huron, MI: Research Psychologists Press.

Jackson, F. (2002). Considerations for community-based research with African American women. American Journal of Public Health. 561-664.

(The) Jacob Wetterling Crimes against Children and Sexually Violent Offender Registration Act, 42 USC Sec. 14071, (2008).

Johnson, R., Ross, M., Taylor, W., Williams, M., Carvajal, R., \& Peters, R. (2006). Prevalence of childhood sexual abuse among incarcerated males in county jail. Child Abuse \& Neglect, 30, 75-86.

Johnson, C. (1992). Coping with compassion fatigue. Nursing, 22(4), 116-122.

Johnston, J. \& Ward, T. (1996) Social cognition and sexual offending: A theoretical framework. Sexual Abuse: A Journal of Research and Treatment, 8, 55-80.

Jojura, G,, Tripplett. R, \& Brinker, G. (2002). Growing up poor: Examining the link between persistent poverty and delinquency. Journal of Qualitative Criminology. 159-167.

(The) Juvenile Justice Information Center (2009). Data \& evaluation reports Detention charts and trends (2007). Available on line at http://www.oregon.gov/OYA/reports/jjis/2008/2007_Detention_Charts_Trends .pdf

Kaufman, K. (2001). Supervision Questionnaire. Available from author, Portland, OR: Portland State University. 
Kaufman, K., Hilliker, D.., Lathrop, P., \& Daleiden, E. (1998), Assessing child sexual offenders' modus operandi: Accuracy in self-reported use of threats and coercion. Sexual Abuse: A Journal of Research and Treatment. 213-229.

Kendall-Tacket, K., Williams, L., \& Finkelhor, D. (1993). Impact of sexual abuse on children: A review and synthesis of recent empirical Studies. Psychological Bulletin. 113, 164-180.

Kenny, M., Rice, K.. (1995). Attachment to parents and adjustment in late adolescent college students. The Counseling Psychologist, 23, 433-456.

Kerns, K., Klepac, L., \& Cole, A. (1996). Peer relationships and preadolescents' perceptions of security in the child -mother relationship. Developmental Psychology, $457-466$.

Kessler, D.B., \& Hyden, P. (1991). Physical, Sexual, and Emotional Abuse of Children. (CIBA-GEIGY Clinical Symposia, Vol. 43, No. 1). Summit, NJ: Pharmaceuticals Division, CIBA-GEIGY Corporation, 1991.

Kirkpatrick, L., \& Davis, K., (1994). Attachment style, gender, and relationship stability: A longitudinal analysis. Journal of Personality and Social Psychology, 502-512.

Knox, L. (2009). Juvenile Sex Offenders: A Consideration of Attachment Deficits in the Etiology of Offending. An Unpublished Thesis. Portland State University.

Koenig L., Doll L, O’Leary A, Pequegnat W, (2004) From child sexual abuse to adult sexual risk: Trauma, revictimization, and intervention. Washington, DC: American Psychological Association; 2004.

Koss, M. P.,\& Oros, C. J. (1982). Sexual experiences survey:Aresearch instrument investigating sexual aggression and victimization. Journal of Consulting and Clinical Psychology, 455-457.

Kovacs, M., and Beck, A. T. (1977). An empirical and clinical approach towards defining childhood depression. In Schulterbrandt, J. G., and Rasbin, A. (eds.), Depression in Childhood: Diagnosis, Treatment and Conceptual Models, Raven Press, New York,

Kreager, D., \& Staff, J. (2009). The sexual double standard and adolescent peer acceptance. Social Psychology Quarterly, 143-164. 
Kutchinsky, B. (1991) Pornography and rape: Theory and practice? Evidence from crime data in four countries where pornography is easily available. International Journal of Law and Psychiatry, 47-64.

Kring, A., Smith, D., \& Neile, J. (1994). Individual differences in dispositional expressiveness: Development and validation of the motional expressivity scale. Journal of Personality and Scoial Psychology, 934-949.

Lahoti, S., McClain, N., Girardet, R., McNeese, M. \& Cheung, K. (2001). Evaluating the child for sexual abuse. American Family Physician, 883-892.

Laible, D., Carlo, G., \& Raffaelli, M. (2000). The differential relations of parent and peer attachmet to adolescent adjustment. Faculty publications. University of Nebraska. Lincoln, NE, USA.

Liable, D. J., Carlo, G., \& Roesch, S. C. (2004). Pathways to self-esteem in late adolescence: The role of parent and peer attachment, empathy, and social behaviours. Journal of Adolescence, 27, 703-716.

Langan, P., \& Levin, D., (2002) Recidivism of Prisoners released in 1994. Washington D.C., U.S. Department of Justice. Bureau of Justice Statistics.

Langan, P. A., Schmitt, E., \& DuRose, M. (2003). Recidivism of sex offenders released from prison in 1994. Washington, DC: U.S. Department of Justice, Bureau of Justice Statistics.

Larson, K., \& Halfon, N. (2010). Family income gradients in the health and health care access of US children. Maternal and child health journal. 332-342.

Laumann, E. O., Gagnon, J. H., Michael, R. T., \& Michaels, S. (2000). The Social Organization of Sexuality: Sexual practices in the United States. Chicago, IL: The University of Chicago Press

Letourneau, E., Henggeler, S., Borduin, C., Schewe, P., McCart, M., Chapman, J., \& Saldana, L. (2009). Multisystemic therapy for juvenile sexual offenders: 1-year results from a randomized effectiveness trial. Journal of Family Psychology. 89-102.

Letourneau, E. \& Miner, M. (2005). Juvenile sex offenders: A case against the legal and clinical status quo. Sexual Abuse: A Journal of Research and Treatment, 293-312.

Levenson, J. S., Brannon, Y., Fortney, T., \& Baker, B. (2007). Public perceptions about sex offenders and community protection policies. Analyses of Social Issues and Public Policy, 1-25. 
Levenson, J., \& Cotter, L. (2005a). The effect of Megan's Law on sex offender reintegration. Journal of Contemporary Criminal Justice, 21, 49-66.

Levenson, J., \& Cotter, L. (2005b). The impact of sex offender residence restrictions: 1,000 feet from danger or one step from absurd? International Journal of Offender Therapy and Comparative Criminology, 49, 168-178.

Levine, J. (2002). Harmful to minors: The perils of protecting children from sex. University of Minnesota Press,

Lewis-Beck, M., Bryman, A. \& Liao, T. (2004). The SAGE Encyclopedia of Social Science Research Methods. Sage, Thousand Oaks California.

Lieb, R., Quinsey, V., and Berliner, L., (1998). Sexual predators and social policy in M. Tonry (ed.), Crime and Justice.(pp. 43-114), University of Chicago,

Lotke, E. (1997). Politics and irrelevance: Community notification statutes. Federal Sentencing Reporter, 10, 64-68.

Lyn, T., \& Burton, D. (2005). Attachment, anger and anxiety of male sexual offenders. Journal of Sexual Aggression. 127-137.

Lindsay, D., \& Read, J, (1994). Psychotherapy and memories of childhood sexual abuse: a cognitive perspective. Applied Cognitive Psychology. 8, 281-338.

Linder, J., Crick, N., \& Collins, W. (2002). Relational aggression and victimization in young adults' romantic relationships: Association with perceptions of parent, peer and romantic relationship quality. Social Development, 11, 69-86.

Lizak, D. (1991). Sexual Aggression, Masculinity, and Fathers. Signs. 238-262

Lisak, D., \& Roth, S. (1990). Motives and psychodynamics of self-reported, unincarcerated rapists. American Journal of Orthopsychiatry, 268-280.

Lisak, D., Hopper, J., \& Song, P. (1996). Factors in the cycle of violence: Gender rigidity and emotional constriction. Journal of Traumatic Stress, 721-743.

Lyons-Ruth, K., Repacholi, B., McLeod, S., \& Silva, E. (1991). Disorganized attachment behavior in infancy: Short-term stability, maternal and infant correlates and risk related subtypes. Development and Psychopathology, 3, 377-396. 
Lyons-Ruth, K., Connell, D., Zoll, D. \& Stahl, J. (1987). Infants at social risk: relations among infant maltreatment, maternal behavior, and infant attachment behavior. Developmental Psychology. 23, 223-232.

Ma, C., \& Huebner, S., (2008). Attachment relationships and adolescents' life satisfaction: Some relationships matter more to girls than boys. Psychology in the Schools, Published online in Wiley InterScience (www.interscience.wiley.com) DOI: 10.1002/pits.20288

MacMillian, H., Fleming, J., Trocome, N., Boyle, M.., Wong, M., Racine, Y.. et al. (1997). Prevalence of child physical and sexual abuse in the community: Results from the Ontario Health Supplement. Journal of the American Medical Association, 278, 131-135

Magnavita, J. J. (2006). In search of the unifying principles of psychotherapy: Conceptual, empirical, and clinical convergence. American Psychologist, 61, 882-892.

Main, M., Kaplan, N., \& Cassidy; J. (1985). Security in infancy; childhood, and adulthood: A move to the level of representation. Monographs of the Society for Researching Child Development, 66-104.

Main, M., \& Weston, D. (1981). The quality of the toddler's relationship to mother and to father: Related to conflict behavior and readiness to establish new relationships. Child Development, 52, 932-940.

Main, M., \& Solomon, J. (1990). Procedures for identifying infants as disorganized/disoriented during the strange situation. In M. T. Greenberg, D. Cicchetti \& E. M. Cummings (eds.), Attachment in the preschool years: Theory, research, and intervention (pp. 121-160). Chicago: University of Chicago Press.

Malamuth, N. (1996). Research on the confluence model of sexual aggression based on feminist and evolutionary perspectives. In Buss, D., \& Malamuth, N. (Eds.). Sex, power, conflict: Evolutionary and feminist perspectives. (pp. 269-295). New York: Oxford University Press.

Malamuth, N.M., Heavey, C., \& Linz, D. (1993). Predicting men's antisocial behavior against women: The "interaction model" of sexual aggression. In G. N. Hall, R. Hirschmann, J. R. Graham, \& M. S. Zaragoza (Eds.), Sexual aggression: Issues in etiology and assessment and treatment (pp. 63-97). New York: Hemisphere. 
Malamuth, N., Sockloskie, R., Koss, M., \& Tanaka, J. (1991). The characteristics of aggressors against women: Testing a model using a national sample of college students. Journal of Consulting and Clinical Psychology 670-681.

Marlatt, A., \& George, W. (1984) . Relapse prevention: Introduction and overview of the model. British Journal of Addiction. 261-273.

Marsa, F., O’Reilly, G., Carr, A., Murphy, P., O’Sullivan, M., Cotter, A. \& Hevey, D. (2004) attachment styles and psychological profiles of child sex offenders in Ireland. Journal of Interpersonal Violence, 228-251.

Marshall, W. L. (1989). Intimacy, loneliness and sexual offenders. Behaviour Research and Therapy, 491-503.

Marshall, W. L. (1993). The role of attachments, intimacy, and loneliness in the etiology and maintenance of sexual offending. Sexual and Marital Therapy, 109-121.

Marshall, W. L., Hudson, S. M., \& Hodkinson, S. (1993). The importance of attachment bonds in the development of juvenile sex offending. In H. E. Barbaree, W. L. Marshall \& S. M. Hudson (Eds.), The juvenile sex offender (pp. 164-181). New York: Guilford Press.

Marshall, W. L., Laws, D. R., \& Barbaree, H. E. (1990). Handbook of sexual assault: Issues, theories, and treatment of the offender. New York: Plenum Press.

Marshall, W. L., \& Mazzuco, A. (1995). Self-esteem and parental attachments in child molesters. Sexual Abuse: A Journal of Research and Treatment. 279-285.

Martorell, G. (2009). Personal communication February 18, 2009.

Maslow, A. (1943). A theory of human motivation. Psychological Review, 50, 370396. Retrieved June 2001, from http://psychclassics.yorku.ca/Maslow/motivation.htm.

Matsueda, R., Kreager, D., \& Huizinga, D. (2006), Deterring delinquents: A rational choice model of theft and violence, American Sociological Review, 95-122.

Matson, S., \& Lieb, R. (1996). Community notification in Washington State: 1996 survey of law enforcement. Olympia, WA: Washington State Institute for Public Policy. Matson, S., \& Lieb, R. (1996b). Sex offender community 
notification: A review of state laws. Olympia, WA: Washington State Institute for Public Policy.

(The) Mayo Clinic (2011). Post-traumatic Stress Disorder. Obtained December 10, 2011 from http://www.mayoclinic.com/health/post-traumatic-stressdisorder/DS00246

McLean, K., \& Thorne, A. (2003). Late adolescents' self-defining memories about relationships. Developmental Psychology. 635-645

McCubbin, H., Thompson, A., \& Elver, K. (1995). FPSC: Family problem solving communication. In H. McCubbin, A. Thompson, \& M. McCubbin (Eds.). Family assessment: Resiliency, coping and adaptation, inventories for research and practice (pp. 639-686). Madison: University of Wisconsin Press.

McElhaney, K., Immese, A., Smith, F., \& Allen, J.. (2006). Attachment organization as a moderator of the link between friendship quality and adolescent delinquency. Attachment and Human Development, 33-46.

McElhaney, K., Antonishak, J., \& Allen, J. (2008). "They like me, they like me not": Popularity and perception of acceptance predicting social functioning over time. Child Development, 720-731.

McMahon, P.M., \& Puett, R. C. (1999). Child sexual abuse as a public health issue: Recommendations of an expert panel. Sexual Abuse: A Journal of Research and Treatment, 11, 257-266.

McCormack, J., Hudson, S., \& Ward, T. (2002). Sexual offenders' perceptions of their early interpersonal relationships: an attachment perspective. Journal of Sex Research. Retrieved from http://www.taasa.org/library/pdfs/TAASALibrary148.pdf

McCreary Centre Society. (2004). Healthy youth development: Highlights from the 2003 adolescent health survey. Burnaby, BC: MCS.

Meares, T., Katyal, N., \& Kahan, D. (2004), Updating the Study of Punishment, Stanford Law Review, 1171-1210.

Meloy, M. (2006). Sex Offenses and the Men Who Commit Them: An Assessment of Sex Offenders on Probation. Northeastern University Press.

Meloy, M. L., Miller, S. L., \& Curtis, K. M. (2008). Making Sense Out of Nonsense: The Deconstruction. American Journal of Criminal Justice, vol. 33, no. 2, 209222. 
MIDSA clinical manual. (2007). Bend, OR: Augur Enterprises. Retrieved June 10, 2011, from www.midsa.us

Mikulincer, M. (1998). Attachment working models and the sense of trust: An exploration of interaction goals and affect regulation. Journal of Personality and Social Psychology, 1209-1224.

Mikulincer, M., \& Shaver, P. (2005). Mental representations of attachment security: Theoretical foundation for a positive social psychology. In Interpersonal Cognition. M. W. Baldwin. New York, NY, US: Guilford Press. 233-266

Miller, T., Cohen, M., \& Wiersma, B. (1996). Victim costs and consequences: a new look. Washington, DC: National Institute of Justice Research Report, US Department of Justice.

Million, T., Million, C., \& Davis, R. D. (1994). Million Clinical Multiaxial InventoryIII. Minneapolis, MN: National Computer Systems.

Milne, L. C., \& Lancaster, S. (2002) Predictors of depression in female adolescents. Adolescence, 207-223.

Miner, M., Robinson, B., Knight, R ., Berg, D., Swinburne-Romine R, \& Netland J. (2010). Understanding sexual perpetration against children: Effects of attachment style, interpersonal involvement, and hypersexuality. Sexual Abuse: A Journal of Research and Treatment. 58-77.

Moffitt TE, Caspi A, Dickson N, Silva P, Stanton W. (1996). Childhood-onset versus adolescent-onset antisocial conduct problems in males: Natural history from ages 3 to 18 years. Development and Psychopathology. 399-424.

Molnar, B., Buka, S., \& Kessler, R., (2001). Child sexual abuse and subsequent psychopathology: Results from the national comorbidity survey. American Journal of Public Health. 753-760.

Montebarocci, O., Codispoti, M., Baldara, B., \& Rossi, N. (2004). Adult attachment style and alexithymia. Personality and Individual Differences, 36, 499-507.

Morris, R. E. (2005). Health care for incarcerated adolescents: Significant needs with considerable obstacles. Ethics Journal of the American Medical Association, 7. Available online at http://virtualmentor.ama-assn.org/2005/03/pfor20503.html.

Morrows, V., \& Richards, M. (1996). The ethics of social research with children: An overview. Children \& Society. 90-105. 
Motiuk, L., \& Porporino, F. (1992). The prevalence, nature and severity of mental health problems among federal male inmates in Canadian penitentiaries. A report by the Research and Statistics Branch Correctional Service Canada.

Mullen, P.E., Martin, J. L., Anderson, J.C., Romans, S.E., \& Herbison, G. P., (1996). The long-term impact of the physical, emotional, and sexual abuse of children: A community study. Child Abuse \& Neglect, 20, 7-21.

Murphy, W. D. \& Page, I. J. (2000). Relapse prevention with adolescent sex offenders in Laws, D. R., Hudson, S. \& Ward, T. (eds.) Remaking relapse prevention with sex offenders: a sourcebook. Sage, Thousand Oaks CA, USA.

Murphy, W. D., Haynes, M. R., \& Page, I. J. (1992). Adolescent sex offenders. In W. O'Donohue \& J. H. Geer (Eds). The sexual abuse of children: Clinical issues: Vol. II (pp. 394-429). Hillsdale, NJ: Erlbaum Associates.

Myrick, S., \& Martorell, G. (2011). Sticks and stones may break my bones: Protective factors for the effects of perceived discrimination on social competence in adolescence Personal Relationships, 487-501.

National Coalition to Prevent Child Sexual Abuse and Exploitation. (2012). National Plan to Prevent the Sexual Abuse and Exploitation of Children (Rev. ed.). Retrieved from www.preventtogether.org

National Woman's Law Center (2012). Women and Poverty, State by State: An analysis of the latest data on women and poverty. Available from http://www.nwlc.org/resource/women-and-poverty-state-state

National Research Council (1993). Understanding Child Abuse Neglect, Washington, DC: National Academy Press.

National Resource Center on Child Sexual Abuse (1994). Statistics in child sexual abuse. Huntsville, AL.

National Society for the Prevention of Cruelty to Children (NSPCC) (2005). Protecting children our children from sexual abuse. Retrieved from http://www.enfield.gov.uk/if/ProtectingChildrenFromSexualAbuse.pdf on September 23, 2008.

Novaco, R. (1994). Anger as a risk factor for violence among the mentally disordered. In J. Monaghan \& H. Steadman (Eds.), Violence and mental disorder. 
Developments in risk assessment (pp. 100-134). Chicago: University of Chicago Press.

Nowicki, S. (1976). Adult Nowicki-Strickland Internal-External Locus Of Control Scale. Test Manual available from S. Nowicki, Jr., Department of Psychology, Emory University, Atlanta, GA 30322, USA.

O'Koon, J. (1997). Attachment to parents and peers in late adolescence and their relationship with self-image. Adolescence, 471-483.

Osher, D., Amos, L. B., \& Gonsoulin, S. (2012). Successfully transitioning youth who are delinquent between institutions and alternative and community schools. American Institutes for Research. Available at http://www.neglecteddelinquent.org/sites/default/files/docs/successfully transitioning_youth.pdf

Paolucci, E. O., Genuis, M. L., \& Violato, C. (2001). A meta-analysis of the published research on the effects of child sexual abuse. The Journal of Psychology. 1736.

Papin, D. R. \& Roggmen, L.A. (1992). Adolescent perceived attachment to parents in relation to competence, depression, and anxiety: A longitudinal study. Journal of Early Adolescence, 12, 420-440.

Paras, M., Hurad, M., Chen, L., Goranson, E., Sattler, A, Colbenson, K., (2009) Sexual Abuse and Lifetime Diagnosis of Somatic Disorders: A Systematic Review and Meta-analysis. Journal of the American Medical Association. 550561.

Parker, G.,Tupling, H., \&Brown, L. B. (1979).A parental bonding instrument. British Journal of Medical Psychology, 52, 1-10.

Parker, J. G., \& Asher, S. R. (1993). Friendship and friendship quality in middle childhood: Links with peer group acceptance and feelings of loneliness and social dissatisfaction. Developmental Psychology, $611-621$.

Paterson, J., Pryor, J., Field, J. (1995). Adolescent attachment to parents and friends in relation to aspects of self-esteem. Journal of Youth and Adolescence, 365-376.

Patterson, G., DeBaryshe, B., \& Ramsey, E. (1989). A developmental perspective on antisocial behavior. American Psychologist. 329-335.

Paulhus, D. (1991). Balanced inventory of desirable responding. In J. P. Robinson, P. R. Shaver \& L. S. Wrightsman (Eds.), Measures of Personality and Social Psychological Attitudes (pp. 37-/41). San Diego: Academic Press. 
Pavlidis, K., \& McCauley, E. (2001). Autonomy and relatedness in family interactions with depressed adolescents. Journal of Abnormal Child Psychology, 29, 11-21.

Pekarik, E. G., Prinz, R. J., Liebert, D. E., Weintraub, S., \& Neale, J. (1976). The pupil evaluation inventory: A sociometric technique for assessing children's social behavior. Journal of Abnormal Child Psychology, 4, 83 - 97.

(The) Pennsylvania Advisory Committee of the Office of Mental Health and Substance Abuse Services (OMHSAS) (2006). Retrieved On September 23, 2008 from http://www.dpw.state.pa.us/Resources/Documents/Presentations/PaStrategyFor AdultSuicidePrevention.pdf.

Phares, V. (1992). Where's poppa? The relative lack of attention to the role of fathers in child and adolescent psychopathology. American Psychologist. 656-664.

Pickering, L. K. (2003) Red Book: 2003 Report of the Committee on Infectious Diseases by American Academy of Pediatrics, American Academy of Pediatrics Committee on Infectious Diseases, American Academy of Pediatrics.

Pithers, W. D., Marques, J. K., Gibat, C. C., \& Marlatt, G. A. (1983). Relapse prevention with sexual aggressives: A self-control model of treatment and maintenance of change. In J. G. Greer \& I. R. Stuart (Eds.), The sexual aggressor: Current perspectives on treatment (pp. 214-239). New York: Van Nostrand Reinhold.

Polusny, M. A., \& Follette, V. M. (1995). Long-term correlates of child sexual abuse: Theory and review of the empirical literature. Applied and Preventive Psychology, 143-166.

Prentky, R \& Burgess, A. W. (1990). Rehabilitation of child molesters: A cost-benefit analysis. American Journal of Orthopsychiatry, 60. 108-117.

Putnam, F. W. (2001). The Cost of Child Maltreatment: Who Pays? Edited by K. Franey, R. Geffner, R. Falconer. Family Violence and Sexual Assault Institute, San Diego, CA, pp. 185-198.

Radke-Yarrow, M., Cummings, M., Kuczynski, L. \& Chapman, M. (1985). Patterns of attachment in two- and three-year-olds in normal families and families with parental depression. Child Development. 56, 884-893 
Ratliff-Crain, J., Donald, K. M., \& Dalton, J. (1999). Knowledge, beliefs, peer norms, and past behaviors as correlates of risky sexual behaviors among college students. Psychology \& Health, 14, 625-643.

Reynolds, C. R., and Richmond, B. O. (1985). The Revised Childhood Manifest Anxiety Scale (RCMAS Manual), Western Psychological Services, Los Angeles.

Rhodes, J., Grossman, J., \& Resch, N. (2000). Agents of change: Pathways through which mentoring relationships influence adolescent' academic adjustment. Child Development, 1662-1671.

Rich, P. (2006). Understanding and applying attachment theory to the treatment of juvenile sexual offenders. John Wiley \& Sons. West Sussex England.

Rich, P. (2010). Attachment informed treatment. A presentation at the Clackamas County Juvenile Department. May 13, 2009.

Riggs, S., \& Gottlieb, M. (2009). Attachment network in family law matters: A developmental-contextual approach. Journal of Forensic Psychology Practice. 208-236

Rind, B., \& Tromovitch, P. (1997). A meta-analytic review of findings from national samples on psychological correlates of child sexual abuse. Journal of Sex Research, 34, 237-255.

Roberts, N., \& Noller, P. (1998). The association between adult attachment and couple violence: The role of communication patterns and relationship satisfaction. In J. A. Simpson \& W. S. Rholes (Eds.), Attachment theory and close relationships (pp. 317-353). New York: Guildford.

Robertson, S. (2009) "Age of Consent Laws," in Children and Youth in History, George Mason University. http://chnm.gmu.edu/cyh/teaching-modules/230 (accessed September 16, 2010).

Rohner, R. (1976). Parental acceptance-rejection questionnaire. Storrs, CT: Center for the Study of Parental Acceptance and Rejection.

Rose, D., \& Clear. T.(1998). Incarceration, social capital, and crime: Implications for social disorganization theory. Criminology. 441-480.

Rose, A. J., \& Rudolph, K. D. (2006). A review of sex differences in peer relationship processes: Potential trade-offs for the emotional and behavioral development of girls and boys. Psychological Bulletin, 98-131. 
Rosenberg, M. (1965). Society and the adolescent self-image. Princeton, NJ: Princeton University Press.

Rubin, K. (1982). Nonsocial play in preschoolers: Necessarily evil? Child Development. : 651-657.

Rubin, K., Coplan, R., Bowker, J., \& Menzer, M.(2010) Social Withdrawal and Shyness, in The Wiley-Blackwell Handbook of Childhood Social

Development, Second Edition (eds PK Smith and CH Hart), Wiley-Blackwell, Oxford

Rumstein-McKean, O., \& Hunsley, J. (2001) Interpersonal and family functioning of female survivors of childhood sexual abuse. Clinical Psychology Review, Pages 471-490.

Russell, D. E. H. (1983). The incidence and prevalence of intrafamilial and extra familial sexual abuse of female children. Child Abuse \& Neglect, 9, 191-199.

Russell, D., Peplau, L., \& Cutrona, C. (1980). The revised UCLA Loneliness Scale. Journal of Personality and Social Psychology, 39, 472-480.

Ryan, G. (2010). Theories of etiology. In Juvenile Sexual Offending. G. Ryan, T. Leversee \& S. Lane. John Wiley \& Sons.

Ryan, G. (1999a). Treatment of sexually abusive youth: The evolving consensus. The Journal of Interpersonal Violence, 14, 422-436.

Ryan, B., Gillies, E., Kent, J., Baker, S., Durfee, M., Winterstein, M., \& Knapp, P. (2001). Treatment of intrafamilial crime victims in mental health care for child crime victims: Standards of care task force guidelines. Eds, Michele Winterstein and Scott R. Scribner. State of California Victim Compensation and Government Claims Board, Victims of Crime Program. Retrieved June 13, 2011 from http://www.vcgcb.ca.gov/docs/forms/victims/standardsofcare/Chapter_6.pdf

Ryan, S., Rodriguez, J., Anderson, R. and Foy, D. (1992, August). Psychometric analysis of the sexual abuse exposure questionnaire (SAEQ). Paper presented at the American Psychological Association, Washington, D.C.

Ryan, G., \& Lane, S. (1991). Juvenile sexual offending: Causes, consequences and correction. Lexington, MA: Lexington Books. 
Salter, A. (2003). Predators, pedophiles, rapists, and other sex offenders : Who they are, how they operate and how we can protect ourselves and our children. Basic Books. New York, NY.

Sample, L. \& Bray, T. (2003). Are sex offenders dangerous? Criminology \& Public Policy. 3, 59-82.

Sampson, R., \& Laub, J. (2005).A life-course view of the development of crime. Annals of the American Academy of Political and Social Science, 602, 12 - 45.

Santrock, John. (2009). Human Adjustment. Boston: McGraw Hill, publisher.

Saunders, E., Awad, G., \& Levene, J. (1984). A clinical study of male adolescent sex offenders. International Journal of Offender Therapy and Comparative Criminology, 28, 105-115

Schachter, S., \& Singer, J. (1962). Cognitive, social and physiological determinants of emotional state. Psychological Review, 379-399.

Schultheiss, D., \& Blustein, D. (1994). Contributions of family relationship factors to the identity formation process. Journal of Counseling \& Development. 159166.

Sedlak, A. J., Mettenburg, J., Basena, M., Petta, I., McPherson, K., Greene, A., and Li, S. (2010). Fourth National Incidence Study of Child Abuse and Neglect (NIS4): Report to Congress, Executive Summary. Washington, DC: U.S.

Department of Health and Human Services, Administration for Children and Families.

Senn, T., Carey, M., \& Vanable, P. (2008). Childhood and Adolescent Sexual Abuse and Subsequent Sexual Risk Behavior: Evidence from Controlled Studies, Methodological Critique, and Suggestions for Research. Clinical Psychology Review. 711-735

Seto, M., Kjellgren, C., Priebe, G., Mossige, S., Svedin, C., \& Langstrom, N. (2010). Sexual coercion experience and sexually coercive behavior: a population study of Swedish and Norwegian male youth Child Maltreatment, 219-228.

Seto, M., Maric, A., \& Barbaree (2001). The role of pornography in the etiology of sexual aggression. Aggression and Violent Behavior. 35-53. 
Shaeffer, C. \& Borduin, C. (2005). Long-term follow-up to a randomized clinical trial of multisystemic therapy with serious and violent offenders. Journal of Consulting and Clinical Psychology. 73, 445-453.

Shanahan, M. \& Donato, R. (2001). Counting the cost: Estimating the economic benefit of pedophile treatment programs. Child Abuse \& Neglect, 25, 541-555.

Sharpsteen, D., \& Kirkpatrick, L. (1997). Romantic jealousy and adult romantic attachment. Journal of Personality and Social Psychology, 627-640.

Shaver, P. R. \& Clark, C. L. (1996). Forms of adult romantic attachment and their cognitive and emotional underpinnings. In G. G. Noam \& K. W. Fischer (Eds), Development and vulnerability in close relationships, Mahwah, NJ: Lawrence Erlbaum.

Shi, L, \& Nicol, J. (2007). Into the mind of a juvenile sex offender: A clinical analysis and recommendation from an attachment perspective. The American Journal of Family Therapy, 395-402,

Sickmund, M., Snyder, H., \& Poe-Yamagata, E. (1997). Juvenile Offenders and Victims: 1997 Update on Violence. Office of Juvenile Justice and Delinquency Prevention, Washington, DC.

Siegel, J. M. (1986). The multi-dimensional anger inventory. Journal of Personality and Social Psychology, 51, 191_/200.

Siegel, J. M., Sorenson, S. B., Golding, J. M., Burnam, M. A., \& Stein, J. A. (1987). The Prevalence of childhood sexual assault: The Los Angeles Epidemiologic catchment area. American Journal of Epidemiology, 126, 1141-1164.

Silva, P. A. (1987). Epidemiology, longitudinal course, and some associated factors: An update. In W Yule \& M. Rutter (Eds.), Language development and disorders (pp. 1-15). Oxford, England: MacKeith.

Simon, K., Paternite, C., \& Shore, C (2001). Quality of parent/adolescent attachment and aggression in young adolescents. Journal of Early Adolescence, 182-203.

Simpson, J. (1990). Influence of attachment styles on romantic relationships. Journal of Personality and Social Psychology, 971-980.

Simpson, J., Rholes, W., \& Nelligan, J. (1992). Support seeking and support giving within couples in an anxiety-provoking situation: The role of attachment styles. Journal of Personality and Social Psychology, 434-446. 
Smallbone, S., \& Dadds, M. (2000). Attachment and Coercive Sexual Behavior. Sexual Abuse: A Journal of Research and Treatment. 3-15.

Smallbone, S., \& Dadds, M. (2001). Further evidence for a relationship between attachment insecurity and coercive sexual behavior in non-offenders. Journal of Interpersonal Violence, 16, 22-35.

Smallbone, S., \& McCabe, B. (2003). Child attachment, childhood sexual abuse, and onset of masturbation among adult sexual offenders. Sexual Abuse: A Journal of Research and Treatment 15, 1-9.

Smith, M., \& Calam, R. (2009). Psychological factors linked to self-reported depression symptoms in late adolescence. Behavioural and Cognitive Psychotherapy, 37, 73-85.

Sprott, J., Jenkins, J. \& Doob, A. (2000). Early Offending: Understanding the Risk and Protective Factors of Delinquency. Publication W-01-1-9E. Human Resources Development Canada Publications Centre., Quebec, Canada.

Stark, E. and Flitcraft, A. (1988). Women and children at risk: a feminist perspective on child abuse. International Journal of Health Services, 18, 97-118.

Stewart, E. ( 2007). The sexual health and behaviour of male prisoners: The need for research. The Howard Journal of Criminal Justice, 46, 43-59.

Steinberg, J. (2006) Evidence-Based Programming within Residential Settings to Reduce Recidivism. Presentation the Juvenile Services Juvenile Justice \& Delinquency Prevention 2006 Conference, June 2006. Williamsburg, Virginia.

Sternberg, R. (1986). A triangular theory of love. Psychological Review, 119-135.

Stevenson, J. (1984). Predictive value of speech and language screening. Developmental Medicine \& Child Neurology, 26, 528-538.

Strong, B., Devault, C., \& Cohen, T. (2008). The marriage and family experience: Intimate relationships in a changing society. Thomas \& Wadsworth, Belmont, California.

Suess, G., Grossmann, K., \& Sroufe, L. (1992). Effects of Infant attachment to mother and father on quality of adaptation in preschool: From dyadic to individual organization of self. International Journal of Behavioral Development. 43-65.

Sullivan, H. (1953). The interpersonal theory of psychiatry. Norton, New York: 
Sund, A. M. \& Wichstrom, L. (2002). Insecure attachment as a risk factor for future depressive symptoms in early adolescence. Journal of the American Academy of Child and Adolescent Psychiatry, 1478-1485.

Tewksbury, R. (2005). Collateral Consequences of Sex Offender Registration. Journal of Contemporary Criminal Justice, 21, 67-81.

Thomas, T., \& Femouw, W. (2009). Moderating variables of the sexual "victim to offender cycle" in males. Aggression and Violent Behavior. 382-387.

Tabachnick, B. G., \& Fidell, L. S. (1996). Using multivariate statistics ( ${ }^{\text {rd }}$ ed.). New York: Harper Collins.

Tabachnick, B. G., \& Fidell, L. S. (2001). Using multivariate statistics ( $^{\text {th }} \mathrm{ed}$.). Needham Heights, MA: Allyn \& Bacon

Taxman, F. (2002). Supervision: Exploring the dimensions of effectiveness. Federal Probation. 14-27.

Tofte, S. (2007). No easy answers: Sex offender laws in the US. Human Rights Watch. Available at http://www.hrw.org/en/reports/2007/09/11/no-easy-answers.

Tricker, R., Casaburi, R., Storer, T. W., Clevenger, B., Berman, N., Shirazi, A. \& Bhasin, S. (1996). The effects of supraphysiological doses of testosterone on angry behavior in healthy eugonadal men: a clinical research center study. Journal of Clinical Endocrinology and Metabolism, 3754-3758.

Ullman, S. E. (1996), social reactions, coping strategies, and self-blame attributions in adjustment to sexual assault. Psychology of Women Quarterly, 20: 505-526

U.S. Department of Agriculture. (2005). Measurement of food insecurity and hunger: Phase 1 report. National Research Council. Washington, D.C., Natation Academies Press.

U.S. Department of Justice. (1996). Child victimizers: Violent offenders and their victims (NCJ-153258). Washington, DC: Government Printing Office.

U.S. Department of Justice. (1997). Sex offender community notification (NCJ162364). Washington, DC: Government Printing Office.

U.S. Department of Justice (2008). The Dru Sjodin National Sex Offender Public Website Available at http:www.nsopw.gov/Core/About.Aspx. 
Vogeltanz, N., Wilsnak, S., Harris, T. R, Wilsnack, R., Wondrlich, S., \& Kirsjanson, A. (1999). Prevalence and risk factors for childhood sexual abuse in women: National survey findings. Child Abuse \& Neglect, 23, 579-592.

Waite, D., Keller, A., McGarvey, E. L., Wieckowski, E., Pinkerton, R., \& Brown, G. L. (2005). Juvenile sex offender re-arrest rates for sexual, violent nonsexual and property crimes: A 10-year follow-up. Sexual Abuse: A Journal of Research and Treatment, 313-331.

Wang, C., \& Holton, J. (2007). Total Estimated Cost of Child Abuse and Neglect in the United States. Prevent Child Abuse America. Retrieved September 5, 2008 from http://member.preventchildabuse.org/site/DocServer/cost_analysis.pdf?docID= 144

Ward, T., \& Beech, A. R. (2006). An integrated theory of sexual offending. Aggression and Violent Behavior, 44-63.

Ward, T., Polascheck, D., \& Beech, A. (2006). Theories of sexual offending. John Wiley \& Sons. West Sussex, England.

Ward, T., Hudson, S., \& Keenan, T. (1998). A self-regulation model of the sexual offense process. Sexual Abuse: A Journal of Research and Treatment, 141-157.

Ward, T., Hudson, S., \& Marshall, W. (1996). Attachment style in sex offenders: A preliminary study. The Journal of Sex Research, 33, 17-26.

Ward, T., \& Siegert, R. J. (2002). Toward and comprehensive theory of child sexual abuse: A theory knitting perspective. Psychology, Crime, and Law, 319-351.

Warr, M. (1993). Parents, peers, and delinquency. Social Forces. 247-264.

Waters, E., \& Sroufe, L. A. (2006). Social competence as a developmental construct. Psychological Bulletin. 98-131

Waters, E, Hamilton, C., \& Weinfield, N. (2000). The stability of attachment security from infancy to adolescence and early adulthood: General introduction. Child Development. 678-683.

Weinberger, D. A. (1991). Social-emotional adjustment in older children and adults: I. Psychometric properties of the Weinberger Adjustment Inventory, Unpublished manuscript, Case Western Reserve University, Columbus, $\mathrm{OH}$ 
Weinrott, M. (1996). Sexual aggression: A critical review. Boulder Center for the Study and Prevention of Violence, Institute for the Behavioral Sciences, University of Colorado, Boulder.

Weinrott. M., \& Saylor., M. (1991). Self-report of crimes committed by sex offenders. Journal of Interpersonal Violence. 286-300.

Werner, E. (1995). Resilience in development. Current Directions in Psychological Science. 81-84

World Health Organization (2003). Guidelines for medico-legal care for victims of sexual violence. Geneva: World Health Organization. ISBN 924154628 X

Widom, C. S., \& Morris, C. (1997). Accuracy of adult recollections of childhood victimization (part 2): Childhood sexual abuse. Psychological Assessment, 9, 34-46.

Widom, C. S., \& Shepard, R. (1996). Accuracy of adult recollections of childhood victimization. Psychological Assessment, 8, 412-421.

Williams, L. M. (1994). Recall of childhood trauma: A prospective study of women's memories of child sexual abuse. Journal of Consulting and Clinical Psychology, 62(6), 1167-1176.

Wilkinson, D. (2001), Violent events and social identity: Specifying the relationship between respect and masculinity in inner-city youth violence, sociological studies of children and youth, 231-265.

Wissow, L. S. (1995). Detecting abuse and neglect: Obtaining credible accounts of abuse and neglect. New England Journal of Medicine, 1425-1431

Worling, J., \& Curwen, T. (2000). Adolescent sexual offender recidivism: Success of specialized treatment and implications for risk prediction, Child Abuse \& Neglect, 24, 965-982.

Wright, R. (2008). Sex offender post-incarceration sanctions: Are there any limits? New England Journal on Criminal and Civil Confinement. 17-50.

Wyatt, G. E. (1985). The sexual abuse of African American and European American women in childhood. Child Abuse \& Neglect, 9, 507-519.

Wyatt, G. E. \& Peters S. D. (1986) Issues in the definition of child: Sexual abuse in prevalence research. Child Abuse and Neglect, 10, 231-240. 
Wyatt, G., Loeb, T., Solis, B., Carmona, J. \& Romero, G. (1999). The prevalence and circumstances of child sexual abuse: Changes across a decade. Child Abuse \& Neglect, 23, 45-60.

Zalewski, M., Lengua, L. J., Fisher, P. A., Trancik, A., Bush, N. R., \& Meltzoff, A. N. (2012). Poverty and Single Parenting: Relations with Preschoolers' Cortisol and Effortful Control. Infant and Child Development, 537-554.

Zevitz, R. \& Farkas, M. (2000). Sex offender community notification: Managing high risk criminals or exacting further vengeance? Behavioral Sciences and the Law, 18, 375-391.

Zevitz, R (2004). Sex offender Placement and neighborhood Social Integration: The making of a scarlet letter community. Criminal Justice Studies. 17, 203-222.

Zimmerman, P, \& Becker-Stoll, F. (2002). Stability of attachment representations during adolescence: The influence of ego-identity status. Journal of Adolescence. 107-124. 


\section{Appendix A:}

\section{Oregon Revised Statutes (ORS)}

\section{Oregon Registerable Sex Crimes}

\section{SEXUAL OFFENSES}

163.305 Definitions. As used in chapter 743, Oregon Laws 1971, unless the context requires otherwise:

(1) "Deviate sexual intercourse" means sexual conduct between persons consisting of contact between the sex organs of one person and the mouth or anus of another.

(2) "Forcible compulsion" means to compel by:

(a) Physical force; or

(b) A threat, express or implied, that places a person in fear of immediate or future death or physical injury to self or another person, or in fear that the person or another person will immediately or in the future be kidnapped.

(3) "Mentally defective" means that a person suffers from a mental disease or defect that renders the person incapable of appraising the nature of the conduct of the person.

(4) "Mentally incapacitated" means that a person is rendered incapable of appraising or controlling the conduct of the person at the time of the alleged offense because of the influence of a controlled or other intoxicating substance administered to the person without the consent of the person or because of any other act committed upon the person without the consent of the person.

(5) "Physically helpless" means that a person is unconscious or for any other reason is physically unable to communicate unwillingness to an act.

(6) "Sexual contact" means any touching of the sexual or other intimate parts of a person or causing such person to touch the sexual or other intimate parts of the actor for the purpose of arousing or gratifying the sexual desire of either party.

(7) "Sexual intercourse" has its ordinary meaning and occurs upon any penetration, however slight; emission is not required. [1971 c.743 §104; 1975 c.461 §1; 1977 c.844 §1; 1979 c.744 §7; 1983 c.500 §1; 1999 c.949 §1]

Note: Legislative Counsel has substituted “chapter 743, Oregon Laws 1971," for the words "this Act" in section 104, chapter 743, Oregon Laws 1971, compiled as 163.305. Specific ORS references have not been substituted, pursuant to 173.160. These sections may be determined by referring to the 1971 Comparative Section Table located in Volume 20 of ORS. 
163.315 Incapacity to consent; effect of lack of resistance. (1) A person is considered incapable of consenting to a sexual act if the person is:

(a) Under 18 years of age;

(b) Mentally defective;

(c) Mentally incapacitated; or

(d) Physically helpless.

(2) A lack of verbal or physical resistance does not, by itself, constitute consent but may be considered by the trier of fact along with all other relevant evidence. [1971 c.743 $\S 105 ; 1999$ c.949 §2; 2001 c.104 §52]

163.325 Ignorance or mistake as a defense. (1) In any prosecution under ORS 163.355 to 163.445 in which the criminality of conduct depends on a child's being under the age of 16, it is no defense that the defendant did not know the child's age or that the defendant reasonably believed the child to be older than the age of 16 .

(2) When criminality depends on the child's being under a specified age other than 16, it is an affirmative defense for the defendant to prove that the defendant reasonably believed the child to be above the specified age at the time of the alleged offense.

(3) In any prosecution under ORS 163.355 to 163.445 in which the victim's lack of consent is based solely upon the incapacity of the victim to consent because the victim is mentally defective, mentally incapacitated or physically helpless, it is an affirmative defense for the defendant to prove that at the time of the alleged offense the defendant did not know of the facts or conditions responsible for the victim's incapacity to consent. [1971 c.743 $\S 106]$

163.345 Age as a defense in certain cases. (1) In any prosecution under ORS $163.355,163.365,163.385,163.395,163.415,163.425,163.427$ or 163.435 in which the victim's lack of consent was due solely to incapacity to consent by reason of being less than a specified age, it is a defense that the actor was less than three years older than the victim at the time of the alleged offense.

(2) In any prosecution under ORS 163.408, when the object used to commit the unlawful sexual penetration was the hand or any part thereof of the actor and in which the victim's lack of consent was due solely to incapacity to consent by reason of being less than a specified age, it is a defense that the actor was less than three years older than the victim at the time of the alleged offense.

(3) In any prosecution under ORS 163.445 in which the victim's lack of consent was due solely to incapacity to consent by reason of being less than a specified age, it is a defense that the actor was less than three years older than the victim at the time of the alleged offense if the victim was at least 15 years of age at the time of the alleged offense. [1971 c.743 §108; 1991 c.386 §3; 1991 c.830 §4; 1999 c.626 §24; amendments by 1999 c.626 $\$ 45$ repealed by 2001 c. $884 \S 1]$

163.355 Rape in the third degree. (1) A person commits the crime of rape in the third degree if the person has sexual intercourse with another person under 16 years of age.

(2) Rape in the third degree is a Class C felony. [1971 c.743 §109; 1991 c.628 $\S 1]$

163.365 Rape in the second degree. (1) A person who has sexual intercourse with another person commits the crime of rape in the second degree if the other person is 
under 14 years of age.

(2) Rape in the second degree is a Class B felony. [1971 c.743 §110; 1989 c.359 $\S 1 ; 1991$ c.628 §2]

163.375 Rape in the first degree. (1) A person who has sexual intercourse with another person commits the crime of rape in the first degree if:

(a) The victim is subjected to forcible compulsion by the person;

(b) The victim is under 12 years of age;

(c) The victim is under 16 years of age and is the person's sibling, of the whole or half blood, the person's child or the person's spouse's child; or

(d) The victim is incapable of consent by reason of mental defect, mental incapacitation or physical helplessness.

(2) Rape in the first degree is a Class A felony. [1971 c.743 §111; 1989 c.359 §2; 1991 c.628 §3]

163.385 Sodomy in the third degree. (1) A person commits the crime of sodomy in the third degree if the person engages in deviate sexual intercourse with another person under 16 years of age or causes that person to engage in deviate sexual intercourse.

(2) Sodomy in the third degree is a Class C felony. [1971 c.743 §112]

163.395 Sodomy in the second degree. (1) A person who engages in deviate sexual intercourse with another person or causes another to engage in deviate sexual intercourse commits the crime of sodomy in the second degree if the victim is under 14 years of age. c.359 §3]

(2) Sodomy in the second degree is a Class B felony. [1971 c.743 §113; 1989

163.405 Sodomy in the first degree. (1) A person who engages in deviate sexual intercourse with another person or causes another to engage in deviate sexual intercourse commits the crime of sodomy in the first degree if:

(a) The victim is subjected to forcible compulsion by the actor;

(b) The victim is under 12 years of age;

(c) The victim is under 16 years of age and is the actor's brother or sister, of the whole or half blood, the son or daughter of the actor or the son or daughter of the actor's spouse; or

(d) The victim is incapable of consent by reason of mental defect, mental incapacitation or physical helplessness.

(2) Sodomy in the first degree is a Class A felony. [1971 c.743 §114; 1989 c.359

163.408 Unlawful sexual penetration in the second degree. (1) Except as permitted under ORS 163.412, a person commits the crime of unlawful sexual penetration in the second degree if the person penetrates the vagina, anus or penis of another with any object other than the penis or mouth of the actor and the victim is under 14 years of age.

(2) Unlawful sexual penetration in the second degree is a Class B felony. [1981 c.549 §2; 1989 c.359 §5; 1991 c.386 §1]

163.411 Unlawful sexual penetration in the first degree. (1) Except as permitted under ORS 163.412, a person commits the crime of unlawful sexual penetration in 
the first degree if the person penetrates the vagina, anus or penis of another with any object other than the penis or mouth of the actor and:

(a) The victim is subjected to forcible compulsion;

(b) The victim is under 12 years of age; or

(c) The victim is incapable of consent by reason of mental defect, mental incapacitation or physical helplessness.

(2) Unlawful sexual penetration in the first degree is a Class A felony. [1981 c.549 §3; 1989 c.359 §6; 1991 c.386 §2]

163.412 Exceptions to unlawful sexual penetration prohibition. Nothing in ORS $163.408,163.411$ or 163.452 prohibits a penetration described in those sections when:

(1) The penetration is part of a medically recognized treatment or diagnostic procedure; or

(2) The penetration is accomplished by a peace officer or a corrections officer acting in official capacity, or by medical personnel at the request of such an officer, in order to search for weapons, contraband or evidence of crime. [1981 c.549 §4; 2005 c.488 §5]

163.415 Sexual abuse in the third degree. (1) A person commits the crime of sexual abuse in the third degree if the person subjects another person to sexual contact and:

(a) The victim does not consent to the sexual contact; or

(b) The victim is incapable of consent by reason of being under 18 years of age.

(2) Sexual abuse in the third degree is a Class A misdemeanor. [1971 c.743 §115; 1979 c.489 §1; 1991 c.830 §1; 1995 c.657 §11; 1995 c.671 §9]

163.425 Sexual abuse in the second degree. (1) A person commits the crime of sexual abuse in the second degree when that person subjects another person to sexual intercourse, deviate sexual intercourse or, except as provided in ORS 163.412, penetration of the vagina, anus or penis with any object other than the penis or mouth of the actor and the victim does not consent thereto.

(2) Sexual abuse in the second degree is a Class C felony. [1971 c.743 §116; 1983 c.564 §1; 1991 c.386 §14; 1991 c.830 §2]

163.427 Sexual abuse in the first degree. (1) A person commits the crime of sexual abuse in the first degree when that person:

(a) Subjects another person to sexual contact and:

(A) The victim is less than 14 years of age;

(B) The victim is subjected to forcible compulsion by the actor; or

(C) The victim is incapable of consent by reason of being mentally defective, mentally incapacitated or physically helpless; or

(b) Intentionally causes a person under 18 years of age to touch or contact the mouth, anus or sex organs of an animal for the purpose of arousing or gratifying the sexual desire of a person.

(2) Sexual abuse in the first degree is a Class B felony. [1991 c.830 §3; 1995 c.657 §12; 1995 c.671 §10]

Note: 163.427 was enacted into law by the Legislative Assembly but was not added to or made a part of ORS chapter 163 or any series therein by legislative action. See Preface to Oregon Revised Statutes for further explanation. 
163.431 Definitions for ORS 163.432 to 163.434. As used in ORS 163.432 to 163.434:

(1) "Child" means a person who the defendant reasonably believes to be under 16 years of age.

(2) "Online communication" means communication that occurs via electronic mail, personal or instant messaging, chat rooms, bulletin boards or any other method of communicating over the Internet.

(3) "Sexual contact" has the meaning given that term in ORS 163.305.

(4) "Sexually explicit conduct" has the meaning given that term in ORS 163.665.

(5) "Solicit" means to invite, request, seduce, lure, entice, persuade, prevail upon, coax, coerce or attempt to do so. [2007 c.876 §1]

Note: 163.431 to 163.434 were enacted into law by the Legislative Assembly but were not added to or made a part of ORS chapter 163 or any series therein by legislative action. See Preface to Oregon Revised Statutes for further explanation.

163.432 Online sexual corruption of a child in the second degree. (1) A person commits the crime of online sexual corruption of a child in the second degree if the person is 18 years of age or older and:

(a) For the purpose of arousing or gratifying the sexual desire of the person or another person, knowingly uses an online communication to solicit a child to engage in sexual contact or sexually explicit conduct; and

(b) Offers or agrees to physically meet with the child.

(2) Online sexual corruption of a child in the second degree is a Class $\mathrm{C}$ felony. [2007 c.876 §2]

Note: See note under 163.431.

163.433 Online sexual corruption of a child in the first degree. (1) A person commits the crime of online sexual corruption of a child in the first degree if the person violates ORS 163.432 and intentionally takes a substantial step toward physically meeting with or encountering the child.

(2) Online sexual corruption of a child in the first degree is a Class B felony. [2007 c.876 §3]

Note: See note under 163.431.

163.434 Provisions applicable to online sexual corruption of a child. (1) It is an affirmative defense to a prosecution for online sexual corruption of a child in the first or second degree that the person was not more than three years older than the person reasonably believed the child to be.

(2) It is not a defense to a prosecution for online sexual corruption of a child in the first or second degree that the person was in fact communicating with a law enforcement officer, as defined in ORS 163.730, or a person working under the direction of a law enforcement officer, who is 16 years of age or older.

(3) Online sexual corruption of a child in the first or second degree is committed in either the county in which the communication originated or the county in which the 
communication was received. [2007 c.876 §4]

163.435 Contributing to the sexual delinquency of a minor. (1) A person 18 years of age or older commits the crime of contributing to the sexual delinquency of a minor if:

(a) Being a male, he engages in sexual intercourse with a female under 18 years of age; or

(b) Being a female, she engages in sexual intercourse with a male under 18 years of age; or

(c) The person engages in deviate sexual intercourse with another person under 18 years of age or causes that person to engage in deviate sexual intercourse.

(2) Contributing to the sexual delinquency of a minor is a Class A misdemeanor. [1971 c.743 §117]

163.445 Sexual misconduct. (1) A person commits the crime of sexual misconduct if the person engages in sexual intercourse or deviate sexual intercourse with an unmarried person under 18 years of age.

(2) Sexual misconduct is a Class C misdemeanor. [1971 c.743 §118]

163.465 Public indecency. (1) A person commits the crime of public indecency if while in, or in view of, a public place the person performs:

(a) An act of sexual intercourse;

(b) An act of deviate sexual intercourse; or

(c) An act of exposing the genitals of the person with the intent of arousing the sexual desire of the person or another person.

(2)(a) Public indecency is a Class A misdemeanor.

(b) Notwithstanding paragraph (a) of this subsection, public indecency is a Class $\mathrm{C}$ felony if the person has a prior conviction for public indecency or a crime described in ORS 163.355 to 163.445 or for a crime in another jurisdiction that, if committed in this state, would constitute public indecency or a crime described in ORS 163.355 to 163.445. [1971 c.743 §120; 1999 c.962 §1; 2005 c. $434 \S 1]$

163.466 Public indecency; felony; sentencing classification. The Oregon Criminal Justice Commission shall classify felony public indecency as a person felony and crime category 6 of the sentencing guidelines grid of the commission. [1999 c.962 §3]

Note: 163.466 was enacted into law by the Legislative Assembly but was not added to or made a part of ORS chapter 163 or any series therein by legislative action. See Preface to Oregon Revised Statutes for further explanation.

163.467 Private indecency. (1) A person commits the crime of private indecency if the person exposes the genitals of the person with the intent of arousing the sexual desire of the person or another person and:

(a) The person is in a place where another person has a reasonable expectation of privacy;

(b) The person is in view of the other person;

(c) The exposure reasonably would be expected to alarm or annoy the other person; and 
(d) The person knows that the other person did not consent to the exposure.

(2) Private indecency is a Class A misdemeanor.

(3) Subsection (1) of this section does not apply to a person who commits the act described in subsection (1) of this section if the person cohabits with and is involved in a sexually intimate relationship with the other person.

(4) For purposes of this section, "place where another person has a reasonable expectation of privacy" includes, but is not limited to, residences, yards of residences, working areas and offices. [1999 c.869 §2]

163.476 Unlawfully being in a location where children regularly congregate. (1) A person commits the crime of unlawfully being in a location where children regularly congregate if the person:

(a)(A) Has been designated a sexually violent dangerous offender under ORS

(B) Has been designated a predatory sex offender under ORS 181.585 and does not have written approval from the State Board of Parole and Post-Prison Supervision or the person's supervisory authority or supervising officer to be in or upon the specific premises;

(C) Has been sentenced as a dangerous offender under ORS 161.725 upon conviction of a sex crime; or

(D) Has been given a similar designation or been sentenced under a similar law of another jurisdiction; and

(b) Knowingly enters or remains in or upon premises where persons under 18 years of age regularly congregate.

(2) As used in this section:

(a) "Premises where persons under 18 years of age regularly congregate" means schools, child care centers, playgrounds, other places intended for use primarily by persons under 18 years of age and places where persons under 18 years of age gather for regularly scheduled educational and recreational programs.

(b) "Sex crime" has the meaning given that term in ORS 181.594.

(3) Unlawfully being in a location where children regularly congregate is a Class A misdemeanor. [2005 c.811 §1]

Note: 163.476 and 163.479 were enacted into law by the Legislative Assembly but were not added to or made a part of ORS chapter 163 or any series therein by legislative action. See Preface to Oregon Revised Statutes for further explanation.

163.479 Unlawful contact with a child. (1) A person commits the crime of unlawful contact with a child if the person:

(a)(A) Has been designated a sexually violent dangerous offender under ORS 137.765;

(B) Has been designated a predatory sex offender under ORS 181.585;

(C) Has been sentenced as a dangerous offender under ORS 161.725 upon conviction of a sex crime; or

(D) Has been given a similar designation or been sentenced under a similar law of another jurisdiction; and

(b) Knowingly contacts a child with the intent to commit a crime or for the purpose of arousing or satisfying the sexual desires of the person or another person.

(2) As used in this section: 
(a) "Child" means a person under 18 years of age.

(b) "Contact" means to communicate in any manner.

(c) "Sex crime" has the meaning given that term in ORS 181.594.

(3) Unlawful contact with a child is a Class C felony. [2005 c.811 §2]

Note: See note under 163.476.

163.525 Incest. (1) A person commits the crime of incest if the person marries or engages in sexual intercourse or deviate sexual intercourse with a person whom the person knows to be related to the person, either legitimately or illegitimately, as an ancestor, descendant or brother or sister of either the whole or half blood.

(2) Incest is a Class C felony. [1971 c.743 §172]

\section{VISUAL RECORDING OF SEXUAL CONDUCT OF CHILDREN}

\subsection{Definitions for ORS 163.670 to 163.693. As used in ORS 163.670 to}

163.693:

(1) "Child" means a person who is less than 18 years of age, and any reference to a child in relation to a photograph, motion picture, videotape or other visual recording of the child is a reference to a person who was less than 18 years of age at the time the original image in the photograph, motion picture, videotape or other visual recording was created and not the age of the person at the time of an alleged offense relating to the subsequent reproduction, use or possession of the visual recording.

(2) "Child abuse" means conduct that constitutes, or would constitute if committed in this state, a crime in which the victim is a child.

(3) "Sexually explicit conduct" means actual or simulated:

(a) Sexual intercourse or deviant sexual intercourse;

(b) Genital-genital, oral-genital, anal-genital or oral-anal contact, whether between persons of the same or opposite sex or between humans and animals;

(c) Penetration of the vagina or rectum by any object other than as part of a medical diagnosis or treatment or as part of a personal hygiene practice;

(d) Masturbation;

(e) Sadistic or masochistic abuse; or

(f) Lewd exhibition of sexual or other intimate parts.

(4) "Visual depiction" includes, but is not limited to, photographs, films, videotapes, pictures or computer or computer-generated images or pictures, whether made or produced by electronic, mechanical or other means. [1985 c.557 §2; 1987 c.864 §1; 1991 c.664 §4; 1995 c.768 §4; 1997 c.719 §5]

163.670 Using child in display of sexually explicit conduct. (1) A person commits the crime of using a child in a display of sexually explicit conduct if the person employs, authorizes, permits, compels or induces a child to participate or engage in sexually explicit conduct for any person to observe or to record in a photograph, motion picture, videotape or other visual recording.

(2) Using a child in a display of sexually explicit conduct is a Class A felony. [1985 c.557 §3; 1987 c.864 §3; 1991 c.664 §5]

163.676 Exemption from prosecution under ORS 163.684. (1) No employee is 
liable to prosecution under ORS 163.684 or under any city or home rule county ordinance for exhibiting or possessing with intent to exhibit any obscene matter or performance provided the employee is acting within the scope of regular employment at a showing open to the public.

(2) As used in this section, "employee" means any person regularly employed by the owner or operator of a motion picture theater if the person has no financial interest other than salary or wages in the ownership or operation of the motion picture theater, no financial interest in or control over the selection of the motion pictures shown in the theater, and is working within the motion picture theater where the person is regularly employed, but does not include a manager of the motion picture theater. [Formerly $163.495 ; 1995$ c.768 §5]

163.682 Exceptions to ORS 163.665 to 163.693. The provisions of ORS 163.665 to 163.693 do not apply to:

(1) Any legitimate medical procedure performed by or under the direction of a person licensed to provide medical services for the purpose of medical diagnosis or treatment, including the recording of medical procedures;

(2) Any activity undertaken in the course of bona fide law enforcement activity or necessary to the proper functioning of the criminal justice system, except that this exception shall not apply to any activity prohibited by ORS 163.670 ;

(3) Any bona fide educational activity, including studies and lectures, in the fields of medicine, psychotherapy, sociology or criminology, except that this exception shall not apply to any activity prohibited by ORS 163.670 ;

(4) Obtaining, viewing or possessing a photograph, motion picture, videotape or other visual recording as part of a bona fide treatment program for sexual offenders; or

(5) A public library, as defined in ORS 357.400, or a library exempt from taxation under ORS 307.090 or 307.130 , except that these exceptions do not apply to any activity prohibited by ORS 163.670. [1991 c.664 §3]

163.684 Encouraging child sexual abuse in the first degree. (1) A person commits the crime of encouraging child sexual abuse in the first degree if the person:

(a)(A) Knowingly develops, duplicates, publishes, prints, disseminates, exchanges, displays, finances, attempts to finance or sells any photograph, motion picture, videotape or other visual recording of sexually explicit conduct involving a child or possesses such matter with the intent to develop, duplicate, publish, print, disseminate, exchange, display or sell it; or

(B) Knowingly brings into this state, or causes to be brought or sent into this state, for sale or distribution, any photograph, motion picture, videotape or other visual recording of sexually explicit conduct involving a child; and

(b) Knows or is aware of and consciously disregards the fact that creation of the visual recording of sexually explicit conduct involved child abuse.

c.768 §2]

(2) Encouraging child sexual abuse in the first degree is a Class B felony. [1995

163.686 Encouraging child sexual abuse in the second degree. (1) A person commits the crime of encouraging child sexual abuse in the second degree if the person:

(a)(A)(i) Knowingly possesses or controls any photograph, motion picture, videotape or other visual recording of sexually explicit conduct involving a child for the purpose of arousing or satisfying the sexual desires of the person or another person; or 
(ii) Knowingly pays, exchanges or gives anything of value to obtain or view a photograph, motion picture, videotape or other visual recording of sexually explicit conduct involving a child for the purpose of arousing or satisfying the sexual desires of the person or another person; and

(B) Knows or is aware of and consciously disregards the fact that creation of the visual recording of sexually explicit conduct involved child abuse; or

(b)(A) Knowingly pays, exchanges or gives anything of value to observe sexually explicit conduct by a child or knowingly observes, for the purpose of arousing or gratifying the sexual desire of the person, sexually explicit conduct by a child; and

(B) Knows or is aware of and consciously disregards the fact that the conduct constitutes child abuse.

(2) Encouraging child sexual abuse in the second degree is a Class C felony. [1995 c.768 §3]

163.687 Encouraging child sexual abuse in the third degree. (1) A person commits the crime of encouraging child sexual abuse in the third degree if the person:

(a)(A)(i) Knowingly possesses or controls any photograph, motion picture, videotape or other visual recording of sexually explicit conduct involving a child for the purpose of arousing or satisfying the sexual desires of the person or another person; or

(ii) Knowingly pays, exchanges or gives anything of value to obtain or view a photograph, motion picture, videotape or other visual recording of sexually explicit conduct involving a child for the purpose of arousing or satisfying the sexual desires of the person or another person; and

(B) Knows or fails to be aware of a substantial and unjustifiable risk that the creation of the visual recording of sexually explicit conduct involved child abuse; or

(b)(A) Knowingly pays, exchanges or gives anything of value to observe sexually explicit conduct by a child or knowingly observes, for the purpose of arousing or gratifying the sexual desire of the person, sexually explicit conduct by a child; and

(B) Knows or fails to be aware of a substantial and unjustifiable risk that the conduct constitutes child abuse.

(2) Encouraging child sexual abuse in the third degree is a Class A misdemeanor. [1995 c.768 §3a]

163.688 Possession of materials depicting sexually explicit conduct of a child in the first degree. (1) A person commits the crime of possession of materials depicting sexually explicit conduct of a child in the first degree if the person:

(a) Knowingly possesses any visual depiction of sexually explicit conduct involving a child or any visual depiction of sexually explicit conduct that appears to involve a child; and

(b) Uses the visual depiction to induce a child to participate or engage in sexually explicit conduct.

(2) Possession of materials depicting sexually explicit conduct of a child in the first degree is a Class B felony. [1997 c.719 §3]

163.689 Possession of materials depicting sexually explicit conduct of a child in the second degree. (1) A person commits the crime of possession of materials depicting sexually explicit conduct of a child in the second degree if the person:

(a) Knowingly possesses any visual depiction of sexually explicit conduct involving a child or any visual depiction of sexually explicit conduct that appears to involve 
a child; and

(b) Intends to use the visual depiction to induce a child to participate or engage in sexually explicit conduct.

(2) Possession of materials depicting sexually explicit conduct of a child in the second degree is a Class C felony. [1997 c.719 §4]

163.690 Lack of knowledge of age of child as affirmative defense. It is an affirmative defense to any prosecution under ORS 163.684, 163.686, 163.687 or 163.693 that the defendant, at the time of engaging in the conduct prohibited therein, did not know and did not have reason to know that the relevant sexually explicit conduct involved a child. [1985 c.557 §7; 1987 c.864 §13; 1991 c.664 §9; 1995 c.768 §6]

\section{KIDNAPPING AND RELATED OFFENSES}

163.215 Definitions for ORS 163.215 to 163.257. As used in ORS 163.215 to 163.257, unless the context requires otherwise:

(1) "Without consent" means that the taking or confinement is accomplished by force, threat or deception, or, in the case of a person under 16 years of age or who is otherwise incapable of giving consent, that the taking or confinement is accomplished without the consent of the lawful custodian of the person.

(2) "Lawful custodian" means a parent, guardian or other person responsible by authority of law for the care, custody or control of another.

(3) "Relative" means a parent, ancestor, brother, sister, uncle or aunt. [1971 c.743 §97]

163.225 Kidnapping in the second degree. (1) A person commits the crime of kidnapping in the second degree if, with intent to interfere substantially with another's personal liberty, and without consent or legal authority, the person:

(a) Takes the person from one place to another; or

found.

(b) Secretly confines the person in a place where the person is not likely to be

(2) It is a defense to a prosecution under subsection (1) of this section if:

(a) The person taken or confined is under 16 years of age;

(b) The defendant is a relative of that person; and

(c) The sole purpose of the person is to assume control of that person.

(3) Kidnapping in the second degree is a Class B felony. [1971 c.743 §98; 2005 c. $22 \S 111]$

163.235 Kidnapping in the first degree. (1) A person commits the crime of kidnapping in the first degree if the person violates ORS 163.225 with any of the following purposes:

(a) To compel any person to pay or deliver money or property as ransom;

(b) To hold the victim as a shield or hostage;

(c) To cause physical injury to the victim; or

(d) To terrorize the victim or another person.

(2) Kidnapping in the first degree is a Class A felony. [1971 c.743 §99; 2005 c.22 
167.012 Promoting prostitution. (1) A person commits the crime of promoting prostitution if, with intent to promote prostitution, the person knowingly:

(a) Owns, controls, manages, supervises or otherwise maintains a place of prostitution or a prostitution enterprise; or

(b) Induces or causes a person to engage in prostitution or to remain in a place of prostitution; or

(c) Receives or agrees to receive money or other property, other than as a prostitute being compensated for personally rendered prostitution services, pursuant to an agreement or understanding that the money or other property is derived from a prostitution activity; or

(d) Engages in any conduct that institutes, aids or facilitates an act or enterprise of prostitution.

(2) Promoting prostitution is a Class C felony. [1971 c.743 §251]

167.017 Compelling prostitution. (1) A person commits the crime of compelling prostitution if the person knowingly:

(a) Uses force or intimidation to compel another to engage in prostitution; or

(b) Induces or causes a person under 18 years of age to engage in prostitution; or

(c) Induces or causes the spouse, child or stepchild of the person to engage in prostitution.

(2) Compelling prostitution is a Class B felony. [1971 c.743 §252] 


\section{Appendix B: \\ Residency Restriction Zones}

Residency Restriction Zones

\begin{tabular}{|c|c|c|c|c|}
\hline$\underline{\text { State }}$ & \multicolumn{3}{|c|}{ Citation } & $\begin{array}{r}\text { Year } \\
\text { Enacted } \\
\end{array}$ \\
\hline 1 Alabama & $2,000 \mathrm{ft} /$ & school, child care facility & Ala. Code $\S 15-20-26$ & 2005 \\
\hline 2 Arizona & $1,000 \mathrm{ft} /$ & school, childcare facility for level & $\begin{array}{l}\text { A.R.S. Title 13, } \\
\text { Chapter } 37 \text { 13-3726 }\end{array}$ & 2007 \\
\hline 3 Arkansas & $2,000 \mathrm{ft} /$ & school, day care center & Ark. Code Ann $\S 5-14-128$ & 2003 \\
\hline 4 California & $2,000 \mathrm{ft} /$ & school, park, where children gather & Cal. Penal Code $\S 3003.5$ & 2006 \\
\hline 5 Florida & $1,000 \mathrm{ft} /$ & where children gather & Fla. Stat. ch. 948.30 & 2003 \\
\hline 6 Georgia & $1,000 \mathrm{ft} /$ & where children gather & Ga. Code Ann. $\S 42-1-15$ & 2006 \\
\hline 7 Idaho & $500 \mathrm{ft} /$ & school with children under 18 & Idaho Code $\$ 18-8329$ & 2006 \\
\hline 8 Illinois & $500 \mathrm{ft} /$ & school 720 & Ill. Comp. Stat. 5/11-9.4 & 2006 \\
\hline 9 Indiana & $1,000 \mathrm{ft} /$ & school, park, youth program center & Ind. Code $\S 35-42-4-11$ & 2006 \\
\hline 10 Iowa & $2,000 \mathrm{ft} /$ & school, child care facility & Iowa Code $\S 692 \mathrm{~A} .2 \mathrm{~A}$ & 2002 \\
\hline 11 Kentucky & $1,000 \mathrm{ft} /$ & $\begin{array}{l}\text { school, child care facility, } \\
\text { playground, ball field }\end{array}$ & Ky. Rev. Stat. $§ 17.545$ & 2006 \\
\hline 12 Louisiana & $1,000 \mathrm{ft} /$ & $\begin{array}{l}\text { school, related activities, } \\
\text { school buses }\end{array}$ & La. Rev. Stat. Ann. § 14:91.1 2006 & \\
\hline 13 Maryland & & $\begin{array}{l}\text { Parole Commission restricts } \\
\text { where feasible }\end{array}$ & $\begin{array}{l}\text { Md. Code Ann., Crim. } \\
\text { Procedure } § 11-724\end{array}$ & 2006 \\
\hline $\begin{array}{l}14 \text { Michigan } \\
15 \text { Minnesota }\end{array}$ & $1,000 \mathrm{ft} /$ & $\begin{array}{l}\text { school (student safety zone) Mich. } \\
\text { End-of-Confinement }\end{array}$ & omp. Laws $\S \S 28.733-735$ & 2006 \\
\hline & & Review Committee decides & at. Ann. § 244.0521996 & \\
\hline 16 Mississippi & $1,500 \mathrm{ft} /$ & school, child care facility & Miss. Code Ann. $\S 45-33-252006$ & \\
\hline 17 Missouri & $1,000 \mathrm{ft} /$ & school, child care facility & Mo. Rev. Stat. § 566.147 & 2006 \\
\hline 18 Montana & & Judge decides & Mont. Code Ann. $§ 46-18-255$ & 2001 \\
\hline $\begin{array}{l}19 \text { Nebraska } \\
20 \text { New Mexico }\end{array}$ & $500 \mathrm{ft} /$ & $\begin{array}{l}\text { school, child care facility } \\
\text { School/day care center in } 1 \text { mile }\end{array}$ & Neb. Rev. Stat. $§ 29-4017$ & 2006 \\
\hline & & radius contacted & N.N & 2000 \\
\hline 21 Ohio & $1,000 \mathrm{ft} /$ & $\begin{array}{l}\text { school, child care facility } \\
\text { where children gather }\end{array}$ & Ohio Rev. Code Ann. $\S 2950.031$ & 2003 \\
\hline 22 Oklahoma & $2,000 \mathrm{ft} /$ & school, day care center, park & Okla. Stat. tit. $57 \S 590$ & 2006 \\
\hline 23 Oregon & & Department of Corrections decides & Or. Rev. Stat. $\S \S 144.642,144.644$ & 2001 \\
\hline 24 South Dakota & $500 \mathrm{ft} /$ & community safety zones & $\begin{array}{l}\text { S.D. Codified Laws } \\
\S \S 22-24 \mathrm{~B}-22,23,24\end{array}$ & 2006 \\
\hline 25 Tennessee & $1,000 \mathrm{ft} /$ & school, child care facility, victim & Tenn. Code Ann. $\S 40-39-211$ & 2004 \\
\hline 26 Texas & & Distance specified by Parole Board & Tex. Gov’t Code Ann. $\S 508.187$ & 1997 \\
\hline 27 Virginia & $100 \mathrm{ft} /$ & school, child care center & Va. Code Ann. § 18.2-370.2 2000 & \\
\hline 28 Washington & $880 \mathrm{ft} /$ & school, day care center & $\begin{array}{l}\text { Wash. Rev. Code } \\
\S \S 9.94 \text { A.030, 9.94A.712 }\end{array}$ & 2006 \\
\hline 29 West Virginia & $1,000 \mathrm{ft} /$ & school, child care facility & W. Va. Code $\S 62-12-26$ & 2006 \\
\hline
\end{tabular}

Source: The Council of State Government retrieved from

http://www.csg.org/policy/pubsafety/documents/ResidencyRestrictionLaws.pdf 


\title{
Appendix C: Charge List
}

\author{
1. Rape III \\ 2. Rape II \\ 3. Rape I \\ 4. Sodomy III \\ 5. Sodomy II \\ 6. Sodomy I \\ 7. Sexual Penetration II \\ 8. Sexual Penetration I \\ 9. Sexual Abuse III \\ 10. Sexual Abuse II \\ 11. Sexual Abuse I \\ 12. Online Sexual Corruption of a Child II \\ 13. Online Sexual Corruption of a Child I \\ 14. Contributing to Sexual Delinquency of a Minor \\ 15. Sexual Misconduct \\ 16. Custodial Sexual Misconduct I \\ 17. Custodial Sexual Misconduct II \\ 18. Public Indecency \\ 19. Private Indecency \\ 20. Unlawful Location where Children Congregate \\ 21. Unlawful Contact with Child \\ 22. Harassment/Touch of an Intimate Part \\ 23. Criminal Mischief I \\ 24. Attempted Sodomy I \\ 25. Theft III \\ 26. Failure to Report as Sex Offender - Misdemeanor \\ 27. Failure to Report as Sex Offender - Felony \\ 28. Attempted B/E - Felony \\ 29. Attempted Sexual Penetration II \\ 30. Harassment A \\ 31. Assault IV - Misdemeanor \\ 32. Criminal Mischief II \\ 33. Criminal Mischief III \\ 34. Burglary I \\ 35. Burglary II \\ 36. Burglary III \\ 37. Incest \\ 38. Parole Violation \\ 39. Assault I \\ 40. Attempted Rape \\ 41. Concealed Weapon - Misdemeanor
}


42. Theft II

43. Attempted Sodomy I

44. Arson I

45. Attempted Sexual Penetration I

46. Theft I

47. Attempted Sexual Abuse

48. Assault III

49. MIP

50. Trespassing

51. Larceny

52. Coercion

53. Drug Dealing

54. Drug Possession

55. Driving without a license

56. Grand Theft Auto

57. Bomb Making/Explosives

58. Unlawful use of a weapon

59. Measure 11

60. Vandalism

61. Unlawful penetration

62. Child abuse

63. Luring a Minor

64. Kidnapping

65. Resisting Arrest

66. Disorderly Conduct

67. Manslaughter

68. Attempted Murder

69. Assault II

70. DUII

71. Attempted Robbery I

72. Riot

73. Unlawful Entry

74. Robbery

75. Threatening to Kill

76. Robbery II

77. NA

78. Possession of A firearm (Misdemeanor)

79. Menacing

80. Unlawful use of a deadly weapon

81. Arson II

82. Reckless Burning

83. Attempted Aggravated Murder

84. Robbery I with a firearm

85. Endangerment to Others 
86. Attempted Arson

87. SA I (Sexual Assault I)

88. NA

89. Identity Theft

90. Fraud (use of a credit card)

91. Assault with a weapon

92. Kidnapping II

93. Escape III

94. Robbery III

95. Physical Harassment

96. Discharge of a firearm

97. Tampering of a witness

98. Unlawful entry of a motor vehicle

99. n/a (used for missing variable)

100. Warrant for arrest

101. Running away

102. Attempted Burglary

103. Attempted assault I

104. Unlawful use of a motor vehicle

105. Fighting

106. Assaulting a public safety officer

107. Possession of a deadly weapon

108. Recklessly endangering another

109. Unlawful use of a firearm 


\section{Appendix D:}

\section{Cover Sheet: JSO}

Please write in the total number of children you have sexually abused who were related to you and/or lived with you and were:

1. older than 12 years old

3. older than 12 years old
2. Males

4. Females

Please write in the total number of children you sexually abused who were NOT related to you and NOT living with you and were:

5. older than 12 years old Males younger than 12 years old

7. older than 12 years old
6. Males

8. Females

\section{STOP HERE! PLEASE RAISE YOUR HAND!}

A research assistant will check your answers to these questions to help you determine who you will fill out the rest of the IMOQ for. Please do not turn the page until a research assistant tells you to do so.

\section{THE GROUP WITH THE MOST CONTACT:}

Please answer the following questions for the year leading up to the last time you sexually abused a child.

The year I'm reporting on is from to 
Cover Sheet: JD

Please answer the following questions for the year leading up to the last time you were incarcerated.

The year I'm reporting on is from to 


\section{Appendix E:}

\section{DEMOGRAPHICS (FORM JSO)}

This questionnaire will help us know more about you. The questions give us general information about you. They also ask about your history. The directions are at the beginning of each section. If you have any questions, please raise your hand.

QUESTIONS ABOUT YOU

\begin{tabular}{|c|c|}
\hline A-1 & How old are you? \\
\hline A-2 & Which sex are you? (circle one) FEMALE MALE \\
\hline A-3 & $\begin{array}{l}\text { What is your current marital status? (check }[\checkmark \text { ] one) } \\
\text { [ ] Never been married [ ] Married } \\
\text { [ ] Divorced [ ] Separated } \\
\text { [ ] Widow }\end{array}$ \\
\hline A-4 & 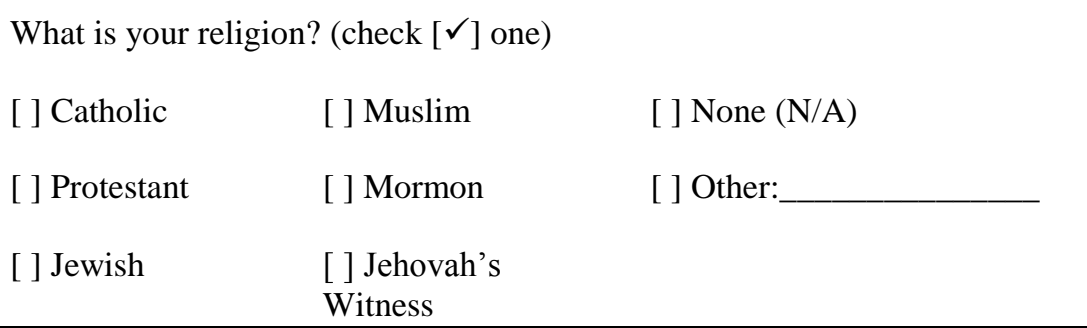 \\
\hline A-5 & $\begin{array}{l}\text { Did you graduate from high school or get your G.E.D? (circle one) YES NO } \\
\text { If no, what is the highest grade you completed? }\end{array}$ \\
\hline A-6 & $\begin{array}{l}\text { Are you still going to school? (circle one) YES NO } \\
\text { If yes, which grade of high school or year of college? (check [ } \checkmark \text { cone) } \\
\text { [ ] } 9^{\text {th }} \text { grade high school [ ] } 11^{\text {th }} \text { grade high school [ ] } 1^{\text {st }} \text { year college } \\
\text { [ ] } 10^{\text {th }} \text { grade high school [ ] } 12^{\text {th }} \text { grade high school [ ] } 2^{\text {nd }} \text { year college }\end{array}$ \\
\hline
\end{tabular}




\begin{tabular}{|c|c|c|c|}
\hline A-7 & \multicolumn{3}{|c|}{$\begin{array}{l}\text { Did you attend vocational or technical school? (circle one) YES NO } \\
\text { If yes, how many years? }\end{array}$} \\
\hline A - 8 & $\begin{array}{l}\text { What is the highest gr } \\
\text { [ ] Grade School } \\
\text { [ ] Middle School } \\
\text { [ ] Some High Schoc }\end{array}$ & $\begin{array}{r}\text { e your female caregive } \\
\text { [ ] High Schoo } \\
\text { Graduate or G } \\
\text { [ ] Some Colle } \\
\text { [ ] College }\end{array}$ & $\begin{array}{l}\text { completed in school? (check }[\checkmark] \text { one) } \\
\text { D. } \\
\text { [ ] Graduate School } \\
\text { [ ] Vocational or } \\
\text { Technical School }\end{array}$ \\
\hline A - 9 & \multicolumn{3}{|c|}{$\begin{array}{lll}\text { [ ] Grade School } & \begin{array}{l}\text { [ ] High School } \\
\text { Graduate or G.E.D. }\end{array} & \text { [ ] Graduate School } \\
\text { [ ] Middle School } & \text { [ ] Some College } & \text { [ ] Vocational or } \\
& & \text { Technical School }\end{array}$} \\
\hline A-10 & $\begin{array}{l}\text { What was your job be } \\
\text { [] Student } \\
\text { [] Homemaker }\end{array}$ & $\begin{array}{l}\text { [ ] Professional } \\
\text { (for } \\
\text { example, a } \\
\text { teacher) } \\
\text { ara-professional (for } \\
\text { nple, a secretary) }\end{array}$ & $\begin{array}{l}\text { (check }[\checkmark \text { one) } \\
\text { ctail (for example, a } \\
\quad \text { [ ] Laborer (for example, a } \\
\quad \text { construction worker) }\end{array}$ \\
\hline A-11 & $\begin{array}{l}\text { What was your (yearly } \\
\text { [] Less than } \\
\$ 10,000 \\
\text { [] } \$ 10,001-\$ 15,000 \\
\text { [] } \$ 15,001-\$ 20,000 \\
\text { [] } \$ 20,001-\$ 25,000\end{array}$ & $\begin{array}{l}\text { family income before y } \\
\text { [ ] } \$ 25,001-\$ 30,000 \\
\text { [ ] } \$ 30,001-\$ 35,000 \\
\text { [ ] } \$ 35,001-\$ 40,000 \\
\text { [ ] } \$ 40,001-\$ 45,000\end{array}$ & $\begin{array}{l}\text { were incarcerated? (check [ } \checkmark \text { ] one) } \\
\text { [ ] } \$ 45,001-\$ 50,000 \\
\text { [ ] } \$ 50,001-\$ 55,000 \\
\text { [ ] } \$ 55,001-\$ 60,000 \\
\text { [ ] More than } \$ 60,000 \\
\text { [] Don't know }\end{array}$ \\
\hline
\end{tabular}




\section{QUESTIONS ABOUT YOUR CULTURAL OR ETHNIC BACKGROUND}

In this country, people come from a lot of different cultures. There are many words to describe the different ethnic groups that people come from. Some names of ethnic groups are Mexican-

American, Hispanic, Black, Asian-American, American-Indian, Anglo-American, and White.

Every person is born into an ethnic group. People differ on how they feel about their ethnicity.

These questions are about your ethnic group and how you feel about it.

B-1 a) Were you born in the United States? (circle one) YES NO

b) If no, which country were you born in?

c) How long have you lived in the United States? years

B-2 My ethnicity is: (check $[\checkmark]$ one)
[ ] Asian, Asian-American, or Oriental
[ ] Black or African-American
[ ] Hispanic or Latino
[ ] White, Caucasian, European (not Hispanic)
[] American-Indian
[ ] Mixed (parents are from two different groups)
[ ] Other:

B-3 a) Was your mother born in the United States? (circle one) YES NO

b) If no, which country was she born in?

c) How long has she lived in the United States? years

B-4 Her ethnicity is: (check $[\checkmark]$ one)
[ ] Asian, Asian-American, or Oriental
[ ] Black or African-American
[ ] Hispanic or Latino
[ ] White, Caucasian, European (not Hispanic)
[ ] American-Indian
[ ] Mixed (parents are from two different groups)
[ ] Other:

B-5 a) Was your father born in the United States? (circle one) YES NO

b) If no, which country was he born in?

c) How long has he lived in the United States? years 


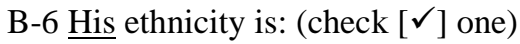

\author{
[ ] Asian, Asian-American, or Oriental \\ [ ] Black or African-American \\ [ ] Hispanic or Latino \\ [ ] White, Caucasian, European (not Hispanic) \\ [ ] American-Indian \\ [ ] Mixed (parents are from two different groups) \\ [ ] Other:
}




\section{QUESTIONS ABOUT YOUR OFFENSE HISTORY}

G-1 How many times have you been arrested for non-sexual charges?

G-2 How old were you the first time you were arrested for non-sexual charges?

G-3 On what non-sexual legal charge(s) were you most recently convicted?

G-4 How old were you the first time you sexually abused someone, even if you were not caught for that offense (like peeping, exposing yourself, obscene phone calls, etc.)?

G-5 How old were you the last time you sexually abused someone, even if you were not caught for that offense?

G-6 How many times have you been arrested on sexually-related charges?

G-7 How old were you the first time you were arrested on sexually-related charges?

G-8 What were you charged with the first time you were arrested on sexually-related charges?

G-9 On what sexually-related charge(s) were you most recently convicted?

G-10 How old were you when you first got treatment for sexual abuse?

G-11 What month and year did you come to this institution? month year

G-12 How long have you been in treatment for sexual abuse at this place?

G-13 How long have you been in treatment for sexual abuse in your lifetime?

G-14 How old were you when you first got treatment for something other than sexual abuse?

G-15 How long have you been in treatment for crimes other than sexual abuse in your lifetime? 


\section{DEMOGRAPHICS (FORM JD)}

This questionnaire will help us know more about you. The questions give us general information about you. They also ask about your history. The directions are at the beginning of each section.

If you have any questions, please raise your hand.

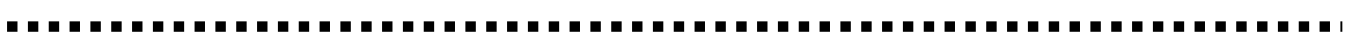

\section{QUESTIONS ABOUT YOU}

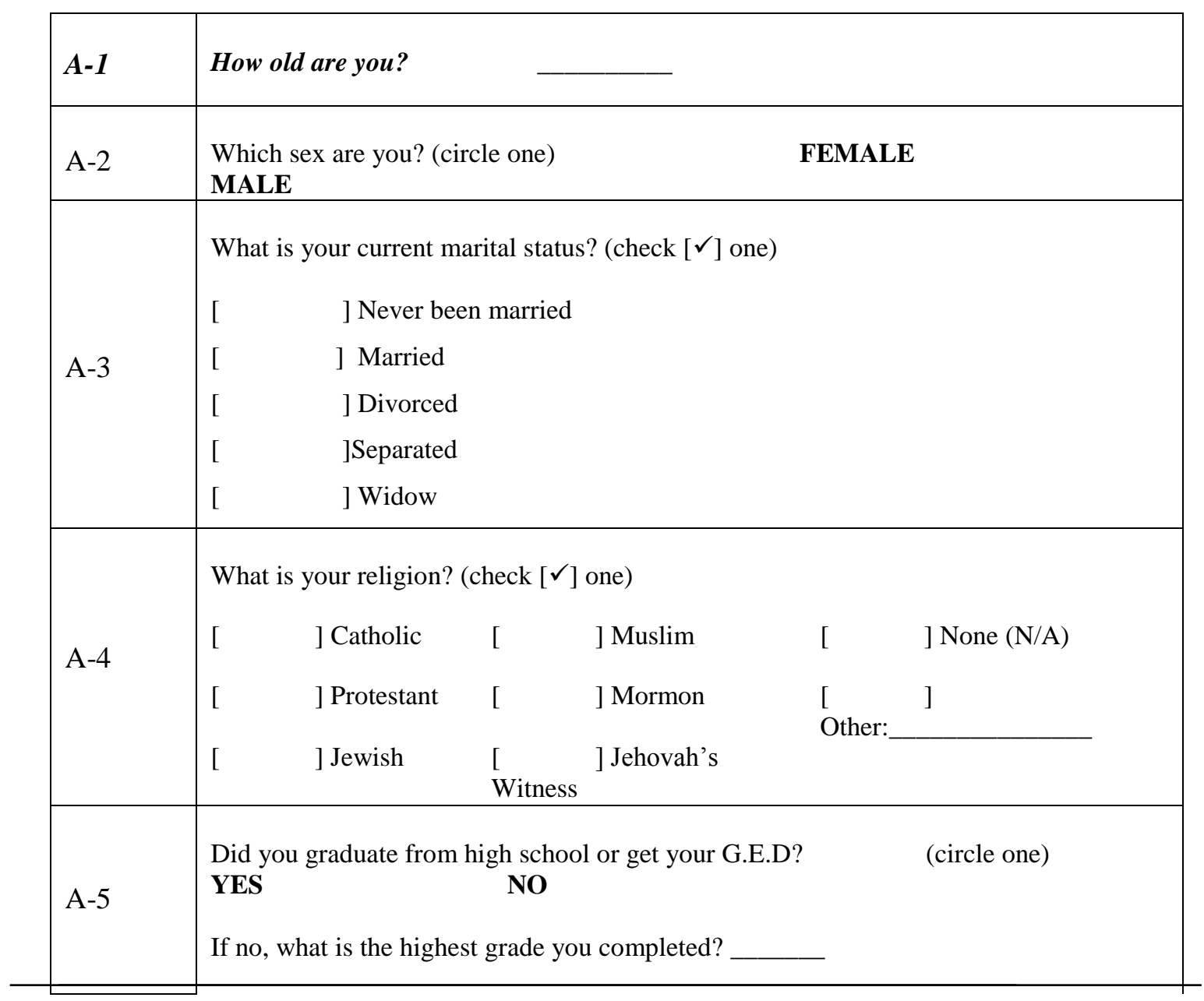




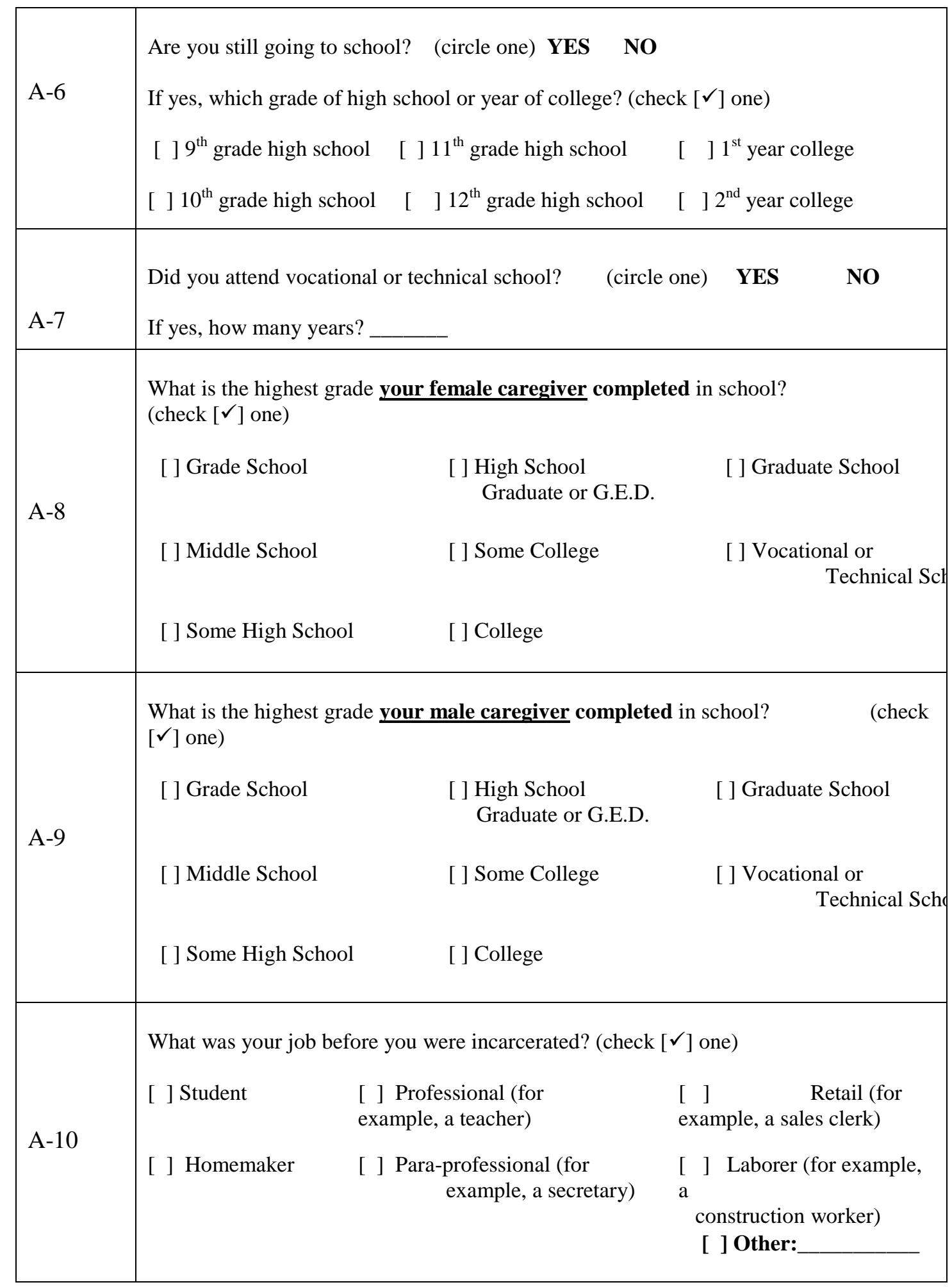




\begin{tabular}{|c|c|c|c|}
\hline \multirow{6}{*}{ A-11 } & \multicolumn{3}{|c|}{$\begin{array}{l}\text { What was your (yearly) family income before you were incarcerated? } \\
\text { (check }[\checkmark] \text { one) }\end{array}$} \\
\hline & [] Less than $\$ 10,000$ & [ ] $\$ 25,001-\$ 30,000$ & [] $\$ 45,001-\$ 50,000$ \\
\hline & [ ] ] $\$ 10,001-\$ 15,000$ & [] $\$ 30,001-\$ 35,000$ & [ ] $\$ 50,001-\$ 55,000$ \\
\hline & [ ] $\$ 15,001-\$ 20,000$ & [ ] $\$ 35,001-\$ 40,000$ & [] $\$ 55,001-\$ 60,000$ \\
\hline & [ ] $\$ 20,001-\$ 25,000$ & [] $\$ 40,001-\$ 45,000$ & [ ] More than $\$ 60,000$ \\
\hline & & & [ ] Don't know \\
\hline
\end{tabular}

\section{QUESTIONS ABOUT YOUR CULTURAL OR ETHNIC BACKGROUND}

In this country, people come from a lot of different cultures. There are many words to describe the different ethnic groups that people come from. Some names of ethnic groups are Mexican-American, Hispanic, Black, Asian-American, American-Indian, AngloAmerican, and White. Every person is born into an ethnic group. People differ on how they feel about their ethnicity. These questions are about your ethnic group and how you feel about it.

B-1 a) Were you born in the United States? (circle one) YES NO

b) If no, which country were you born in?

c) How long have you lived in the United States? years

B-2 My ethnicity is: (check $[\checkmark]$ one)

$\begin{array}{lll}{[} & ] & \text { Asian, Asian-American, or Oriental } \\ {[} & & \text { Black or African-American } \\ {[} & ] & \text { Hispanic or Latino } \\ {[} & ] & \text { White, Caucasian, European (not Hispanic) } \\ {[} & ] & \text { American-Indian } \\ {[} & ] & \text { Mixed (parents are from two different groups) } \\ {[} & \text { [ } & \text { Other: }\end{array}$

B-3 a) Was your mother born in the United States? (circle one) YES NO

b) If no, which country was she born in?

c) How long has she lived in the United States? years 


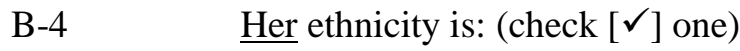

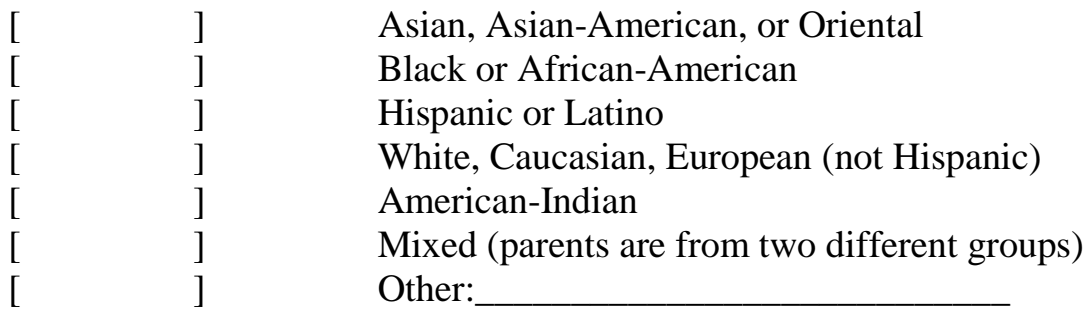

B-5 a) Was your father born in the United States? (circle one) YES NO

b) If no, which country was he born in?

c) How long has he lived in the United States? years

B-6 $\quad$ His ethnicity is: (check $[\checkmark]$ one)

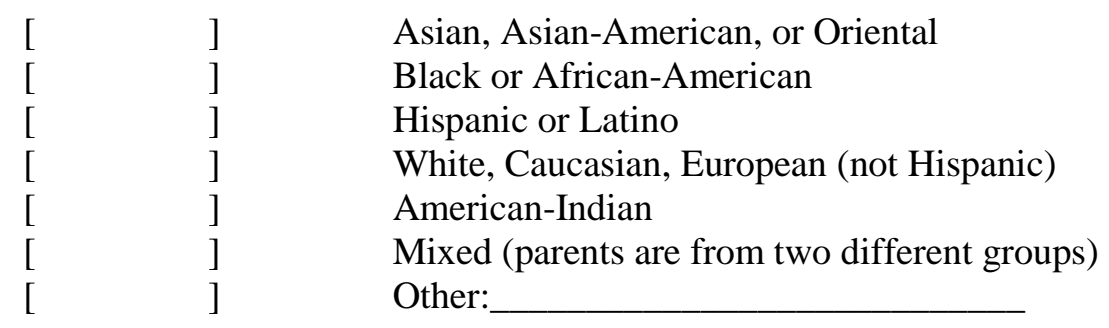




\section{Appendix F: IPPA}

The following statements ask about your feelings about your mother, female caregiver, or the person who has acted as your mother (like a step-mother, grandmother, aunt, foster mother, or female non-relative who takes care of you). If you have had more than one person acting as your mother, answer the questions for the one you feel has influenced you most or the one you have lived with the longest.

If you have never had contact with your mother or a female caregiver, please put a check here and Skip to Part 2, page 3.

Please reach each statement and circle the one number that best describes your relationship with your mother/female caregiver.

Please use the following response scale to answer the following questions:

\begin{tabular}{|c|c|c|c|c|}
\hline $\begin{array}{c}1 \\
\text { Almost } \\
\text { never or } \\
\text { never true }\end{array}$ & $\begin{array}{c}\mathbf{2} \\
\text { Not very } \\
\text { often true }\end{array}$ & $\begin{array}{c}\mathbf{3} \\
\begin{array}{c}\text { Sometimes } \\
\text { true }\end{array}\end{array}$ & $\begin{array}{c}\mathbf{4} \\
\text { Often } \\
\text { true }\end{array}$ & $\begin{array}{c}\mathbf{5} \\
\text { Almost } \\
\text { always or } \\
\text { always } \\
\text { true. }\end{array}$ \\
\hline
\end{tabular}

\begin{tabular}{|c|c|}
\hline My mother/female caregiver respects my feelings. & $\begin{array}{lllll}1 & 2 & 3 & 4 & 5\end{array}$ \\
\hline $\begin{array}{l}\text { I feel my mother/female caregiver does a good job } \\
\text { as my mother/female caregiver. }\end{array}$ & $\begin{array}{lllll}1 & 2 & 3 & 4 & 5\end{array}$ \\
\hline I wish I had a different mother/female caregiver. & $\begin{array}{lllll}1 & 2 & 3 & 4 & 5\end{array}$ \\
\hline My mother/female caregiver accepts me as I am. & $\begin{array}{lllll}1 & 2 & 3 & 4 & 5\end{array}$ \\
\hline $\begin{array}{l}\text { I like to get my mother/female caregiver's point of } \\
\text { view on things I'm concerned about. }\end{array}$ & $\begin{array}{lllll}1 & 2 & 3 & 4 & 5\end{array}$ \\
\hline $\begin{array}{l}\text { I feel it's no use letting my feelings show around } \\
\text { my mother/female caregiver. }\end{array}$ & $\begin{array}{lllll}1 & 2 & 3 & 4 & 5\end{array}$ \\
\hline $\begin{array}{l}\text { My mother/female caregiver can tell when I'm } \\
\text { upset about something. }\end{array}$ & $\begin{array}{lllll}1 & 2 & 3 & 4 & 5\end{array}$ \\
\hline $\begin{array}{l}\text { Talking over my problems with my mother/female } \\
\text { caregiver makes me feel ashamed or foolish. }\end{array}$ & $\begin{array}{lllll}1 & 2 & 3 & 4 & 5\end{array}$ \\
\hline $\begin{array}{l}\text { My mother/female caregiver expects too much } \\
\text { from me. }\end{array}$ & $\begin{array}{lllll}1 & 2 & 3 & 4 & 5\end{array}$ \\
\hline $\begin{array}{l}\text { I get upset easily around my mother/female } \\
\text { caregiver. }\end{array}$ & $\begin{array}{lllll}1 & 2 & 3 & 4 & 5\end{array}$ \\
\hline $\begin{array}{l}\text { I get upset a lot more than my mother/female } \\
\text { caregiver knows about. }\end{array}$ & $\begin{array}{lllll}1 & 2 & 3 & 4 & 5\end{array}$ \\
\hline $\begin{array}{l}\text { When we discuss things, my mother/female } \\
\text { caregiver cares about my point of view. }\end{array}$ & $\begin{array}{lllll}1 & 2 & 3 & 4 & 5\end{array}$ \\
\hline
\end{tabular}

\section{Please use the following response scale to answer the following questions:}




\begin{tabular}{|c|c|c|c|c|}
\hline $\mathbf{1}$ & $\mathbf{2}$ & $\mathbf{3}$ & $\mathbf{4}$ & $\mathbf{5}$ \\
$\begin{array}{c}\text { Almost } \\
\text { never or } \\
\text { never true }\end{array}$ & $\begin{array}{c}\text { Not very } \\
\text { often true }\end{array}$ & $\begin{array}{c}\text { Sometimes } \\
\text { true }\end{array}$ & $\begin{array}{c}\text { Often } \\
\text { true }\end{array}$ & $\begin{array}{c}\text { Almost } \\
\text { always or } \\
\text { always true. }\end{array}$ \\
\hline
\end{tabular}

\begin{tabular}{|c|c|}
\hline My mother/female caregiver trusts my judgment. & $\begin{array}{lllll}1 & 2 & 3 & 4 & 5\end{array}$ \\
\hline $\begin{array}{l}\text { My mother/female caregiver has her own } \\
\text { problems, so I don't bother her with mine. }\end{array}$ & $\begin{array}{lllll}1 & 2 & 3 & 4 & 5 \\
\end{array}$ \\
\hline $\begin{array}{l}\text { My mother/female caregiver helps me understand } \\
\text { myself better. }\end{array}$ & $\begin{array}{lllll}1 & 2 & 3 & 4 & 5 \\
\end{array}$ \\
\hline $\begin{array}{l}\text { I tell my mother/female caregiver about my } \\
\text { problems and troubles. }\end{array}$ & $\begin{array}{lllll}1 & 2 & 3 & 4 & 5\end{array}$ \\
\hline I feel angry with my mother/female caregiver. & $\begin{array}{lllll} & 2 & 3 & 4 & 5\end{array}$ \\
\hline $\begin{array}{l}\text { I don't get much attention from my mother/female } \\
\text { caregiver. }\end{array}$ & $\begin{array}{lllll}1 & 2 & 3 & 4 & 5\end{array}$ \\
\hline $\begin{array}{l}\text { My mother/female caregiver helps me talk about } \\
\text { my difficulties. }\end{array}$ & $\begin{array}{lllll}1 & 2 & 3 & 4 & 5\end{array}$ \\
\hline My mother/female caregiver understands me. & $\begin{array}{lllll}1 & 2 & 3 & 4 & 5\end{array}$ \\
\hline $\begin{array}{l}\text { When I am angry about something, my } \\
\text { mother/female caregiver tries to be understanding. }\end{array}$ & $\begin{array}{lllll}1 & 2 & 3 & 4 & 5\end{array}$ \\
\hline I trust my mother/female caregiver. & $\begin{array}{lllll}1 & 2 & 3 & 4 & 5\end{array}$ \\
\hline $\begin{array}{l}\text { My mother/female caregiver doesn't understand } \\
\text { what I'm going through these days. }\end{array}$ & $\begin{array}{lllll}1 & 2 & 3 & 4 & 5\end{array}$ \\
\hline $\begin{array}{l}\text { I can count on my mother/female caregiver when I } \\
\text { need to get something off my chest. }\end{array}$ & $\begin{array}{lllll}1 & 2 & 3 & 4 & 5\end{array}$ \\
\hline $\begin{array}{l}\text { If my mother/female caregiver knows something } \\
\text { is bothering me, she asks me about it. }\end{array}$ & $\begin{array}{lllll}1 & 2 & 3 & 4 & 5\end{array}$ \\
\hline
\end{tabular}


The following statements ask about your feelings about your father, male caregiver, or the person who has acted as your father (like a step-father, grandfather, uncle, foster father, or male non-relative who takes care of you). If you have had more than one person acting as your father, answer the questions for the one you feel has influenced you most or the one you have lived with the longest.

If you have never had contact with your father or a male caregiver, please put a check here and skip to part 3 .

Please use the following response scale to answer the following questions:

\begin{tabular}{|c|c|c|c|c|}
\hline $\begin{array}{c}\text { Almost never or } \\
\text { never true }\end{array}$ & $\begin{array}{c}\mathbf{2} \\
\text { Not very } \\
\text { often true }\end{array}$ & $\begin{array}{c}\text { Sometimes } \\
\text { true }\end{array}$ & $\begin{array}{c}\mathbf{4} \\
\text { Often } \\
\text { true }\end{array}$ & $\begin{array}{c}\text { Almost always or } \\
\text { always true. }\end{array}$ \\
\hline
\end{tabular}

\begin{tabular}{|c|c|}
\hline My father/male caregiver respects my feelings. & $\begin{array}{lllll}1 & 2 & 3 & 4 & 5\end{array}$ \\
\hline $\begin{array}{l}\text { I feel my father/male caregiver does a good job as my } \\
\text { father/male caregiver. }\end{array}$ & \begin{tabular}{lllll|}
1 & 2 & 3 & 4 & 5 \\
\end{tabular} \\
\hline I wish I had a different father/male caregiver. & $\begin{array}{lllll}1 & 2 & 3 & 4 & 5\end{array}$ \\
\hline My father/male caregiver accepts me as I am. & $\begin{array}{lllll}1 & 2 & 3 & 4 & 5\end{array}$ \\
\hline $\begin{array}{l}\text { I like to get my father/male caregiver's point of view } \\
\text { on things I'm concerned about. }\end{array}$ & $\begin{array}{lllll}1 & 2 & 3 & 4 & 5 \\
\end{array}$ \\
\hline $\begin{array}{l}\text { I feel it's no use letting my feelings show around my } \\
\text { father/male caregiver. }\end{array}$ & $\begin{array}{lllll}1 & 2 & 3 & 4 & 5\end{array}$ \\
\hline $\begin{array}{l}\text { My father/male caregiver can tell when I'm upset } \\
\text { about something. }\end{array}$ & $\begin{array}{lllll}1 & 2 & 3 & 4 & 5\end{array}$ \\
\hline $\begin{array}{l}\text { Talking over my problems with my father/male } \\
\text { caregiver makes me feel ashamed or foolish. }\end{array}$ & $\begin{array}{lllll}\mathbf{1} & \mathbf{2} & \mathbf{3} & \mathbf{4} & \mathbf{5}\end{array}$ \\
\hline My father/male caregiver expects too much from me. & $\begin{array}{lllll}1 & 2 & 3 & 4 & 5\end{array}$ \\
\hline I get upset easily around my father/male caregiver. & $\begin{array}{lllll}1 & 2 & 3 & 4 & 5\end{array}$ \\
\hline $\begin{array}{l}\text { I get upset a lot more than my father/male caregiver } \\
\text { knows about. }\end{array}$ & $\begin{array}{lllll}1 & 2 & 3 & 4 & 5\end{array}$ \\
\hline $\begin{array}{l}\text { When we discuss things, my father/male caregiver } \\
\text { cares about my point of view. }\end{array}$ & $\begin{array}{lllll}1 & 2 & 3 & 4 & 5\end{array}$ \\
\hline My father/male caregiver trusts my judgment. & $\begin{array}{lllll}1 & 2 & 3 & 4 & 5\end{array}$ \\
\hline $\begin{array}{l}\text { My father/male caregiver has her own problems, so I } \\
\text { don't bother her with mine. }\end{array}$ & $\begin{array}{lllll}1 & 2 & 3 & 4 & 5\end{array}$ \\
\hline $\begin{array}{l}\text { My father/male caregiver helps me understand myself } \\
\text { better. }\end{array}$ & $\begin{array}{lllll}1 & 2 & 3 & 4 & 5\end{array}$ \\
\hline
\end{tabular}


Please use the following response scale to answer the following questions:

\begin{tabular}{|c|c|c|c|c|}
\hline $\mathbf{1}$ & $\mathbf{2}$ & $\mathbf{3}$ & $\mathbf{4}$ & $\mathbf{5}$ \\
$\begin{array}{c}\text { Almost never } \\
\text { or never true }\end{array}$ & $\begin{array}{c}\text { Not very often } \\
\text { true }\end{array}$ & $\begin{array}{c}\text { Sometimes } \\
\text { true }\end{array}$ & $\begin{array}{c}\text { Often } \\
\text { true }\end{array}$ & $\begin{array}{c}\text { Almost always or } \\
\text { always true. }\end{array}$ \\
\hline
\end{tabular}

\begin{tabular}{|c|c|}
\hline $\begin{array}{l}\text { I tell my father/male caregiver about my problems and } \\
\text { troubles. }\end{array}$ & $\begin{array}{lllll}1 & 2 & 3 & 4 & 5\end{array}$ \\
\hline I feel angry with my father/male caregiver. & $\begin{array}{lllll}1 & 2 & 3 & 4 & 5\end{array}$ \\
\hline $\begin{array}{l}\text { I don't get much attention from my father/male } \\
\text { caregiver. }\end{array}$ & $\begin{array}{lllll}1 & 2 & 3 & 4 & 5\end{array}$ \\
\hline $\begin{array}{l}\text { My father/male caregiver helps me talk about my } \\
\text { difficulties. }\end{array}$ & $\begin{array}{lllll}1 & 2 & 3 & 4 & 5\end{array}$ \\
\hline My father/male caregiver understands me. & $\begin{array}{lllll}1 & 2 & 3 & 4 & 5\end{array}$ \\
\hline $\begin{array}{l}\text { When I am angry about something, my father/male } \\
\text { caregiver tries to be understanding. }\end{array}$ & $\begin{array}{lllll}1 & 2 & 3 & 4 & 5\end{array}$ \\
\hline I trust my father/male caregiver. & $\begin{array}{lllll}1 & 2 & 3 & 4 & 5\end{array}$ \\
\hline $\begin{array}{l}\text { My father/male caregiver doesn't understand what I'm } \\
\text { going through these days. }\end{array}$ & $\begin{array}{lllll}1 & 2 & 3 & 4 & 5\end{array}$ \\
\hline $\begin{array}{l}\text { I can count on my father/male caregiver when I need } \\
\text { to get something off my chest. }\end{array}$ & $\begin{array}{lllll}1 & 2 & 3 & 4 & 5\end{array}$ \\
\hline $\begin{array}{l}\text { If my father/male caregiver knows something is } \\
\text { bothering me, she asks me about it. }\end{array}$ & $\begin{array}{lllll}1 & 2 & 3 & 4 & 5\end{array}$ \\
\hline
\end{tabular}


The following statements ask about feelings and relationships with your close friends.

Please read each statement and circle the ONE number that describes your relationship with your close friends the last time you were with these people.

Please use the following response scale to answer the following questions:

\begin{tabular}{|c|c|c|c|c|}
\hline $\mathbf{1}$ & $\mathbf{2}$ & $\mathbf{3}$ & $\mathbf{4}$ & $\mathbf{5}$ \\
$\begin{array}{c}\text { Almost never } \\
\text { or never true }\end{array}$ & $\begin{array}{c}\text { Not very often } \\
\text { true }\end{array}$ & $\begin{array}{c}\text { Sometimes } \\
\text { true }\end{array}$ & $\begin{array}{c}\text { Often } \\
\text { true }\end{array}$ & $\begin{array}{c}\text { Almost always or } \\
\text { always true. }\end{array}$ \\
\hline
\end{tabular}

\begin{tabular}{|c|c|}
\hline $\begin{array}{l}\text { I like to get my friends' point of view on things I'm } \\
\text { concerned about. }\end{array}$ & $\begin{array}{lllll}1 & 2 & 3 & 4 & 5\end{array}$ \\
\hline My friends can tell when I'm upset about something. & $\begin{array}{lllll}1 & 2 & 3 & 4 & 5\end{array}$ \\
\hline $\begin{array}{l}\text { When we discuss things, my friends care about my } \\
\text { point of view. }\end{array}$ & $\begin{array}{lllll}1 & 2 & 3 & 4 & 5\end{array}$ \\
\hline $\begin{array}{l}\text { Talking over my problems with friends makes me feel } \\
\text { ashamed or foolish. }\end{array}$ & $\begin{array}{lllll}1 & 2 & 3 & 4 & 5\end{array}$ \\
\hline I wish I had different friends. & $\begin{array}{lllll}1 & 2 & 3 & 4 & 5\end{array}$ \\
\hline My friends understand me & $\begin{array}{lllll}1 & 2 & 3 & 4 & 5\end{array}$ \\
\hline My friends encourage me to talk about my difficulties. & $\begin{array}{lllll}1 & 2 & 3 & 4 & 5\end{array}$ \\
\hline My friends accept me as I am. & $\begin{array}{lllll}1 & 2 & 3 & 4 & 5\end{array}$ \\
\hline $\begin{array}{l}\text { I feel the need to be in touch with my friends more } \\
\text { often. }\end{array}$ & $\begin{array}{lllll}1 & 2 & 3 & 4 & 5\end{array}$ \\
\hline $\begin{array}{l}\text { My friends don't understand what I'm going through } \\
\text { these days. }\end{array}$ & $\begin{array}{lllll}1 & 2 & 3 & 4 & 5\end{array}$ \\
\hline I feel alone or apart when I am with my friends. & $\begin{array}{lllll}1 & 2 & 3 & 4 & 5\end{array}$ \\
\hline My friends listen to what I have to say. & $\begin{array}{lllll}1 & 2 & 3 & 4 & 5\end{array}$ \\
\hline I feel my friends are good friends. & $\begin{array}{lllll}1 & 2 & 3 & 4 & 5\end{array}$ \\
\hline My friends are fairly easy to talk to. & $\begin{array}{lllll}1 & 2 & 3 & 4 & 5\end{array}$ \\
\hline $\begin{array}{l}\text { When I am angry about something, my friends try to } \\
\text { be understanding. }\end{array}$ & $\begin{array}{lllll}1 & 2 & 3 & 4 & 5\end{array}$ \\
\hline My friends help me to understand myself better.. & $\begin{array}{lllll}1 & 2 & 3 & 4 & 5\end{array}$ \\
\hline My friends care about how I am. & $\begin{array}{lllll}1 & 2 & 3 & 4 & 5\end{array}$ \\
\hline I feel I can be angry with my friends. & $\begin{array}{lllll}1 & 2 & 3 & 4 & 5\end{array}$ \\
\hline $\begin{array}{l}\text { I can count on my friends when I need to get } \\
\text { something off my chest. }\end{array}$ & $\begin{array}{lllll}1 & 2 & 3 & 4 & 5\end{array}$ \\
\hline
\end{tabular}


Please use the following response scale to answer the following questions:

\begin{tabular}{|c|c|c|c|c|}
\hline $\mathbf{1}$ & $\mathbf{2}$ & $\mathbf{3}$ & $\mathbf{4}$ & $\mathbf{5}$ \\
$\begin{array}{c}\text { Almost } \\
\text { never or } \\
\text { never true }\end{array}$ & $\begin{array}{c}\text { Not very } \\
\text { often true }\end{array}$ & $\begin{array}{c}\text { Sometimes } \\
\text { true }\end{array}$ & $\begin{array}{c}\text { Often } \\
\text { true }\end{array}$ & $\begin{array}{c}\text { Almost } \\
\text { always or } \\
\text { always true. }\end{array}$ \\
\hline
\end{tabular}

\begin{tabular}{|c|c|}
\hline I trust my friends. & $\begin{array}{lllll}1 & 2 & 3 & 4 & 5\end{array}$ \\
\hline My friends respect my feelings.. & $\begin{array}{lllll}1 & 2 & 3 & 4 & 5\end{array}$ \\
\hline $\begin{array}{l}\text { I get upset a lot more than my friends know } \\
\text { about. }\end{array}$ & $\begin{array}{lllll}1 & 2 & 3 & 4 & 5\end{array}$ \\
\hline $\begin{array}{l}\text { It seems as if my friends are irritated with me for } \\
\text { no reason. }\end{array}$ & $\begin{array}{lllll}1 & 2 & 3 & 4 & 5\end{array}$ \\
\hline $\begin{array}{l}\text { I can tell my friends about my problems and } \\
\text { troubles. }\end{array}$ & $\begin{array}{lllll}1 & 2 & 3 & 4 & 5\end{array}$ \\
\hline $\begin{array}{l}\text { If my friends know something is bothering me, } \\
\text { they ask me about it. }\end{array}$ & $\begin{array}{lllll}1 & 2 & 3 & 4 & 5\end{array}$ \\
\hline
\end{tabular}




\section{APPENDIX G: RSE}

Instructions: below is a list of statements dealing with your general feelings about yourself. If you strongly agree, circle SA. If you agree with the statement, circle A. If you disagree, circle D. If you strongly disagree, circle SD.

$$
\begin{aligned}
& \text { strongly agree disagree strongly } \\
& \text { agree disagree }
\end{aligned}
$$

1. On the whole, I am satisfied with myself. $\quad$ SA A $\quad$ D $\quad$ SD

2. At times I think I am no good at all. $\quad$ SA $\quad$ A $\quad$ D $\quad$ SD

3. I feel that I have a number of good qualities. SA A $\quad$ D $\quad$ SD

4. I am able to do things as well as most other SA A $\quad$ D $\quad$ SD people.

5. I feel I do not have much to be proud of. $\quad$ SA A $\quad$ D $\quad$ SD

6. I certainly feel useless at times. $\quad$ SA $\quad$ A $\quad$ D $\quad$ SD

7. I feel that I'm a person of worth, at least on an SA A $\quad$ D $\quad$ SD equal plane with others.

8. I wish I could have more respect for myself. SA $\quad$ A $\quad$ D $\quad$ SD

9. All in all, I am inclined to feel that I am a $\quad$ SA $\quad$ A $\quad$ D $\quad$ SD failure.

10. I take a positive attitude toward myself. $\quad$ SA $\quad$ A $\quad$ D $\quad$ SD 


\section{APPENDIX H: Data Collection Script}

Hi my name is Dr. Keith Kaufman. I'm a clinical psychologist and a professor of psychology a Portland State University. We've come down from Portland to ask you for your help with a research project that we hope will help us learn more about both how to do better treatment for folks like yourself who have been charged with a sexual crime (or crime with JDs) and how to improve prevention to keep the community safe.

I want to thank all of you for your willingness to hear about our research and to think about helping us with it. Our group has been doing research to learn about treatment and prevention for more than 20 years and we've gotten a lot of very helpful information from teens and adults all across the country. We're here with your today, but we will be collecting this research information from OYA teens and young adults at facilities across the State of Oregon over the next few months

To help explain what the search project is about we have a handout that we are passing around. If you look at the top of the first page, it says Assent Form". Assent means that you agree to do something. This form explains what we are trying to do with this research, what it means for you to help us with the study, and what you can expect from us.

Now-a-days, when you do research you need prove that people who are a part of the study understood what it was about, knew that they were volunteering, and knew what was being done to protect them. When you sign the assent form it protects us by making clear that you volunteered to be a part of the study and it protects you by saying what you will be asked to do and how we will protect the information that you give us.

Let me quickly go through the assent form with you to explain what we are doing and then I will be happy to answer any questions that you may have.

If you look at the first question in bold, it states "What is the study about?" As I said earlier, we are trying to learn more about how sexual assault and abuse happens, how we can prevent it, and how we can improve treatment.

Under the second question, it says that I'm a professor at Portland State University and that I am in charge of the research.

Next, is says that you will be asked to spend about an hour and 15 minutes filling out 6 different, short surveys. Four of the surveys ask about your relationship with your parents or caregivers, one of the surveys asks about your internet use in the past, and one survey asks you to tell a little about yourself. This form also talks about us coming back to have you fill out one of the surveys a second time. 
The next question is "Will the Study Help Me". Your answers may be helpful to other people in the future, even if it doesn't directly help you. You may learn more about yourself, your behaviors, and you're offending. Being a part of this study may also give you a way to "give back" or make restitution which is sometimes a part of treatment. However, being a part of the study will not count toward any court ordered community service that you may have to do.

Under the section "What bad or not so good things might happen to me if I'm a part of the study" The survey will ask you about your feelings about your caregivers and things that you did as part of your offending. Some of the questions may make you feel upset. If this happens, you can talk with an OYA counselor or staff person.

The assent form also explains what is being done to protect you. All of the surveys will be kept anonymous. That means that you will not put your name on any of them and the assent form that you sign will be kept separate from the surveys so that we can't tell who filled out which surveys.

I also want to mention that there is no question that asks you to report on an unreported crime. The only way that this would come up is if someone wrote in detail of a crime in a blank space and identified themselves. Please don't do this. If you want to report an unreported crime, tell one of the OYA staff.

Take a look at the question "What if I don't want to be in this study". It is ok if you decide that you don't want to be a part of the study and it won't have any bad effect on your treatment in any way. You can also stop being a part of the study at any time and that won't have a bad effect on your treatment either.

Finally you can ask me or the folks that work with me questions at any time. After we leave you can still call the number on this form to ask questions.

So... Does anyone have any questions about the assent for or about the Research?

\section{TIME FOR QUESTIONS}

When you are ready, please print your name, sign your name and fill in today's date. Today's date is ......

For those of you who are under 18 years of age, OYA will be giving permission for you to be part of this study.

We will be giving you each a snack when you get about $1 / 2$ the way through the surveys. We will also be buying pizza for a pizza party that will be held sometime soon. 
We will be going around and collecting the assent forms and giving you the first questionnaire. Wait until we tell you to begin. There are a few places on the first questionnaire that can be confusing and we would like to explain them so that the survey will be easier to fill out

Please take this very seriously and give us good information. Take your time, read each question carefully and answer every question on each survey. Raise your hand if you have any questions and we will come around and help you individually. It is really important to give us the best information that you can so that it can be most helpful. 


\section{APPENDIX I: Oregon Sentencing Guidelines (2010)}

The Oregon Sentencing Guidelines Grid

\begin{tabular}{|c|c|c|c|c|c|c|c|c|c|c|c|c|}
\hline $\begin{array}{c}\text { Crime } \\
\text { Seriousness }\end{array}$ & A & B & C & D & $E$ & $F$ & $\mathbf{G}$ & $\mathrm{H}$ & I & $\begin{array}{l}\text { Prob } \\
\text { Term }\end{array}$ & Max & PPS \\
\hline 11 & $\begin{array}{r}225- \\
269\end{array}$ & $\begin{array}{l}196- \\
224\end{array}$ & $\begin{array}{l}178 \\
194\end{array}$ & $\begin{array}{l}164- \\
177\end{array}$ & $\begin{array}{c}149- \\
163\end{array}$ & $\begin{array}{r}135- \\
148\end{array}$ & $\begin{array}{l}129 \\
134\end{array}$ & $\begin{array}{l}122- \\
128\end{array}$ & $\begin{array}{l}120- \\
121\end{array}$ & \multirow{3}{*}{$\begin{array}{c}5 \\
\text { Years }\end{array}$} & & \multirow{5}{*}{$\begin{array}{c}3 \\
\text { Years }\end{array}$} \\
\hline 10 & $\begin{array}{l}121- \\
130\end{array}$ & $\begin{array}{l}116- \\
120\end{array}$ & $\begin{array}{l}111 . \\
115\end{array}$ & $\begin{array}{l}91- \\
110\end{array}$ & $\begin{array}{l}81- \\
90\end{array}$ & $\begin{array}{c}71- \\
80\end{array}$ & $\begin{array}{l}66- \\
70\end{array}$ & $\begin{array}{l}61- \\
65\end{array}$ & $\begin{array}{l}58- \\
60\end{array}$ & & & \\
\hline 9 & $\begin{array}{l}66- \\
72\end{array}$ & $\begin{array}{l}61- \\
65\end{array}$ & $\begin{array}{c}56- \\
60\end{array}$ & $\begin{array}{c}51- \\
55\end{array}$ & $\begin{array}{c}46- \\
50\end{array}$ & $\begin{array}{l}41- \\
45\end{array}$ & $\begin{array}{c}39- \\
40\end{array}$ & $\begin{array}{l}37- \\
38\end{array}$ & $\begin{array}{c}34- \\
36\end{array}$ & & & \\
\hline 8 & $\begin{array}{l}41- \\
45\end{array}$ & $\begin{array}{c}35- \\
40\end{array}$ & $\begin{array}{l}29- \\
34\end{array}$ & $\begin{array}{l}27- \\
28\end{array}$ & $\begin{array}{l}25- \\
26\end{array}$ & $\begin{array}{c}23- \\
24\end{array}$ & $\begin{array}{l}21- \\
22\end{array}$ & $\begin{array}{l}19- \\
20\end{array}$ & $\begin{array}{c}16- \\
18\end{array}$ & \multirow{3}{*}{$\begin{array}{c}3 \\
\text { Years }\end{array}$} & & \\
\hline 7 & $\begin{array}{l}31- \\
36\end{array}$ & $\begin{array}{c}25- \\
30\end{array}$ & $\begin{array}{l}21- \\
24\end{array}$ & $\begin{array}{c}19- \\
20\end{array}$ & $\begin{array}{c}16- \\
18\end{array}$ & $\begin{array}{c}180 \\
90\end{array}$ & $\begin{array}{c}180 \\
90\end{array}$ & $\begin{array}{c}180 \\
90\end{array}$ & $\begin{array}{c}180 \\
90\end{array}$ & & \multirow{2}{*}{$\begin{array}{c}18 \\
\text { Mos. }\end{array}$} & \\
\hline 6 & $\begin{array}{c}25- \\
30\end{array}$ & $\begin{array}{c}19- \\
24\end{array}$ & $\begin{array}{c}15- \\
18\end{array}$ & $\begin{array}{c}13- \\
14\end{array}$ & $\begin{array}{c}10- \\
12\end{array}$ & $\begin{array}{c}180 \\
90\end{array}$ & $\begin{array}{c}180 \\
90\end{array}$ & $\begin{array}{c}180 \\
90\end{array}$ & $\begin{array}{c}180 \\
90\end{array}$ & & & \multirow{3}{*}{$\stackrel{2}{\text { Years }}$} \\
\hline 5 & $\begin{array}{r}15- \\
16\end{array}$ & $\begin{array}{r}13- \\
14\end{array}$ & $\begin{array}{r}11- \\
12\end{array}$ & $\begin{array}{l}9- \\
10\end{array}$ & $\begin{array}{c}6- \\
8\end{array}$ & $\begin{array}{c}180 \\
90\end{array}$ & $\begin{array}{c}120 \\
60\end{array}$ & $\begin{array}{c}120 \\
60\end{array}$ & $\begin{array}{c}120 \\
60\end{array}$ & \multirow{3}{*}{$\begin{array}{c}2 \\
\text { Years }\end{array}$} & \multirow{2}{*}{$\begin{array}{c}12 \\
\text { Mos. }\end{array}$} & \\
\hline 4 & $\begin{array}{r}10- \\
11\end{array}$ & $\begin{array}{c}8- \\
9\end{array}$ & $\begin{array}{r}120 \\
60\end{array}$ & $\begin{array}{r}120 \\
60\end{array}$ & $\begin{array}{r}120 \\
60\end{array}$ & $\begin{array}{r}120 \\
60\end{array}$ & $\begin{array}{r}120 \\
60\end{array}$ & $\begin{array}{c}120 \\
60\end{array}$ & $\begin{array}{c}120 \\
60\end{array}$ & & & \\
\hline 3 & $\begin{array}{r}120 \\
60\end{array}$ & $\begin{array}{c}120 \\
60\end{array}$ & $\begin{array}{r}120 \\
60\end{array}$ & $\begin{array}{r}120 \\
60\end{array}$ & $\begin{array}{r}120 \\
60\end{array}$ & $\begin{array}{r}120 \\
60\end{array}$ & $\begin{array}{l}90 \\
30\end{array}$ & $\begin{array}{l}90 \\
30\end{array}$ & $\begin{array}{l}90 \\
30\end{array}$ & & \multirow{3}{*}{$\begin{array}{c}6 \\
\text { Mos. }\end{array}$} & \multirow{3}{*}{$\begin{array}{c}1 \\
\text { Year }\end{array}$} \\
\hline 2 & $\begin{array}{l}90 \\
30\end{array}$ & $\begin{array}{l}90 \\
30\end{array}$ & $\begin{array}{l}90 \\
30\end{array}$ & $\begin{array}{l}90 \\
30\end{array}$ & $\begin{array}{l}90 \\
30\end{array}$ & $\begin{array}{l}90 \\
30\end{array}$ & $\begin{array}{l}90 \\
30\end{array}$ & $\begin{array}{l}90 \\
30\end{array}$ & $\begin{array}{l}90 \\
30\end{array}$ & \multirow{2}{*}{$\begin{array}{c}11 / 2 \\
\text { Years }\end{array}$} & & \\
\hline 1 & $\begin{array}{l}90 \\
30\end{array}$ & $\begin{array}{l}90 \\
30\end{array}$ & $\begin{array}{l}90 \\
30\end{array}$ & $\begin{array}{l}90 \\
30\end{array}$ & $\begin{array}{l}90 \\
30\end{array}$ & $\begin{array}{l}90 \\
30\end{array}$ & $\begin{array}{l}90 \\
30\end{array}$ & $\begin{array}{l}90 \\
30\end{array}$ & $\begin{array}{l}90 \\
30\end{array}$ & & & \\
\hline
\end{tabular}

The presumptive grid block for any felony conviction is the intersection where the crime seriousness ranking and the criminal history classification meet. Grid blocks in the shaded area represent the range of presumptive imprisonment and post-prison supervision (PPS). Non-shaded grid blocks are presumptive sentences of probation (Prob. Term) with local custodial sanctions in days (upper number) and maximum jail days without a departure (lower number).

The probation term of 5 years applies to levels $9-11$, the term of 3 years applies to levels 68,2 years applies to levels $3-5$, and $1 \frac{1}{2}$ years applies to levels $1-2$.

The upward dispositional departure maximum sentence (Max Dispositional Depart) for a presumptive probation sentence shall be:

(a) Up to six months for offenses classified in Crime Categories 1 and 2, or grid blocks 3-G, 3-H and 3-I;

(b) Up to twelve months for offenses classified in grid blocks 3-A through 3-F, 4-C through 4-I and 5-G through 5-I; and

(c) Up to eighteen months for offenses classified in grid blocks $5 \mathrm{~F}$, $6 \mathrm{~F}$ through $6-\mathrm{I}$, and 7-F through $7-$ I. 


\section{APPENDIX J: Child Abuse Laws State-by-State}

Alabama

Alaska

Arizona

Arkansas

California

Colorado

Connecticut

Delaware

District Of

Columbia

Florida

Georgia
Statute defines child abuse as harm or threatened harm of physical abuse, neglect, sexual abuse, sexual exploitation, or emotional/mental injury against a child under the age of 18. Statute contains an exemption for religious reasons for a parent's failure to obtain medical help for the child.

Statute defines child abuse as harm or threatened harm of physical abuse, neglect, sexual abuse, sexual exploitation, or emotional/mental injury of a child under the age of 18. Statute contains an exemption for religious reasons for a parent's failure to obtain medical help for the child.

Statute defines child abuse as inflicting or allowing physical abuse, neglect, sexual abuse, sexual exploitation, emotional/mental injury, or abandonment of a child under the age of 18. Statute contains an exemption for Christian Scientists or unavailability of reasonable resources for a parent's failure to obtain medical help for the child.

Statute defines child abuse as intentionally, knowingly, or negligently without cause inflicting physical abuse, neglect, sexual abuse, sexual exploitation, abandonment or emotional/mental injury of a child under the age of 18 . Statute contains exemptions for poverty or corporal punishment.

Statute defines child abuse as inflicting by non-accidental means physical abuse, neglect, sexual abuse, or sexual exploitation of a child under the age of 18. Statute contains exemptions for religion, reasonable force, and informed medical decision.

Statute prohibits threats to a child's health and welfare due to physical abuse, neglect, sexual abuse, sexual exploitation, emotional/mental injury, or abandonment. Statute contains exemptions for corporal punishment, reasonable force, religious practices, and cultural practices.

Statute prohibits injuries inflicted by non-accidental means involving physical abuse, neglect, sexual abuse, sexual exploitation, emotional/mental injury, or abandonment. Statute contains exemption for Christian Scientists.

Statute prohibits injuries inflicted by non-accidental means involving physical abuse, neglect, sexual abuse, sexual exploitation, emotional/mental injury, or abandonment. Statute contains exemption for religion.

Statute prohibits persons from inflicting and requires people to take reasonable care not to inflict injuries involving physical abuse, neglect, sexual abuse, sexual exploitation, or emotional/mental injury. Statute contains exemption for poverty and religion.

Statute prohibits willful or threatened act that harms or is likely to cause harm of physical abuse, neglect, sexual abuse, sexual exploitation, abandonment, or emotional/mental injury. Statute contains exemptions for religion, poverty, or corporal punishment.

Statute prohibits injuries inflicted by non-accidental means involving physical abuse, neglect, sexual abuse, or sexual exploitation. Statute contains exemption for religion and corporal punishment. 
Hawaii

Idaho

Illinois

Indiana

Kentucky

Maryland

Michigan

Mississippi

Nebraska

New Mexico

North Dakota

Oklahoma

Pennsylvania
Statute prohibits acts or omissions resulting in the child being harmed or subject to any reasonably foreseeable, substantial risk of being harmed with physical abuse, neglect, sexual abuse, sexual exploitation, or emotional/mental injury. Statute contains no exemptions.

Statute prohibits conduct or omission resulting in physical abuse, neglect, sexual abuse, sexual exploitation, abandonment, or emotional/mental injury. Statute contains exemption for religion.

Statute prohibits persons from inflicting, causing to be inflicted, or allowing to be inflicted, or creating a substantial risk, or committing or allowing to be committed, physical abuse, neglect, sexual abuse, sexual exploitation, or emotional/mental injury. Statute contains exemptions for religion, school attendance, and plan of care.

Statute prohibits act or omission resulting in physical abuse, neglect, sexual abuse, sexual exploitation, abandonment, or emotional/mental injury. Statute contains exemptions for religion, prescription drugs, or corporal punishment.

Statute prohibits harm or threat of harm, or infliction or allowance of infliction of physical abuse, neglect, sexual abuse, sexual exploitation, abandonment, or emotional/mental injury. Statute contains exemptions for religion.

Statute prohibits harm or substantial risk of harm resulting in physical abuse, neglect, sexual abuse, sexual exploitation, or emotional/mental injury. Statute contains no exemptions.

Statute prohibits harm or threatened harm of physical abuse, neglect, sexual abuse, sexual exploitation, or emotional/mental injury. Statute contains exemptions for religion.

Statute prohibits persons from causing or allowing to be caused physical abuse, neglect, sexual abuse, sexual exploitation, or emotional/mental injury. Statute contains exemption for religion and corporal punishment.

Statute prohibits knowingly, intentionally, or negligently causing or permitting physical abuse, neglect, sexual abuse, sexual exploitation, or emotional/mental injury. Statute contains no exemptions.

Statute prohibits knowingly, intentionally, or negligently causing or permitting physical abuse, neglect, sexual abuse, sexual exploitation, abandonment, or emotional/mental injury. Statute contains exemption for religion.

Statute prohibits serious harm caused by non-accidental means resulting in physical abuse, neglect, sexual abuse, sexual exploitation, abandonment, or emotional/mental injury. Statute contains no exemptions.

Statute prohibits harm or threat of harm resulting in physical abuse, neglect, sexual abuse, sexual exploitation, abandonment, or emotional/mental injury. Statute contains exemptions for religion or corporal punishment.

Statute prohibits recent act or failure to act resulting in physical abuse, neglect, sexual 
abuse, sexual exploitation, or emotional/mental injury. Statute contains exemptions for religion or poverty.

South Dakota Statute prohibits threat with substantial harm resulting in physical abuse, neglect, sexual abuse, sexual exploitation, abandonment, or emotional/mental injury. Statute contains no exemptions.

Tennessee Statute prohibits persons from committing or allowing to be committed physical abuse, neglect, sexual abuse, sexual exploitation, or emotional/mental injury. Statute contains no exemptions.

Utah Statute prohibits harm or threat of harm resulting in physical abuse, neglect, sexual abuse, sexual exploitation, or emotional/mental injury. Statute contains no exemptions.

Washington Statute prohibits harm of health, welfare, or safety resulting from physical abuse, neglect, sexual abuse, or sexual exploitation. Statute contains exemptions for Christian Scientists, corporal punishment, or physical disability.

Retrieved from http://family.findlaw.com/child-abuse/state-child-abuse-laws.html May 2, 2008. 


\title{
APPENDIX K: Assent Forms
}

\author{
Assent Form \\ Portland State University \\ Department of Psychology \\ (JSO Form)
}

You are being asked to take part in a research study. We would like to tell you about the study, so you can decide if you want to be in it. You can choose to be a part of the study, or you can choose not to take part - either choice is OK.

Please read all the information on this form. If you don't understand, or if you have any questions, please raise your hand and ask. You will get a copy of this form to keep.

\section{What is this study about?}

The goal of this study is to find out more about how child sexual abuse happens, and how it can be prevented. This study will also ask questions that can help make treatment better for people who have offended sexually.

Who is in charge of this study?

This study is being led by Dr. Keith Kaufman, a professor at Portland State University.

\section{What will happen if you take part in the study?}

If you decide to take part in this study, you will be asked to answer 1 short survey today. It is the same survey you took two weeks ago that asked about how you used the Internet while you were sexually offending. It will take about 15 minutes to fill out.

When you took this survey two weeks ago, we put a number on it. That number was matched with your name on a list. When you take the survey today, we will ask you to tell us your name so we can match this survey with the one you took two weeks ago. After we do this, Dr. Kaufman will destroy the list of names and numbers. We will also take the number off your survey. This will happen today whether you take the survey or not.

\section{Will the study help me?}

You may not receive any direct benefits from being part of this study, but your answers to the survey questions may help other people in the future. Answering these surveys may help you learn more about yourself, your behaviors, and your sexual offending, which may help your treatment. Being part of this study may also give you a chance to "give back" or make restitution, which is sometimes a part of treatment. However, being part of this study will not count towards any court-ordered community service you may have to do.

\section{What bad or not-so-good things might happen to me if I'm part of the study?}

This study will ask you questions about things you did while you were sexually offending. Some of these questions may cause you to feel upset. If you do feel upset, you can talk with a counselor, either in a group or by yourself. 


\section{What is being done to protect me if I am in the study?}

Dr. Kaufman and his research team will keep your surveys anonymous - this means that no one will know which surveys you answered. To the extent permitted by law, they will also keep your answers confidential and protect the confidentiality of you and anyone else in this study. This means no one will know you participated in the study, unless you decide to tell them.

Also, there is no question that asks you to report an unreported crime. However, if you were to write-in enough information in a blank space to let us know who you are and who an unreported victim was, we would have to report this to the authorities. Please don't do this. If you feel you need to report an unreported crime, please talk to one of your Oregon Youth Authority counselors or staff.

\section{What if I don't want to be in this study?}

It's OK if you decide you don't want to be part of this study. Choosing not to be part of the study won't affect your treatment in any way. You can also stop being part of this study at any time, even after you've started, without affecting your treatment.

\section{What if I have questions?}

If you have questions about this study or what you are being asked to do, you can ask Dr. Kaufman or any of the people on his research team. If you have questions after they leave, you can reach them by telephone (503-725-3984).

If you want to participate, please sign the form below.

Name (Please Print)

Signature

Date

If you have any questions about this study, please contact Dr. Keith Kaufman at 317 Cramer Hall, Portland State University, 866-779-8368. If you have questions or concerns about your rights as a research subject or about your participation in this study, or if you experience any problems as a result of participation, please contact the chair of the HSRRC, Portland State University, Unitus Building, $6^{\text {th }}$ Floor, 503-725-4288. 


\section{Assent Form \\ Portland State University \\ Department of Psychology}

(JD Form)

You are being asked to take part in a research study. We would like to tell you about the study, so you can decide if you want to be in it. You can choose to be a part of the study, or you can choose not to take part - either choice is OK.

Please read all the information on this form. If you don't understand, or if you have any questions, please raise your hand and ask. You will get a copy of this form to keep.

\section{What is this study about?}

The goal of this study is to find out more about how child sexual abuse happens, and how it can be prevented. This study will also ask questions that can help make treatment better for people who have offended sexually.

\section{Who is in charge of this study?}

This study is being led by Dr. Keith Kaufman, a professor at Portland State University.

\section{What will happen if you take part in the study?}

If you decide to take part in this study, you will be asked to answer 6 surveys today. Four surveys will ask about your relationship with your parents or caregivers. Another survey will ask about how you used the Internet before you went to jail. You will also be asked to fill out a brief survey telling us a little about yourself. These surveys will take about 75 minutes to fill out.

If you decide to take the surveys today, you will also be asked to take one more short survey in about two weeks. That survey will take about 15 minutes to fill out. You don't have to take the survey in two weeks, even if you take the surveys today. None of the surveys will be seen by any of the OYA staff at any time.

We will put a number on the surveys you take today so that we can put them together with the survey you may take in two weeks. This number will be kept on a list with your name. The list will be kept here at your facility by one of the people in charge. All of the filled-out surveys will be kept by Dr. Kaufman at Portland State University. Dr. Kaufman will destroy the list of names and numbers once we come back to get the second set of surveys from youth here at OYA - this will happen in about two weeks whether you take the second survey or not.

\section{Will the study help me?}

You may not receive any direct benefits from being part of this study, but your answers to the survey questions may help other people in the future. Answering these surveys may help you learn more about yourself and your behaviors which may help your treatment. Being part of this study may also give you a chance to "give back" or make restitution, which is sometimes a part of treatment. However, being part of this study will not count towards any court-ordered community service you may have to do.

What bad or not-so-good things might happen to me if I'm part of the study? 
This study will ask you questions about your feelings about your caregivers, as well as things you did while you were offending. Some of these questions may cause you to feel upset. If you do feel upset, you can talk with a counselor, either in a group or by yourself.

\section{What is being done to protect me if I am in the study?}

Dr. Kaufman and his research team will keep your surveys anonymous - this means that no one will know which surveys you answered. To the extent permitted by law, they will also keep your answers confidential and protect the confidentiality of you and anyone else in this study. This means no one will know you participated in the study, unless you decide to tell them.

Also, there is no question that asks you to report an unreported crime. However, if you were to write-in enough information in a blank space to let us know who you are and who an unreported victim was, we would have to report this to the authorities. Please don't do this. If you feel you need to report an unreported crime, please talk to one of your Oregon Youth Authority counselors or staff.

\section{What if I don't want to be in this study?}

It's OK if you decide you don't want to be part of this study. Choosing not to be part of the study won't affect your treatment in any way. You can also stop being part of this study at any time, even after you've started, without affecting your treatment.

\section{What if I have questions?}

If you have questions about this study or what you are being asked to do, you can ask Dr. Kaufman or any of the people on his research team. If you have questions after they leave, you can reach them by telephone (503-725-3984).

If you want to participate, please sign the form below.

Name (Please Print)

Signature

Date

If you have any questions about this study, please contact Dr. Keith Kaufman at 317 Cramer Hall, Portland State University, 866-779-8368. If you have questions or concerns about your rights as a research subject or about your participation in this study, or if you experience any problems as a result of participation, please contact the chair of the HSRRC, Portland State University, Unitus Building, $6^{\text {th }}$ Floor, 503-725-4288. 